Doctoral Thesis

Madrid, Spain 2017

\title{
Energy Management in Smart Cities
}

Christian Francisco Calvillo MuÑOZ
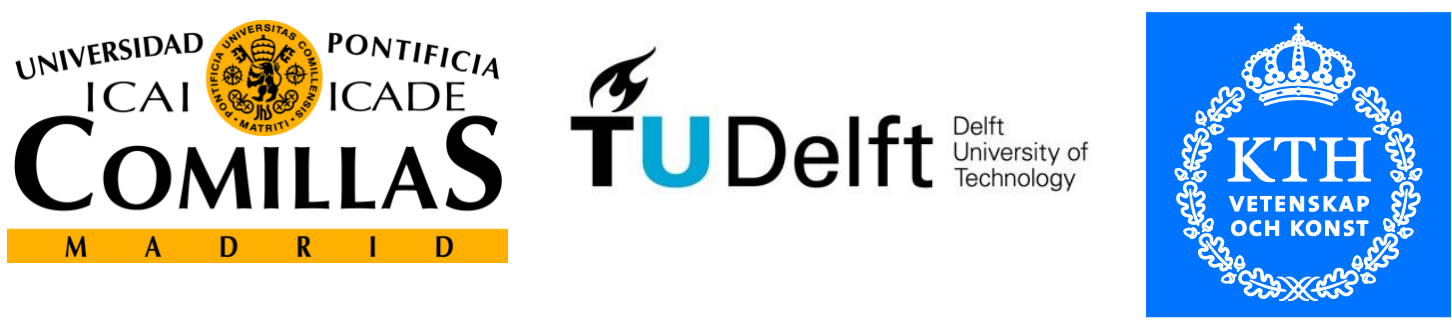

Doctoral Thesis supervisors:

Prof. Alvaro Sánchez-Miralles,

Prof. José Villar Collado,

Members of the Examination Committee:

\begin{tabular}{|c|c|}
\hline XXX & XXX \\
\hline XXX & XXX \\
\hline XXX & XXX \\
\hline XXX & XXX \\
\hline & XXX \\
\hline
\end{tabular}

TRITA-XX 2017:XXX

ISSN XXXX-XXXX

ISBN XXX-XX-XXX-XXXX-X

Copyright (C) Christian F. Calvillo Muñoz, 2016

Printed in Spain
XXX

XXX

XXX

$x x$

XXX
Universidad Pontificia Comillas

Universidad Pontificia Comillas

This doctoral research was funded by the European Commission through the Erasmus Mundus Joint Doctorate Programme, and by the Institute for Research in Technology at Universidad Pontificia Comillas.

XXX 


\section{SETS Joint Doctorate}

The Erasmus Mundus Joint Doctorate in Sustainable Energy Technologies and Strategies, SETS Joint Doctorate, is an international programme run by six institutions in cooperation:

- Comillas Pontifical University, Madrid, Spain

- Delft University of Technology, Delft, the Netherlands

- KTH Royal Institute of Technology, Stockholm, Sweden

- Florence School of Regulation, Florence, Italy

- Johns Hopkins University, Baltimore, USA

- University Paris-Sud 11, Paris, France

The Doctoral Degrees issued upon completion of the programme are issued by Comillas Pontifical University, Delft University of Technology, and KTH Royal Institute of Technology.

The Degree Certificates are giving reference to the joint programme. The doctoral candidates are jointly supervised, and must pass a joint examination procedure set up by the three institutions issuing the degrees.

This Thesis is a part of the examination for the doctoral degree.

The invested degrees are official in Spain, the Netherlands and Sweden, respectively.

SETS Joint Doctorate was awarded the Erasmus Mundus excellence label by the European Commission in year 2010, and the European Commission's Education, Audiovisual and Culture Executive Agency, EACEA, has supported the funding of this programme.

The EACEA is not to be held responsible for contents of the Thesis.
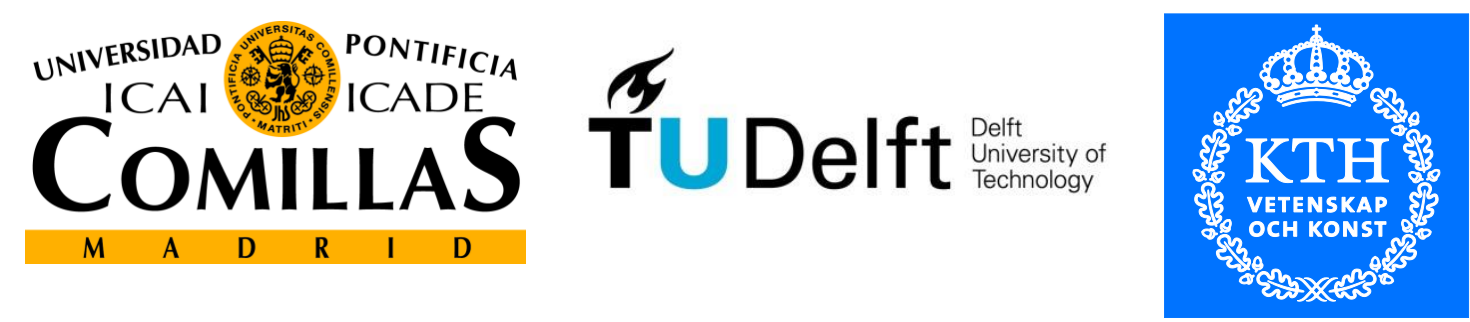



\section{SUMMARY}

Models and simulators have been widely used in urban contexts for many decades. The drawback of most current models is that they are normally designed for specific objectives, so the elements considered are limited and they do not take into account the potential synergies between related systems. The necessity of a framework to model complex smart city systems with a comprehensive smart city model has been remarked by many authors.

Therefore, this $\mathrm{PhD}$ thesis presents: i) a general conceptual framework for the modelling of energy related activities in smart cities, based on determining the spheres of influence and intervention areas within the city, and on identifying agents and potential synergies among systems, and ii) the development of a holistic energy model of a smart city for the assessment of different courses of action, given its geo-location, regulatory and technical constraints, and current energy markets. This involves the creation of an optimization model that permits the optimal planning and operation of energy resources within the city.

In addition, several analyses were carried out to explore different hypothesis for the smart city energy model, including:

a) an assessment of the importance of including network thermal constraints in the planning and operation of DER systems at a low voltage distribution level,

b) an analysis of aggregator's market modelling approaches and the impact on prices due to DER aggregation levels, and

c) an analysis of synergies between different systems in a smart city context.

Some of the main findings are:

- It is sensible to not consider network thermal constraints in the planning of DER systems. Results showed that the benefit decrement of considering network constraints was approximatively equivalent to the cost of reinforcing the network when necessary after planning without considering network constraints.

- The level of aggregation affects the planning and overall benefits of DER systems. Also, price-maker approaches could be more appropriate for the planning and operation of energy resources for medium to large aggregation sizes, but could be unnecessary for small sizes, with low expected impact on the market price.

- Synergies between different energy systems exist in an interconnected smart city context. Results showed that the overall benefits of a joint management of systems were greater than those of the independently managed systems.

Lastly, the smart city energy model was applied to a case study simulating a real smart city implementation, considering five real districts in the southern area of Madrid, Spain. This analysis allowed to assess the potential benefits of the implementation of a real smart city programme, and showed how the proposed smart city energy model could be used for the planning of pilot projects. To the best of our knowledge, such a smart city energy model and modelling framework had not been developed and applied yet, and no economic results in terms of the potential benefits of such a smart city initiative had been previously reported. 


\section{RESUMEN}

Diferentes modelos y simuladores se han utilizado extensivamente en ciudades por varias décadas. La limitación de muchos de los modelos actuales es que están diseñados para algún objetivo específico, por lo que los elementos considerados son limitados y no toman en cuenta potenciales sinergias entre sistemas. La necesidad de un marco estratégico de modelado de sistemas en ciudades inteligentes y un modelo energético integral de ciudades inteligentes ha sido reconocida por muchos autores.

Por lo tanto, en esta tesis se presenta: i) un marco conceptual general para el modelado de actividades relacionadas con la energía en ciudades inteligentes, basado en determinar las esferas de influencia y las áreas de intervención dentro de la ciudad, e identificando agentes y potenciales sinergias entre sistemas; ii) el desarrollo de un modelo energético integral de ciudades inteligentes para la evaluación de diferentes cursos de acción, considerando la ubicación geográfica, restricciones técnicas y regulatorias, y los mercados de energía actuales. Esto requiere la creación de un modelo de optimización que permita la planificación y operación optima de los recursos energéticos en una ciudad.

Además, varios análisis se han llevado a cabo para explorar diferentes hipótesis para el modelo energético de ciudades inteligentes, incluyendo:

a) la evaluación de la importancia de considerar restricciones de red (en baja tensión) en la planificación y gestión de recursos energéticos distribuidos (DER),

b) el análisis de modelado del mercado para agregadores, y de impactos en el precio de la energía debido a los niveles de agregación de DER, y

c) el análisis de sinergias entre diferentes sistemas en un contexto de ciudades inteligentes.

Entre los principales resultados, destacan:

- Se pueden no considerar las restricciones de red en la planificación de DER. Los resultados muestran que el decremento en beneficios por considerar las restricciones de red es equivalente al coste de reforzar la red cuando se realiza la planificación sin restricciones de red.

- Los niveles de agregación afectan los beneficios y la planificación de los sistemas DER. Además, los planteamientos "fijador de precio" podrían ser más apropiados para la planificación y operación de sistemas con agregaciones de medianas a grandes, aunque este planteamiento puede ser innecesario para pequeñas agregaciones donde el impacto al precio de mercado puede ser insignificante.

- Existen sinergias entre diferentes sistemas de energía en un contexto interconectado de ciudades inteligentes. Los resultados muestran que los beneficios globales dada la gestión conjunta de los sistemas son mayores que los beneficios de los sistemas gestionados independientemente.

Finalmente, el modelo de energía de ciudades inteligentes fue aplicado simulando una implementación real de ciudades inteligentes, considerando cinco distritos reales en el área sur de Madrid, España. El análisis de este caso de estudio ha permitido evaluar los beneficios 
potenciales de una implementación real de un programa de ciudades inteligentes, y ha mostrado como el modelo propuesto puede ser utilizado para planificar proyectos piloto. A nuestro mejor saber y entender, un modelo energético de ciudades inteligentes y un marco conceptual como los propuestos en esta tesis, no han sido desarrollados y aplicados antes, igualmente, datos de resultados económicos, en términos de beneficios potenciales de iniciativas de ciudades inteligentes como las mostradas, tampoco han sido reportados con anterioridad. 
SAMMANFATTNING 


\section{SAMENVATTING}

Modellen en simulators worden al vele decennia gebruikt in een stedelijke context. De keerzijde van de meeste huidige modellen is dat ze gewoonlijk zijn ontworpen voor specifieke doelen, waardoor de beschouwde onderdelen beperkt zijn en zij geen rekening houden met de potentiële synergiën tussen samenhangende systemen. De noodzaak van een raamwerk om de complexe smart-city-systemen te modelleren met een alomvattend smart-city-model is opgemerkt door vele auteurs.

Dit proefschrift presenteert daarom: i) een algemeen conceptueel raamwerk voor het modelleren van energie-gerelateerde activiteiten in de slimme steden, gebaseerd op het vaststellen van de invloedssferen en interventiegebieden binnen de stad, en op het identificeren van agenten en potentiële synergiën tussen systemen, en ii) de ontwikkeling van een holistisch energiemodel van een smart city voor de beoordeling van verschillende handelswijzen, gegeven haar geografische locatie, wettelijke en technische randvoorwaarden, en huidige energiemarkten. Dit omvat de creatie van een optimalisatiemodel dat de optimale planning en benutting van energiebronnen binnen de stad mogelijk maakt.

Bovendien zijn meerdere analyses uitgevoerd om verschillende hypotheses te verkennen voor het smart-city-energiemodel, inclusief:

a) een evaluatie van het belang van het opnemen van thermische netwerklimieten in de planning en bedrijfsvoering van DER-systemen op een laagspanningsdistributieniveau,

b) een analyse van de marktmodelleermethodes van de aggregator en van de impact op prijzen vanwege DER-aggregatieniveaus, en

c) een analyse van synergiën tussen verschillende systemen in een smart-city-context.

Enkele hoofdbevindingen zijn:

- Het is verstandig om thermische netwerklimieten niet mee te nemen in de planning van DER-systemen. Resultaten lieten zien dat de profijtafname van het meenemen van netwerkbeperkingen ongeveer equivalent was aan de kosten van het versterken van het netwerk wanneer noodzakelijk na planning zonder het meenemen van netwerkbeperkingen.

- Het aggregatieniveau beïnvloedt de planning en algemene voordelen van DERsystemen. Verder zouden prijszettermethodes geschikter kunnen zijn voor de planning en benutting van energiebronnen voor gemiddelde tot grote aggregatieformaten, maar zouden onnodig kunnen zijn voor kleine formaten, met een lage verwachte impact op de marktprijs.

- Synergiën tussen verschillende energiesystemen bestaan in een aaneengesloten smart-city-context. Resultaten lieten zien dat de algemene voordelen van een gezamenlijk beheer van systemen groter waren dan die van zelfstandig beheerde systemen. 
Tot slot is het smart-city-energiemodel toegepast op een casestudy waarin een echte smartcity-implementatie is gesimuleerd, en waarin vijf echte districten in het zuidelijke deel van Madrid, Spanje, zijn beschouwd. Deze analyse maakte het mogelijk om de potentiële voordelen van de implementatie van een echt smart-city-programma in te schatten, en liet zien hoe het voorgestelde smart-city-energiemodel gebruikt zou kunnen worden voor de planning van proefprojecten. Voor zover bij ons bekend was een dergelijk smart-cityenergiemodel en -modelleerraamwerk nog niet ontwikkeld en toegepast, en zijn er niet eerder economische resultaten gerapporteerd met betrekking tot de potentiële voordelen van een dergelijk smart-city-initiatief. 


\section{CONTENTS}

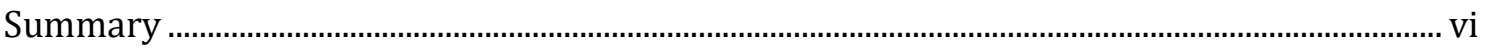

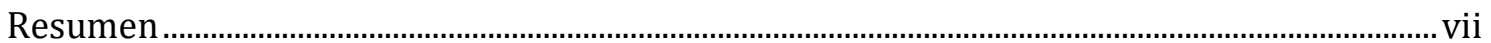

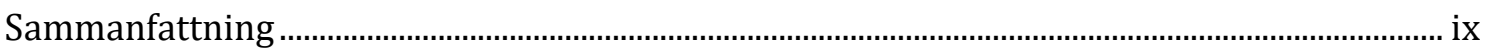

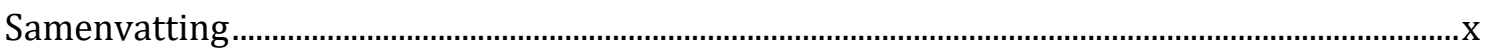

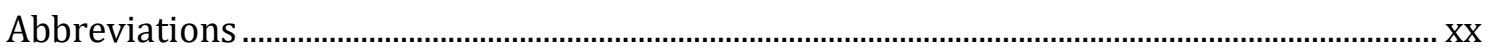

Nomenclature

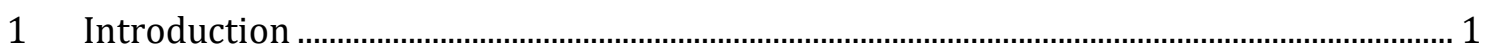

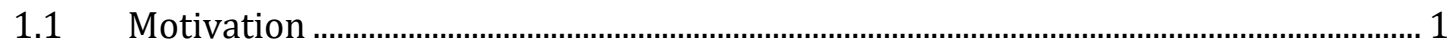

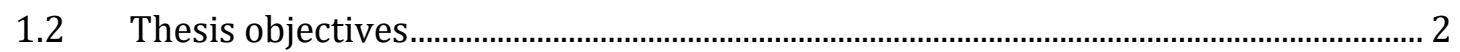

1.3 Methodology to build the smart city energy model …………..................................... 3

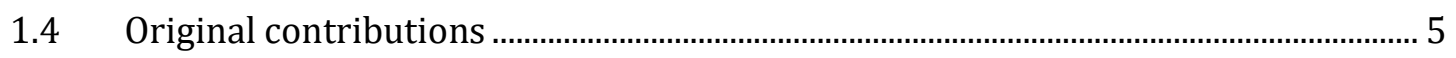

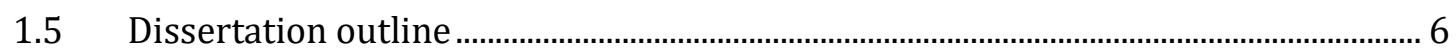

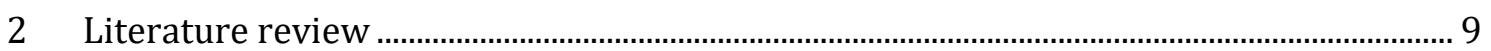

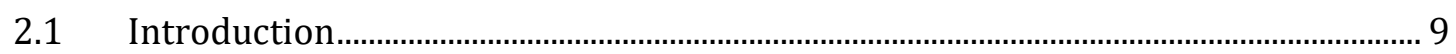

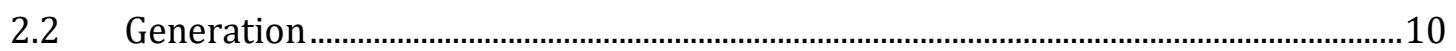

2.2.1 Generation technology review ...........................................................................11

2.2.2 Distributed generation applications and tools ....................................................12

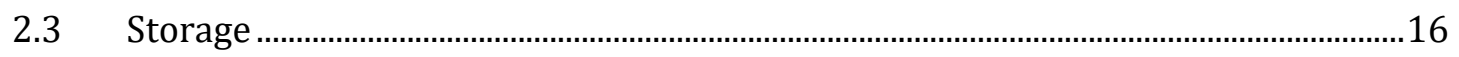

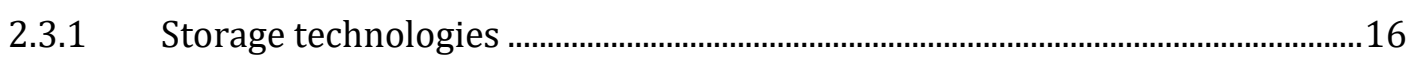

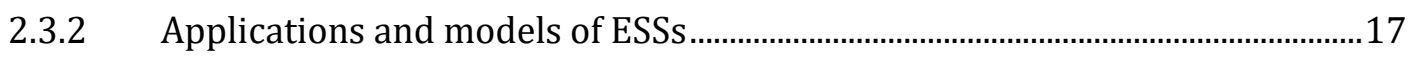

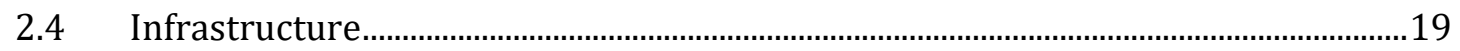

2.4.1 Research on and applications of smart-grid infrastructure..............................20

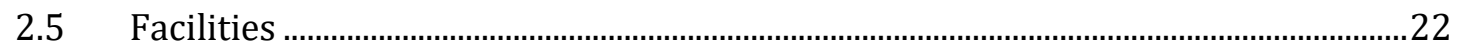

2.5.1 Applications and research in facilities .................................................................23

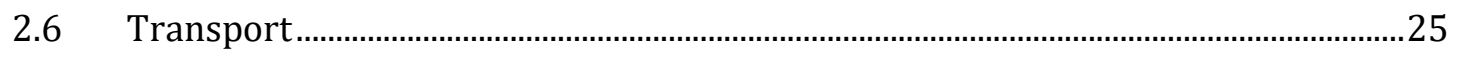

2.6.1 Advances in transport systems and technologies ...............................................25

2.6.2 Applications and research in transport systems .................................................27

2.7 Smart City Energy Models..............................................................................................

2.7.1 Urban-planning models and energy........................................................................

2.7.2 Designing energy system models in a smart city context ...................................31

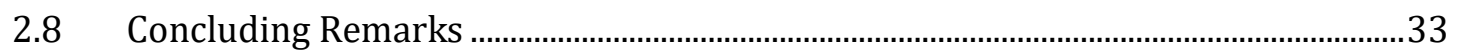

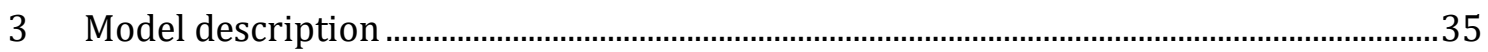

Energy Management of Smart Cities $\quad$ xiii 


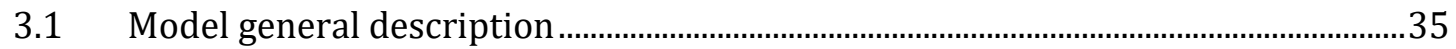

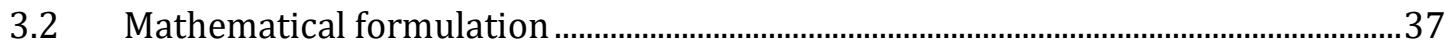

3.2.1 Generation models .....................................................................................................

3.2.2 Storage models..........................................................................................................

3.2.3 Facilities models....................................................................................................... 40

3.2.4 Transport models ...................................................................................................... 41

3.2.5 Balance equations (infrastructure) ....................................................................... 42

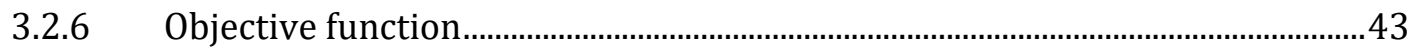

4 Assessing the importance of network constraints in the planning process ......................46

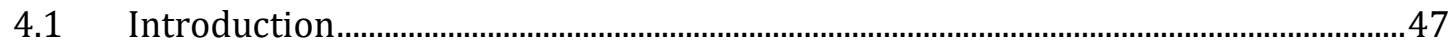

4.1.1 Modifications of the smart city energy model for this analysis..........................49

$4.2 \quad$ Scenarios and Case Studies ………………….................................................................50

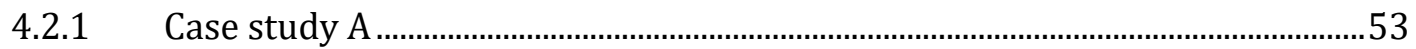

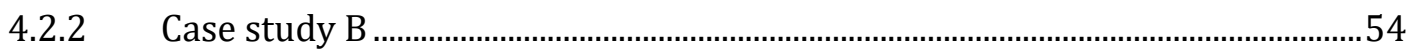

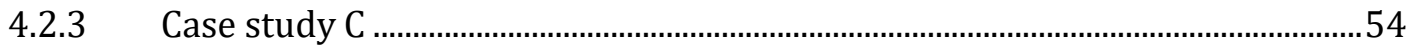

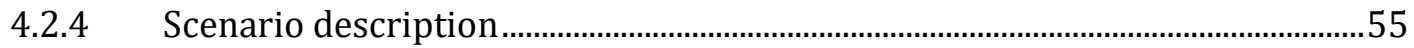

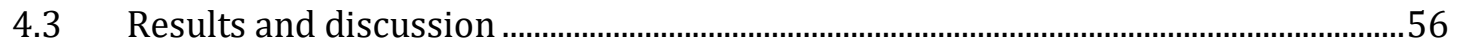

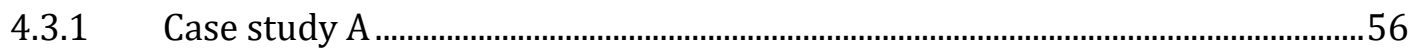

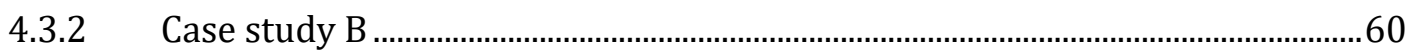

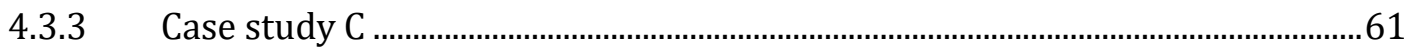

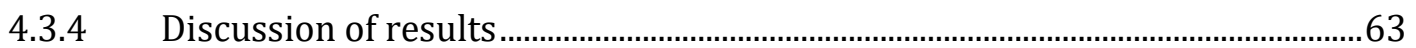

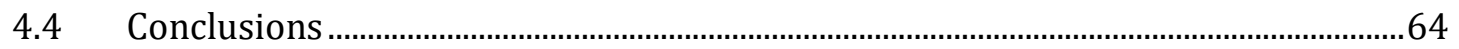

5 Assessing the impact of aggregated DER systems in the energy market..........................66

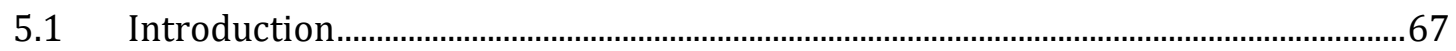

5.1.1 Examples of price-taker models for aggregated energy resources...................68

5.1.2 Examples of price-maker models for aggregated energy resources ................69

5.1.3 Modifications of the smart city energy model for this analysis..........................70

5.1.4 Piecewise linear function constraints: ...................................................................

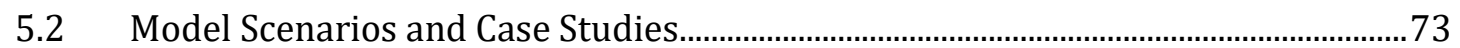

5.2.1 Case study description and parameters ....................................................................

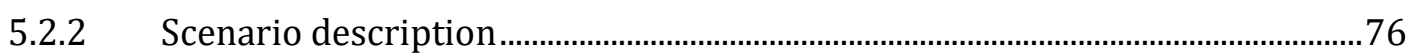

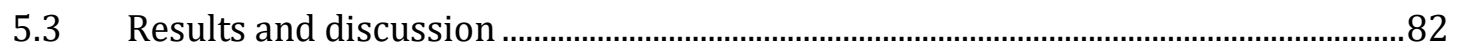

5.3.1 Result discussion and case study comparison ........................................................82

5.3.2 Aggregated system behaviour for all study cases .................................................92

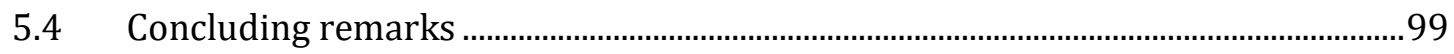


6 analysis of synergies between DER and transport systems.

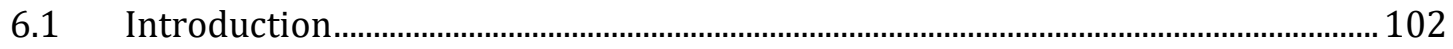

6.1.1 Modifications of the smart city energy model for this analysis....................... 104

6.2 Case study description and parameters........................................................................ 106

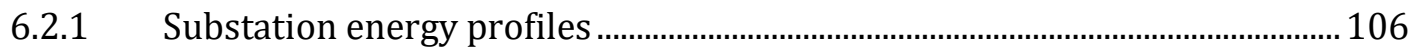

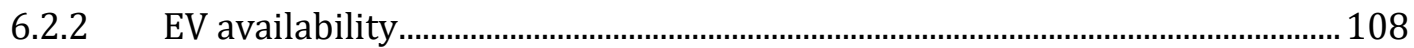

6.2.3 DER characteristics and district energy profiles ............................................... 109

6.2.4 Energy price parameters …………………............................................................ 109

6.2.5 Case studies description ....................................................................................... 110

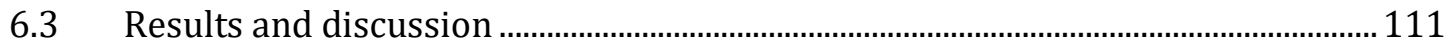

6.3.1 Analysis of the effect of EV penetration and district size................................... 111

6.3.2 Assessment of synergies between systems........................................................... 116

6.3.3 System saturation due to EV penetration.............................................................. 119

6.4 Concluding remarks ................................................................................................... 126

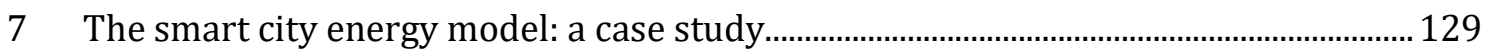

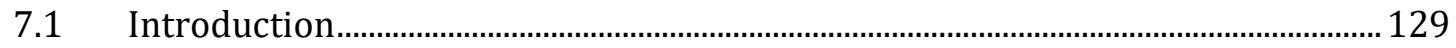

7.2 Case study description and parameters....................................................................... 130

7.2.1 motivation for this study ………………............................................................ 130

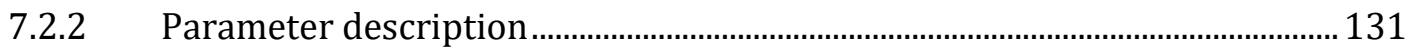

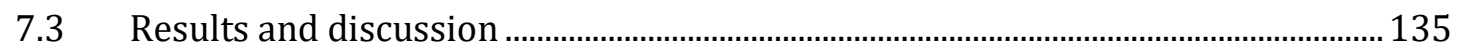

7.3.1 Result discussion and case study comparison..................................................... 135

7.3.2 Aggregated system behaviour for all study cases .............................................. 140

$7.4 \quad$ Concluding remarks ......................................................................................................... 154

8 Conclusions, Contributions and Future Work ....................................................................... 156

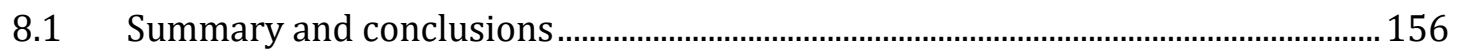

8.2 Original contributions ................................................................................................ 160

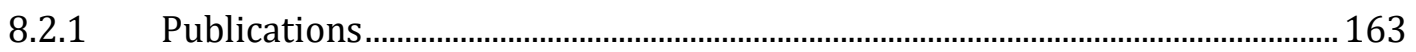

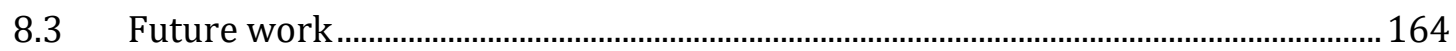

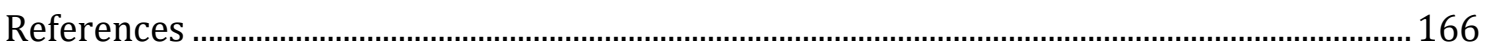




\section{LIST OF FIGURES}

Fig. 1. Structure of the document. 7

Fig. 2. Classification of energy intervention areas in the Smart City.......................................10

Fig. 3. General energy system design model............................................................................... 32

Fig. 4. Diagram of the model time structure

Fig. 5. block diagram of the assessment of network thermal constraint in der systems

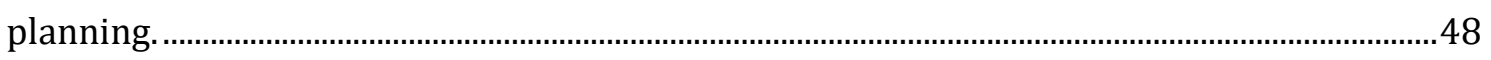

Fig. 6. Demand curves and annual evolution for residential sector in Spain............................51

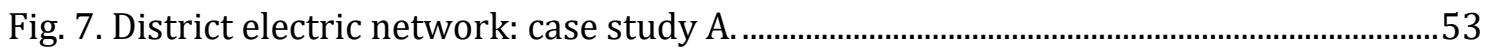

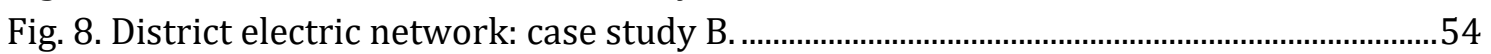

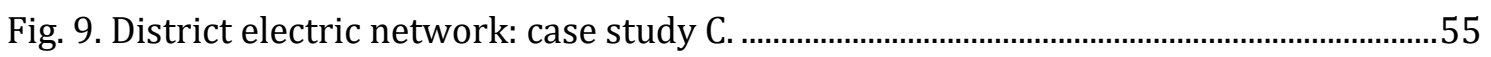

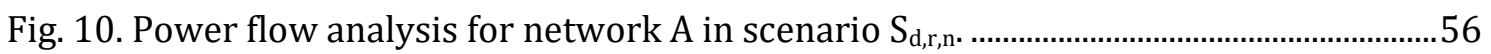

Fig. 11. Load flow analysis detail for the representative day of December (case study A)..59

Fig. 12. Normalized demand curves for winter time........................................................................ 73

Fig. 13. Normalized demand curves for summer time. ................................................................ 74

Fig. 14. Monthly demand variation for the residential electric sector in Spain .........................75

Fig. 15. Residual demand curves of all days of January at hour 10 and the computed

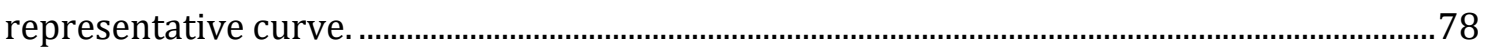

Fig. 16. Piecewise linear approximation of the energy cost curve (Case study A, January

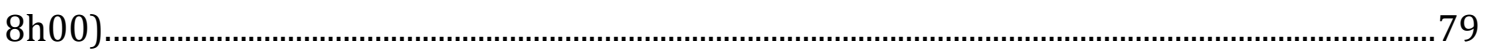

Fig. 17. Piecewise linear approximation of the energy cost curves (Case study B and C,

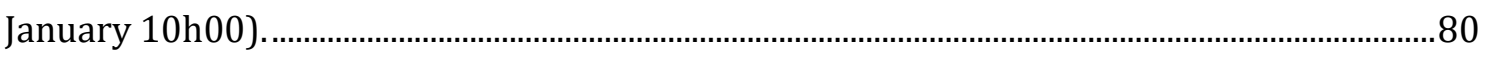

Fig. 18. Adjusted residual demand curve (January 10h00).........................................................

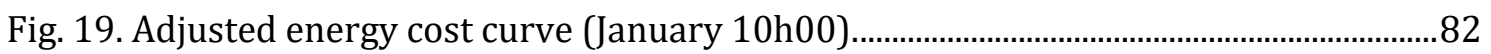

Fig. 20. Approximate demand distribution of the spanish system.............................................83

Fig. 21. Total costs per household (at the end of the 20 years project lifespan)......................90

Fig. 22. Percentage of economic benefits in comparison with the base case............................91

Fig. 23. Aggregator energy transactions and effect on energy price for the representative day of January (Case study A), a) for 40000 , b) 1000000 and c) 8000000 houses.................93

Fig. 24. Aggregator energy transactions and effect on energy price for the representative day of July (Case study A), a) for 40000, b) 1000000 and c) 8000000 houses........................94

Fig. 25. Aggregator energy transactions and effect on energy price for the representative day of January (Case study B), a) for 40000 , b) 1000000 and c) 8000000 houses.................95

Fig. 26. Aggregator energy transactions and effect on energy price for the representative day of July (Case study B), a) for 40000, b) 1000000 and c) 8000000 houses........................96

Fig. 27. Aggregator energy transactions and effect on energy price for the representative day of January (Case study C), a) for Sc1, b) Sc2 and c) Sc3, all with 1000000 houses.........97 Fig. 28. Aggregator energy transactions and effect on energy price for the representative day of July (Case study C), a) for Sc1, b) Sc2 and c) Sc3, all with 1000000 houses................98 Fig. 29. demand response and battery operation for the representative day of July (Case study C), for Sc3 with 1000000 houses.................................... Error! Bookmark not defined.

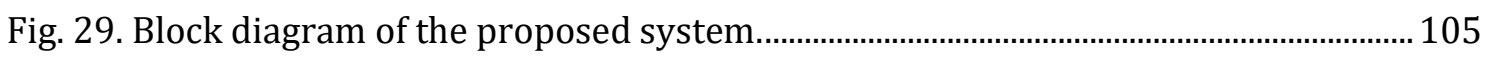

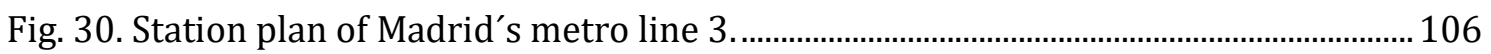

Fig. 31. Villaverde Alto substation electric energy profiles......................................................... 108 
Fig. 32. EV user availability and minimum State-of-charge requirement.

Fig. 33. Installed capacity of DER systems for different district sizes, and with full connection metro-EV.

Fig. 34. Annual electric energy and power costs for the metro substation. ........................... 113

Fig. 35. Metro electrical substation contracted power.............................................................. 114

Fig. 36. Total electric energy costs for the district.................................................................. 115

Fig. 37. Total annual costs for all the considered systems including DER investments, and without EV costs.

Fig. 38. Annual metro electricity costs for $\mathrm{CS}_{250 \mathrm{DCl}}, \mathrm{CS}_{250 \mathrm{dCl}}$ and $\mathrm{CS}_{250 \mathrm{DCl}}$, and different levels of EV penetration.

Fig. 39. Annual energy transfers Metro-EV for $\mathrm{CS}_{250 \mathrm{DCl}} \mathrm{CS}_{250 \mathrm{dCl}}$ and $\mathrm{CS}_{250 \mathrm{DCL}}$, and different levels of EV penetration.

Fig. 40. District electricity costs for different levels of EV penetration (with EV costs)....123

Fig. 41. Annual total costs for different levels of EV penetration (without EV costs)......... 124

Fig. 42. Operation of the district loads and DER systems for CS250Dcl and 150 EVs in a summer day

Fig. 43. Operation Savings of the three case studies in comparison with the base case.... 126

Fig. 44. districts of Madrid city and selected area for this study............................................. 132

Fig. 45. section of a geographic metro map of Madrid city...................................................... 133

Fig. 46. Total electric energy usage for the selected metro lines............................................. 134

Fig. 47. Aggregator energy transactions and effect on energy price for the representative day of January (Case study A) for 1000 EVS............................................................................ 142

Fig. 48. Aggregator energy transactions and effect on energy price for the representative day of July (Case study A) for 1000 EVS..................................................................................... 143

Fig. 49. Aggregator energy transactions and effect on energy price for the representative day of January (Case study A) for 15000 EVS. ...................................................................... 144

Fig. 50. Aggregator energy transactions and effect on energy price for the representative day of july (Case study A) for 15000 EVS. 145

Fig. 51. Aggregator energy transactions and effect on energy price for the representative day of January (Case study B) for 15000 EVS.

Fig. 52. Aggregator energy transactions and effect on energy price for the representative day of july (Case study B) for 15000 EVS.

Fig. 53. Aggregator energy transactions and effect on energy price for the representative day of January (Case study C, scenario 1) for 15000 EVS.

Fig. 54. Aggregator energy transactions and effect on energy price for the representative day of January (Case study C, scenario 2) for 15000 EVS.

Fig. 55. Aggregator energy transactions and effect on energy price for the representative day of January (Case study C, scenario 3) for 15000 EVS.

Fig. 56. Aggregator energy transactions and effect on energy price for the representative day of july (Case study C, scenario 1 ) for $15000 \mathrm{EVS}$.

Fig. 57. Aggregator energy transactions and effect on energy price for the representative day of july (Case study C, scenario 2) for 15000 EVS.

Fig. 58. Aggregator energy transactions and effect on energy price for the representative day of july (Case study C, scenario 3) for 15000 EVS. 153 


\section{LIST OF TABLES}

Table 1.Comparison of most common distributed energy sources ............................................11

Table 2. Summary of DG application examples. ……...............................................................15

Table 3. Comparison of common electric storage technologies....................................................17

Table 4. Summary of ESS application examples............................................................................19

Table 5. Summary of smart infrastructure application examples. ............................................22

Table 6. Summary of facilities application examples......................................................................25

Table 7. Comparison of non-fossil fuel vehicle technologies........................................................26

Table 8. Summary of Transport systems application examples....................................................29

Table 9. Energy system modeling, input description and information sources. ......................33

Table 10. Average annual energy consumption per household in Spain (2011).....................51

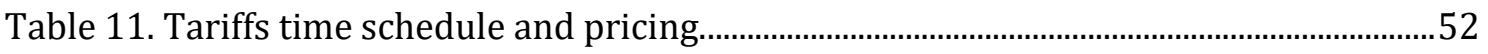

Table 12. Technology costs and expected energy losses................................................................52

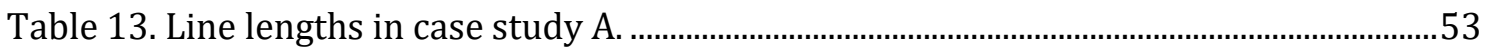

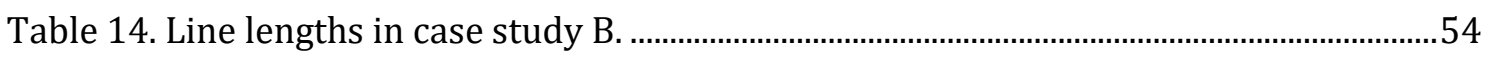

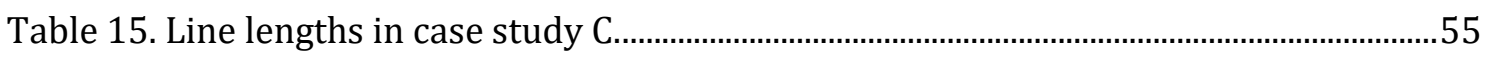

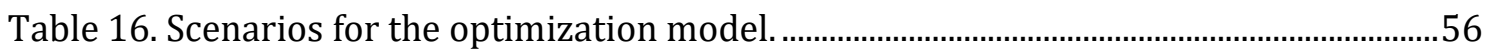

Table 17. Installed PV power in case study A (kW).......................................................................57

Table 18. Installed heat pump power in case study A (kW). ....................................................5

Table 19. Installed Battery system capacity in case study A (kWh) ..........................................58

Table 20. Contracted electric power per node in Case study A (kW) .......................................58

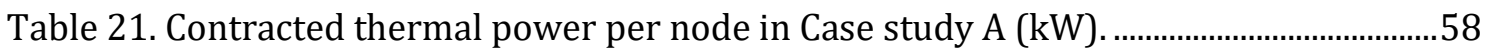

Table 22. Total costs in Case study A........................................................................................60

Table 23. Total installed capacity and contracted power in case study B (kW).....................61

Table 24. Total costs in case study B. ....................................................................................61

Table 25. Total installed capacity and contracted power in case study C (kW)......................62

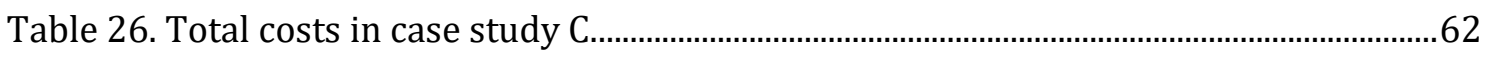

Table 27. Summary of benefits for all case studies.................................................................63

Table 28. Summary of resource aggregation models with market participation. ....................68

Table 29. Total annual energy consumption per client type....................................................... 74

Table 30. Power tariffs and thermal energy pricing. ……………….............................................76

Table 31. Technology costs and expected energy losses.............................................................76

Table 32. DER installed capacity for all case studies. .................................................................. 84

Table 33. Total system cost (energy, DER investments and o\&M) for all case studies.........84

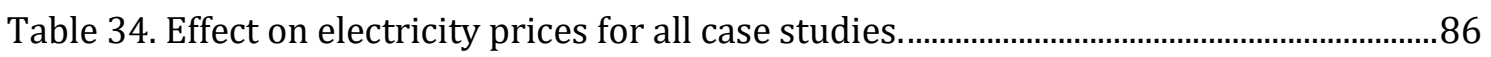

Table 35. Effect on electric energy cost for all case studies. ........................................................87

Table 36. impacts of electric energy costs for all market participans (energy prices of case

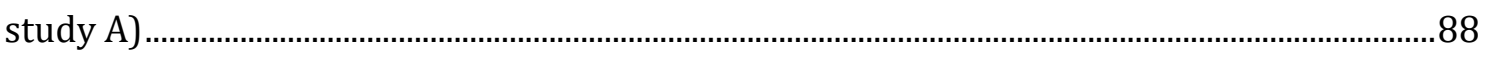

Table 37. average weighted energy prices for all market participans (energy prices of case

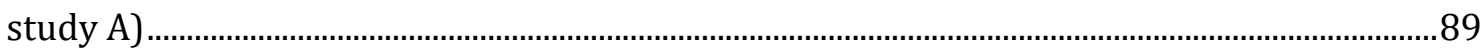

Table 38. Total costs per household (including DER investments)...........................................89

Table 39. Percentage of total savings in comparison with the base system costs of each case

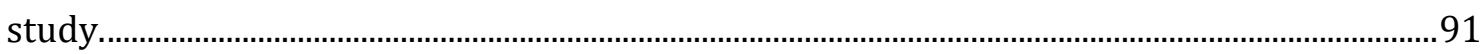

Table 40. Percentage of savings per house in comparison with the smallest district............92 
Table 41. Consumed and regenerated energy per train and journey, between the Villaverde Alto and C. de los Angeles metro stations............................................................................... 107

Table 42. Residential energy tariffs and time schedules........................................................... 110

Table 43. Metro energy tariffs and time schedules.................................................................... 110

Table 44. Summary of case studies considered........................................................................ 111

Table 45. Summary of capacity and costs increments when the EV number goes from 25 to

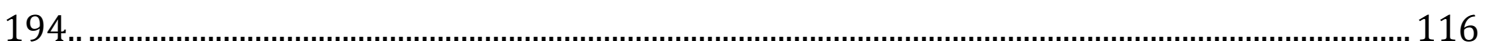

Table 46. Energy costs for all case studies (250x4 households)............................................. 117

Table 47. Power costs for all case studies (250x4 households)................................................117

Table 48. Der and total cost for all case studies (250x4 households).....................................117

Table 49. Sensitivity analysis for metro energy profiles (total costs with 194 EVs AND 250x4

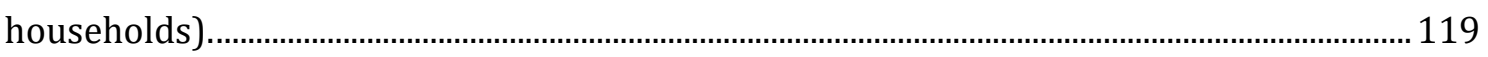

Table 50. Impacts on the three case studies comparing the $25 \mathrm{EVs}$ case with the EV

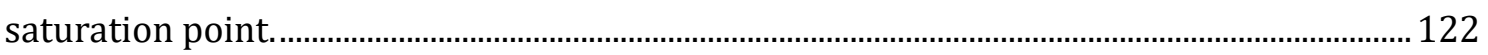

Table 51. Savings of the case studies in comparison with the base case...................................126

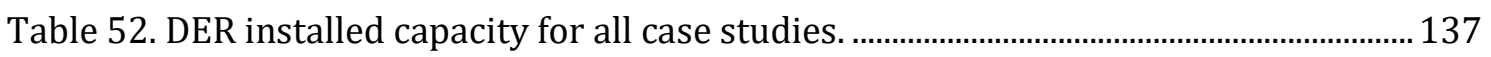

Table 53. Total system cost (Metro, EV and district energy and DER costs) for all case studies (at the end of the 20 years project lifespan).............................................................................. 137

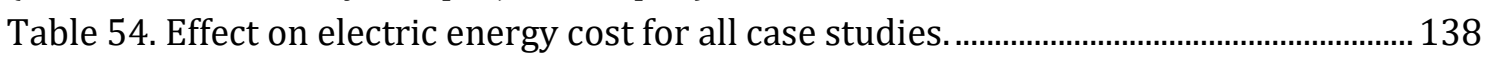

Table 55. Effect on electricity prices for all case studies.......................................................... 139

Table 56. Percentage of total savings (considering all systems and all costs) in comparison with the base system costs of each case study. ......................................................................... 140 


\section{ABBREVIATIONS}

\begin{tabular}{ll} 
AC & Alternate current \\
CAES & Compressed Air Energy Storage \\
CHCP & Combined heat, cooling and power \\
CHP & Combined heat and power \\
CO2 & Carbon dioxide \\
COP & Coefficient of performance \\
CS & Case study \\
CSP & Concentrated solar-power \\
DC & Direct current \\
DER & Distributed energy resources \\
DG & Distributed generation \\
DNI & Direct normal irradiance \\
DSO & Distribution system operator \\
EPEC & Equilibrium problem with equilibrium constraints \\
ESS & Energy storage system \\
EV & Electric vehicle \\
FACTS & Flexible AC transmission systems \\
GHG & Greenhouse gas \\
GHP & Geothermal heat pump \\
HEV & Hybrid electric vehicle \\
HF & Head of the family \\
HP & Heat pump \\
HVAC & Heating, ventilation and air conditioning \\
ICE & Internal combustion engine \\
LCOE & Levelised cost of energy \\
MCP & Mixed complementarity problem \\
MILP & Mixed integer linear programming \\
MPEC & Mathematical problem with equilibrium constraints \\
NLP & Non-linear problem \\
NPV & Net present value \\
PHEV & Plug-in hybrid electric vehicle \\
PQ & Powe quality \\
PV & Solar photovoltaic panel \\
PV/T & hybrid photovoltaic/thermal panel \\
RDC & Residual demand curves \\
RES & Renewable energy sources \\
ROI & Return of investment \\
S & Scenario \\
SMES & Superconducting Magnetic Energy Storage \\
SOC & State-of-charge \\
SW & Software \\
TC & Thermal collector \\
VPP & Virtual power plant \\
WT & \\
& Wind turbine \\
\hline
\end{tabular}




\section{NOMENCLATURE}

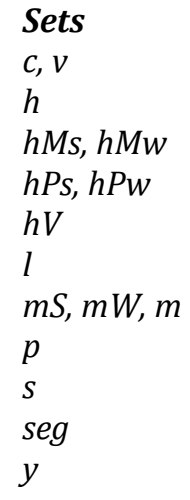

\section{Parameters}

$p A v E V_{v, h}$ pAvgSystDemand $_{m, h}$ pBuyEprice $H_{m, h}$, pBuyEprice $M_{m, h}$ $p C O P$

pCostBat

$p \operatorname{CostPV}, p \operatorname{CostHP}$

$p \operatorname{Cost} T_{y}, p \operatorname{Cost} E_{y}, p S e l l E_{y}$

pDays $M_{m}$ pDemandElec $c, m, h$

pDemandShift

pDemandTherm ${ }_{c, m}$ pDNIm,h pDRequipCost pEffBat pEffCHPe, $p$ EffCHPt pEffTC pEVcap pEVnum

pFixEpow, pFixTpow

pGridTariffEE

pHouseMultiplier pHouseNum

pLifespan

pLineCap

pLineReinforcementCost pLossesCHPe, pLossesCHPt pLossesPV, pLossesHP pLossesTC pLossesWT

pMetLoad $_{h}$ pMetReg $h$ pOMfixPV, pOMfixHP
Type of houses (1- pHouseNum) and EV users $(1,2)$

Hour (1-24)

Summer and winter mid-peak hours for time-of-use tariffs Summer and winter peak hours for the time-of-use tariffs Off-peak hours for the electric time-of-use tariffs

Power lines in the considered network (1-n, according to the network)

Summer (3-8), winter (1,2,9-12) and all months (1-12)

Points of the piecewise linear function $=1-23$

Number of scenarios $=1-3$

Linear segments of the piecewise linear function $=1-22$

Years $(1-$ LLifespan $)$

Max. available capacity of EVs (kWh)

Average total system demand (MWh)

Electricity base residential and commercial prices $(€ / \mathrm{kWh})$

Coeff. of Performance for HP

Total upfront cost of batteries, considering a replacement every 8 years $(€ / \mathrm{MWh})$

Total cost per installed Watt of PV and HP (€/MW)

Annual increment of thermal and electric energy base buying and selling prices (\%)

Number of days in month $m$

Base electric demand curve for 12 representative days (MWh)

Maximum allowed load to be shifted per day of the base electric demand (\%)

Total thermal demand for 12 representative days (MWh)

Direct normal irradiance for solar production (W)

Costs of equipment required to do load shifting (€/client)

Battery charge and discharge efficiency (\%)

CHP electric and thermal efficiency (\%)

Thermal collector efficiency (\%)

Max. storage capacity per EV (kWh)

Number of equivalent vehicles per EV user type

Annual access tariff for residential electric and thermal power $(€ / \mathrm{kW}$, $€ /$ client)

Share of the variable electricity tariff that correspond to network costs $(€ / M W h)$

Number of equivalent clients per house type

Number of different houses

Expected lifespan for PV and HP systems in the study (20 years)

Maximum power line capacity (MWh)

Power line reinforcement cost $(€ / \mathrm{m})$

Total electric and thermal losses for CHP systems (\%)

Total losses in the PV and HP systems (\%)

Total losses for TC systems (\%)

Total losses for WT systems (\%)

Base electric demand curve and regenerative braking energy for the metro trains connected to the substation (kWh)

Fixed annual operation and maintenance costs per installed Watt of PV and HP (€/MW) 
pPeakPowM, pMidPpowM, Annual access tariff for commercial (metro) electric power at peak, midpOffPpowM pProbAvgs

pProbs $s, m, h$ pSellEpriceH pSOCinitEV $V_{v, h}$ pSOCminEV $V_{v, h}$ $p$ Vwind $_{m, h}$ pXparameter ${ }_{s, p, m, h}$

pYparameter ${ }_{s, p, m, h}$ peak and off-peak hours $(€ / \mathrm{kW})$

Average probabilities for each scenario (\%)

Probabilities for each scenario and each hour (\%)

Electricity base selling price $(€ / \mathrm{kWh})$

SOC of the arriving EV (\%)

Minimum SOC requirement for EV (\%)

Wind speed for wind turbine production $(\mathrm{m} / \mathrm{s})$

"X" value (energy) of the point $p$ in the piecewise linear functions (MWh) " $Y$ " value (energy cost) of the point $p$ in the piecewise linear functions $(€ / \mathrm{MWh})$

\section{Variables}

$v$ BatCap $_{c}$

$v$ ChBat $_{c, m, h}, v$ DisBat $_{c, m, h}$

$v C h E V_{v, m, h}, v$ DisEV $V_{v, m, h}$

vChMetro ${ }_{v, m, h}$

${ }_{\text {DisMetro }}, m, h$

$v$ DecDemand $c_{c, m, h}$

$v$ DemandNew $w_{c, m, h}$

vfuel $l_{c, m, h}$

$v$ GridCostE $E_{s, m, h}$

vGridEnTotalPosm,h

vGridEnTotalNeg ${ }_{m, h}$

$v$ HPenInput $t_{c, m, h}$

vIncDemand $_{c, m, h}$

vLoadMnew,$h$

$\checkmark P o w C H P_{c}$

$v$ PowElect

$v$ PowHP

Battery installed capacity (MWh)

Battery charged and discharged Energy (MWh)

Energy charged and discharged to/from EV (MWh)

Energy charged and discharged from EV to the metro system (MWh)

Decrease in base demand(MWh)

New consumption curve after changing the base profile (MWh)

Input fuel for CHP production (MWh)

Cost related to network operation and maintenance $(€)$

Total energy transaction to the grid (buying, positive, and selling, negative) (MWh)

Electricity for thermal production with HP (MWh)

Increase in base demand (MWh)

New metro consumption curve after changing the base profile (MWh)

CHP installed capacity (MW)

Contracted annual electric power (MW)

HP installed capacity (MW)

$v$ PowPeakM, vPowMidpM, Contracted annual electric power for the metro system at peak, midvPowOffpM

$v P_{P o w P}$

$v \operatorname{PowTC}_{c}$

$v P o w W T_{c}$

$v$ ProdCHPe $_{c, m, h}$

$v$ ProdCHPt $_{c, m, h}$

$v$ ProdHP $P_{c, m, h}$

$v \operatorname{ProdPV}_{c, m, h}$

$v \operatorname{ProdTC}_{c, m, h}$

$v \operatorname{Prod} W T_{c, m, h}$

$v S O C_{c, m, h}$

$v S O C E V_{v, m, h}$

vThBuy ${ }_{c, m}$

$\lambda_{s, p, m, h}$ peak and off-peak hours (MW)

PV installed capacity (MW)

TC installed capacity (MW)

Wind turbine installed capacity (MW)

Electric CHP production (MWh)

Thermal CHP production (MWh)

Thermal HP production (MWh)

Electric PV production (MWh)

Thermal TC production (MWh)

Electric WT production (MWh)

Battery State-of-Charge (MWh)

EV State-of-Charge (MWh)

Thermal energy bought (natural gas) from the grid to meet the daily demand (MWh)

Auxiliary continuous variable for the piecewise linear functions

\section{Free Variables}

vAbsPriceChange

$v$ AvgPriceOriginal

$v$ CostBat

$v$ CostClientNewDistrict

$v$ CostClientSmallestDistrict

$v$ CostDR

$v$ CostDistEE

$v$ CostDistPowE

$v$ CostET

Change, in absolute values, of electricity price due to aggregator's actions (\%)

Original average market electricity price $(€ / \mathrm{MWh})$

Total battery investment costs (€)

Total costs per client at all other considered districts (€)

Total costs per client at the smallest considered district (€)

Total considered costs for demand response equipment (€)

Total electric energy cost for the considered district (€)

Total electric power cost for the considered district (€)

Total thermal energy cost for the considered district $(€)$ 


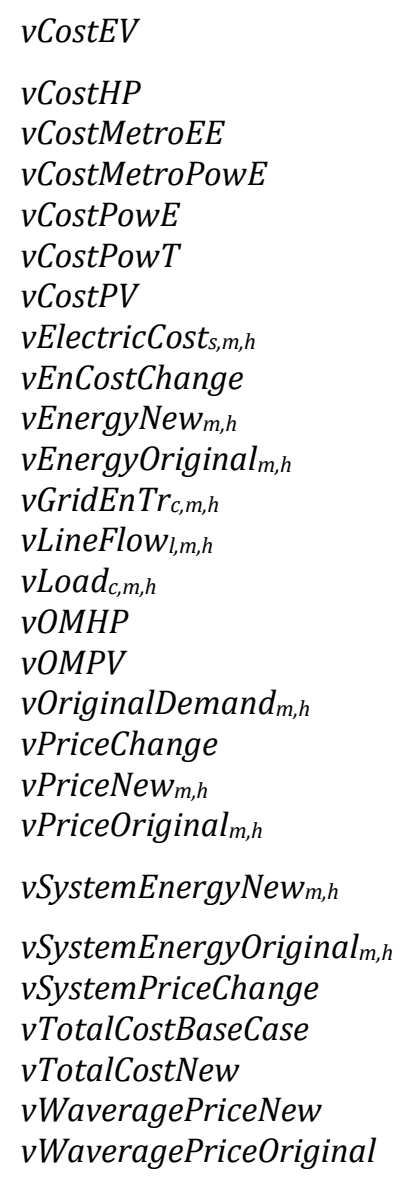

\section{Binary Variables}

$\chi_{s, \text { seg, } m, h}$
Extra EV costs due to batteries degradation for extra charging and discharging $(€)$

Total heat pump investment costs (€)

Total electric energy cost for the considered metro system (€)

Total electric power cost for the considered metro system (€)

Total electric power cost for the considered district (€)

Total thermal power cost for the considered district $(€)$

Total PV investment costs (€)

Cost or benefit of electric energy transaction (€)

Electric energy cost change (\%)

New energy transactions from the district (with DER) (MWh)

Original energy transactions from the district (No DER) (MWh)

Energy transaction to the grid (MWh)

Energy flow through power line $l(\mathrm{MWh})$

Household load (MWh)

Total HP operation and maintenance costs (€)

Total PV operation and maintenance costs (€)

Original electric demand of the considered district (MWh)

Change of electricity price due to aggregator's actions (\%)

New market electricity price (€/MWh)

Original market electricity price $(€ / M W h)$

New energy (after the DER penetration) of the Spanish electric system (MWh)

Original energy of the Spanish electric system (MWh)

Average system price change (\%)

Total costs at the end of the study for the base case (No DER) (€)

New total costs at the end of the study for the districts (with DER) ( $€$ )

Energy weighted new average system price (€/MWh)

Energy weighted original average system price (€/MWh)

Auxiliary binary variable for the piecewise linear functions 


\section{1 \\ INTRODUCTION}

This first chapter introduces the motivation behind this thesis, and describes its main objectives. In addition, it provides the reader with the methodology followed to achieve the thesis objectives, and presents a general overview of the organization and structure of the dissertation to make it easy to follow.

\subsection{Motivation}

Today, $54 \%$ of the world's population lives in urban areas, and it is expected that this proportion will increase to $2 / 3$ of the total population by 2050 . In absolute values, more than 6 billion people could live in cities by 2050, produced by urbanization projections combined with the overall growth of the world's population [1]. In a European context, currently, 78\% of Europe's population live in cities, and 85\% of the EU's GDP is generated in cities. Therefore, cities are forerunners in the much-needed transition towards a low carbon, efficient and competitive economy [2]. Certainly, cities have been recognized as one of the main players in addressing many key challenges for the society and economy, including low-carbon development, $\mathrm{CO}_{2}$-reduction, energy-efficiency, renewable sources innovation, economic growth, job creation, etc.

The smart city is a relatively new concept that has been defined by many authors and institutions and used by many more. In a very simple way, the smart city is intended to deal with or mitigate, through the highest efficiency and resource optimization, the problems generated by rapid urbanization and population growth, such as energy supply, waste management, and mobility. The smart city concept, just like the smart grid, is heavily based on the interconnectivity of systems, where information and communication technologies play a key role [3]. Many classifications of smart-city intervention areas can be found in the literature, as in [4] and [5]. A drawback of these classifications is that they categorize energy aspects mainly based on the smart grid (focusing in distributed generation and storage), but overlook other relevant energy elements like transport and facilities. Another drawback is that these classifications does not explore the synergies that could result from the interconnectivity of systems.

Cities' energy requirements are complex and abundant. In consequence, modern cities should improve present systems and implement new solutions in a coordinated way and 
through an optimal approach, by profiting from the synergies among all these energy solutions. The intermittency of renewable sources, the increasing demand, and the necessity of energy-efficient transport systems, among other things, represent important energy challenges that are better addressed as a whole [6] rather than separately, as is usually the case.

Simulation models have been developed to assist stakeholders in understanding urban dynamics and in evaluating the impact of energy-policy alternatives. However, very often these efforts address energy areas separately (very specialized tools that focus in particular systems). For instance, a model for smart EV charging that only consider EV loads, might not take into account other transportation systems, the state of the power network, the presence of distributed generation, the possibility to supply energy to facilities, etc. This approach could be adequate for its original purpose, but it can be insufficient if the objective is to take the maximum advantage from the energy systems. Going back to the previous example, the EV smart charging model can take advantage of introducing other distributed energy resources and participating in the electricity market.

Therefore, a comprehensive smart-city model that includes all energy-related activities, while keeping the size and complexity of the model manageable, is highly desirable to plan and design the best routes of action to successfully meet the increasing energy needs of present and future cities.

\subsection{ThESIS OBJECTIVES}

Models and simulators have been widely used in urban context for many decades. The drawback of most current models is that they are normally designed for specific objectives such as traffic control, planning of urban growth, expansion planning of generation capacity or transmission lines, etc. Therefore, the elements considered are limited and they do not take into account the potential synergies between related systems. The former is especially important due to the expected increasing interdependency of systems, facilitated by the increasing presence of information and communication technologies that should allow more global approaches for planning and operation of such systems.

The necessity of a framework to model the complex smart city systems with a comprehensive smart city model has been remarked by many authors. The desired smart city energy model is intended to be used by decision makers (national or local public administrations, but could also be useful for particular industries) to simulate, analyse and select the best systems at a minimum cost, fostering the creation of smarter and more efficient cities.

Therefore, the main research objectives approached in this $\mathrm{PhD}$ thesis are:

- The proposal of a general conceptual framework for the modelling of energy related activities in the smart cities, based on determining the spheres of influence and intervention areas within the city, and on identifying agents and potential synergies among systems.

- The development of a holistic energy model of a smart city for the assessment of different courses of action of most intervention areas identified in the precedent objective, given its geo-location, regulatory and technical constraints, and current 
energy markets. This involves the creation of an optimization model that permits the optimal planning and operation of energy resources within the city.

Indeed, the model should be comprehensive, so the synergies between systems can be identified and properly assessed. It should also provide the optimal planning and operation of the energy systems, according to the economic costs and benefits. This can help decision makers in the assessment of the profitability of the considered systems, assisting them in their implementation. Finally, the model should be flexible and scalable, so that it can be used for different technologies and urban contexts. Such a model could assist decision makers in evaluating technological and regulatory requirements of the city energy systems.

In [7], it is remarked the importance of using a methodology to model complex systems successfully. Unfortunately, it was not possible to find in the literature a methodology to create a smart city energy model like the one proposed in this thesis. Hence, a methodology is proposed, trying to fill this gap.

\subsection{METHODOLOGY TO BUILD THE SMART CITY ENERGY MODEL}

The following methodology will be employed to achieve the thesis objectives of creating a comprehensive smart city energy model, for the planning and operation of energy resources. It is formed by four main tasks:

1. Identification of energy systems

a. Evaluation of energy systems and its applicability to the smart city context, assessing their importance and possible synergies.

b. Review of the existing models and tools, and identification of features and limitations from current energy models.

c. Review of modelling methodologies, including types of suitable optimization problems.

d. Selection of the energy systems to be modelled, and ways to do it. Making sure to include representative energy systems from all the intervention areas identified.

2. Selection of models

a. Identification of inputs and outputs.

b. Identification of model characteristics, including scope, timeframes, modelling approach, etc.

3. Exploration of model considerations and restrictions (hypothesis for the model). Different features and elements are modelled to contrast the thesis hypothesis, which are proposed with the objective of focusing the scope and to simplify the final smart city energy model. Also, note that these features have not been analysed by current energy system models.

a. Hypothesis 1: considering the objective of the model (planning and operation of energy systems), it is not necessary to consider electric network constraints (power line thermal limits) in the planning process, and just reinforce the network when needed (analysed in chapter 4).

b. Hypothesis 2: the level of aggregation impacts the planning and operation of the considered distributed energy systems (analysed in chapter 5). 
c. Hypothesis 3: there are synergies between the considered energy systems when they are interconnected and a joint management is carried out (analysed in chapter 6).

4. Analysis of the designed smart city energy model, attending at the results of step 3.

a. Development of a case study simulating a small real smart city application, to show some of the potential analysis that can be carried out with the smart city energy model.

Note that there are other models and software tools for the planning and operation of energy systems. For instance, DERCAM [8] and HOMER [9] have been used extensively for several years (see chapter 2 for examples of applications of these models). However, these models have been designed for particular objectives and might not be able to exploit all the possibilities and synergies present in a smart city. Some of the features that are not considered by current energy system models are:

- Current models commonly consider the energy market in a simplistic way, and the impact of aggregation on energy market prices could be overlooked, as these models normally follow a price-taker approach. Such approaches could not be suitable when the amount of aggregated resources increases significantly. Hence, a smart city energy model should be able to consider the active participation of agents (aggregators and retailers) in the energy market and the impacts on the energy prices to assess its relevance, to obtain a more realistic approximation of the maximum possible benefit from the synergies and the systems considered.

- Indeed, current models consider most generation and storage technologies, but do not include other relevant urban energy systems (such as public transport) in their planning process, which is a key feature for an interconnected smart city environment. Even though it is impossible to integrate all the elements into a smart city model, it should consider all intervention areas studied in this thesis, including the most relevant agents and technologies. In this thesis, the energy-related elements considered are: EVs, DER systems, facilities (including demand response schemes), and public transport systems (metro lines).

- Many current energy system planning models do not consider network constraints (following a single-node approach), without being able to assess its relevance for the planning and operation of systems, or how much this affects the outcomes. However, the need of assessing the impact of grid reinforcement is a major concern in the related literature on energy systems planning, although before this dissertation was written, this issue had not been successfully addressed.

Therefore, the three hypotheses previously mentioned are explored to assess the importance of including these characteristics in the smart city energy model.

Following this methodology and with the objectives of the thesis in mind, the smart city energy model proposed will have the following characteristics:

- The scope of the model is the long term, with a time step of 1 hour, considering 12 representative days per year (i.e. 288 hours per year). This gives an adequate level of detail without increasing considerably the computational burden. Indeed, some 
kind of hourly detail is advisable to adequately represent the daily stationarity renewable generation and consumption patterns.

- A stochastic mixed integer linear programming problem has been selected, as suitable to solve the desired optimal planning and operation of energy systems, considering a certain level of uncertainty, with a reasonable level of detail and complexity.

- The proposed smart city energy model includes DER, EVs, residential districts with demand-response capabilities, and metro lines, which are representative systems of the five intervention areas defined in the literature review (see chapter 2).

- All the modelled energy systems will be considered to be interconnected, so energy can flow among the DER systems located at the residential district, the EVs, and the metro electrical substations (see chapter 6).

- The energy systems are managed by an aggregator that participates in the wholesale electricity market (day-ahead session) as a price-maker agent than can influence the final price (depending on its size), modelled with residual demand curves. The stochasticity of the MILP problem allows to model different energy residual demand curve scenarios, obtaining more robust planning results (see chapter 5).

- Network thermal constraints are not considered in the final model, but they were implemented to test hypothesis 1 in this methodology. This assessment (see chapter 4) revealed that the impact of such constraints could be neglected (at least in the analysed scenarios), avoiding additional model complexities.

\subsection{ORIGINAL CONTRIBUTIONS}

The main original contributions of this thesis are the following:

1. A comprehensive literature review of the smart city energy related elements, and the modelling approaches developed so far, and a classification of all the reviewed smart city energy systems and technologies, grouping them in 5 intervention areas.

2. A framework to create smart city energy models, describing the modelling options and the systems that should be taken into account. Note that a modelling framework and literature review such as the ones developed here, have not been found in the literature.

3. A comprehensive smart city energy model. Which considers representative systems from all the intervention areas described in the literature review, and it can be tailored to include different technologies and to participate in different energy markets. To the best of the author's knowledge, such a smart city energy model has not been developed yet, and it can serve as a tool for researchers, investors and policy makers to analyse smart city schemes, business models and policies.

4. An assessment of the importance of including network thermal constraints in the planning and operation of DER systems at a low voltage distribution level. This has been a concern to many researchers in the field. However, before this dissertation, there was no analysis addressing this question in the literature.

5. A price-maker DER systems planning and operation model, and an analysis of the impact on prices due to the aggregation levels. In DER systems planning, most of the available research work followed a price-taker approach, and the few price-maker 
models only considered the short-term operation. Hence, the proposed price-maker model filled a gap in the literature, also providing an important analysis on the changes of the price curves produced by DER aggregation.

6. The analysis of synergies of different systems in a smart city context. So far, researchers have focused in DER systems, only considering EVs from the transport area (but mainly modelling it as a battery). However, other relevant energy systems have been overlooked. The analysis developed included metro systems besides the EVs and DER, showing that such a scheme could be very profitable to all the involved systems, and it presents synergies that does not appear when the systems are managed independently.

\subsection{DISSERTATION OUTLINE}

Besides this introduction chapter, this document is structured around six central chapters (from chapter two to seven) plus a final chapter that summarizes the main findings of the research work, identifies the main contributions and outlines potential future works. The organization of this document is represented graphically in Fig. 1.

As anticipated in this introduction, the first task in this research work consisted in finding and choosing the most relevant energy systems and technologies that could be considered in the proposed smart city framework and model. Chapter 2 provides an extensive review that covers most of the energy related elements and smart city modelling approaches that can be found in the literature, and proposes a classification of all these elements, as well as a smart city energy modelling framework. This framework provides examples and guidelines for a successful smart city energy model for the planning and operation of energy systems to be implemented in an urban context. See [10] for a journal publication of this work.

With the energy technologies and systems identified, the modelling task is carried out in chapter 3. In this chapter, the full mathematical description of all the chosen smart city energy systems is provided (organized in 5 intervention areas: generation, storage, infrastructure, facilities and transports), and the particular considerations of the model (inputs, outputs, type, scope, and other features) are presented. It is important to remark that different analyses have been developed in this dissertation, and therefore, different versions of the model have been used by tailoring the general approach to the desired specific analyses. The particularities of the model used in each study are mentioned in their corresponding chapter. 


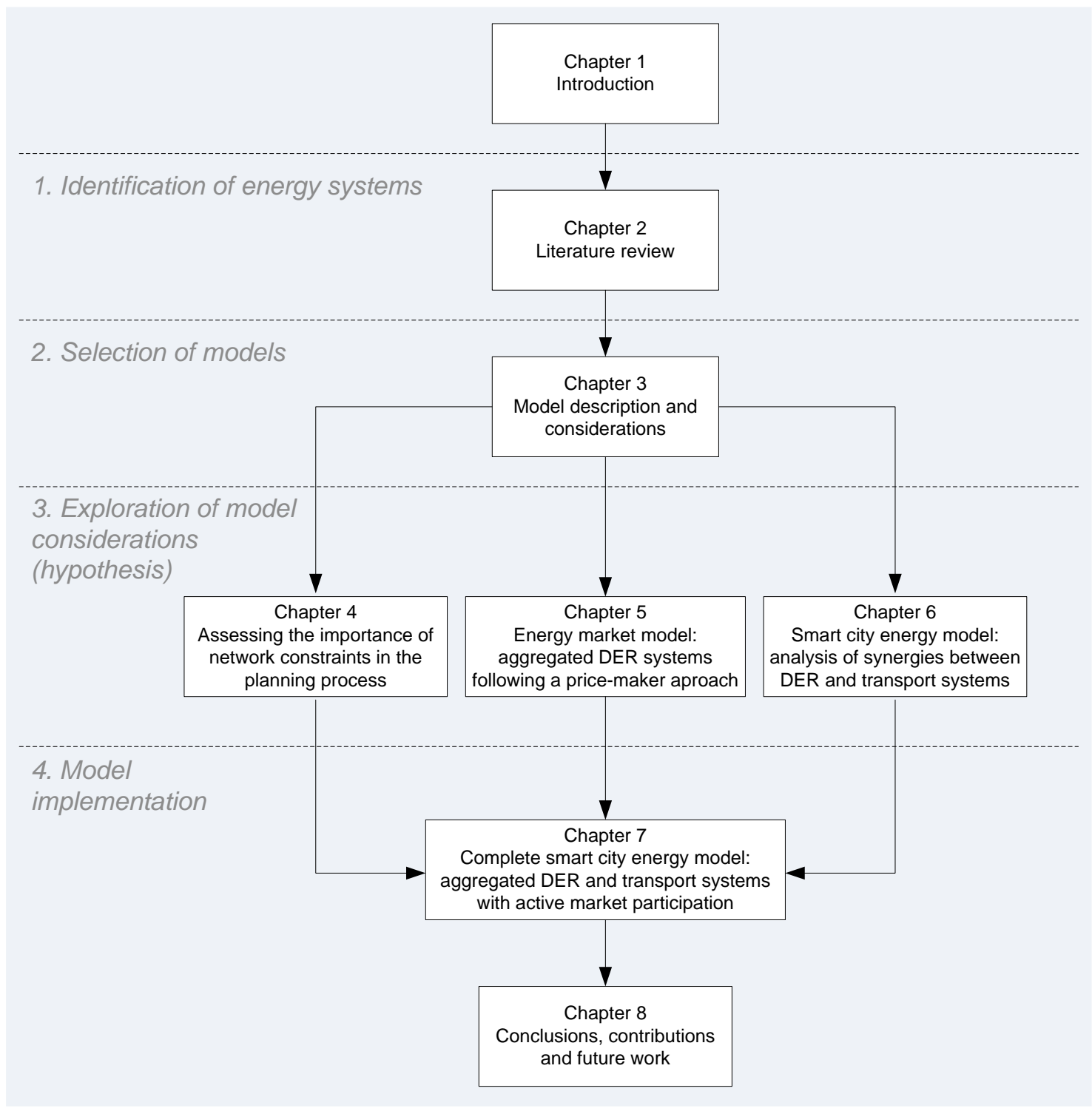

FIG. 1. STRUCTURE OF THE DOCUMENT.

Chapters 4, 5 and 6 present different analyses to assess the hypotheses made in section 1.3, and assist in the adequate modelling of the smart city. These chapters do not represent a sequence, as the hypothesis are complementary and the analysis for each one can be done independently (see Fig. 1).

The first analysis (chapter 4) addresses hypothesis 1, assessing to what extend it is worth considering or not the network thermal constraints at the planning stage of the smart city distributed energy resources, a question not previously clearly addressed in the literature. Results of the analysis show that in the case examples studied, it was more profitable not to include network thermal constraints at the planning stage, and just reinforce the power lines when it becomes necessary, suggesting that a similar strategy may be adopted for other district types with a similar impact. See [11] for a journal publication of this work.

The second analysis (chapter 5) addresses hypothesis 2, studying the impact of aggregation on the planning and operation of energy systems, and how the level of aggregation of the considered systems impacts the electricity market. Also, it is analysed how to model the 
electricity market adequately considering the characteristics of the desired smart city energy model. To do so, a price-maker model for optimal planning and operation of aggregated DER systems is proposed, and the changes on electricity prices is assessed. Results suggest that even for relatively small aggregations, the impact on electricity prices should always be considered in order to find optimal planning and operation strategies. See [12] for a journal publication of this work.

The third analysis (chapter 6) addresses hypothesis 3, exploring the possible synergies of different energy systems in the smart city, under an interconnected scheme with joint management of transport, facilities and distributed energy resources. It is also analysed the impact of EV penetration level and look for the saturation level at which the system does not profit anymore from the additional energy storage the EV may provide. Outcomes of this study show important economic benefits for the overall system, especially reducing the metro energy costs, even with a relatively small numbers of EVs. The work carried out in this chapter has been collected in two journal articles submitted and are currently under revision.

With all the knowledge and experience acquired from the previous analyses, the full smart city energy model is applied in chapter 7 , to a representative smart city case study, which can be considered as an example of a possible real smart city pilot project. The results obtained show the model can be successfully implemented and suggest ways in which the framework developed and the smart city energy model can be used.

Finally, chapter 8 summarizes the main conclusions and contributions of the thesis, summarizing the publications that have up to now resulted from the present research. In addition, it describes future research directions that seem worth exploring to complement the results obtained, as well as ways to improve the proposed model and framework, and the alternatives suggested to broaden the application scope of the solutions presented. 


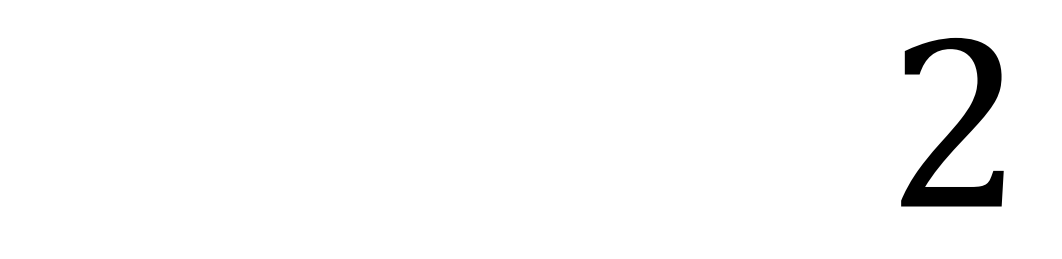

\section{LITERATURE REVIEW}

This chapter presents the identification of energy systems task, corresponding to the smart city energy model methodology described in section 1.3. This includes the evaluation of energy systems available in a smart city, assessing their importance and possible synergies, in addition to the review of the existing models and tools, to select which ones could be used.

The first part of the chapter introduces an overview of energy related work on planning and operation models within the smart city by classifying their scope into five main intervention areas. These areas are generation, storage, infrastructure, facilities, and transport. Then, more complex urban energy models integrating more than one intervention area are reviewed, outlining their advantages and limitations, existing trends and challenges, as well as some relevant smart cities applications. With this revision, important elements and possible synergies in the smart city are identified, and a framework for developing a comprehensive smart city energy model is proposed, along with some additional recommendations.

Therefore, the main contributions of this chapter are, first, a comprehensive literature review of smart city energy systems and related modelling tools, classifying them in five intervention areas, and second, a framework with guidelines and recommendations for developing a comprehensive smart city energy model.

The contents of this chapter draws on the journal article: C. F. Calvillo, A. Sánchez-Miralles, and J. Villar, "Energy management and planning in smart cities," Renewable and Sustainable Energy Reviews, vol. 55, pp. 273-287, Mar. 2016.

\subsection{INTRODUCTION}

The literature review carried out for this thesis has been intended to develop insight into the complexity of the energy-related activities in a smart-city context by reviewing advances and trends and by analysing the synergies among different intervention areas. This is thus the starting point to address the objectives described in section 1.2.

By reviewing some of the most typical applications found in the literature, this work has served to identify five main energy areas and related activities, which have been called intervention areas (see Fig. 2). These intervention areas are generation, storage, 
infrastructure, facilities, and transport (mobility). All these areas relate to each other but contribute to the smart city energy system in different ways: generation provides energy, storage helps in securing its availability, infrastructure involves the distribution of energy and the required information and communication technologies, and facilities and transport are the main final consumers of energy, as they need it to operate.

Common to all intervention areas are the way energy systems are implemented, which is generally supported by three main layers: the intelligence layer, related to control and management systems, the communication layer, and hardware layer, related to physical elements and devices [13]. Hence, multidisciplinary solutions are expected. This literature review mainly focuses on the hardware and intelligence layers (technologies, and simulation and modelling of energy systems).
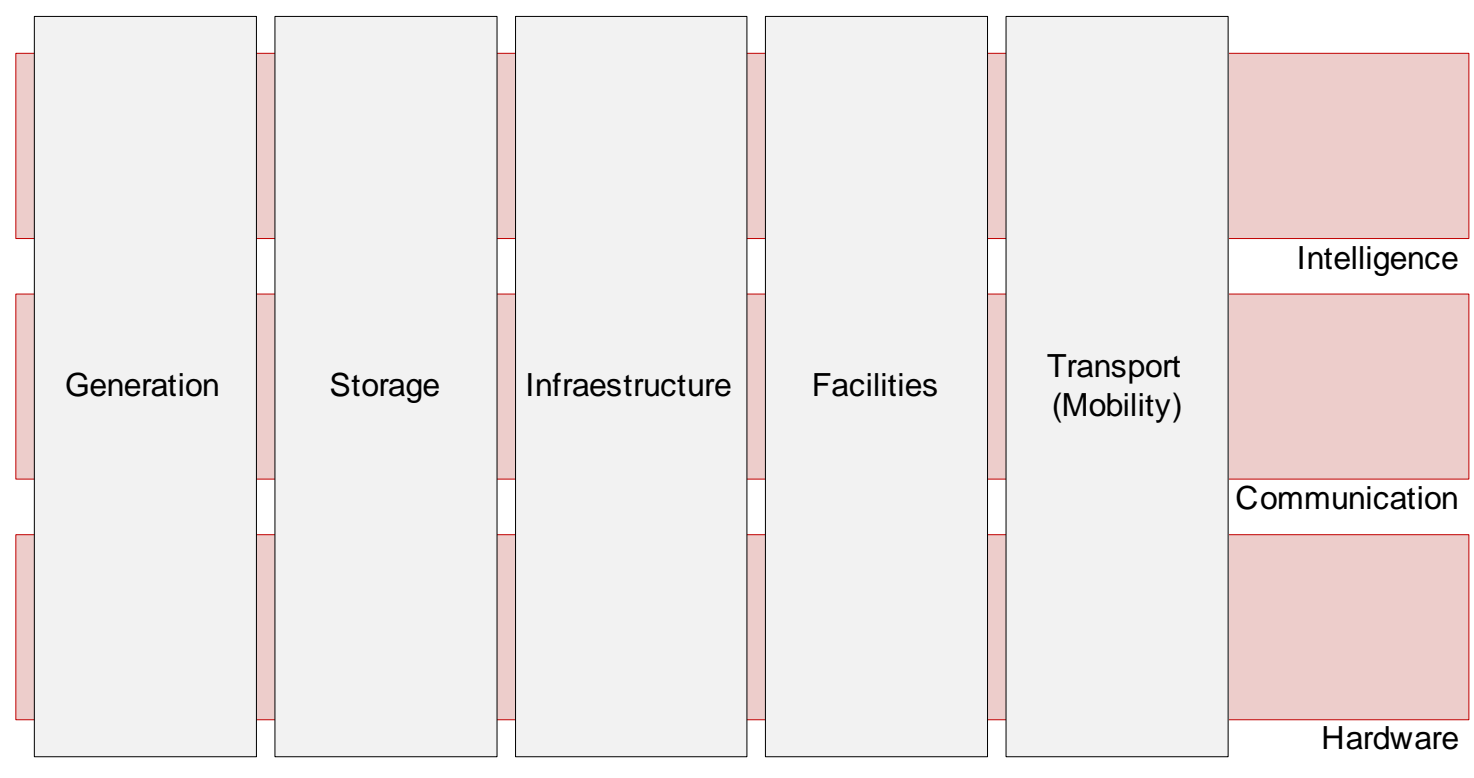

FIG. 2. CLASSIFICATION OF ENERGY INTERVENTION AREAS IN THE SMART CITY.

Operation and planning tools for urban energy-related tasks are also reviewed in this chapter, including existing projects and software tools. This is necessary to develop a framework for the correct design of energy solutions for smart cities, providing strategies for the effective modelling and management of energy systems. This framework will include the most relevant elements and common sources of information required for their mathematical modelling.

The rest of this literature review can be organised in two parts. The first part (sections 2.22.6) presents a review of the research developed in the proposed energy intervention areas. The second part corresponds to section 2.7, and reviews current energy-modelling approaches for smart cities, proposing a methodology for energy-system planning and operation. Finally, concluding remarks and recommendations can be found in section 2.8.

\subsection{GENERATION}

From an energy-generation perspective, two main research lines are attracting the most attention. 
On one hand, renewable-energy sources seem to be a promising mid to long-term investment alternative for energy self-sufficiency without compromising future generations [6]. Other non-renewable sources, such as combined heat and power (CHP) with natural gas and biomass generation (less polluting than conventional generation [14], [15]), are also been considered suitable for the short-term for reducing emissions and meeting the increasing energy demand [16].

On the other hand, distributed generation (DG) is gaining interest as a tool to increase efficiency and to support grid reliability and resiliency [17], which are two very relevant aspects of energy supply. The benefits and requirements of DG have been widely studied [18], [19], [20], [21].

Many authors believe that the smart city should gradually migrate to a full renewableenergy scheme, a goal that can be facilitated by DG (see [17] and [21]). Although conventional generation will still be present in smart cities in the short to medium terms, it has been not addressed in this section, which focuses only on renewable sources of energy.

\subsubsection{GENERATION TECHNOLOGY REVIEW}

Different generation solutions can be successfully implemented in a smart city; Table 1 summarizes important characteristics of the studied technologies.

TABLE 1.COMPARISON OF MOST COMMON DISTRIBUTED ENERGY SOURCES

\begin{tabular}{|c|c|c|c|c|c|}
\hline \multirow[t]{2}{*}{ Generator } & \multicolumn{2}{|c|}{ Generated Power } & \multirow[t]{2}{*}{ Dispatchable } & \multirow[t]{2}{*}{ Efficiency } & \multirow{2}{*}{$\begin{array}{l}\text { Common } \\
\text { application } \dagger\end{array}$} \\
\hline & electric & thermal & & & \\
\hline Solar PV & Yes & No & No & Low $(<30 \%)$ & $\mathrm{Hh}, \mathrm{B}$ \\
\hline Solar TC & No & Yes & No & $\begin{array}{l}\text { Moderate } \\
(<=60 \%)\end{array}$ & $\mathrm{Hh}, \mathrm{B}$, \\
\hline Solar CSP & Yes* & Yes & Yes & $\begin{array}{l}\text { Moderate } \\
(<=60 \%)\end{array}$ & (D)t, (D, P)e \\
\hline Solar PV/T & Yes & Yes & No & $\begin{array}{l}\text { Moderate } \\
(<=60 \%)\end{array}$ & Hh, B, D \\
\hline Wind power & Yes & No & No & $\begin{array}{l}\text { Moderate } \\
(<=60 \%)\end{array}$ & $\mathrm{D}, \mathrm{P}$ \\
\hline Poly-gen. & Yes & Yes & Yes & High $(>60 \%)$ & $\mathrm{B}, \mathrm{D}$ \\
\hline Biomass & Yes & Yes & Yes & $\begin{array}{l}\text { Moderate } \\
(<=60 \%)\end{array}$ & $\begin{array}{l}(\mathrm{Hh}, \mathrm{B}, \mathrm{D}) \mathrm{t}, \\
(\mathrm{D}, \mathrm{P}) \mathrm{e}\end{array}$ \\
\hline Geothermal & Yes* & Yes & Yes & High $(>60 \%)$ & $\begin{array}{l}(\mathrm{Hh}, \mathrm{B}, \mathrm{D}) \mathrm{t} \\
(\mathrm{D}, \mathrm{P}) \mathrm{e}\end{array}$ \\
\hline
\end{tabular}

*Indirect production.

$\dagger$ Hh: Household, B: Building, D: District, P: Power plant.

Photovoltaic (PV) panels convert solar energy into direct-current electricity using semiconducting materials. They have been extensively studied and highly preferred in small-scale generation, mainly due to their significant cost reduction in recent years resulting in more competitive values of their levelized cost of energy (LCOE) [22], [23]

Thermal collectors (TCs) collect heat by absorbing sunlight. They have been proved a reliable source for heating water or any other heat-transfer fluid for any kind of application [24]. TCs have affordable prices on a small scale, and can be implemented as concentrated solar power (CSP) plants for utility-scale electricity generation [25]; they are normally used 
with some sort of thermal generation. This kind of generation has a competitive LCOE, but it is not suitable in cities due to its large size. Photovoltaic-thermal collectors (PV/T) work as regular PV cells but also deliver thermal energy in order to heat water or other fluids, and although they present high efficiencies, there are few commercial modules, and exist only in small scale [26].

Wind turbines (WT) are used to extract power from an air flow to produce mechanical or electrical power. This is a mature technology with a wide variety of sizes, producing cheap energy at utility scale. However, it is expensive at small scale, and owing to wind's high unpredictability, wind turbines would perform better if accompanied by other energy sources or storage systems [27] when used in small applications.

Biomass has become a topic of increasing importance in recent years. It is a versatile energy source that can be used directly via combustion to produce heat or indirectly after converting it to a gaseous or liquid biofuel, and is capable of providing heat or electricity at competitive prices [28]. However, farming biomass crops needs to be done responsibly in order to be sustainable. Indeed, new European directives cap the first-generation biofuels, made with sugars and vegetable oils found in arable crops, while favouring the secondgeneration biomass compound of woody crops, agricultural residues, and waste [29].

Heat pumps (HP) are used for heating and cooling purposes. They use the difference on indoor-outdoor temperatures to move thermal energy, absorbing heat from a cold space and releasing it to a warmer one. The air-source heat pumps are considered a simple and cheap solution to install and operate, but with lower performance in comparison with geothermal heat pumps. Alternatively, geothermal heat pumps use the thermal energy flux from inside the earth. This geothermal energy can be used only for thermal production (lowmedium temperatures, appropriate for residential heating) and also for co-generation (high temperatures, appropriate for power plants). Geothermal electricity is very cheap when the proper ground conditions are met, although not many cities have those soil characteristics [30].

Finally, poly-generation or multi-generation emerged as an effort to use fossil fuels more efficiently by delivering different kinds of energy vectors from a single source of fuel (usually natural gas burnt to produce steam for electricity, while waste heat is used for other purposes like domestic heating). Along with increasing the overall efficiency, this approach also reduces $\mathrm{CO}_{2}$ emissions [16]. The main disadvantage of this technology is its elevated cost on a very small scale [31]. For instance, hydrogen fuel cells represent one of the technologies available for very small applications, but the cost of the produced energy is higher (more than double) than that of conventional generation [32].

\subsubsection{DISTRIBUTED GENERATION APPLICATIONS AND TOOLS}

One of the main research challenges related to DG is determining the optimal configuration, location, type and sizing of the generation units, so that the system meets the energy requirements at a minimum cost [33]. Reference [34] reviews most of the design aspects for hybrid DG systems, such as sizing methodologies (analytical, iterative, and hybrid methods), electrical connection configurations (DC coupled or AC coupled or hybrid DC-AC coupled), and reference [35] analyses control-system arrangements (centralized, decentralized, or hybrid). 
From the examples found in the literature, it is clear that many DG schemes contain hybrid systems with more than one generation source. For instance, DG systems are often used for both thermal and electric generation in buildings, as shown in [36]. Despite the fact that the former also analyses geothermal heat pumps (GHP), it does not consider other applicable sources, and the cost estimations of the technologies (investment and operation) are unclear. Natural-gas-fuelled poly-generation is studied in [14], which proposes a model for estimating the energy and $\mathrm{CO}_{2}$-emission performance but disregards economic aspects or comparison with other technologies. Reference [37] presents a feasibility analysis of GHP, $\mathrm{PV}$, and other co-generation technologies for buildings, but the level of detail in the system models, demand profiles, and energy-production calculation might be insufficient for an accurate economic analysis (only one scenario is analysed, and many of the input parameters seem to be arbitrary). Unlike previous examples that consider only one or two sources, other works, such as [38] and [39], model several DG technologies and analyse their economic and technical feasibility. The former proposes an analytical method for the sizing of DG systems, while the latter proposes a linear programming problem to find the optimal DG capacity. Both studies analyse DG systems following a single-node approach.

Unlike previous applications that design their DG systems according to their own methodology, other interesting applications use specialized software tools for this purpose. Indeed, [40] reviews 37 different computer tools that can be used to analyse the integration of renewable energy. One such tool that stands out is HOMER [41]. This software, developed by the National Renewable Energy Laboratory [9], is quite popular and is used extensively in the literature. For instance, reference [42] presents a HOMER application of optimal DG planning for microgrids in Serbia. The authors find the optimal technology mix under different scenarios of $\mathrm{CO}_{2}$ minimum reduction constraints, considering $\mathrm{CHP}$, micro-hydro, PV, and WT systems. Another similar tool is DERCAM, developed by Berkeley Lab [8], used for example for assessing the impact of electric vehicles (EVs) on other distributed energy resources (DER) solutions considering uncertainty in EV driving schedules [43]. Another interesting example is reference [41] where the authors analyse the same DG case study using two different software tools (HOMER and RETScreen) noting that the outcomes are considerably different in terms of DG production given the same inputs. Therefore, the appropriate model or tool should be selected with caution, checking whether the chosen software has the required features and outcomes for the desired application. A summary of several other interesting applications that use these tools can be found in [41], [35], and [33].

It is important to note that modelling tools like the ones previously mentioned could be considered adequate for the planning and operation of DG, but given their scope and considerations, they cannot be considered as complete as the smart city energy model sought in this thesis. Some of the features not considered in these current models are:

- They do not include all the possible intervention areas (see Fig. 2). For instance, transport systems (apart from EVs) are not considered, overlooking possible synergies and possible benefits of a joint management of energy systems.

- These tools follow a price-taker approach, not being able to assess the impact of actively participating in the energy market, or the relevance of the size of the aggregated resources in its interaction with the market. 
- Similarly, these models follow a single-node approach, paying little attention to the network thermal constraints. The implications of following such approach have not been assessed with the required depth in previous works, and more detailed analysis is required to determine the convenience of including these constraints in the planning process.

Other important feature of the modelling tools is the level of detail needed to obtain sensible results in a reasonable time. For instance, the authors of [43] use time steps of one hour and a simulation length of one year, as the objective of the study is to find the optimal DER investment and operation scheduling. Conversely, reference [44] studies the optimal operation of residential appliances within five-minute time slots, considering the uncertainty of electricity prices. The latter paper, unlike the previous one, focuses on realtime operation; hence, the difference in level of detail (time intervals). Other models focusing on the planning and long-term operation of DG systems also use a 1-hour (or even larger) time step. For instance, both HOMER and DERCAM in their DG planning models use 1-hour time steps (DERCAM also features shorter time steps in their real-time operation models [8]). Therefore, this 1-hour time step is selected for the smart city energy model proposed in this thesis.

Regarding the applicability of DG in smart city applications, several pieces of research focus on the technical issues of such technologies. For instance, reference [20] presents an extensive review of flexible AC transmission systems (FACTS) and DG systems and their impacts on the network, addressing different methodologies for placement and coordinated control schemes for such systems. Other non-technical challenges for DG systems are reviewed in [45], which notes that competitive mechanisms and regulatory measures can assist the implementation of DG in a cost-effective way. This paper includes real-case studies of four locations in the United States.

Table 2 summarizes all the DG applications just mentioned, organized by technology (rows). The table summarizes (in the columns from left to right) the DG technologies used, the study reference, the system sizing methodology (the methodology used to define the size of the DG technologies, according to the classification made in [34]), the date when the study was published, and the main results reported in the studies (in the 4 right-most columns): economic benefits obtained from the DG system (in comparison with the total energy costs without DG), $\mathrm{CO}_{2}$ emission reductions, energy supplied by the DG system in comparison with the original demand, and investment payback time in years. Some references appear several times, as they analyse different DG technologies. The table shows that the kind of results obtained and the way of presenting them differ among studies; for example, not all of them assess $\mathrm{CO}_{2}$ emissions reduction. The economic results, such as the payback time or the expected benefits (equivalent to the return on investment [ROI]), of different works can also vary significantly, especially considering the year when the study was carried out and specific pricing considerations. Therefore, although these economic metrics and studies could be used to compare various systems and methodologies, this kind of comparison should be undertaken with caution. 
TABLE 2. SUMMARY OF DG APPLICATION EXAMPLES.

\begin{tabular}{|c|c|c|c|c|c|c|c|}
\hline $\begin{array}{l}\text { Generation } \\
\text { technology }\end{array}$ & Ref. & $\begin{array}{l}\text { System } \\
\text { dimensioning } \\
\text { methodology }\end{array}$ & $\begin{array}{l}\text { Study } \\
\text { pub. } \\
\text { year }\end{array}$ & $\begin{array}{l}\text { Expected } \\
\text { benefits } \\
(\%)^{*}\end{array}$ & $\begin{array}{l}\mathrm{CO}_{2} \\
\text { reduction } \\
(\%)^{* *}\end{array}$ & $\begin{array}{l}\text { Energy } \\
\text { supplied } \\
\text { by DG } \\
(\%)\end{array}$ & $\begin{array}{l}\text { Payback } \\
\text { time } \\
\text { (years) }\end{array}$ \\
\hline PV & {$[36]$} & $\begin{array}{l}\text { Graphic } \\
\text { construction }\end{array}$ & 2011 & $\mathrm{~N} / \mathrm{A}$ & $43,4 \%$ & $53 \%$ & 12.5 \\
\hline $\mathrm{PV}$ & [38] & $\begin{array}{l}\text { Graphic } \\
\text { construction }\end{array}$ & 2013 & $<1 \%$ & $\mathrm{~N} / \mathrm{A}$ & $22.8 \%$ & 14 \\
\hline PV & [39] & Optimization & 2013 & $\begin{array}{ll}3,5 & - \\
10,4 \% & \\
\end{array}$ & $\mathrm{~N} / \mathrm{A}$ & $\mathrm{N} / \mathrm{A}$ & $\mathrm{N} / \mathrm{A}$ \\
\hline $\mathrm{TC}$ & [36] & $\begin{array}{l}\text { Graphic } \\
\text { construction }\end{array}$ & 2011 & $\mathrm{~N} / \mathrm{A}$ & $20 \%$ & $58 \%$ & 7 \\
\hline $\mathrm{TC}$ & [38] & $\begin{array}{l}\text { Graphic } \\
\text { construction }\end{array}$ & 2013 & $<1 \%$ & $\mathrm{~N} / \mathrm{A}$ & $65.3 \%$ & 17,7 \\
\hline $\mathrm{TC}$ & [39] & Optimization & 2013 & $8,8 \%$ & $\mathrm{~N} / \mathrm{A}$ & $\mathrm{N} / \mathrm{A}$ & $\mathrm{N} / \mathrm{A}$ \\
\hline WT & [38] & $\begin{array}{l}\text { Graphic } \\
\text { construction }\end{array}$ & 2013 & $<1 \%$ & $\mathrm{~N} / \mathrm{A}$ & $66.6 \%$ & 15,5 \\
\hline WT & [39] & Optimization & 2013 & $1-18,8 \%$ & $\mathrm{~N} / \mathrm{A}$ & $\mathrm{N} / \mathrm{A}$ & $\mathrm{N} / \mathrm{A}$ \\
\hline CHP & [14] & Analytical & 2008 & $20 \%$ & $40 \%$ & $\mathrm{~N} / \mathrm{A}$ & $\mathrm{N} / \mathrm{A}$ \\
\hline CHP & [38] & $\begin{array}{l}\text { Graphic } \\
\text { construction }\end{array}$ & 2013 & $<2 \%$ & $\mathrm{~N} / \mathrm{A}$ & $100 \%$ & 9.5 \\
\hline CHP & [42] & $\begin{array}{l}\text { SW } \\
\text { (HOMER) }\end{array}$ & 2014 & $9.08 \%$ & $10 \%$ & $\mathrm{~N} / \mathrm{A}$ & 10 \\
\hline CHP & [39] & Optimization & 2013 & $1-2 \%$ & $\mathrm{~N} / \mathrm{A}$ & $\mathrm{N} / \mathrm{A}$ & $\mathrm{N} / \mathrm{A}$ \\
\hline HP & [37] & Analytical & 2011 & $2 \%$ & $16 \%$ & $100 \%$ & $\mathrm{~N} / \mathrm{A}$ \\
\hline GHP & [37] & Analytical & 2011 & $4 \%$ & $48 \%$ & $100 \%$ & $\mathrm{~N} / \mathrm{A}$ \\
\hline GHP & [36] & $\begin{array}{l}\text { Graphic } \\
\text { construction }\end{array}$ & 2011 & $\mathrm{~N} / \mathrm{A}$ & $28,7 \%$ & $100 \%$ & 8.5 \\
\hline GHP & [38] & $\begin{array}{l}\text { Graphic } \\
\text { construction }\end{array}$ & 2013 & $<2 \%$ & $\mathrm{~N} / \mathrm{A}$ & $100 \%$ & 19,4 \\
\hline GHP & [39] & Optimization & 2013 & $13,8 \%$ & $\mathrm{~N} / \mathrm{A}$ & $\mathrm{N} / \mathrm{A}$ & $\mathrm{N} / \mathrm{A}$ \\
\hline CHP, HP & [37] & Analytical & 2011 & $43 \%$ & $24 \%$ & $100 \%$ & $\mathrm{~N} / \mathrm{A}$ \\
\hline CHP, GHP & [37] & Analytical & 2011 & $43 \%$ & $41 \%$ & $100 \%$ & $\mathrm{~N} / \mathrm{A}$ \\
\hline GHP, PV & [37] & Analytical & 2011 & $88 \%$ & $99 \%$ & $\mathrm{~N} / \mathrm{A}$ & 11 \\
\hline $\begin{array}{l}\text { CHP, PV, } \\
\text { microhydro }\end{array}$ & [42] & $\begin{array}{l}\text { SW } \\
\text { (HOMER) }\end{array}$ & 2014 & $10.1 \%$ & $50 \%$ & $\mathrm{~N} / \mathrm{A}$ & 11,1 \\
\hline $\begin{array}{l}\text { CHP, } \\
\text { microhydro, } \\
\text { PV, WT }\end{array}$ & [42] & $\begin{array}{l}\text { SW tool } \\
\text { (HOMER) }\end{array}$ & 2014 & $6.92 \%$ & $97 \%$ & $\mathrm{~N} / \mathrm{A}$ & 13.5 \\
\hline PV, CHP & [43] & $\begin{array}{l}\text { SW tool } \\
\text { (DERCAM) }\end{array}$ & 2014 & $7,7 \%$ & $28,3 \%$ & $\mathrm{~N} / \mathrm{A}$ & 12 \\
\hline PV, CHP, EV & [43] & $\begin{array}{l}\text { SW tool } \\
\text { (DERCAM) }\end{array}$ & 2014 & $9,3 \%$ & $24,1 \%$ & $\mathrm{~N} / \mathrm{A}$ & 12 \\
\hline
\end{tabular}

* Economic benefit in comparison with the total energy costs without DG systems.

** Considering only reductions due equivalent energy production.

In general, as expected, optimization approaches obtain better expected economic benefits (mainly energy costs reduction) than other methodologies do. Hence, as remarked in [33], the optimal sizing of these renewable-energy-based systems can significantly improve their economic and technical performance, while promoting the widespread use of such environmentally friendly sources. 


\subsection{STORAGE}

Energy storage systems (ESSs) can be used to store several kinds of energy (e.g., electric, thermal, kinetic). Within smart cities, ESSs are mainly expected to serve two purposes: contribute to the integration of renewable sources and the delivery of demand-response schemes. Indeed, ESSs can store clean energy from renewable sources when it is produced and not needed (when it is also very often cheaper), saving it for use when it is most needed (and usually more expensive) [46], and thus smoothing net load shape and contributing to cleaner and more-efficient energy production [47]. In a similar way, electric ESSs can participate in demand-response schemes by locally helping to manage the demand curve, smoothing peaks and valleys. This can contribute to covering new energy loads, such as DC buildings and EVs [48].

\subsubsection{STORAGE TECHNOLOGIES}

Batteries store electricity as chemical energy, and are a long-established technology with a high presence in many applications. They are built from one or more electrochemical cells composed of various elements, such as the mature lead-acid (Pb-acid) system, or more recent ones such as sodium-sulphur, sodium-nickel chloride, and lithium-ion systems. Their main disadvantages are high prices, possible environmental hazards, limited life cycle, and voltage and current limitations [49]. Nevertheless, several battery chemistries have seen a remarkable cost reduction in recent years, and it is expected that this trend will continue [50].

In applications where a fast response is needed and large amounts of energy must be released in a short time-for instance, in frequency control systems- superconducting magnetic energy storage (SMES), the super-capacitor, and the flywheel can be implemented. The first technology is a large superconducting coil that stores electric energy in the magnetic field generated by a DC flow [49]. The second one is a double-layer capacitor designed to charge and discharge at very high current [51]. The third one is a mechanical rotatory device that stores kinetic energy [52]. These technologies also have very long lifecycles but a much higher cost than batteries, and can provide energy only for very short periods [51]. Also, it is important to note that these technologies are mainly used for grid stability and power quality, not for bulk energy storage.

Hydroelectric (hydro-pumping) storage is commonly used in many countries. It uses the potential energy of water pumped from a lower- to a higher-elevation reservoir to later produce electricity by passing it through a turbine [53]. These systems are commonly used by utilities and systems operators for load balancing, but they have important disadvantages in small-scale applications, such as large unit sizes and topographic and environmental limitations [49].

Hydrogen can be used to produce electricity in fuel cells, gas boilers, or gas turbines. After combustion in a mixture with oxygen, the exhausted gas is water vapour with no polluting emissions. However, hydrogen gas has to be artificially produced from other compounds, such as water [54], or from fossil fuels in pre-combustion $\mathrm{CO}_{2}$-capture processes by transforming carbon fuel into a clean, carbonless fuel. The inconvenience of this is that both alternatives are costly and energy inefficient [55]. 
Compressed-air energy storage (CAES) is another way to store energy at the utility scale [56]. Energy is stored as compressed air, and the storage vessel is often an underground cavern [57]. Like hydro storage, this kind of ESS is commonly subject to topographic limitations.

From the foregoing technology descriptions, the applications for ESSs can be classified into three groups by discharge time: bulk storage (1-8h) for load levelling or spinning reserve; DG storage $(0.5-4 \mathrm{~h})$ for integration of distributed renewable sources, peak shaving, transmission deferral, and so on; and power-quality storage (1-30s) for end-use power quality and reliability [53]. Table 3 summarizes ESS technologies and proposes their most potentially effective applications [48], [53], [58] and [59].

TABLE 3. COMPARISON OF COMMON ELECTRIC STORAGE TECHNOLOGIES.

\begin{tabular}{|c|c|c|c|c|c|c|c|}
\hline \multirow[b]{2}{*}{ Type } & \multirow[b]{2}{*}{$\begin{array}{l}\text { Price } \\
(€ / \text { kWh })\end{array}$} & \multirow[b]{2}{*}{$\begin{array}{l}\text { Eff. } \\
\text { (\%) }\end{array}$} & \multicolumn{2}{|l|}{ Density } & \multirow{2}{*}{$\begin{array}{l}\text { Resp. } \\
\text { time } \\
\text { (ms) }\end{array}$} & \multirow[b]{2}{*}{$\begin{array}{l}\text { Cycle life } \\
\text { (times) }\end{array}$} & \multirow[b]{2}{*}{ App. * } \\
\hline & & & $\begin{array}{l}\text { Energy } \\
(w h / k g)\end{array}$ & $\begin{array}{l}\text { Power } \\
(w / k g)\end{array}$ & & & \\
\hline $\begin{array}{l}\text { Battery } \\
\text { (Pb-acid) }\end{array}$ & $50-300^{* *}$ & $60-95$ & $30-50$ & $75-300$ & 20 & $\begin{array}{l}100- \\
1000^{* *}\end{array}$ & $B, D G$ \\
\hline $\begin{array}{l}\text { Battery } \\
\text { (NiCd) }\end{array}$ & $200-1000^{* *}$ & $60-90$ & $40-60$ & $150-300$ & 20 & $\begin{array}{l}1000- \\
3000^{* *}\end{array}$ & $B, D G$ \\
\hline $\begin{array}{l}\text { Battery } \\
\text { (Li-Ion) }\end{array}$ & $200-1800^{* *}$ & $85-99$ & $75-250$ & $150-315$ & 20 & $\begin{array}{l}1000- \\
10000^{* *}\end{array}$ & B, DG \\
\hline SMES & $700-7000$ & $95-98$ & $30-100$ & 1e4-1e5 & 5 & 1e6 & $\mathrm{PQ}$ \\
\hline Flywheel & $1000-3500$ & 95 & $5-50$ & $1 \mathrm{e} 3-5 \mathrm{e} 3$ & 5 & $>20000$ & DG, PQ \\
\hline $\begin{array}{l}\text { Super } \\
\text { Capacitor }\end{array}$ & $300-4000$ & 95 & $<50$ & 4000 & 5 & $>50000$ & $P Q$ \\
\hline CAES & $10-120$ & $70-80$ & $\mathrm{~N} / \mathrm{A}$ & $\mathrm{N} / \mathrm{A}$ & $>1000$ & $>1 \mathrm{e} 6$ & B \\
\hline Hydroelectric & $60-150$ & $70-85$ & $\mathrm{~N} / \mathrm{A}$ & $\mathrm{N} / \mathrm{A}$ & $>1000$ & $>1 \mathrm{e} 6$ & B \\
\hline
\end{tabular}

* B: bulk storage; DG: distributed gen. storage; PQ: power quality storage. ** These numbers depend heavily on the battery chemistry and overall quality.

Thermal storage systems use a fluid or other material in a reservoir to store thermal energy for later use. The most common use of these ESSs in smart cities involves water tanks that are capable of meeting thermal demand in both residential and commercial facilities [60]. More recently, molten salt tanks have been used, mainly at the utility scale, for hightemperature thermal storage for electricity generation in concentrated solar-power plants [61].

Therefore, considering the size limitations and the intended application of the proposed smart city model (planning and operation of energy systems), batteries seem to be an adequate technology for electric energy storage, while (in the same urban context) hot water tanks can be used for thermal energy storage.

\subsubsection{APPLICATIONS AND MODELS OF ESSS}

Applications for ESSs can be found in a multitude of technologies. The scale and the means of the storage system can also vary widely. On a large scale, reference [57] analyses the economic feasibility of CAES for increasing the grid integration of wind generation in the German power system. On a small to medium scale, most research works include batterybased systems for integrating renewable energy sources, as in [62]. Other works consider different ESS technologies, focusing more on power quality. For instance, [52] presents a 
wind-diesel power system that includes flywheel storage (for maintaining the power quality) in isolated microgrid applications. Similarly, reference [51] analyses supercapacitor banks for load frequency control in power systems. These examples of ESS are especially interesting for isolated systems. However, in a highly interconnected environment such as the smart city, where the grid is available most of the time, these systems might be less used.

Other interesting approaches include hybrid storage systems, combining different storage technologies in order to reduce the limitations of the independent devices and to improve overall performance. In [48], the benefits of hybrid ESSs are studied in a microgrid context, and in [63], a hybrid flywheel-battery system is presented for EV applications, showing the validity of the scheme.

Plug-in EVs represent another major application of ESSs, and many related studies can be found in the literature. In this area, most work focuses on the charge and discharge control of EV fleets, as stated in [64], where a review of different smart-charging strategies is presented. In addition, the advantages and drawbacks of centralized and decentralized control are analysed.

Smart-charging strategies can have different objectives. For instance, examples of renewable-energy integration assisted by EV technology are listed in [65]. Other interesting related research can be found in [66], where the impact on the grid of high penetration of EVs in two real distribution areas is assessed. A similar approach is presented in [67], which examines not only load balancing but also the impact of a large penetration of EVs on energy prices and analyses thermal-generation dispatch decisions. A different approach is presented in [68], where used EV batteries are installed as stationary energy storage for a microgrid, and the system's economic feasibility is analysed. This analysis concludes that a second use of the EV batteries can improve significantly the profitability of EV adoption. In contrast to previous references, which mainly focus on the economic impact of ESSs, considering with little detail important characteristics such as battery degradation, the authors of reference [69] present a detailed degradation model of the lithium-ion batteries for EV application and propose charging strategies to maximize battery life cycle.

With respect to thermal storage, most research is related to the optimal usage and control of thermal energy for buildings. Reference [70] presents an electric thermal ESS governed by electricity price signals. In [60], a complex predictive control system with water thermal storage is proposed and then compared with other control methods. Additionally, solar TC and co-generation systems commonly comprise thermal storage for residential and commercial use, as in [36] and [14].

Table 4 summarizes the examples reviewed in this section. It can be seen that the focus of each work varies greatly, although two main applications stand out: the integration of renewable energy (including power quality and the security of supply-related studies) and the integration of EVs (including impact on the grid and vehicle-to-grid [V2G] interaction). 
TABLE 4. SUMMARY OF ESS APPLICATION EXAMPLES.

\begin{tabular}{|c|c|c|c|c|c|}
\hline ESS & Ref. & $\begin{array}{l}\text { Other } \\
\text { technologies }\end{array}$ & Proposes & focus & $\begin{array}{l}\text { Reported } \\
\text { outcome }\end{array}$ \\
\hline EV & [69] & None & $\begin{array}{l}\text { Charging control } \\
\text { and degradation } \\
\text { model }\end{array}$ & $\begin{array}{l}\text { Minimize } \\
\text { battery } \\
\text { degradation }\end{array}$ & $\begin{array}{ll}6.39 \% & \text { less } \\
\text { degradation } & \end{array}$ \\
\hline EV & [66] & None & $\begin{array}{l}\text { Impact analysis } \\
\text { of high } \\
\text { penetration of } \\
\text { EV }\end{array}$ & $\begin{array}{l}\text { Distribution } \\
\text { network } \\
\text { reinforcement } \\
\text { costs }\end{array}$ & $\begin{array}{l}\text { up to } 15 \% \text { of } \\
\text { increment in total } \\
\text { investment }\end{array}$ \\
\hline EV & [67] & Hydro & $\begin{array}{l}\text { Impact analysis } \\
\text { of high } \\
\text { penetration of } \\
\text { EV }\end{array}$ & $\begin{array}{lr}\text { Energy } & \text { prices } \\
\text { and } & \text { load } \\
\text { curves } & \end{array}$ & $\begin{array}{l}\text { Reduction of } 70 \% \\
\text { of load and } 15 \% \text { of } \\
\text { energy prices at } \\
\text { peak hours with } \\
\text { smart charging }\end{array}$ \\
\hline EV & [43] & PV, CHP & $\begin{array}{l}\text { Planning and } \\
\text { operation of } \mathrm{DER}\end{array}$ & $\begin{array}{l}\text { Maximize } \\
\text { benefit of DG } \\
\text { and ESS }\end{array}$ & $\begin{array}{l}9.3 \% \text { benefits in } \\
\text { energy costs }\end{array}$ \\
\hline Batteries & [68] & None & $\begin{array}{l}\text { Planning and } \\
\text { operation of ESS }\end{array}$ & $\begin{array}{lr}\text { Maximize } & \\
\text { benefit } & \text { of } \\
\text { reused } & \mathrm{EV} \\
\text { batteries } & \\
\end{array}$ & $\begin{array}{l}14.8 \% \text { benefits in } \\
\text { energy costs }\end{array}$ \\
\hline Batteries & [62] & PV & $\begin{array}{l}\text { Integration of } \\
\text { RES }\end{array}$ & $\begin{array}{l}\text { Technical/ } \\
\text { economic } \\
\text { feasibility } \\
\text { analysis }\end{array}$ & $\begin{array}{l}\text { Pros and cons of } \\
\text { different battery } \\
\text { technologies. }\end{array}$ \\
\hline $\begin{array}{l}\text { Batteries, } \\
\text { super } \\
\text { capacitor }\end{array}$ & {$[48]$} & None & $\begin{array}{l}\text { System model } \\
\text { and control for } \\
\text { hybrid ESS in } \\
\text { microgrid }\end{array}$ & $\begin{array}{l}\text { Power system } \\
\text { stability }\end{array}$ & $\begin{array}{lr}\text { Effective } & \text { control } \\
\text { system } & \text { to } \\
\text { maintain } & \text { power } \\
\text { quality } & \\
\end{array}$ \\
\hline $\begin{array}{l}\text { Batteries, } \\
\text { flywheel }\end{array}$ & [63] & None & $\begin{array}{l}\text { System model } \\
\text { and control for } \\
\text { hybrid ESS in EV } \\
\text { applications }\end{array}$ & $\begin{array}{l}\text { Power quality } \\
\text { and efficiency }\end{array}$ & $\begin{array}{l}\text { Average efficiency } \\
\text { of } 87 \% \text {, unity } \\
\text { power factor and } \\
\text { low distortion. }\end{array}$ \\
\hline Flywheel & {$[52]$} & $\begin{array}{l}\text { WT, Diesel } \\
\text { generator. }\end{array}$ & $\begin{array}{l}\text { System model } \\
\text { and control for } \\
\text { ESS in microgrid }\end{array}$ & $\begin{array}{ll}\text { Power } & \text { quality } \\
\text { and } & \text { system } \\
\text { stability } & \\
\end{array}$ & $\begin{array}{l}44 \% \text { less } \\
\text { frequency } \\
\text { variation. }\end{array}$ \\
\hline $\begin{array}{l}\text { Super- } \\
\text { capacitor }\end{array}$ & [51] & None & $\begin{array}{l}\text { System model } \\
\text { and control for } \\
\text { ESS }\end{array}$ & Power quality & $\begin{array}{l}\text { Almost } 80 \% \\
\text { reduction in peak } \\
\text { frequency } \\
\text { deviation }\end{array}$ \\
\hline CAES & [57] & WT & $\begin{array}{l}\text { System model of } \\
\text { ESS }\end{array}$ & $\begin{array}{l}\text { Economic } \\
\text { feasibility } \\
\text { analysis } \\
\end{array}$ & $\begin{array}{l}\text { Return of } \\
\text { investment in } 13- \\
19 \text { years }\end{array}$ \\
\hline $\begin{array}{l}\text { Thermal } \\
\text { storage }\end{array}$ & [70] & None & $\begin{array}{l}\text { Optimal usage } \\
\text { and control of } \\
\text { thermal energy }\end{array}$ & $\begin{array}{l}\text { Minimize } \\
\text { thermal energy } \\
\text { cost }\end{array}$ & $\begin{array}{l}20-31 \% \text { benefits } \\
\text { in energy costs }\end{array}$ \\
\hline $\begin{array}{l}\text { Thermal } \\
\text { storage }\end{array}$ & [60] & None & $\begin{array}{l}\text { Optimal usage } \\
\text { and control of } \\
\text { thermal energy }\end{array}$ & $\begin{array}{l}\text { Control } \\
\text { method } \\
\text { performance } \\
\end{array}$ & $\begin{array}{l}19 \% \text { better } \\
\text { performance }\end{array}$ \\
\hline
\end{tabular}

\subsection{INFRASTRUCTURE}

In this thesis, infrastructure mainly refers to the urban electric power grids, in particular, the concept of smart grid. However, district energy networks are also discussed. These networks are also an interesting example of smart infrastructure, supplying thermal and 
electric energy to different interconnected facilities [16]. This kind of network is discussed in more detail in section 2.5 .

The electric grid is the energy backbone of any city, and it is used for transmitting energy from generators to consumers with the required quality and reliability. Conventional grids can have technical hitches, such as unidirectional protections and a lack of the required communication infrastructure and control systems, and they might not be ready for increasing demand and DG. Therefore, the smart grid [71] appears as a solution to address these problems.

Similar to the smart city concept, a smart grid infrastructure can be defined in many ways. The core of the smart grid consists of implementing modern information and communication technologies, enabling real-time bidirectional communication among all participating entities. Every device and system in a smart grid is expected to provide information about its own energy consumption or production and to be able to accept commands from a smart grid controller, to schedule its load depending on factors such as system load, prices, and contractual obligations [72].

Some of the main features proposed for a smart grid in [71] include the capacity to meet increasing consumer demand without building new infrastructure; a resilient structure resistant to attacks and natural disasters (with self-healing capacity); a quality-focused power supply with a combined power-source structure, composed of separated energy networks (microgrids) capable of exchanging power and operating separately and independently if necessary; and the implementation of real-time communication between all participant agents, facilitating all these tasks.

\subsubsection{RESEARCH ON AND APPLICATIONS OF SMART-GRID INFRASTRUCTURE.}

There is a substantial amount of smart-grid-related research addressing all sorts of problems. This research covers aspects from regulation and business models to power electronics, communication protocols, and control systems. Along with the economic aspects, infrastructure investments are a major concern. Long-term smart-grid investmentplanning models are analysed in [18], [66], and [73], which calculate the effects of DG or EVs on distribution-network investment planning. These works conclude that the storage provided by the EVs and the presence of DG (facilitated by smart grid infrastructure) can reduce significantly the network investments and operation costs.

Similarly, adequate regulation and energy markets for smart grids are commonly addressed. For instance, adequate regulatory frameworks and energy markets and services required for demand-response schemes are studied in [72], proposing the scheme of a district energy market, and describing the roles of the different participants. However, that study models the smart grids only conceptually, without entering into technical details. Other examples analyse several European projects, such as [74], which studies a marketprice mechanism for smart-grid environments.

Infrastructure for integrating renewable resources is another important research topic. Effects on the grid are addressed in [19], and the authors remark on the necessity of smart grid infrastructure. Similarly, energy storage and EV integration are widely studied, as EVs represent a considerable challenge for future power grids. The effects of a large penetration 
of EVs in utility operation and energy market prices are addressed in [67]. Reference [75] simulates and analyses the number of EVs that can be connected in a region of the German grid, and reference [76] proposes a conceptual regulatory framework for charging EVs, describing business models and the role of the agents involved. Note that the focus of these works is the optimal management of infrastructure systems, and how to use the smart grid infrastructure to cope with the new challenges of a larger penetration of EVs, DER systems, etc. Therefore, the smart grid can be considered as the foundation to implement all the other smart city energy systems.

Smart metering is the next step in this direction, and many works describe the necessity of an advanced metering infrastructure to carry out most of the smart grid features. For instance, the energy savings achieved by modifying consumers' behaviour by using smart metering systems , incrementing the awareness of the users, are estimated in [77], achieving up to $16 \%$. However, reference [78] discusses not only these possible benefits but also disadvantages, risks (for instance, hacker attacks), and the prevalent uncertainty regarding the technology, being information privacy the main concern. In any case, smart metering and other communication technologies must be implemented to achieve the proposed interconnected smart city scheme.

Pilot microgrids with smart-grid features have been developed for the simulation and demonstration of DG technologies and control systems. For instance, the LABEIN commercial feeder located in Derio, Spain, comprises more than 5kW of PV installations, $6 \mathrm{~kW}$ of WT, two $55 \mathrm{~kW}$ diesel back-up generators, a $50 \mathrm{~kW}$ microturbine, and a variety of electric storage devices. These and other examples of European microgrid implementations can be found in [79].

Table 5 summarizes most of the research examples mentioned in this section. Even though high-scale penetration of smart-grid infrastructure is still a long way off, the tendencies apparent in the reviewed works show that these technologies are gaining presence in many urban centres and could become standard in the long term. 


\begin{tabular}{|c|c|c|c|}
\hline Concern & Ref. & Focus & Reported outcome \\
\hline $\begin{array}{l}\text { Impact of DG on } \\
\text { distribution network } \\
\text { infrastructure. }\end{array}$ & {$[18]$} & $\begin{array}{l}\text { Investment deferral in } \\
\text { the long-term. }\end{array}$ & $\begin{array}{l}\text { With a DG penetration of } 50 \% \text {, the } \\
\text { load can increase } 200-225 \% \\
\text { before adding new investments. }\end{array}$ \\
\hline $\begin{array}{l}\text { Impact of DG on } \\
\text { distribution network } \\
\text { infrastructure. }\end{array}$ & [73] & $\begin{array}{l}\text { Distribution network } \\
\text { costs }\end{array}$ & $\begin{array}{l}\text { With very large DG penetration, } \\
\text { the increment in total network } \\
\text { costs decreases with a higher level } \\
\text { of demand. }\end{array}$ \\
\hline $\begin{array}{l}\text { Impact of DG on } \\
\text { distribution network } \\
\text { infrastructure. }\end{array}$ & {$[19]$} & $\begin{array}{l}\text { Regulatory aspects for } \\
\text { DG and RES integration. }\end{array}$ & $\begin{array}{l}\text { Remarks the necessity of smart } \\
\text { grid infrastructure, and provides } \\
\text { several recommendations. }\end{array}$ \\
\hline $\begin{array}{l}\text { Impact of EV on } \\
\text { distribution network } \\
\text { infrastructure. }\end{array}$ & [75] & $\begin{array}{l}\text { Quantity of EVs that can } \\
\text { be integrated in an } \\
\text { existing network }\end{array}$ & $\begin{array}{l}\text { If EVs are charged at the best } \\
\text { locations, a penetration level of } \\
\text { about } 50 \% \text { does not lead to } \\
\text { considerable overloading of } \\
\text { components. }\end{array}$ \\
\hline $\begin{array}{l}\text { Impact of EV on } \\
\text { network } \\
\text { infrastructure. }\end{array}$ & {$[76]$} & $\begin{array}{l}\text { Regulatory framework } \\
\text { and business models for } \\
\text { EV charging }\end{array}$ & $\begin{array}{l}\text { Regulatory recommendations and } \\
\text { requirements for EV integration. }\end{array}$ \\
\hline $\begin{array}{l}\text { Impact of EV on } \\
\text { distribution network } \\
\text { infrastructure. }\end{array}$ & {$[66]$} & $\begin{array}{l}\text { Investment deferral in } \\
\text { the long-term. }\end{array}$ & $\begin{array}{l}\text { With smart charging strategies, up } \\
\text { to } 60 \%-70 \% \text { of the required } \\
\text { incremental investment can be } \\
\text { avoided. }\end{array}$ \\
\hline $\begin{array}{l}\text { Impact of EV on } \\
\text { network operation. }\end{array}$ & [67] & $\begin{array}{lc}\text { energy prices and } \\
\text { thermal generation } \\
\text { dispatch decisions }\end{array}$ & $\begin{array}{l}\text { Smart charging methods reduce } \\
\text { aprox. } 70 \% \text { of peak load and } 15 \% \\
\text { of energy prices at peak hours. }\end{array}$ \\
\hline $\begin{array}{l}\text { Smart grid } \\
\text { demonstration } \\
\text { project in an island in } \\
\text { Denmark. }\end{array}$ & {$[74]$} & $\begin{array}{l}\text { Control methodologies } \\
\text { of DER systems for } \\
\text { participation on energy } \\
\text { markets. }\end{array}$ & N/A \\
\hline Smart metering & {$[77]$} & $\begin{array}{l}\text { Smart metering system } \\
\text { for Korean residential } \\
\text { environments. }\end{array}$ & $\begin{array}{l}7.5-15.9 \% \text { of reduction in energy } \\
\text { consumption by just giving } \\
\text { information to the consumer. }\end{array}$ \\
\hline Smart metering & {$[78]$} & $\begin{array}{l}\text { Policy implications of } \\
\text { advanced metering } \\
\text { infrastructure. }\end{array}$ & $\begin{array}{l}\text { Discussion of expected benefits, } \\
\text { possible risks and the uncertainty } \\
\text { related to these technologies. }\end{array}$ \\
\hline Power Quality & {$[80]$} & $\begin{array}{l}\text { Electromagnetic } \\
\text { compatibility }\end{array}$ & $\begin{array}{l}\text { Analysis of the effects on power } \\
\text { quality by the high exposure of } \\
\text { smart grid technologies. }\end{array}$ \\
\hline
\end{tabular}

\subsection{FACILITIES}

In this thesis, facilities comprise commercial and residential buildings, but they do not include the industrial sector, which is less likely to be present within the cities limits.

In an urban context, buildings are the largest energy consumers. These amenities (considering construction and energy usage) are responsible for approximately threequarters of total greenhouse-gas emissions in urban areas [6]. Hence, one of the major challenges in smart buildings is minimizing power consumption without compromising users' comfort [81].

The first approach to addressing this energy problem is providing efficient control of the energy systems in buildings. Indeed, optimized operation and management can save 
between $20 \%$ and $30 \%$ of a building's energy consumption without changing the structure or hardware configuration of the system [82].

Demand-response is another popular topic. The idea behind demand-response is to change the role of the building from a passive, unresponsive user of energy to an active participant in the power system [72]. This paradigm shift can be developed by demand-response schemes, applying information and control systems to manage loads and energy consumption, and by taking advantage of DG technologies and energy-storage devices.

One of the best examples of smart facilities, implementing demand-response schemes, are the microgrids, composed by several micro generators, loads and energy storage, which are geographically concentrated (for instance, in residential districts or in a university campus), and can operate connected or isolated from the grid [83].

The microgrids can vary in size (from one household to a small town or island) and technologies considered. On a medium-size scale (neighbourhood, district, or small town), a microgrid application features a wide range of suitable technologies. For instance, the district energy networks, which are implemented for distributing energy generated in a centralized location within the district for residential and commercial use. Traditionally, district energy networks have been used exclusively for heating purposes, yet with advances in co-generation, electricity and cooling are being added [16].

Finally, passive systems (that do not require any particular management) can be implemented as a complementary approach. These systems are designed to collect and preserve thermal energy within a building. Elements to be considered include thermal insulation, thermal mass, window placement and glazing type, and shading (in this context, these factors are commonly named as building envelope). However, most of these changes can be considered only for new buildings owing to the high cost of installing them in existing structures [84].

\subsubsection{APPLICATIONS AND RESEARCH IN FACILITIES}

Significant research has been conducted in the field of home automation (domotics) and control systems for energy and comfort management. Reference [81] includes a comprehensive review of control techniques for smart buildings (energy and comfort management) but without considering energy generation or storage. Within this kind of buildings, heat ventilation and air-conditioning systems (HVAC) are the focus of most efforts. For instance, [85] presents an adaptive fuzzy controller for temperature comfort, obtaining better energy performance than conventional controllers. Besides HVAC, lightning control and features such as appliance control are commonly included, resulting in complex information schemes, as shown in [86]. The control system proposed in the former work, obtains energy savings of up to $24 \%$.

Demand-response and microgrid-related research has developed considerably in the last several years. Controlling and scheduling renewable sources and storage are proposed in [87], with a mixed-integer programming problem for minimizing energy costs in a building, considering dynamic energy prices and demand. Thermal load management in district energy networks is implemented in [60] and [88], including combined heat, cooling and 
power systems to improve energy efficiency. Both works presents important thermal energy reductions, and overall higher system efficiency.

From reviewing the previous works, it can be seen that the optimal management of resources in a demand-response scheme can provide important improvements in energy efficiency and overall economic benefits. Therefore, these elements should be considered in the smart city energy model.

In the passive-systems area, building envelope has been widely researched, producing interesting energy-savings results in heating and air conditioning. In [84], an environmental evaluation of three different wall envelopes is presented, considering different climate scenarios and economic benefits, and concluding that in the considered cases, the ventilated wall has considerable better energy performance. A similar analysis is developed in [89] for hot and humid locations, comparing different thermal isolations, windows, and shading. In this case, the improvement in energy performance reached 34\%. Lastly, reference [90] simulates the impact of window design in a hotel building, achieving up to $40 \%$ reduction in energy use. Most of these considerations must be implemented at the construction stage in order to be cost effective [89], [90].

Table 6 summarizes the examples provided in this section, organized by facility type, and includes generation components and energy systems relative to the reviewed facilities. It can be seen that the smart building focuses on comfort management, energy efficiency, and passive systems. Microgrid research mainly considers demand-response schemes and DG control, whereas district energy networks relate to energy efficiency and load control. It is interesting that several European projects have been commissioned in the infrastructure and facilities areas to address communication issues [91], [92], [93], [94], [95] and [96], demand response [97], [98], [99] and [100], [74] and energy-efficient buildings and districts [101], [102], [103] and [104]. 
TABLE 6. SUMMARY OF FACILITIES APPLICATION EXAMPLES.

\begin{tabular}{|c|c|c|c|c|c|}
\hline $\begin{array}{l}\text { Facility } \\
\text { type }\end{array}$ & Ref. & DG/ESS & Proposes & Objective & Reported outcome \\
\hline $\begin{array}{l}\text { Smart } \\
\text { building }\end{array}$ & [81] & $\mathrm{N} / \mathrm{A}$ & $\begin{array}{l}\text { Control system } \\
\text { for energy } \\
\text { management }\end{array}$ & $\begin{array}{lr}\begin{array}{l}\text { User } \\
\text { and }\end{array} & \text { comfort } \\
\text { usage. } & \\
\end{array}$ & $\begin{array}{l}\text { Percentage of People } \\
\text { Dissatisfied index is } \\
\text { less than } 6 \%\end{array}$ \\
\hline $\begin{array}{l}\text { Smart } \\
\text { building }\end{array}$ & [85] & N/A & $\begin{array}{l}\text { Control system } \\
\text { for } \quad \text { energy } \\
\text { management }\end{array}$ & $\begin{array}{l}\text { Reduce energy } \\
\text { consumption }\end{array}$ & $\begin{array}{l}\text { Approx. } 10-25 \% \\
\text { reduction in energy } \\
\text { consumption }\end{array}$ \\
\hline $\begin{array}{l}\text { Smart } \\
\text { building }\end{array}$ & [86] & N/A & $\begin{array}{lr}\text { Control } & \text { system } \\
\text { and } & \text { network } \\
\text { configuration. }\end{array}$ & $\begin{array}{l}\text { Reduce energy } \\
\text { consumption }\end{array}$ & $\begin{array}{l}\text { Power saving of } \\
\text { approximately } \\
24 \%\end{array}$ \\
\hline $\begin{array}{l}\text { Smart } \\
\text { building }\end{array}$ & {$[84]$} & N/A & $\begin{array}{ll}\text { Comparison of } \\
\text { building } \\
\text { envelope } \\
\text { alternatives } \\
\end{array}$ & $\begin{array}{l}\text { Energy } \\
\text { performance } \\
\text { and payback } \\
\text { time }\end{array}$ & $\begin{array}{l}\text { Ventilated wall has } \\
\text { considerable better } \\
\text { energy performance } \\
\text { than other materials. }\end{array}$ \\
\hline $\begin{array}{l}\text { Smart } \\
\text { building }\end{array}$ & [89] & N/A & $\begin{array}{ll}\text { Comparison } & \text { of } \\
\text { building } & \\
\text { envelope } & \\
\text { alternatives } & \\
\end{array}$ & $\begin{array}{l}\text { Energy } \\
\text { performance }\end{array}$ & $\begin{array}{l}\text { The energy saving } \\
\text { rate of window } \\
\text { materials is up to } \\
33.89 \% \text {. }\end{array}$ \\
\hline $\begin{array}{l}\text { Smart } \\
\text { building }\end{array}$ & [90] & $\mathrm{N} / \mathrm{A}$ & $\begin{array}{ll}\text { Design } & \text { of } \\
\text { building } & \\
\text { envelope } & \end{array}$ & $\begin{array}{l}\text { Energy } \\
\text { performance }\end{array}$ & $\begin{array}{l}\text { Up to } 40 \% \text { reduction } \\
\text { on total site energy. }\end{array}$ \\
\hline microgrid & [87] & $\begin{array}{l}\text { PV, CHP, } \\
\text { Batteries }\end{array}$ & Operation of DER & $\begin{array}{l}\text { Minimize } \\
\text { energy costs }\end{array}$ & $\begin{array}{lrr}6-10 \% & \text { of extra } \\
\text { reduced costs by } \\
\text { including } & \text { battery } \\
\text { storage. } & \end{array}$ \\
\hline $\begin{array}{l}\text { District } \\
\text { energy } \\
\text { network }\end{array}$ & {$[60]$} & N/A & $\begin{array}{l}\text { Control system } \\
\text { for } \quad \text { energy } \\
\text { management }\end{array}$ & $\begin{array}{l}\text { Reduce thermal } \\
\text { energy } \\
\text { consumption }\end{array}$ & $\begin{array}{lr}19 \% & \text { better } \\
\text { performance } & \text { on } \\
\text { controller. } & \end{array}$ \\
\hline $\begin{array}{l}\text { District } \\
\text { energy } \\
\text { network }\end{array}$ & {$[88]$} & CHCP & $\begin{array}{l}\text { Comparison of } \\
\text { tri-generation } \\
\text { technologies }\end{array}$ & $\begin{array}{l}\text { Performance } \\
\text { analysis }\end{array}$ & $\begin{array}{l}\text { Proposed system is } 10 \\
\% \text { more efficient than } \\
\text { electric compressor } \\
\text { absorption chillers. }\end{array}$ \\
\hline
\end{tabular}

\subsection{TRANSPORT}

The transport sector is a considerable consumer of energy and one of the main air polluters within cities, creating important health costs [105]. Furthermore, the quality of transport systems in a city directly affects the quality of life for its inhabitants (air and noise pollution, commuting times, etc.), so future transport systems, both public and private, should be cleaner and more efficient. While the former can be achieved by replacing old vehicles with newer more efficient ones, and by replacing fossil-fuel technologies with reduced-emission vehicles (considered a comparatively cleaner energy source), the latter can be attained by planning and developing better and more-efficient travel routes in order to save energy and time.

\subsubsection{ADVANCES IN TRANSPORT SYSTEMS AND TECHNOLOGIES}

Besides the natural gas vehicles, the most popular way to reduce $\mathrm{CO}_{2}$ and other polluting emissions is to replace gasoline-powered vehicles (public or private) with EVs and hybrid EVs. Therefore, numerous studies have examined EV technologies that consider charge control, their storage capability, and their impact on the grid, as reviewed in section 2.3 ("Storage"). 
A different research line for the transport industry is represented by the use of hydrogen as fuel, where steam is the only exhaust gas. However, creating a hydrogen-supply infrastructure poses several problems, as it requires considerable investments for charging stations, storage tanks, hydrogen-production plants, etc. Another approach consists of using fuel cells (electric batteries fuelled by hydrogen) in electric cars. The main drawbacks to this are the chemical sustainability of the required compounds and the current price, which is about 10 times higher than that of gasoline per kilowatt of energy [106].

Other alternative is to use biofuels instead of fossil fuels. A key driver of this approach is the net fixation of $\mathrm{CO}_{2}$ (i.e., the $\mathrm{CO}_{2}$ absorbed by the crop is the same released when burnt); it might even work as a carbon sink [15]. Biofuels can be used in a straightforward way, usually mixed with diesel or gasoline. Using information extracted from [107], [108], [109], [110], [111] and [112], the types of vehicles reviewed are compared in Table 7. It is important to note that real insight into the possible environmental benefits of alternativefuel vehicles requires an adequate life-cycle analysis. For instance, reference [113] presents the product-life-cycle assessment of an electric drive for automotive applications, assessing the ecological impact of the proposed engine.

TABLE 7. COMPARISON OF NON-FOSSIL FUEL VEHICLE TECHNOLOGIES.

\begin{tabular}{|c|c|c|c|c|}
\hline Vehicle & $\begin{array}{l}\text { Init. cost } \\
\text { (kUSD) }\end{array}$ & Efficiency* & $\begin{array}{l}\text { Commercial } \\
\text { availability }\end{array}$ & Main challenges \\
\hline EV & 21.3 & High $(>50 \%)$ & Now & $\begin{array}{l}\text { Chemical } \\
\text { sustainability, battery } \\
\text { costs }\end{array}$ \\
\hline $\mathrm{HEV}$ & 24.2 & $\begin{array}{l}\text { Moderate } \\
(<=50 \%)\end{array}$ & Now & $\begin{array}{l}\text { Chemical } \\
\text { sustainability, battery } \\
\text { costs }\end{array}$ \\
\hline $\begin{array}{l}\text { Hydrogen } \\
\text { ICE }\end{array}$ & 18 & Low $(<25 \%)$ & In 2-3 years & Lack of infrastructure \\
\hline Fuel-Cell & 40 & Low $(<25 \%)$ & In $2-3$ years & $\begin{array}{l}\text { Lack of infrastructure, } \\
\text { high costs }\end{array}$ \\
\hline Biofuels & 17.1 & Low $(<25 \%)$ & Now & $\begin{array}{l}\mathrm{CO}_{2} \text { fixation, } \\
\text { responsible farming }\end{array}$ \\
\hline
\end{tabular}

In addition to the shift to less polluting fuels, energy saving is a crucial requirement. Moreefficient trips can be achieved with travel-assistance systems (travel planners) [114], which provide real-time information on traffic, routes, public-transport options, available parking places, and charging points for EVs, among other features. A more sophisticated smart transport system could also implement traffic-demand-management tools. These schemes implement real-time speed-limit-control and traffic-signal-control optimization, among others [115], [116]. The goal of this kind of information system is to optimize the journey and deliver a better and more-efficient travel experience for the user.

Another important concern about private transport in modern cities is parking. During rush hour, the traffic caused by cars searching for free parking spots constitutes up to $40 \%$ of the total traffic [117]. Smart parking systems have been proposed to address this problem, assisting drivers in finding and reserving the vacant parking spaces efficiently [118]. 
Research on automated vehicles is underway [119]. Automation in transport seeks to improve the safety and efficiency of mobility, highways and freeways being the first targets for this kind of vehicle [120].

Regarding public-transport systems, metropolitan transit (metro) systems are one of the preferred options in many cities for providing the required quality and quantity of service [121]. Several technologies and strategies for energy efficiency in urban rail systems can be found in the literature. A review of such efficiency solutions is presented in [122], where five main groups of actions have been identified: regenerative braking, energy-efficient driving, comfort functions, traction efficiency, and smart measurement and management. Given the nature of the metro, with its numerous and frequent stops, regenerative braking can potentially provide important energy savings [58]. Pilot projects like [123] has shown the possibilities of using the regenerative braking energy in other context. This possibility is explored in more detail in chapter 6.

Another trend in public-transport efficiency is the change from diesel buses to electric or hybrid ones. Reference [124] analyses the benefits of urban electric buses in terms of costs and pollution, concluding that plug-in hybrid and electric city buses have the best potential to reduce energy consumption and emissions.

\subsubsection{APPLICATIONS AND RESEARCH IN TRANSPORT SYSTEMS}

Several applications of vehicles using cleaner fuels are mentioned in the literature. Starting with EVs, [125] provides a general overview of the tendencies, advantages, and disadvantages of such cars. Similarly, in [105], smart-charging strategies are proposed, and the impact on their externality costs such as emissions, health benefits, and energy dependence is analysed, concluding that the EV penetration has a positive impact on such externalities. A comprehensive review of hydrogen-fuelled cars and their infrastructure requirements is developed in [126], highlighting the limitations of other technologies and the possible benefits of using hydrogen as an energy carrier. Moreover, the author of reference [106] heavily criticizes fuel-cell vehicles, considering them an unfeasible solution in the short to medium term. From the biofuels perspective, the use of ethanol as a transportation fuel is studied in [15], considering environmental benefits, production, and political and economic aspects.

The travel planners designed to identify optimal travel routes are studied in [114], [127], and [128]. The first paper proposes a travel-assistance application for EV users, providing information on parking and recharging posts, among other things; however, the application is presented at the simulation level only. The second work implements an Internet-based optimal-route finder for public transport in Hong Kong, which according to authors, have had high user acceptance. The third paper summarizes examples of other systems that have been successfully implemented in various cities, presenting positive results in congestion and emissions reduction.

Regarding goods delivery, a mathematical model for finding a distributor's optimal number and the time-window of service cycles is proposed in [129]. This model includes carbon emissions in its objective function and concludes that a compromise should be found between carbon costs and delivery times. Another interesting example of optimal delivery can be found in [130], where a multi-temperature food-distribution system is proposed for 
finding optimal delivery cycles for foods of different temperature ranges. Results suggest the applicability of such system, providing important cost reductions relative to conventional logistics.

Intelligent traffic management and congestion control have been addressed by many pieces of research. In [128], a congestion toll system for decreasing pollution is reviewed. Reference [131] analyses the emissions-decreasing potential of systems that have already been implemented in cities, such as flexible penalty mechanisms for transport and market mechanisms for private-car-ownership permissions. Similarly, references [115] and [116] deal with traffic-signal control. The former presents a real-time speed-limit-signal controller for emissions reduction. The latter proposes a multi-objective model with predictive traffic control, measuring the trade-offs among emissions, travel time, and cost. The main drawback of such systems is that they require an advanced information and communication infrastructure to apply the coordinated control proposed. To ease parking problems, an Internet-based reservation system is proposed in [118]. In addition, the potential of parking lots as charging posts for EVs is studied in [132], seeking to take advantage of people's working hours and the storage capabilities of EVs. It is important to remark that other online services provide real-time traffic information and route planning, assisting commuters around the world. For instance, Google Maps [133] or Here maps [134].

System architecture and the requirements for fully autonomous cars are reviewed in [119] and [120], including experimental results on highways.

Regenerative braking in public metro systems consists of recovering a vehicle's braking energy in the form of electricity so as to reuse it in the same vehicle or system (or another one). Three main strategies are implemented to maximize the use of this braking energy. For instance, an energy-wise optimal timetable is presented in [135], where a programming problem is designed to synchronize the braking of metro trains arriving at a station with the departure of other trains within the same electrical section. This would allow the regenerated energy to be used directly to accelerate other trains without the need for storage. The second alternative comprises the use of energy-storage systems to save the braking energy. The authors in [58] analyse the main storage technologies for both onboard and wayside applications. The main benefit of this solution is that there is no need to synchronize trains, but the extra infrastructure for storage entails higher costs. Lastly, reversible substations can be implemented to return the braking energy to the grid, as in [136]. Further analysis on this energy efficiency possibility and its implication to other energy systems in the smart city is addressed in chapter 6.

To sum up, Table 8 outlines the transport-related applications discussed in this section. The problems approached and the nature of solutions has a very broad scope, and many of them are complementary. Nevertheless, it is necessary to bear in mind that depending on the specific objectives of a smart city and the particular characteristics of the city itself, certain solutions might provide unwanted outcomes. For instance, a smart traffic-signal system can reduce total travel time for cars, promoting the use of such a transport system, but in the case of conventional-fuel vehicles, this could increase pollution. 
TABLE 8. SUMMARY OF TRANSPORT SYSTEMS APPLICATION EXAMPLES.

\begin{tabular}{|c|c|c|c|c|}
\hline Vehicle type & Ref. & Proposes & Objective & Reported outcome \\
\hline $\mathrm{EV}$ & {$[125]$} & $\begin{array}{l}\text { Discussion of trends } \\
\text { in PHEV and other } \\
\text { technologies }\end{array}$ & $\begin{array}{l}\text { Autonomy and } \\
\text { economic } \\
\text { feasibility. }\end{array}$ & $\begin{array}{l}\text { Battery packs with an all- } \\
\text { electric range of } 32 \mathrm{~km} \text { will } \\
\text { yield up to a } 50 \% \\
\text { reduction in gasoline use. }\end{array}$ \\
\hline $\mathrm{EV}$ & {$[105]$} & $\begin{array}{lr}\text { hydro-thermal } & \text { unit } \\
\text { commitment } & \text { for } \\
\text { different } & \text { EV } \\
\text { scenarios } & \\
\end{array}$ & $\begin{array}{l}\text { Costs and } \\
\text { benefits of EVs } \\
\text { including } \\
\text { externalities }\end{array}$ & $\begin{array}{l}\text { Health accounts for almost } \\
92 \% \text { of the total benefit } \\
\text { obtained from the } \\
\text { externalities. }\end{array}$ \\
\hline Hydrogen ICE & {$[126]$} & $\begin{array}{lr}\text { Discussion } & \text { of } \\
\text { different energy } \\
\text { technologies. }\end{array}$ & $\begin{array}{l}\text { Technical and } \\
\text { economic } \\
\text { feasibility }\end{array}$ & $\begin{array}{l}\text { It is required to develop a } \\
\text { solar hydrogen platform } \\
\text { with urgency. }\end{array}$ \\
\hline $\begin{array}{l}\text { Fuel cell } \\
\text { vehicle }\end{array}$ & {$[106]$} & $\begin{array}{l}\text { Discussion of } \\
\text { challenges in fuel } \\
\text { cell vehicles }\end{array}$ & $\begin{array}{l}\text { Technical and } \\
\text { economic } \\
\text { feasibility. }\end{array}$ & $\begin{array}{l}\text { Main challenge is to } \\
\text { produce hydrogen from } \\
\text { non-fossil fuels at a } \\
\text { reasonable cost. }\end{array}$ \\
\hline $\begin{array}{l}\text { Conventional } \\
\text { fuel vehicles }\end{array}$ & [15] & $\begin{array}{lr}\begin{array}{l}\text { Discussion } \\
\text { opportunities } \\
\text { challenges. }\end{array} & \text { and } \\
\end{array}$ & $\begin{array}{l}\text { Technical and } \\
\text { economic } \\
\text { feasibility. }\end{array}$ & $\begin{array}{l}\text { The major factor in } \\
\text { biodiesel production is the } \\
\text { feedstock ( } 75-80 \% \text { of the } \\
\text { total operating cost). }\end{array}$ \\
\hline $\mathrm{EV}$ & [114] & $\begin{array}{l}\text { Personal assistant } \\
\text { oriented to smart } \\
\text { cites and EVs }\end{array}$ & $\begin{array}{l}\text { Journey } \\
\text { efficiency and } \\
\text { user comfort }\end{array}$ & $\begin{array}{l}\text { Application for mobile } \\
\text { devices }\end{array}$ \\
\hline $\begin{array}{l}\text { Public } \\
\text { transport }\end{array}$ & {$[127]$} & $\begin{array}{lr}\text { web-map } & \text { public } \\
\text { transport } & \text { enquiry } \\
\text { system } & \\
\end{array}$ & $\begin{array}{l}\text { Journey } \\
\text { efficiency and } \\
\text { user comfort } \\
\end{array}$ & $\begin{array}{l}\text { The proposed system } \\
\text { matches at least 95\% of } \\
\text { users' expectations. }\end{array}$ \\
\hline $\begin{array}{l}\text { Public } \\
\text { transport }\end{array}$ & {$[128]$} & $\begin{array}{l}\text { Analysis of smart } \\
\text { transport } \\
\text { trends. }\end{array}$ & $\begin{array}{l}\text { Real examples } \\
\text { developed in } \\
\text { several cities }\end{array}$ & $\begin{array}{l}\text { Several reported results. } \\
\text { Smart cities and transport } \\
\text { systems will be important } \\
\text { areas of growth in the next } \\
\text { years. }\end{array}$ \\
\hline $\begin{array}{l}\text { Conventional } \\
\text { fuel vehicles }\end{array}$ & [115] & Smart traffic control & $\begin{array}{l}\text { High way speed } \\
\text { limits to reduce } \\
\text { emissions. }\end{array}$ & $\begin{array}{l}\text { Reduced travel time, total } \\
\text { emissions and maximum } \\
\text { dispersion levels of } \\
\text { emissions (3.4\%, 36\%, } \\
\text { 19\%, respectively). }\end{array}$ \\
\hline $\begin{array}{l}\text { Conventional } \\
\text { fuel vehicles }\end{array}$ & {$[131]$} & $\begin{array}{l}\text { Analysis of smart } \\
\text { traffic } \\
\text { systems trends. }\end{array}$ & $\begin{array}{l}\text { GHG Emission } \\
\text { Reduction and } \\
\text { Traffic } \\
\text { Congestion } \\
\text { Control }\end{array}$ & $\begin{array}{l}\text { Policy suggestions on for } \\
\text { the Chinese urban } \\
\text { transport sector }\end{array}$ \\
\hline $\begin{array}{l}\text { Conventional } \\
\text { fuel vehicles }\end{array}$ & [116] & $\begin{array}{l}\text { Traffic } \\
\text { system }\end{array}$ & $\begin{array}{l}\text { Reduce } \\
\text { emissions, } \\
\text { travel time and } \\
\text { cost. }\end{array}$ & $\begin{array}{l}\text { Reduction of } \mathrm{CO}_{2} \text { emission } \\
\text { by } 23.1 \% \text {, fuel } \\
\text { consumption is by } 28.2 \% \text {, } \\
\text { and total time spent by } \\
40.5 \% \text {. }\end{array}$ \\
\hline $\begin{array}{l}\text { Electric } \\
\text { vehicles }\end{array}$ & {$[132]$} & $\begin{array}{l}\text { Parking with smart } \\
\text { EV charging }\end{array}$ & $\begin{array}{l}\text { Minimize } \\
\text { emissions and } \\
\text { costs }\end{array}$ & $\begin{array}{l}\text { Payback time of 11years } \\
\text { for parking owner while } \\
\text { still benefiting the EV } \\
\text { owner. }\end{array}$ \\
\hline $\begin{array}{l}\text { Private and } \\
\text { public } \\
\text { transport }\end{array}$ & [119] & Vehicle automation & $\begin{array}{l}\text { Review of } \\
\text { advances in } \\
\text { different fields } \\
\text { of vehicle } \\
\text { automation. }\end{array}$ & $\mathrm{N} / \mathrm{A}$ \\
\hline
\end{tabular}




\begin{tabular}{|l|l|l|l|l|}
\hline $\begin{array}{l}\text { Private } \\
\text { vehicles }\end{array}$ & {$[120]$} & Vehicle automation & $\begin{array}{l}\text { Hardware and } \\
\text { control systems }\end{array}$ & Vehicle prototype. \\
\hline
\end{tabular}

\subsection{SMART City ENERgy Models}

In this thesis, the energy system models refer to tools used in the planning and/or operation of energy systems. They could consider any of the elements reviewed so far in this chapter, but always with the objective of planning and/or operation of energy systems. These kind of models have been around for several decades and are experiencing constant evolution to incorporate new technologies, paradigms, and externalities (such as environmental concerns), as stated in [137].

Indeed, energy system models are commonly used for power-system planning or for operation and management. An example of the former is reference [138], which presents a model for distribution-network expansion planning, considering the sizing, placement, and timing of DG investments and network reinforcements. Similarly, optimal DG allocation in a distribution network is studied in [139].

The operation of power systems can be exemplified as in [140], where a smart grid is modelled based on software agents; the model attempts to recreate the dynamic behaviour of a smart city, yet it considers only electricity. Other examples can be found in the distribution-network operation projects funded by the European Commission [141], [142] and [143]. According to [144], electric-system modelling is normally carried out using some sort of stochastic programming, which involves minimizing an objective function subject to certain constraints. However, other techniques based on artificial intelligence, genetic algorithms, game theory, and so on, are also available.

\subsubsection{URBAN-PLANNING MODELS AND ENERGY}

Besides the energy system models previously described (section 2.7), the urban planning of a city (i.e., the land use and the design of an urban environment, for new and existing cities, and focusing on energy performance) can heavily influence its energy usage and the pollution it produces. Therefore, urban planning models are addressed in this subsection.

Urban infrastructure systems have extended lifespans and affect the inhabitants and the environment for long periods of time. Therefore, urban-planning models are of paramount importance for sustainable growth [145]. For instance, [146] proposes a model to assess a site's potential renewable-energy availability and urban energy-supply plants in order to determine the best places and type of generation to install given geographical constraints. This model uses as an input the current state of the electric network. A case study of a residential district in Korea is carried out, and its applicability is remarked.

Similarly, reference [147] proposes solutions for urban-planning improvements to energy efficiency that rely on information technologies. For instance, using geographic information systems and 3-D modelling to design buildings allows taking advantage of the terrain configuration (e.g., terrain slope: burying part of the building to reduce heating costs), orientation towards the sun (e.g., designing for greater sunlight exposure so as to increase interior temperatures during winter), and wind effects (e.g., considering the direction of wind to promote natural ventilation, reducing air-conditioning costs), among other things. 
This model focuses on the architectural design of new buildings, and can be used independently of other models.

Reference [148] notes that many cities prioritize renewable energy or energy efficiency, as in the aforementioned examples; only a few cities approach urban planning through one strategy that facilitates synergy in energy-related activities at different scales. This is a particular feature that a smart city energy model should take into account, and could be linked to an urban planning model, to also find an optimal land use and urbanisation plan.

Regarding greenhouse-gas emissions, references [149] and [150] analyse the carbon footprint in industrial and residential activities, respectively, and the possible prevention and mitigation solutions that can be carried out through urban-planning models. The former concludes that municipalities can have a decisive influence on the industrial carbon footprint because most reductions can be obtained through urban-planning decision variables, such as the location of industrial plants, waste deposits, transport networks, use of non-urban areas, and so on. The latter mentions that the greatest pollutant source is transport, followed by gas and electricity consumption, and concludes that policymakers can reduce greenhouse-gas emissions by managing the infrastructure design and by including sustainability design criteria in master urban plans.

As mentioned in [148], individual efforts (designing and managing independent smart buildings, for instance) might not be optimal overall, as these tend to overlook many interactions between facilities-hence, the importance of an inclusive urban-planning project that includes a comprehensive energy system model, considering the energy cycles that cut across all the presented intervention areas.

\subsubsection{DESIGNING ENERGY SYSTEM MODELS IN A SMART CITY CONTEXT}

It is clear from the review developed throughout this chapter that modelling a complete smart city energy system is a complex task. However, some elements in all the intervention areas stand out in importance. This section provides several guidelines for the adequate modelling of such systems and describes the elements that should be taken into account and that will be in the model proposed in this thesis. Note that this model is not an urban planning model (like the ones described in section 2.7.1), as it focuses on energy systems and not in land use and other urban issues. However, this smart city energy model could be used in addition to an urban planning one.

Fig. 3 presents a general diagram of an energy-system model, including elements of all the intervention areas reviewed and the main required inputs (left) and expected outputs (right). Regarding the methodology for planning and operation, many approaches can be used, such as analytical, iterative, and hybrid methods. In [34], a classification of the different methodologies for distributed energy-resource dimensioning is provided. 


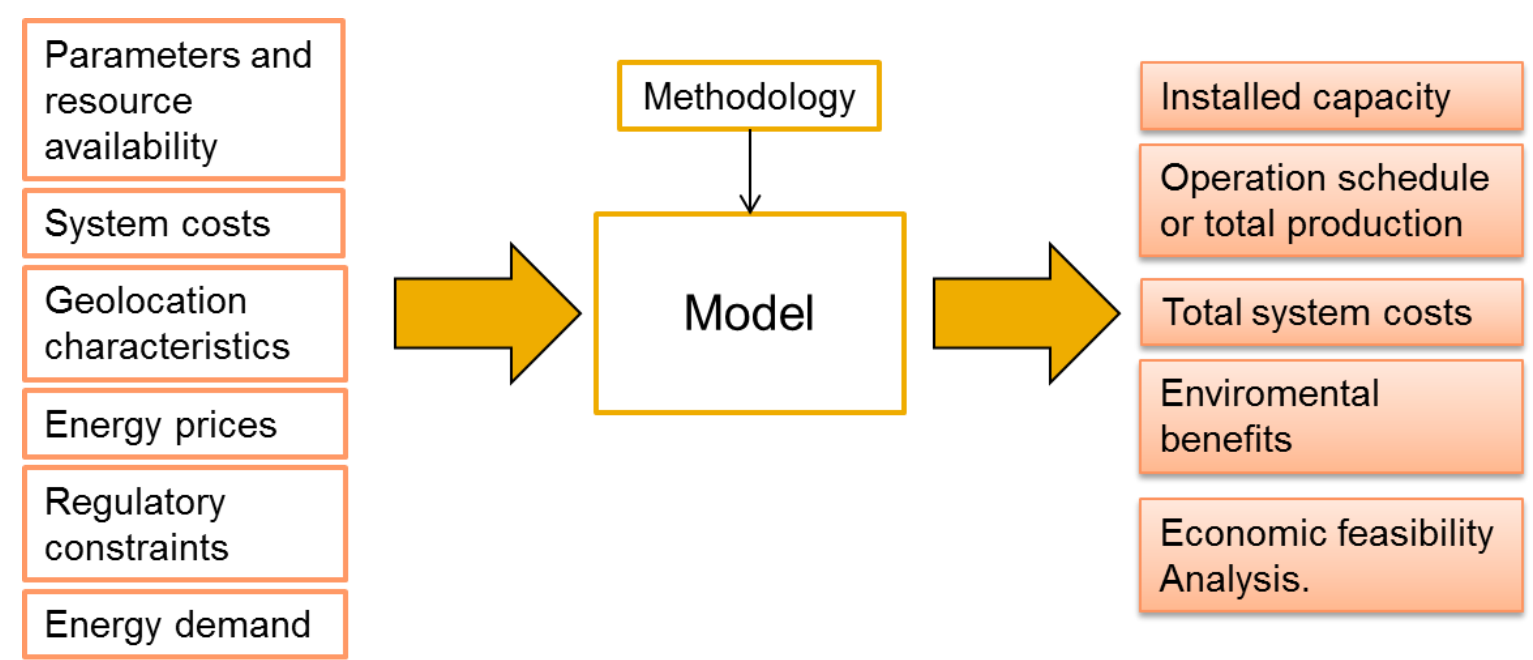

FIG. 3. GENERAL ENERGY SYSTEM DESIGN MODEL.

The input information used in the model considerably affects the quality of results; hence, special attention should be paid to its selection. Table 9 provides a description of the main inputs needed for the successful design of the energy systems and of how these inputs affect the modelled system (e.g., in its profitability, in its performance).

Moreover, Table 9 presents some examples of the information sources that can be used for each input. The list of typical information sources is not intended to be exhaustive but rather to serve as guidance and to suggest possible sources of information. 
TABLE 9. ENERGY SYSTEM MODELING, INPUT DESCRIPTION AND INFORMATION SOURCES.

\begin{tabular}{|c|c|c|c|}
\hline Input & Description & $\begin{array}{l}\text { Mainly impacts } \\
\text { on }\end{array}$ & $\begin{array}{l}\text { Typical information } \\
\text { source }\end{array}$ \\
\hline $\begin{array}{l}\text { Parameters } \\
\text { and resource } \\
\text { availability }\end{array}$ & $\begin{array}{l}\text { Performance parameters. } \\
\text { (e.g. electric efficiency, } \\
\text { thermal efficiency, power } \\
\text { rating, losses) and } \\
\text { availability of the resource } \\
\text { when applicable (e.g. EV } \\
\text { connection times, DG } \\
\text { operation constrains) }\end{array}$ & $\begin{array}{l}\text { Performance } \\
\text { (constraints) of the } \\
\text { systems (e.g. } \\
\text { maximum charge } \\
\text { and discharge } \\
\text { rates of batteries). }\end{array}$ & $\begin{array}{l}\text { Research literature } \\
([38],[39],[35]) \\
\text { SW tools ([8] and [9]) } \\
\text { Datasheets }([151])\end{array}$ \\
\hline System costs & $\begin{array}{l}\text { All the necessary costs to } \\
\text { analyse economic feasibility } \\
\text { of systems (e.g. cost per } \\
\text { installed kW, operation and } \\
\text { maintenance costs) }\end{array}$ & $\begin{array}{l}\text { Profitability of } \\
\text { systems (e.g. } \\
\text { return of } \\
\text { investment (ROI), } \\
\text { payback times, } \\
\text { LCOE, etc.). }\end{array}$ & $\begin{array}{l}\text { Reports ([22], [23], } \\
[31]) \\
\text { Retailer web pages }\end{array}$ \\
\hline $\begin{array}{l}\text { Geolocation } \\
\text { characteristics }\end{array}$ & $\begin{array}{l}\text { Natural sources information } \\
\text { (e.g. solar irradiation, wind } \\
\text { speed, rainfall) }\end{array}$ & $\begin{array}{l}\text { Production of the } \\
\text { systems (e.g. PV } \\
\text { production given } \\
\text { the solar } \\
\text { irradiation } \\
\text { parameter). }\end{array}$ & $\begin{array}{l}\text { Specialized } \\
\text { geographical } \\
\text { information systems } \\
\text { ([152], [153]) } \\
\text { Weather forecast } \\
\text { databases ([154], } \\
[155])\end{array}$ \\
\hline Energy prices & $\begin{array}{l}\text { The cost of energy for } \\
\text { comparative purposes (e.g. } \\
\text { retail energy tariffs, fuel } \\
\text { costs, price increment rate) }\end{array}$ & $\begin{array}{l}\text { Profitability of } \\
\text { systems (e.g. ROI, } \\
\text { payback times, } \\
\text { LCOE, etc.). }\end{array}$ & $\begin{array}{l}\text { Local utility web pages } \\
\text { Reports ([156]) }\end{array}$ \\
\hline $\begin{array}{l}\text { Regulatory } \\
\text { constraints }\end{array}$ & $\begin{array}{l}\text { All relevant constraints and } \\
\text { possibilities for the desired } \\
\text { location (e.g. retailing } \\
\text { conditions, selling energy } \\
\text { back to the grid) }\end{array}$ & $\begin{array}{l}\text { Operation } \\
\text { constraints of } \\
\text { systems. }\end{array}$ & Local regulation \\
\hline $\begin{array}{l}\text { Energy } \\
\text { demand }\end{array}$ & $\begin{array}{l}\text { Energy demand } \\
\text { characteristics for the } \\
\text { desired application (e.g. load } \\
\text { curves) }\end{array}$ & $\begin{array}{l}\text { Sizing and } \\
\text { operation of } \\
\text { systems (e.g. } \\
\text { installed capacity, } \\
\text { when to sell, buy, } \\
\text { store or transfer } \\
\text { energy) }\end{array}$ & Reports ([157], [158]) \\
\hline
\end{tabular}

\subsection{CONCLUDING REMARKS}

In order to achieve optimal energy management in a very complex system like a smart city, not only do most of its energy elements need to be identified and studied, but the implicit relations among them should also be considered. Furthermore, detailed modelling and simulation are required to validate and improve existing and new systems. This chapter has presented an extensive review of the existing approaches on different energy related technologies, organized in five energy-intervention areas. Different currently available energy models and tools have been reviewed and compared, remarking their possible applications and limitations.

Based on this study, some clear trends can be identified in all intervention areas. Benefiting from advances in technologies, reduced prices and regulatory support, it is expected that 
DER (including energy storage and renewable sources) will continue to gain presence in the coming years. Energy-efficient facilities are making their way into future smart cities with better devices, control systems, and demand-response schemes. Similarly, tendencies show that the microgrid and smart-grid paradigms can become a standard in the long term. With respect to the transport sector, travel planners, parking assistants, and other similar system will continue to be implemented, while EVs will probably find an important position in smart cities. Moreover, new solutions on public transport systems are likely to appear. For instance, by taking advantage of the regenerative braking of urban trains, interconnecting them with other systems. Therefore, the technologies and systems to be modelled and included in the smart city energy model are, at least, PV panels and air-source HP as representative DER systems, battery systems and water tanks as representative energy storage, residential facilities with demand response capability, and EVs and metro as representative transport systems.

Models and simulators have been widely used in the urban context for many decades. Current models are normally designed with specific objectives in mind, such as implementing traffic control, planning urban development, planning the expansion of generation capacity or transmission lines, and so on. Therefore, the elements considered are limited and they do not take into account many important interactions and synergies between different systems within the city.

The necessity of a holistic and comprehensive smart-city model has been highlighted by many authors. Even though it might be extremely difficult to integrate all the elements into a single computational model, it should at least consider all the intervention areas studied in this chapter and include the most relevant stakeholders and technologies. Furthermore, the model should be flexible to be applicable in different kinds of cities, and be adaptable to new technologies and systems.

As discussed in this thesis, there are many elements that should be taken into account while modelling energy systems. Special attention should be paid to an adequate selection of the system parameters and energy constraints. For instance, the accurate information about natural resources (wind, solar irradiation, etc.) is important to the proper outcome of a planning process. Moreover, it has been shown that the use of an optimization algorithm considerably improves the expected benefits; hence, it is highly recommended to follow those optimization approaches. Lastly, considering the complexity of the systems, the objectives of the model should be clearly defined and prioritized. Addressing all these issues will allow the creation of a complete and adequate smart-city energy model, one that will assist decision makers in both government and industry to develop, simulate, and implement the best systems at minimum cost, fostering smarter and more-efficient cities. 


\section{MODEL DESCRIPTION}

This chapter presents the selection of models task, corresponding to the smart city energy model methodology described in section 1.3. This includes the definition of inputs and outputs, and the selection of which energy systems and technologies should be modelled, presenting ways to do it., Therefore, the main contribution of this chapter is the presentation of the smart city energy model proposed in this thesis.

The first part of the chapter presents the model overview and description. Then, the full mathematical formulation is presented, structured following the classification of the 5 intervention areas identified in chapter 2.

\subsection{MODEL GENERAL DESCRIPTION}

As described in chapter 1, the proposed smart city energy model will provide the optimal planning and operation of the energy systems, according to the economic costs and benefits, and including representative systems of the five intervention areas described in the literature review (see chapter 2). In particular, the modelled elements selected in this work are photovoltaic panels and air-source heat pumps, which are representative DER for electrical and thermal generation; EVs, which are both a storage resource and a transport system; residential districts with demand-response capabilities, representing typical facilities in the smart grid; and metro trains, representing other transport systems commonly found on cities. For this smart city energy model, the infrastructure is considered as the energy networks (physical power lines and connections), and all the information and communication technologies that allows the smart planning and operation of systems. Therefore, in this thesis, the infrastructure is not modelled as a physical element, but as the equations needed to interconnect systems, allowing the energy transfers between them.

All the modelled systems are considered to be interconnected, so it is possible to transfer energy between the DER systems located at the residential district, the EVs, and the metro electrical substations (this is studied in more detail in chapter 6). The model will have time steps of one hour, and it will be a stochastic MILP (providing an adequate level of complexity and performance, with a reasonable computation time). The aggregated energy systems will interact with the electricity market as a price-maker agent (day-ahead session), and the stochasticity will allow to consider different electricity pricing scenarios (see chapter 5). 
Regarding the optimization model, the main inputs include:

- DER characteristics, including investment, operation and maintenance costs, performance parameters and losses, as well as the sun irradiation for the solar production computation.

- EV availability profiles, setting when the EVs are connected to the grid and how much charge they have.

- Metro substation energy profiles, that is the energy consumption and generation (from the regenerative braking) load curves.

- Facilities energy profiles, that is the energy load curves of the residential districts considered.

- Energy price parameters, including the energy tariffs information (or the residual demand curves in the case of a price-maker model) to compute the energy costs and benefits.

The outputs should include:

- Optimal DER technology planning and costs.

- Optimal operation schedule of DER systems and EVs, including energy transactions with the grid.

- Optimal energy management of the metro substation.

- Impact of the aggregated energy district on the wholesale electric energy prices.

The detailed description of the mathematical model can be found in section 3.2. Nevertheless, the main model considerations and assumptions are summarized below:

- The model includes DER systems, residential loads, EVs and a metro electrical substation. These systems represent elements from the 5 intervention areas defined in chapter 2 .

- All clients are considered to be interconnected, able to exchange energy between them without distribution losses, and are managed by an aggregator that allows them to buy and sell energy from the grid.

- HP, PV and Batteries are the only DER resources considered, in addition to demand response.

- The model has been implemented in GAMS, and uses CPLEX as a solver for both LP and MILP variants of the model.

- This formulation considers a total lifespan of 20 years (with stationary battery replacements every 8 years). A typical year's operation is replicated for the total length of the study. This typical year is characterized by 12 representative days, each one for a different month of the year (see Fig. 4).

- All possible investments take place at the beginning of the study period. See section 3.2.6 for more details on the investment considerations.

- A centralised management of distributed systems is assumed, so the objective of the model is to find an optimal planning and operation from a whole-system perspective, and not necessarily from the perspective of the individual participants.

- Reliability issues and the economic interactions client-retailer (business models) have not been explicitly addressed, as they fall outside the scope of this thesis. 
Nevertheless, it is assumed a regulatory framework similar to the current one in Spain where the objective of the aggregator managing the different systems is to minimise the total costs of his clients.

- For the sake of clarity and readability, the parameters used (consumption profiles, DER characteristics, market scenarios, etc.) and the special model considerations and characteristics for each analysis are described in the chapter where the analysis is presented (see Fig. 1).

Although this smart city energy model does not necessarily propose a novel mathematical modelling method, it includes, however, several elements and systems that, to the best of our knowledge, have not been put together before. In addition, this model proposes new approaches to address different problems, such as: DER planning and operation considering network thermal constraints, price-maker DER aggregation, or optimal management of smart city systems, including transport in the form of EVs and metro systems (with both price-taker and price-maker approaches). We believe that these modelling approaches and corresponding analyses provide novel and valuable insight to the exiting literature.

\subsection{MATHEMATICAL FORMULATION}

\subsubsection{GENERATION MODELS}

From the reviewed generation technologies (see section 2.2), photovoltaic panels (PV) and air-source heat pumps (HP) have been considered for electric and thermal energy production, respectively. These technologies have been selected due to their competitive costs and their relatively easy implementation in a smart city context. It is important to remark that other technologies could also be implemented, but for the case studies analysed in this thesis (Madrid, Spain), other technologies were less cost efficient or more difficult to implement. For instance, wind turbines are a very competitive generation technology on a big scale (larger than $1 \mathrm{MW}$ ), but for very small applications (less than $10 \mathrm{~kW}$ ) they still are too expensive.

\subsubsection{Photovoltaic (PV) Model}

Photovoltaic systems include the panel, mounting structure, inverter and connections. The panels can be built using different materials (commonly poly-crystalline or monocrystalline silicon [159]), varying their efficiency. Nevertheless, PV systems are normally modelled in the same way, just adapting the efficiency parameters [152].

The total effective energy produced by the PV system can be calculated with (1) (taken from [152]), which is an approximation of PV power generation extensively used for DER system planning models, as in [6], [11] and [160].

$$
v \operatorname{ProdPV} V_{c, m, h}=\frac{p D N I_{m, h} * v P o w P V_{c}}{G} *(1-p \operatorname{Losses} P V)
$$

The main input data required are: 
- Direct Normal Irradiance ( $p D N I$, in $\mathrm{W} / \mathrm{m} 2)$, which refers to the energy provided by the sun related to the geographical characteristics, the PV panel inclination and its orientation.

- Peak power ( $v$ PowPV, in $\mathrm{kW}$ ), which is measure of the installed capacity of the PV system. This value already considers the overall efficiency of the PV panel, given its fabrication, materials and size.

- Losses ( $p L o s s e s P V$, in \%), including estimated efficiency reduction due to temperature (higher temperatures reduces efficiency), low irradiance, angular reflectance effects, and other losses related to cables, inverter, etc. [152].

- Global irradiation received on a horizontal plane $(G=1000 \mathrm{~W} / \mathrm{m} 2)$, which is a theoretical maximum generation value (100\% efficiency) used by fabricants as a base line to define the maximum peak power of a PV system.

Note that there are other more detailed PV models, including information on voltage and currents, and modelling PV efficiency as a function of the temperature, but they normally use smaller time steps than the 1-hour step selected in this thesis, and are normally used in real-time operation problems as in [161], [162] or [163]. Therefore, even if they provide a more accurate computation of solar production, the increased complexity does not seem worth for the objective of this work, focusing on long-term planning problem. Hence, it has been considered that the model selected provides sensible results for the long-term planning of systems in the framework of this thesis.

\subsubsection{Heat pump (HP) Model}

The heat pump system can be modelled as an air-source HP or geothermal HP, changing only the costs and the coefficient of performance. In the case of the geothermal system, there are two possible approaches: cogeneration or thermal only. While the former is usually found in large scale applications, the latter stays in the small to medium scales for heating and domestic hot water purposes. Moreover, the geothermal cogeneration plant can be modelled as a steam turbine CHP system.

For small size applications, geothermal or air-source systems are used for thermal power generation, and can be modelled with (2).

$$
\operatorname{vProdHP}_{c, h, m}=\text { vHPenInput }_{c, m, h} * p C O P *(1-\text { pLossesHP })
$$

The main inputs of the model are:

- Electric energy input ( $v H P e n I n p u t$, in $\mathrm{kWh}$ ). The heat pump systems use electricity to extract more heat and use it for heating or cooling purposes.

- Coefficient of Performance: COP (or $p C O P$ in the model, which is a \%). Required to approximate the heat produced with the electricity employed by the heat pump.

- Thermal losses ( $p$ LossesHP, in \%)

The COP of a HP system varies constantly as a function of the difference between indooroutdoor temperatures. In this model, the COP has been considered constant and an average value is used. Indeed, this approximation is expected to cause an error in real-time operation (in summer time the COP is likely to be smaller, and in winter time the COP is likely to be larger). However, given the long-term scope of this study, it is considered that 
using an average value can deliver sensible results. Other works using a similar COP simplification can be found in [160], [164] and [165].

Other constraints are also included for the thermal generation modelling. Constraint ( 3 ) is used to limit the thermal production of the heat pump below the nominal installed electric input power, and (4) forces producing at least $30 \%$ of total demand in the afternoonevening hours, to avoid having thermal generation only in hours that is less likely to be used.

$$
\begin{aligned}
& \text { vHPenInput }_{c, m, h} \leq v \text { PowH }_{c} \\
& \sum_{h}\left(\text { vProdH }_{c, m, h}\right) \geq 0.3 * \text { pDemandTherm }_{c, m} \forall h \in[13,20]
\end{aligned}
$$

\subsubsection{STORAGE MODELS}

As reviewed in section 2.3, there are several storage technologies, designed for different applications, such as power quality control, large bulk storage, or small DG storage. From the literature review, it can be seen that battery systems are the most popular technology for DER systems, and are commonly used in planning and operation models. Other technologies are impractical for an urban context due to size limitations, or are not suitable for the DG storage application intended in this thesis. Hence, only battery systems have been modelled.

\subsubsection{Battery Model}

Different battery chemistries are available, varying in maximum number of cycles, charge and discharge rates, and costs. However, they can be modelled using the same equations, but different parameter values such as charge and discharge efficiency and prices.

The battery system can be modelled with equations (5) - (11). These constraints describe the battery storage systems, limiting the energy charge or discharge given the maximum capacity and state-of-charge (SOC) ((10) and (11)), and computing the current SOC from the previous one, considering the energy charged and discharged (9). Other constraints are related to the SOC, setting a starting point (5) and a maximum capacity (8), and letting the battery system to transfer energy between days ((6) and (7)). This type of model is commonly used in the literature, as in [69], [160] or [166].

$$
\begin{aligned}
& \text { vSOC }_{c, m=1, h=0}=0 \\
& { }^{v S O C_{c, m, h=0}}=\text { vSOC }_{c, m-1, h=24} \forall m \in[2,12] \\
& v S O C_{c, m, h=1}=v S O C_{c, m, h=24} \forall m \in[2,11] \\
& v \text { SOC }_{c, m, h}=v B a t C a p_{c} \\
& v S O C_{c, m, h}=v S O C_{c, m, h-1}-v \text { DisBat }_{c, m, h}+v \text { ChBat }_{c, m, h} \\
& v \text { DisBat }_{c, m, h} \leq v S O C_{c, m, h-1}
\end{aligned}
$$

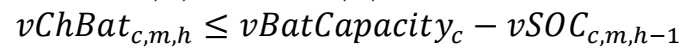

The variables used in this model are:

- The state-of-charge (SOC) of the battery (in this thesis, the related variable is $v S O C$ ), which is the percentage of stored energy with respect to its maximum capacity, similar to a fuel gauge.

- The energy charged per hour ( $v$ ChBat, in $\mathrm{kWh}$ ). 
- The energy discharged per hour (vDisBat, in $\mathrm{kWh}$ ).

- The maximum capacity ( $v B a t C a p$, in $\mathrm{kWh}$ ) of the battery system.

Note that, as for the previous systems, there are more detailed electrical and chemical models, providing very accurate computation of voltages, currents, temperature, degradation, etc. However, these models are commonly very complex (adding considerably to the computation time), and the level of detail provided falls outside the scope of the purpose of this thesis.

\subsubsection{FACILITIES MODELS}

Facilities are mainly modelled as loads and can be characterized by the input parameters of the thermal and electric demand: pDemandTherm and pDemandElec, respectively. The demand response capabilities of facilities are modelled next.

\subsubsection{Demand response Model}

Demand response in one of the most important energy features of facilities. Constraints (12) and (13) model the load shifting for the demand response scheme used in this thesis. From the original load, a maximum amount of load shifting per day is set by the parameter pDemandShift with (14), considering that only certain appliances and loads (such as the washing machine or the dishwasher) can be shifted. Additionally, constraint (15) is used to set a baseload that cannot be shifted in time (that could correspond for example to the energy needed by the fridge which is approximately $100 \mathrm{Wh}$ per house per hour [167]). Note that the hourly increment or decrement of demand is separated in two variables, so the total amount of energy shifted per day can be computed and used in constraint (14). If it was a single variable, the sum of increment and decrements per day would be zero and any amount of load could be shifted without limitations.

$$
\begin{aligned}
& \sum_{h} v \text { DemandNew }_{c, m, h}=\sum_{h} \text { pDemandElec }_{c, m, h} \\
& v \text { DemandNew }_{c, m, h}=\text { pDemandEle }_{c, m, h}+\text { vIncDemand }_{c, m, h}-v \text { DecDemand }{ }_{c, m, h} \\
& \sum_{h} \text { vIncDemand }_{c, m, h} \leq \text { pDemandShift } * \sum_{h} \text { pDemandElec } c_{c, m, h} \\
& v \text { DemandNew } w_{c, m, h} \geq 0.1 \mathrm{kWh}
\end{aligned}
$$

Similar models to the one presented here can be found in [6], [44] and [160], whose main variables and parameters are:

- Original electric demand ( $p$ DemandElec, in $\mathrm{kWh}$ ), which is an input parameter.

- New electric demand ( $v D e m a n d N e w$, in $\mathrm{kWh}$ ), which is an output given by the model.

- Demand increment per hour (vIncDemand, in kWh).

- Demand decrement per hour (vDecDemand, in kWh).

- Maximum load that can be shifted in a day ( $p$ DemandShift, in \%).

Additionally, equation (16) is used to calculate the required contracted electric power ( $v$ PowElec, in $\mathrm{kW}$ ) in the house given the maximum energy peak (since vGridEnTotalPos represents the electric energy that is bought from the grid). 


\subsubsection{TRANSPORT MODELS}

Two transport systems have been modelled in this thesis (from the energy perspective, and not the mobility), covering public and private mobility. For the former, metro systems, and for the latter, electric vehicles (EV). Looking for similarities with previous models, the metro system resembles a facility that consumes and generate power (due to the regenerative breaking). Such systems can be characterized by the input load curve pMetLoad, and the input generation curve pMetReg. On the contrary, EVs can be modelled as batteries but with a limited availability (due to the EV unplugged periods for mobility), and with a SOC than can decrease also when the EV is unplugged. Such EV models, resembling battery systems, have been widely used in the literature as in [64], [69] and [105].

It is important to remark that this work considers a scheme where metro and EVs are interconnected. The metro substation is connected, on one side, to the grid to supply energy to the trains and to other loads at the stations; and on the other side, to a parking where the parked EVs can be used as energy storage for the regenerative braking energy recovered. This scheme is described in more detail in chapter 6.

\subsubsection{Electric Vehicle (EV) model}

As for stationary batteries, the EVs have a set of similar constraints that govern its behaviour. The main differences in the EV model in comparison to the stationary battery system constrains are in (20), where the EV storage capacity (available capacity) changes over time and type of EV user, and in (21) where there is a minimum SOC energy requirement. Moreover, it can be seen in (23) that the EVs can arrive to the parking with a pre-existing charge. These parameters represent the mobility and energy use profiles of the EV drivers.

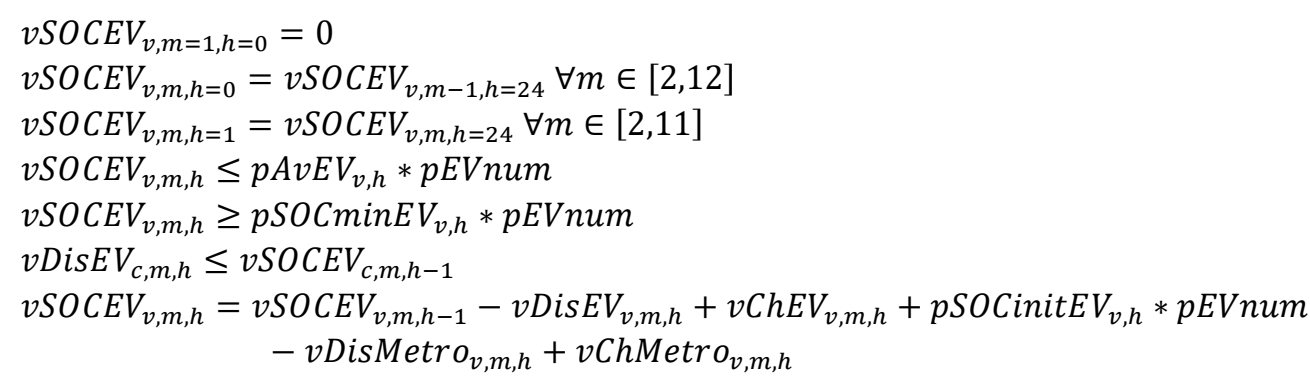

In this EV model, the following variables and parameters are used:

- EV state-of-charge ( $v S O C E V$ ).

- Energy charged to the EV per hour ( $v C h E V$, in $\mathrm{kWh}$ ).

- Energy discharged from the EV per hour ( $v D i s E V$, in $\mathrm{kWh}$ ).

- EV storage availability ( $p A v E V$, in $\mathrm{kWh})$.

- Number of EVs per EV type ( $p E V n u m$ ).

- Minimum SOC required (in energy) for mobility purposes ( $p S O C m i n E V$, in $\mathrm{kWh}$ ).

- Initial EV SOC level (in energy) when they become available (pSOCinitEV, in kWh).

- Energy charged to EVs from the metro system per hour (vChMetro, in kWh). 
- Energy discharged from EVs to the metro system per hour (vDisMetro, in kWh).

\subsubsection{Metro model}

In this thesis, the metro system is considered to be a commercial entity that buys energy through a commercial tariff with time-of-use discrimination, separated in three periods: peak, mid-peak and off-peak times.

Metro constraints limit the energy transfer going to the EV parking lot, which should be less than or equal to the available regenerative braking energy (24), and compute the new electric load curve of the electrical substation, changed from the original by the energy coming from EVs (25). Equations (26) - (30) are used to calculate the contracted power at different time-of-use tariff periods.

$$
\begin{aligned}
& \sum_{v} \text { vChMetro }_{v, m, h} \leq \text { pMetReg }_{h} \\
& \text { vLoadMnew }_{m, h}=\text { pMetLoad }_{h}-\sum_{v} \text { vDisMetro }_{v, m, h} \\
& \text { vPowOffpM } \geq \text { vLoadMnew }_{m, h o} \\
& \text { vPowMidpM } \geq \text { vLoadMnew }_{m s, h M s} \\
& \text { vPowMidpM } \geq \text { vLoadMne }_{m, h M w} \\
& \text { vPowPeakM } \geq \text { vLoadMnew }_{m S, h P s} \\
& \text { vPowPeakM } \geq \text { vLoadMnew }_{m W, h P w}
\end{aligned}
$$

The variables used in the metro model are:

- Energy charged to EVs from the metro system per hour (vChMetro, in kWh).

- Energy discharged from EVs to the metro system per hour (vDisMetro, in kWh).

- Metro regenerative braking energy curve ( $p M e t R e g$, in $\mathrm{kWh}$ ).

- Metro load curve (pMetLoad, in kWh).

- Maximum power used at off-peak time ( $v$ PowOffpM, in kW).

- Maximum power used at mid-peak time ( $v$ PowMidpM, in $\mathrm{kW}$ ).

- Maximum power used at peak time ( $v$ PowPeakM, in kW).

\subsubsection{BALANCE EQUATIONS (INFRASTRUCTURE)}

It is considered that the required physical infrastructure to interconnect systems (including the energy network and the information and communication technologies) will be available. Hence, this section presents the equations needed to interconnect the systems described thus far. Two equations, one for thermal energy and one for electric energy, are used to model such connections and balance the energy transfers between systems.

The total electric energy consumption and production is balanced with (31). In this equation, all energy loads are positive ( $v$ DemandNew, $v$ ChBat, $v$ ChEV and $v H P e n I n p u t$ ) and the energy generated or discharged is negative ( $v$ ProdPV, $v$ DisBat and $v D i s E V)$. Equation (32) separates the energy transactions with the grid ( $v G r i d E n T r$ ) in its positive (vGridEnTotalPos) and negative (vGridEnTotalNeg) parts to use the appropriate tariffs to sell and buy energy. 


$$
\begin{aligned}
& v \text { GridEnTr }_{m, h}=\sum_{c}\left(v \text { DemandNew }_{c, m, h}-\operatorname{vProdPV}_{c, m, h}-v \text { DisBat }{ }_{c, m, h}\right. \\
& \left.+v_{\text {ChBat }} c_{c, m, h} / p E f f B a t+v \text { HPenInput }_{c, m, h}\right) \\
& +\sum_{v}\left(-v D i s E V_{v, m, h}+v C h E V_{v, m, h} / p E f f B a t\right) \\
& v \text { GridEnTr }_{m, h}=v \text { GridEnTotalPos }_{m, h}-\text { vGridEnTotalNeg }_{m, h}
\end{aligned}
$$

Similarly, thermal energy is balanced with (33). Unlike the electricity transactions, the thermal energy transaction is always positive (since only buying from the grid is allowed in this thesis).

$$
v_{\text {ThBuy }}=\sum_{c}\left(\text { pDemandTherm } m_{c, m}-\sum_{h}\left(\operatorname{vProdHP}_{c, m, h}\right)\right)
$$

\subsubsection{OBJECTIVE FUNCTION}

The objective function minimizes the overall economic costs of all the systems considered, including EVs, metro and prosumers (producers-consumers [168]) at the smart city. This formulation considers a total lifespan of 20 years, stationary battery replacements every 8 years, see [169], and for simplicity all possible investments are supposed to take place at the beginning of the study period. Moreover, a typical year's operation is replicated for the total length of the study [11]. This typical year is characterized by 12 representative days, each one for a different month of the year (see Fig. 4). Note that in DER planning and operation, the hourly detail and daily sequence (resembling to real days) is important as the energy consumption and production patterns (for some technologies like PV or WT) vary throughout the day. Also, the chronological order should be respected to be able to model properly the daily energy storage management and load shifting.

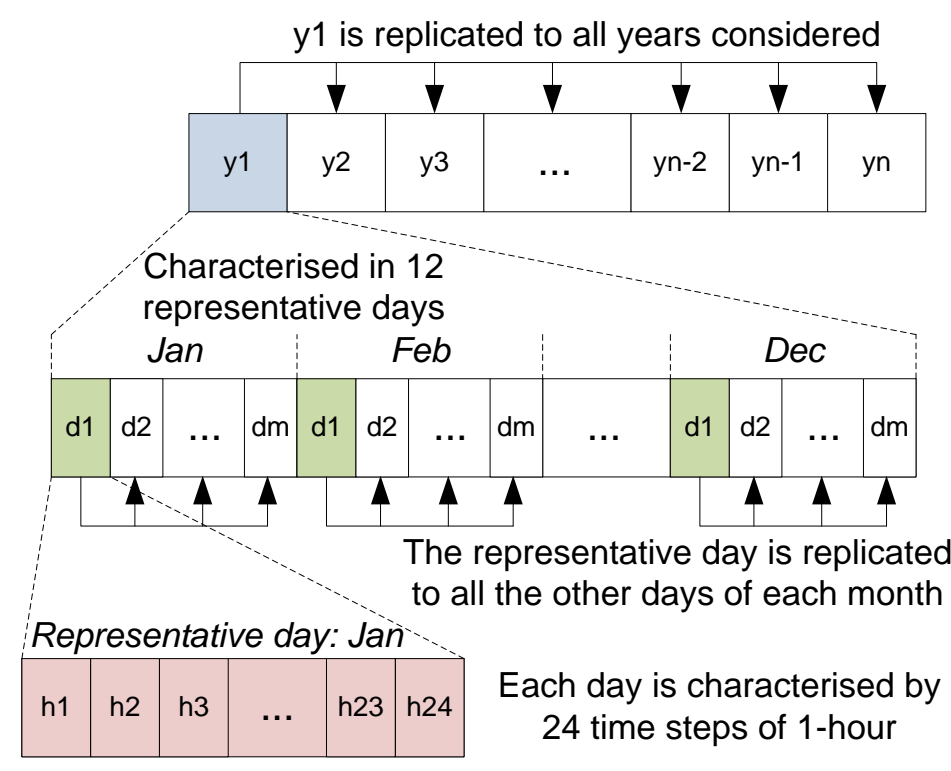

FIG. 4. DIAGRAM OF THE MODEL TIME STRUCTURE. 
The objective function (34) computes the total costs, it is composed by the DER investments and maintenance costs, plus the net energy costs of all systems. Note that the programing problem of this smart city energy model is set as a minimisation of (34), min(TotalCosts).

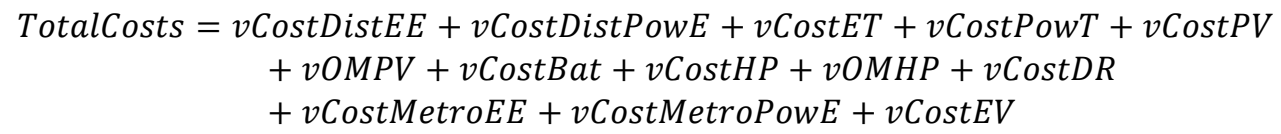

The elements defining (34) are described in equations (35) - (47).

$$
\begin{aligned}
& v \text { CostDistEE }=\sum_{y, m, h}\left(p \operatorname{Cost} E_{y} * p \text { Days }_{m}\right. \\
& *\left(\text { pBuyEprice }_{m, h} * \text { vGridEnTotalPos }_{m, h}-\text { pSellEprice }_{m, h}\right. \\
& \text { *vGridEnTotalNeg } \left.g_{m, h}\right) \text { ) } \\
& \text { vCostDistPowE }=\sum_{y}\left(\text { post } E_{y} * \text { pFixEpow } * \text { vPowElect }\right) \\
& v \operatorname{CostET}=\sum_{y, m}\left(p \operatorname{Cost}_{y} * \text { DDays }_{m} * v \text { ThBuy }_{m}\right) \\
& v \text { CostPowT }=\text { pLifespan } * \text { pHouseMultiplier } * \text { pHouseNum } * \text { pFixTpow } \\
& v \operatorname{Cost} P V=\sum_{c}\left(p \operatorname{Cost} P V * v \operatorname{Pow} V_{c}\right) \\
& \text { vOMPV }=\sum_{C}^{c}\left(\text { pOMfixPV } * \text { vPowPV } V_{c} * \text { pLifespan }\right) \\
& v \operatorname{CostBat}=\sum_{c}\left(p \operatorname{CostBat} * v B a t \operatorname{Cap}_{c}\right) \\
& v \operatorname{CostHP}=\sum_{c}\left(p \operatorname{CostHP} * v \text { PowHP } P_{c}\right) \\
& \text { vOMHP }=\sum_{C}^{c}\left(\text { OOMfixHP } * v \text { PowH } P_{c} * \text { pLifespan }\right) \\
& v \text { CostDR }=\text { pHouseMultiplier } * \text { pHouseNum } * \text { pDRequipCost } \\
& \text { vCostMetroEE }=\sum_{y, m, h}\left(\text { Cost }_{y} * \text { pDays }_{m} * \text { pBuyEpriceM }_{m, h} * \text { vLoadMnew }_{m, h}\right) \\
& \text { vCostMetroPowE } \\
& =\sum_{y}\left(p \operatorname{Cost} E_{y}\right. \\
& *(\text { PPeakPowM } * v \text { PowPeakM }+ \text { pMidPpowM *vPowMidpM } \\
& + \text { pOffPpow } * \text { * } P \text { Pow OffpM)) } \\
& v \text { CostEV }=p \text { CostBat } * p E V \text { num } * p E V \text { cap }
\end{aligned}
$$

These constraints include:

- District net electricity costs ( $v$ CostDistEE) due to transactions with the electric grid (35), considering the cost of buying energy (energy $*$ price $=v$ GridEnTotalPos $*$ pBuyEpriceH) and the benefit of selling energy back to the grid (vGridEnTotalNeg * pSellEpriceH). Note that the electric energy transactions with the grid are separated in two variables, as the pricing of buying and selling energy are different.

- Contracted electric power costs (vCostDistPowE, (36)). 
- District thermal energy ( $v \operatorname{CostET},(37)$ ) and thermal power ( $v \operatorname{CostPowT}$, (38)) costs. Note that the thermal power costs are considered to be a fix value paid by each client, not related to the peak thermal power demand.

- DER investments (vCostPV, vCostBat, vCostHP) and maintenance costs (vOMPV, vOMHP) (39) - (43).

- Demand response related costs ( $v \operatorname{CostDR},(44))$, representing the cost of the control devices needed for demand response.

- Metro energy (vCostMetroEE, (45)) and contracted power (vCostMetroPowE, (46)) costs.

- Extra EV costs ( $v$ CostEV, (47)) in the form of a new set of batteries (due to extra charging and discharging from the metro system), paid at the beginning of the study period.

According to several EV manufacturers, battery packs should be replaced every 5 - 8 years [169], [170]. Hence, it is assumed that the extra degradation in the EV batteries due to the additional charge and discharge cycles produced by the metro system will result in an extra battery pack replacement during the study lifespan. 


\section{4}

\section{ASSESSING THE IMPORTANCE}

\section{OF NETWORK CONSTRAINTS}

\section{IN THE PLANNING PROCESS}

This chapters starts with the exploration of model considerations and restrictions task of the smart city energy model methodology described in section 1.3. The analysis developed addresses hypothesis 1. This hypothesis states that it may be reasonable to neglect the congestion constraints of the electricity network (power line thermal limits) in the planning process, and just reinforce the network when needed.

Many efforts are being devoted towards achieving optimal planning and operation of Distributed Energy Resources (DER). However, little attention has been paid during the planning process to the constraints of the distribution network. Some claim that these constraints should be taken into account while others ignore them by following a single-node approach. The former approach (including network constraints) is especially used when the impacts on the distribution network need to be quantified (for instance in network expansion planning problems), and provides more detailed information on the DER maximum capacity. However, this methodology adds extra complexity to the programming problem, and requires more input information that could be private and difficult to obtain, such as geographical locations of loads and generators, power line characteristics, etc. Many DER planning models use the latter approach (not including network constraints) as it is a simpler problem to model and solve (see chapter 2).

This chapter assesses the effects of the distribution network thermal constraints (limiting power flows) in DER planning, using a deterministic linear programming problem to find the optimal DER planning and operation. Therefore, this assessment is the main contribution of this chapter, as it fills a gap in the literature by proposing a joint solution of an aggregatortype optimization problem, while also including distribution network thermal constraints.

The results of this analysis show that, in the case examples studied (with different sizes and network configurations), it was more profitable not to include network thermal constraints at 46 
the planning stage, and just reinforce the power lines when it becomes necessary. This suggests that a similar strategy may be adopted for other districts types of the smart city with a similar impact.

The contents of this chapter draw heavily from the journal article: C. F. Calvillo, A. SánchezMiralles, and J. Villar, "Assessing low voltage network constraints in distributed energy resources planning," Energy, vol. 84, pp. 783-793, May 2015.

\subsection{INTRODUCTION}

When planning DER systems, an important decision that has to be made is deciding if the network constraints, in terms of power line thermal constraints, have to be considered (other network issues such as losses, voltage and frequency control have not been taken into account in this study, as they are more related to the real-time operation of systems, as shown in [51] and [171], and falls outside the scope of the proposed smart city planning model). Both approaches can be found in the literature. The network is very often considered from the perspective of the distribution system operator (DSO), who is responsible for the correct operation of its distribution network, avoiding overloads and voltages deviations ([138] and [172]). However, the aggregators' perspective often neglects network thermal constraints since they are more concerned with deciding the size of DER systems and the way to operate them ([13] and [43]) to maximize the economic benefits.

In this sense this chapter, as mentioned in the methodological proposal of 1.3 , is intended to provide some answers on the convenience or the need of considering the power line thermal constraints in the planning of DER systems.

Many research work examples of DER system planning can be found in the literature. When the network constraints are considered (the DSO approach), the studies normally focus on the impact of DER planning on the network operation and expansion. A model to plan the expansion of the distribution network considering sizing, placement and timing of DER investments and network reinforcements is proposed in reference [173], and in [73] a quantification of the impact of different penetration levels of distributed generation on distribution network costs is presented, analysing three actual distribution geographical areas. Another relevant example is the Reference Network Model presented in [174] which is a large-scale distribution planning tool used to plan distribution networks from scratch or incrementally from an existing grid. This Reference Network Model is also used in [175] in combination with an algorithm that optimizes the location, size, and supply area of the medium-to-low voltage transformer substations with the objective of minimizing costs. Note that these works do not focus on the economic benefits provided by DER systems, or if they do, only in the form of network investment deferral (but not in energy saving costs).

Unlike the abovementioned models where the network is of prime importance, DER planning models from the aggregator perspective (not considering network constraints) follow a very different approach. For instance, in [8] it is described a commercial tool for optimal sizing and operation of DER in microgrids, with many applications in different research projects, such as those described in [43]. There are numerous examples of Electric 
Vehicle (EV) aggregation, considered an interesting DER given its energy storage capabilities. For instance, a mixed integer linear programming model is proposed in [69], where an aggregator schedules the charge and discharge of EVs, maximizing the profit of the concerned agents while also taking into account energy markets, customer preferences and battery degradation. Nevertheless, these works commonly focus on the optimization and management of energy consumption, considering individual benefits only, and due to the small size of the applications, paying little attention to their impact on the grid (including any extra costs produced by the DER systems on the network).

Furthermore, with large DER penetration, not considering network constraints in the planning problem (normally, the aggregator's perspective) could cause problems to the distribution power system producing bidirectional power flows (most grid protections are not design for such flows), reaching lines thermal limits and producing instability on the grid [66]. Although this concern has been studied more for the medium voltage level, the effects on the final costumers at the low voltage distribution network are starting to attract attention [21].

It is important to note that the joint optimization problem that results from DER planning, combined with its impact on the distribution network and its potential expansion, is complex and has no easy solution. Moreover, despite the amount of related research available, there is no work addressing the mentioned optimization problem as a whole. As the research works giving importance to network thermal constraints do not consider the DER potential on energy costs savings, while the works focusing in these economic benefits of DER, do not consider the network. The study developed in this chapter tries to fill this gap by proposing a joint solution of an aggregator-type optimization problem, but also including distribution network thermal constraints, comparing the total benefits or maximum DER expansion with grid reinforcement when needed with those of DER expansion but limited to the grid maximum capacity.

Although no optimal distribution network expansion is computed, the proposed approach uses an optimization problem to find the optimal planning and operation of DER systems. Then a DC load flow analysis is carried out to detect if thermal limits are reached, computing the corresponding network reinforcement cost, and finally, assessing the benefits of this reinforcement against limiting the power flows (see Fig. 5).

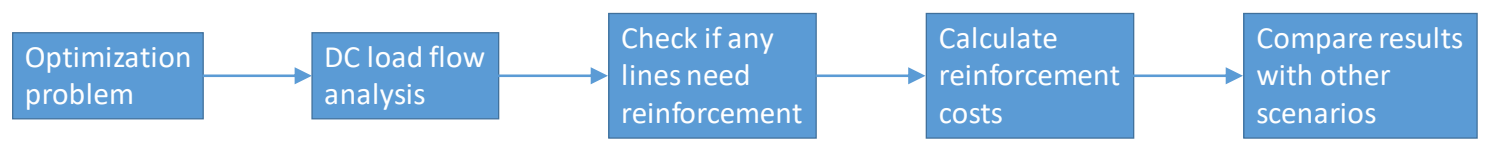

FIG. 5. BLOCK DIAGRAM OF THE ASSESSMENT OF NETWORK THERMAL CONSTRAINT IN DER SYSTEMS PLANNING.

A variation of the optimization model presented in chapter 3 is used to this end. The model accepts different small district network topologies and the climatic characteristics of Madrid, Spain. Solar photovoltaics (PV) and air-source heat pumps (HP) are used as representative DG technologies for electric and thermal energy production, and conventional battery systems are considered for energy storage. 
For this analysis, three case studies showing three generic network topologies are presented, trying to replicate representative network configurations and sizes. The selection of these networks has been done with the objective of comparing the outcomes and analyse how the network topology and size impact the planning of DER systems, and to obtain results from different representative networks that could be extrapolated to other examples.

\subsubsection{MODIFICATIONS OF THE SMART CITY ENERGY MODEL FOR THIS ANALYSIS}

Indeed, the model described in chapter 3 is modified to be able to include the power line thermal constraints. In addition, for the sake of simplicity, some of the energy systems have not been included in this version of the model (such as transport systems), as they do not seem necessary for the objective of this analysis.

The linear programming model used in this chapter includes the constraints described in sections 3.2.1, 3.2.2, 3.2.3, 3.2.4 (removing the EV and metro parts), and 3.2.5 and 3.2.6 (removing the transports elements). In addition, the following network constraints are included:

$$
\begin{aligned}
& \text { vLoad }_{c, m, h}=\text { vGridEnTr } \\
& \text { vLineFlow }_{l, m, h}=\text { vLoad }_{x, m, h}+\text { vLineFlow }_{x, m, h} \\
& \text { vLineFlow }_{l, m, h} \leq \text { pLineCap }
\end{aligned}
$$

The load in each household ( $v L o a d$ ) is related to the energy transaction ( $v$ GridEnTr) it has at a particular hour (positive or negative). The vLineFlow constraints vary depending on the network topology analysis (subindex $x$ indicates that variability, as it can take different value as required by the network considered), and they are designed as a linear combination of vLoads and other vLineFlows as in a DC load flow. Also, the power line flows should not overpass the maximum line thermal capacity (pLineCap). Note that the constraints described in (48) - (50) only apply to those scenarios where network constraints are included into the model.

The particular assumptions and considerations for this analysis are summarized below:

- A DC load flow analysis is used to detect if power line thermal limits are reached. This type of load flow analysis is used instead of a more complex AC one, to keep this study as a linear programming problem (easier to model and faster to solve), and as it allows to analyse violations on the power lines thermal limits, which is the main problem to be addressed with this analysis.

- Certainly, the analysis developed focuses on the impact of low voltage network thermal constraints in the planning of DER systems. However, there are other network problems related to DER penetration that could be as important as the network thermal limits. For example, voltage magnitude and frequency variation, which are particularly relevant in the short-term operation of systems.

○ It is recognised in the literature that distributed generation, such as PV systems, injecting energy into the network can create overvoltage [176].

- On the other hand, extra electric load from HP systems or EVs could create voltage dips [177]. 
- Similarly, imbalances between distributed generation and demand, especially in islanded microgrids, can create frequency problems [178].

Note that, even though these problems also relate to the presence of DER systems, they can be analysed independently from thermal power limit violations. In the one hand, power limit violations relate to active power, while voltage variation could be addressed managing reactive power (for instance, by adding a reactive power control level to PV inverters [176]). In the other hand, there could be networks with voltage problems due to DER penetration, but no power line limits violations. Therefore, due to the added complexity of addressing such problems, and as they mainly appear in the real-time operation of systems, which fall outside the scope and objectives of this thesis, these problems have not been considered here. Nevertheless, a brief discussion on potential implications and possible solutions for these problems is provided in section 4.3.4.

- The loads at the power lines are scaled up as to obtain a load peak that is equal to the thermal power line limit (i.e. each node will have the equivalent load of $5-6$ households). This has been done since in a normal case, the loads would not be enough to surpass the thermal limits (not constraining the optimisation problem) and there will be no need of considering the network thermal constraints.

- All loads are residential and have the same consumption profile.

- All clients use a conventional residential tariff, with an energy and a power cost component, such as the one commonly found in the Spanish households. This type of tariff has been selected with the objective of analysing the importance of the network thermal constraints in a setup similar to the one currently in place in Spain. Note that the power cost component in these tariffs limits the client's peak load (clients cannot consume more than their contracted power), and thus, it passively helps the network to avoid power line saturation. Therefore, it is expected that this power cost component on the energy tariffs will have an important impact on the results of this analysis, potentially reducing the DG systems investments and consequently the overall reinforcement costs (in comparison with a tariff without the power cost component). See section 4.3 .4 for further discussion on this effect.

- HP, PV and Batteries are the only DER resources considered, in addition to demand response.

- Three case studies, corresponding to three different network topologies have been considered. These networks have been designed due to their variety on size and organization of loads, with the objective of being representative of a large number of typical urban networks, and to gain insight on how the network topology affects the results (see section 4.3.4 for further discussion).

- It is assumed that each client (node of the network) has a smart meter. This is assumption is necessary to be able to measure the energy flows and find power line violations in the network.

\subsection{Scenarios And CaSe StUdies}

Three case studies are developed in this chapter. They correspond to three different topologies of generic urban district networks with different number of nodes. These networks have been designed due to their variety on size and organization of loads, with the objective of being representative of a large number of typical urban networks. 
Average solar characteristics of Madrid, Spain have been considered in all cases, and solar production has been calculated with the hourly direct normal irradiance (DNI) data from [152]. The proposed districts consist of standard Spanish households, with average energy consumption. Table 10 shows the average domestic energy consumption per year in Spain, with the corresponding electrical and thermal shares [179].

TABLE 10. AVERAGE ANNUAL ENERGY CONSUMPTION PER HOUSEHOLD IN SPAIN (2011).

\begin{tabular}{l|llll}
$\begin{array}{l}\text { Consumption } \\
\text { per Household }\end{array}$ & Electric & $\begin{array}{l}\text { Thermal: } \\
\text { DHW and } \\
\text { Heating }\end{array}$ & $\begin{array}{l}\text { Thermal: } \\
\text { Others } \\
\text { (kitchen) }\end{array}$ & Total \\
\hline Energy (kWh) & 3698.13 & 6384.85 & 438 & 10.521 \\
Percentage (\%) & $35.15 \%$ & $60.68 \%$ & $4.16 \%$ & $100 \%$
\end{tabular}

Electricity usage curves (taken from [180]) have been used to calculate the optimal generation and storage capacity to be installed. Fig. 6a presents the normalized electricity demand curves for a typical day in summer (Apr. - Sept.) and winter (Oct. - Mar.), where the area below the curve sums $100 \%$. Fig. $6 \mathrm{~b}$ shows the monthly evolution of this demand throughout an average year, the red discontinuous line represents the average monthly average. Note that these demand curves do not include thermal generation, which is considered separately.
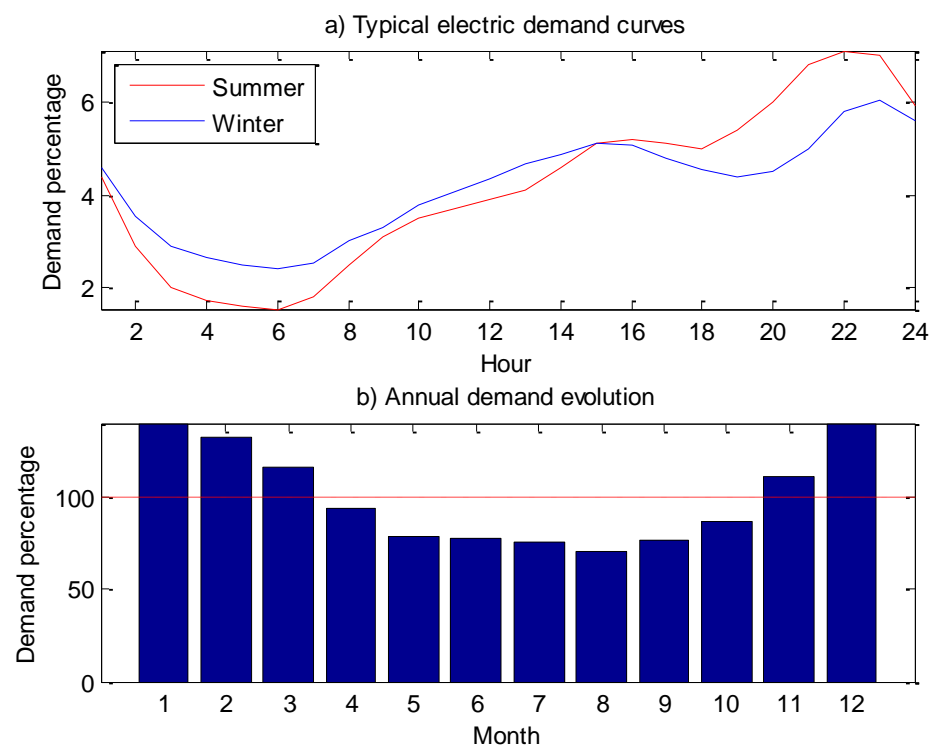

FIG. 6. DEMAND CURVES AND ANNUAL EVOLUTION FOR RESIDENTIAL SECTOR IN SPAIN.

A time-of-use electricity tariff with peak and off-peak prices and a flat tariff for thermal energy have been used (Table 11), which are commonly found within the Spanish residential consumers. Note that these tariffs (taken from [181]) include taxes and thus correspond to final Spanish consumers' tariffs (in year 2013). The price for selling electricity back to the grid has been set to a flat rate, and a 3\% annual increment has been used for all energy prices. 
TABLE 11. TARIFFS TIME SCHEDULE AND PRICING.

\begin{tabular}{l|lc} 
Two-price tariff (electricity): & Peak & Off-Peak \\
\hline Winter & $12-22 \mathrm{~h}$ & $23-11 \mathrm{~h}$ \\
Summer & $13-23 \mathrm{~h}$ & $24-12 \mathrm{~h}$ \\
Energy price (€/kWh) & 0.183 & 0.0624 \\
Contracted power (Annual) & $44.15(€ / \mathrm{kW})$ \\
\hline Natural gas tariff: & Static \\
\hline Price (€/kWh) & \multicolumn{2}{|c}{0.0632} \\
Access (Monthly) & $10.30(€ /$ Client $)$ \\
\hline Electricity selling price: & \multicolumn{2}{|c}{ Static } \\
\hline Price (€/kWh) & \multicolumn{2}{|c}{0.0351}
\end{tabular}

Lastly, Table 12 shows the selected generation and storage technologies data used (taken from [38]). The coefficient of performance (COP) of the heat pump has been set to 2.5 units.

TABLE 12. TECHNOLOGY COSTS AND EXPECTED ENERGY LOSSES.

\begin{tabular}{|c|c|c|c|}
\hline Technology & $\begin{array}{l}\text { Inst. Cost } \\
(€ / W)\end{array}$ & $\begin{array}{l}\text { O\&Mfix } \\
(€ / \mathrm{kW})\end{array}$ & Losses (\%) \\
\hline$\overline{\mathrm{PV}}$ & 2.55 & 36.55 & 24 (electric) \\
\hline HP & 2.64 & 120 & 15 (thermal) \\
\hline Battery & $0.42(€ / \mathrm{Wh})$ & - & 10 (electric) \\
\hline
\end{tabular}

The demand response schemes presented in this study are based on two simultaneous strategies: the management of the heat pump production and the partial shifting of electric load. The pDemandShift parameter is estimated considering the appliances that can be more easily shifted in time, washing machine, dryer and dish washer that, which according to [179], represent $13.3 \%$ of the total electric consumption of a typical Spanish household. Hence, $p$ DemandShift parameter has been set to $13 \%$ of total daily load. A cost $p$ DRequipCost of $250 €$ /house represents the estimated cost of the control devices needed for demand response [182].

In addition, an economic analysis of the proposed case studies is also provided, considering the value of the objective function as equivalent to the Net Present Value (NPV) of the investment with a discount rate of $3 \%$ per year. This NPV value is formulated from the energy and DER systems costs, and serves to assess the economic feasibility of such systems.

Lastly, the network topologies designed for this study have been done with the reference network model presented in [73], all of them following the scale-free model, which is featured in many real world networks [183]. The main characteristics of the selected topology designs are:

- Three different network topologies are selected for the case studies.

- The loads in these networks, considering typical Spanish residential loads (see Table 10), are within normal network operation capacities. In other words, these networks are not already overloaded, which is normally the case in real low-voltage distribution networks. 
- Case study A and B, with similar network structure but different number of nodes, are selected to analyse the impact of network size on the DER planning and operation results, and overall costs.

- Case study C presents a different network configuration than case studies A and B, but with the same number of nodes than case study B. This topology has been selected to analyse the effect of different types of network, presenting different number of saturated lines.

\subsubsection{CASE STUDY A}

This case study includes a small district of 9 households (labelled with numbers, and represented as circles in the network figures), as described in Fig. 7. Table 13 contains the line (labelled with letters) lengths of the network to calculate the cost of the potential network reinforcements. It is important to remark that, in order to solely study the effects of the network thermal constraints given its topology, all houses in the proposed case studies behave equally, according to the consumption patterns of Fig. 6 and Table 10. This approach results in a high simultaneity factor, summing up all peaks on the network, which can be considered an unfavourable but interesting scenario to analyse, since it will produce larger grid congestions that a more realistic one. Finally, the base load peak in all the nodes in this study is dimensioned to meet the maximum power peak for the network thermal limits. In other words, the residential loads are augmented so the peak load is equal to the power line thermal limit (operating to a $100 \%$ of its capacity). Once again, this extreme scenario, despite of being unrealistic, is implemented to be able to assess the importance of network constraints (in a case where the network limits are not meet, the network thermal constraints are not binding, and thus, including them do not affect the results).

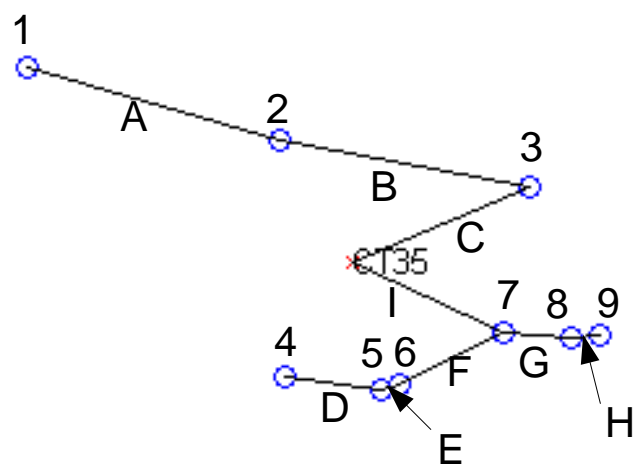

FIG. 7. DISTRICT ELECTRIC NETWORK: CASE STUDY A.

TABLE 13. LINE LENGTHS IN CASE STUDY A.

\begin{tabular}{c|ccccccccc} 
Line & A & B & C & D & E & F & G & H & I \\
\hline Length (m) & 289.4 & 258.48 & 241.14 & 95.63 & 22.67 & 158.4 & 64.03 & 28.23 & 216.65
\end{tabular}

According to [73], the typical thermal capacity for the low voltage distribution electric lines in Spain ranges from $100 \mathrm{~A}$ to $415 \mathrm{~A}$ at $400 \mathrm{~V}$. Moreover, the approximate cost of building 
such power lines is $13600 € / \mathrm{km}$ [73]. For this study, the maximum power flow has been limited to $30 \mathrm{~kW}(\approx 136 \mathrm{~A}$ at $220 \mathrm{~V}$ ) for all power lines, and the costs of reinforcements of a power line has been considered to be half of the original cost of a completely new power line.

\subsubsection{CASE STUDY B}

Case study B comprises a bigger district with 16 houses, so the effect of a more complex network containing more nodes can be analysed. It differs from the previous network in the organization of houses. In case study A, 33.3\% of the houses are on one of the main branches (line $\boldsymbol{C}$ ) and $66.7 \%$ on the other (line $\boldsymbol{I}$ ), whereas the proportion for case B is $56.2 \%$ (line $\boldsymbol{I}$ ) - 44.8\% (line $\boldsymbol{P}$ ). Therefore, the design of this network has been done with the objective of analysing not only a larger and more complex network, but a more balanced one as well.

The organization of the district is depicted in Fig. 8, while Table 14 presents the lengths of network lines.

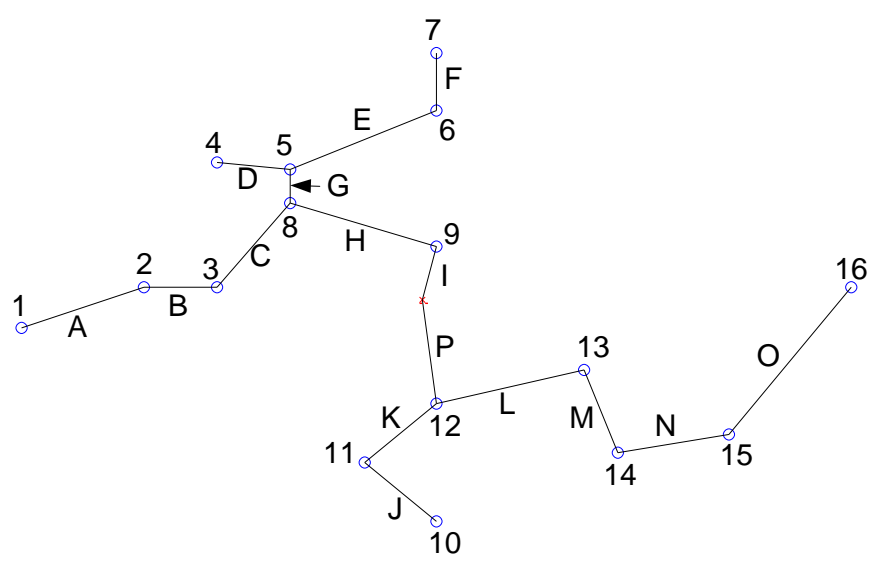

FIG. 8. DISTRICT ELECTRIC NETWORK: CASE STUDY B.

TABLE 14. LINE LENGTHS IN CASE STUDY B.

\begin{tabular}{c|cccccccc} 
Line & A & B & C & D & E & F & G & H \\
\hline Length (m) & 68.6 & 35 & 79.15 & 35.51 & 86.83 & 50 & 29 & 79.61 \\
& $\mathbf{I}$ & $\mathbf{J}$ & $\mathbf{K}$ & $\mathbf{L}$ & $\mathbf{M}$ & $\mathbf{N}$ & $\mathbf{0}$ & $\mathbf{P}$ \\
\hline Length (m) & 46.61 & 61.03 & 61.03 & 76.69 & 71.81 & 56.04 & 139.12 & 89.19
\end{tabular}

\subsubsection{CASE STUDY C}

Unlike previous cases that contain 2 main branches with different number of houses, this case study has a network with 4 main-branches and equally distributed nodes (4 houses each branch). The objective of this design is to understand the effects of a different network structure on the optimization problem results, as this structure differs from the one shown in cases A and B. Fig. 9 illustrates the network topology for this case, and Table 15 lists the line lengths. 


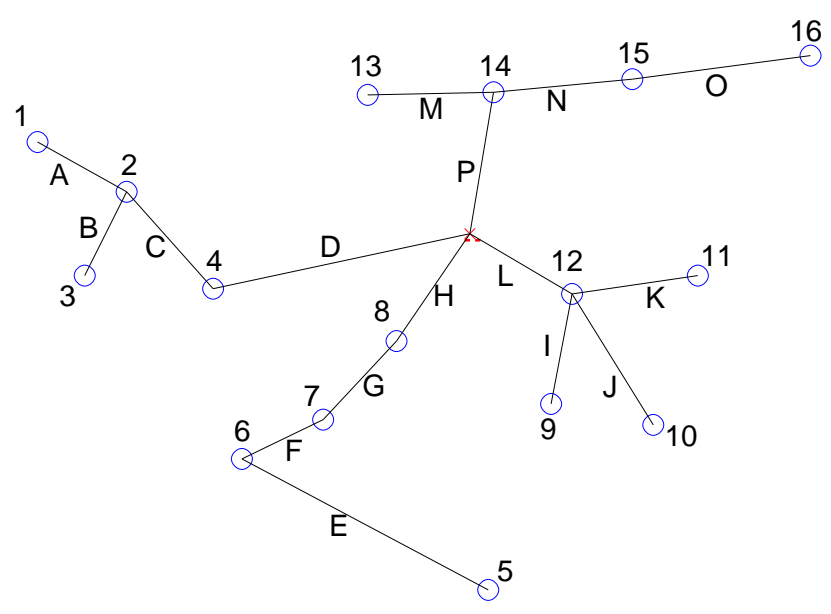

FIG. 9. DISTRICT ELECTRIC NETWORK: CASE STUDY C.

TABLE 15. LINE LENGTHS IN CASE STUDY C.

\begin{tabular}{c|cccccccc} 
Line & $\mathbf{A}$ & $\mathbf{B}$ & $\mathbf{C}$ & $\mathbf{D}$ & $\mathbf{E}$ & $\mathbf{F}$ & $\mathbf{G}$ & $\mathbf{H}$ \\
\hline Length (m) & 40.47 & 42.42 & 55.74 & 98.14 & 109.57 & 35.37 & 45.27 & 57.25 \\
& $\mathbf{I}$ & $\mathbf{J}$ & $\mathbf{K}$ & $\mathbf{L}$ & $\mathbf{M}$ & $\mathbf{N}$ & $\mathbf{0}$ & $\mathbf{P}$ \\
\hline Length (m) & 68.68 & 46.52 & 52.82 & 47.86 & 67.35 & 51.42 & 46.2 & 66.32
\end{tabular}

\subsubsection{SCENARIO DESCRIPTION}

The combination of different DER systems with the inclusion or not of network thermal constraints has been used to design 5 scenarios, summarized in Table 16, for each of the three network topologies designed for case studies A, B and C.

The first scenario serves as a reference to evaluate the impact of DER systems and network constraints, since it corresponds to the "business-as-usual" approach where no DER is implemented. Scenarios 2 and 3 include distributed generation and storage systems (PV, HP and Battery systems), but they do not implement demand response neither in the form of load shifting (the $13 \%$ of residential load previously described cannot be moved) nor in the management of the heat pump production (the production is "flat", as it does not vary throughout the day). Hence, the thermal demand of these scenarios is flat during the whole day. Finally, scenarios 4 and 5 also include demand response schemes, providing a more flexible behaviour of the consumers of the studied networks. For the sake of clarity, the scenarios have been labelled with $\mathbf{D}, \mathbf{R}$, and $\mathbf{N}$, referring to distributed generation, demand response and network constraints, respectively. The uppercase letter indicates the presence of such system on the model, whereas the lower case letter means that the characteristic is not implemented. 
TABLE 16. SCENARIOS FOR THE OPTIMIZATION MODEL.

\begin{tabular}{l|ccc} 
Scenario & $\begin{array}{c}\text { DG and } \\
\text { Storage }\end{array}$ & $\begin{array}{c}\text { Demand } \\
\text { Response }\end{array}$ & $\begin{array}{c}\text { Network } \\
\text { constraints }\end{array}$ \\
\hline $1-\mathrm{S}_{\mathrm{d}, \mathrm{r}, \mathrm{n}}$ & $\mathrm{x}$ & $\mathrm{X}$ & $\mathrm{x}$ \\
$2-\mathrm{S}_{\mathrm{D}, \mathrm{r}, \mathrm{n}}$ & $\checkmark$ & $\mathrm{X}$ & $\mathrm{X}$ \\
$3-\mathrm{S}_{\mathrm{D}, \mathrm{r}, \mathrm{N}}$ & $\checkmark$ & $\mathrm{X}$ & $\checkmark$ \\
$4-\mathrm{S}_{\mathrm{D}, \mathrm{R}, \mathrm{n}}$ & $\checkmark$ & $\checkmark$ & $\mathrm{x}$ \\
$5-\mathrm{S}_{\mathrm{D}, \mathrm{R}, \mathrm{N}}$ & $\checkmark$ & $\checkmark$ & $\checkmark$
\end{tabular}

\subsection{RESULTS AND DISCUSSION}

\subsubsection{CASE STUDY A}

The common practice while designing low voltage distribution networks is to oversize the power lines for the sake of security. However, it can be assumed that the population increase is accompanied with a demand increase in the end-user nodes. Hence, networks with saturated power lines are likely to appear, and reinforcements should be considered. For the purpose of this study, the energy consumption per node is considered to be equal to 5 houses with the characteristics mentioned in Table 10 and Fig. 6, so the network operation is reaching its thermal limits.

For the first scenario, labelled $\boldsymbol{S}_{\boldsymbol{d}, \boldsymbol{r}, \boldsymbol{n}}$, neither DER systems nor network thermal constraints are included in the optimization model. A post-optimization load flow shows, see Fig. 10, that line $\boldsymbol{I}$ reaches the maximum capacity for a short period of time on December. Despite this short and small violation on power limits, it can be considered that these loads are within the limits of the network, and no reinforcement is needed strictly speaking. It is important to remark that line losses are not considered in the load flow analysis and, as all houses have equal energy usage, several lines present similar behaviour, overlapping in the figure.

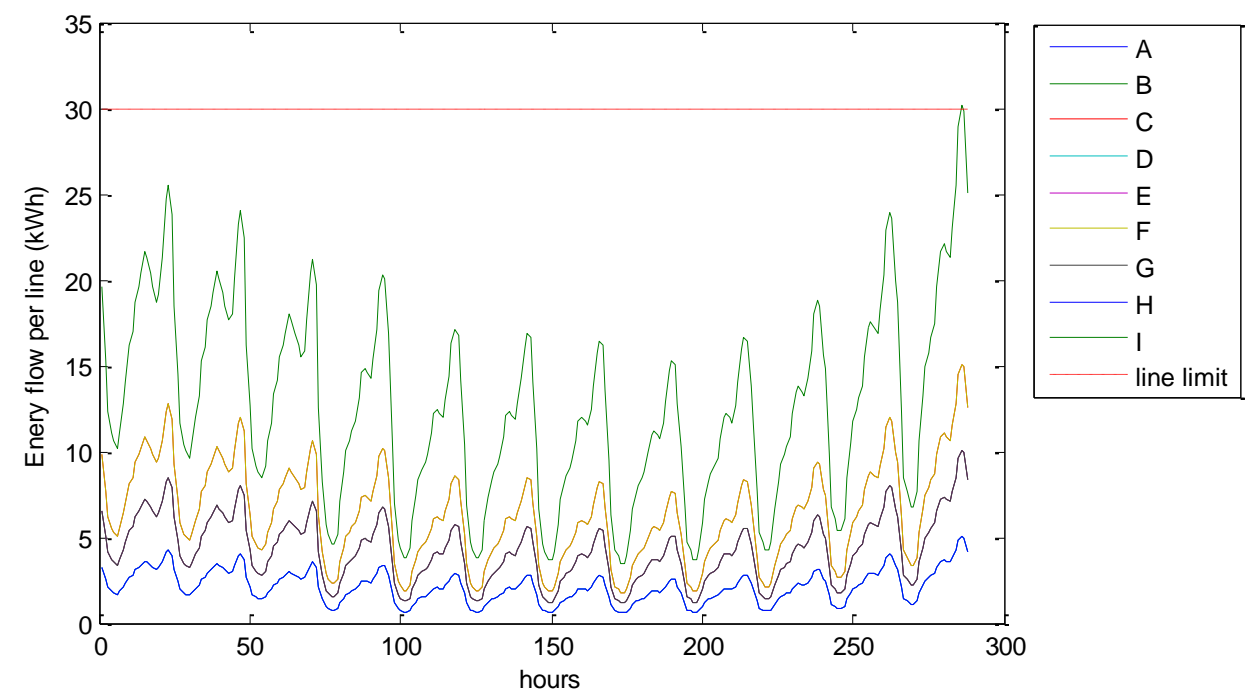

FIG. 10. POWER FLOW ANALYSIS FOR NETWORK A IN SCENARIO S 
The installed PV generation power for all scenarios is listed in Table 17, while the air-source heat pump maximum input power can be found in Table 18. From these results, it can be seen that:

- In those scenarios without network constraints, the optimal amount of generation power is equal for all houses, as it solely depends on the demand characteristics of the client.

- Line capacity constraints modify the installed power when the demand response schemes are not available, as in scenario $\boldsymbol{S}_{\boldsymbol{D}, \boldsymbol{r}, \mathrm{N}}$.

- The difference on installed capacity is greater regarding heat pump power. The houses located in the more saturated branch produce less thermal energy with the heat pump (using more gas, instead) in order to reduce the electricity requirements.

- Under the considered energy pricing scenario, network thermal constraints are not relevant when all DER systems are available, as the installed capacity for scenarios $\boldsymbol{S}_{D, R, n}$ and $\boldsymbol{S}_{\boldsymbol{D}, \boldsymbol{R}, N}$ is the same. This can be attributed to the very small violation (around $3 \%$ ) of line capacity occurred in $\boldsymbol{S}_{D, R, n}$ (see Fig. 11c) that does not affect significantly the operation of DER and, consequently, the DER capacity planning.

TABLE 17. INSTALLED PV POWER IN CASE STUDY A (KW).

\begin{tabular}{c|ccccc} 
Node & $\begin{array}{c}\mathbf{S}_{\mathbf{d}, \mathbf{r}, \mathbf{n}} \\
\text { (base) }\end{array}$ & $\mathbf{S}_{\mathbf{D}, \mathbf{r}, \mathbf{n}}$ & $\mathbf{S}_{\mathbf{D}, \mathbf{r}, \mathbf{N}}$ & $\mathbf{S}_{\mathbf{D}, \mathbf{R}, \mathbf{n}}$ & $\mathbf{S}_{\mathbf{D}, \mathbf{R}, \mathbf{N}}$ \\
\hline $1,2,7,9$ & 0 & 4.059 & 4.059 & 5.346 & 5.346 \\
3 & 0 & 4.059 & 4.011 & 5.346 & 5.346 \\
4 & 0 & 4.059 & 4.087 & 5.346 & 5.346 \\
5,8 & 0 & 4.059 & 4.062 & 5.346 & 5.346 \\
6 & 0 & 4.059 & 4.072 & 5.346 & 5.346 \\
Total: & $\boldsymbol{0}$ & $\mathbf{3 6 . 5 3 1}$ & $\mathbf{3 6 . 5 3 0}$ & $\mathbf{4 8 . 1 1 4}$ & $\mathbf{4 8 . 1 1 4}$
\end{tabular}

TABLE 18. INSTALLED HEAT PUMP POWER IN CASE STUDY A (KW).

\begin{tabular}{c|ccccc} 
Node & $\begin{array}{c}\mathbf{S}_{\mathbf{d}, \mathbf{r}, \mathbf{n}} \\
\text { (base) }\end{array}$ & $\mathbf{S}_{\mathbf{D}, \mathbf{r}, \mathbf{n}}$ & $\mathbf{S}_{\mathbf{D}, \mathbf{r}, \mathbf{N}}$ & $\mathbf{S}_{\mathbf{D}, \mathbf{R}, \mathbf{n}}$ & $\mathbf{S}_{\mathbf{D}, \mathbf{R}, \mathbf{N}}$ \\
\hline $1-3$ & 0 & 1.502 & 1.502 & 1.803 & 1.803 \\
$4-9$ & 0 & 1.502 & 1.002 & 1.803 & 1.803 \\
Total: & $\boldsymbol{O}$ & $\mathbf{1 3 . 5 1 8}$ & $\mathbf{1 0 . 5 1 8}$ & $\mathbf{1 6 . 2 2 7}$ & $\mathbf{1 6 . 2 2 7}$
\end{tabular}

Regarding storage systems, current batteries prices make them unattractive in most scenarios, as shown in Table 19. It is important to remark that scenarios $\boldsymbol{S}_{\boldsymbol{D}, \boldsymbol{r}, \boldsymbol{n}}$ and $\boldsymbol{S}_{\boldsymbol{D}, \boldsymbol{r}, \boldsymbol{N}}$ are the only ones implementing storage capacity, and the houses in more saturated lines are the ones with a slightly higher capacity. Indeed, battery system is selected in these cases due to the network thermal constraints and the lack of flexibility of the distributed generation technologies (demand response is not available). When the demand response capability is added, as in $\boldsymbol{S}_{\boldsymbol{D}, \boldsymbol{R}, \boldsymbol{n}}$ and $\boldsymbol{S}_{\boldsymbol{D}, \boldsymbol{R}, \boldsymbol{N}}$, the battery systems are no longer implemented, given its relatively high cost and because the peak load can be shifted to avoid surpassing the network thermal limits. 
TABLE 19. INSTALLED BATTERY SYSTEM CAPACITY IN CASE STUDY A (KWH).

\begin{tabular}{c|ccccc} 
Node & $\begin{array}{c}\mathbf{S}_{\mathbf{d}, \mathbf{r}, \mathbf{n}} \\
\text { (base) }\end{array}$ & $\mathbf{S}_{\mathbf{D}, \mathbf{r}, \mathbf{n}}$ & $\mathbf{S}_{\mathbf{D}, \mathbf{r}, \mathbf{N}}$ & $\mathbf{S}_{\mathbf{D}, \mathbf{R}, \mathbf{n}}$ & $\mathbf{S}_{\mathbf{D}, \mathbf{R}, \mathbf{N}}$ \\
\hline $1,2,7,9$ & 0 & 0.355 & 0.355 & 0 & 0 \\
3 & 0 & 0.355 & 0.25 & 0 & 0 \\
4 & 0 & 0.355 & 0.416 & 0 & 0 \\
5,8 & 0 & 0.355 & 0.361 & 0 & 0 \\
6 & 0 & 0.355 & 0.384 & 0 & 0 \\
Total: & $\boldsymbol{O}$ & $\mathbf{3 . 1 9 5}$ & $\mathbf{3 . 1 9 2}$ & $\boldsymbol{0}$ & $\boldsymbol{O}$
\end{tabular}

Table 20 and Table 21 summarize the electric and thermal contracted power, respectively. In comparison to the base case, the scenarios including DG increased their contracted electric power while reducing the thermal power. This is caused by the new electric demand of the heat pump. On the other hand, the electric power did not change significantly in the scenarios with demand response schemes; but the contracted thermal power is still reduced considerably.

TABLE 20. CONTRACTED ELECTRIC POWER PER NODE IN CASE STUDY A (KW).

\begin{tabular}{c|ccccc} 
Node & $\begin{array}{c}\mathbf{S}_{\mathbf{d}, \mathbf{r}, \mathbf{n}} \\
\text { (base) }\end{array}$ & $\mathbf{S}_{\mathbf{D}, \mathbf{r}, \mathbf{n}}$ & $\mathbf{S}_{\mathbf{D}, \mathbf{r}, \mathbf{N}}$ & $\mathbf{S}_{\mathbf{D}, \mathbf{R}, \mathbf{n}}$ & $\mathbf{S}_{\mathbf{D}, \mathbf{R}, \mathbf{N}}$ \\
\hline 1,2 & 5.03 & 6.32 & 6.32 & 5.12 & 5.12 \\
3 & 5.03 & 6.32 & 6.37 & 5.12 & 5.12 \\
4 & 5.03 & 6.32 & 4.97 & 5.12 & 5.01 \\
$5-9$ & 5.03 & 6.32 & 4.99 & 5.12 & 5.01 \\
Total: & $\mathbf{4 5 . 2}$ & $\mathbf{5 6 . 8}$ & $\mathbf{4 8 . 9}$ & $\mathbf{4 6 . 8}$ & $\mathbf{4 5 . 4}$
\end{tabular}

TABLE 21. CONTRACTED THERMAL POWER PER NODE IN CASE STUDY A (KW).

\begin{tabular}{c|ccccc} 
Node & $\begin{array}{c}\mathbf{S}_{\mathbf{d}, \mathbf{r}, \mathbf{n}} \\
\text { (base) }\end{array}$ & $\mathbf{S}_{\mathbf{D}, \mathbf{r}, \mathbf{n}}$ & $\mathbf{S}_{\mathbf{D}, \mathbf{r}, \mathbf{N}}$ & $\mathbf{S}_{\mathbf{D}, \mathbf{R}, \mathbf{n}}$ & $\mathbf{S}_{\mathbf{D}, \mathbf{R}, \mathbf{N}}$ \\
\hline 1,2 & 5.32 & 1.33 & 1.33 & 0.53 & 0.53 \\
3 & 5.32 & 1.33 & 1.33 & 0.53 & 0.53 \\
4 & 5.32 & 1.33 & 4.82 & 0.53 & 0.53 \\
$5-9$ & 5.32 & 1.33 & 4.82 & 0.53 & 0.53 \\
Total: & $\mathbf{4 7 . 8}$ & $\mathbf{1 1 . 9}$ & $\mathbf{3 2 . 9}$ & $\mathbf{4 . 7}$ & $\mathbf{3 . 1}$
\end{tabular}

Regarding to the operation of the network, Fig. 11 illustrates the load flow study under the different DER system scenarios for a winter's peak day. In the figure, it can be seen that:

- Scenario $S_{D, r, n}$ (shown in Fig. 11a) includes distributed generation and storage but no network constraints. Consequently, thermal violations take place and line $\boldsymbol{I}$ (see Fig. 7) should be reinforced around $33 \%$ of its original capacity (to around $40 \mathrm{kWh}$ ) to avoid them. 
- Scenario $\boldsymbol{S}_{\boldsymbol{D}, \boldsymbol{r}, \mathrm{N}}$ also includes distributed generation, but implementing network thermal constraints in the optimization problem. Hence, the operation and planning of the distributed resources is optimized but without violating the maximum capacity of the power lines, as shown in Fig. 11b.

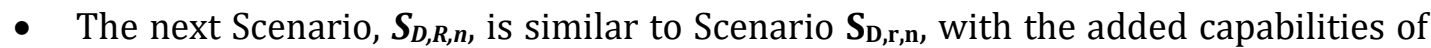
demand response. From Fig. 11c, it can be noted that violation of line $I$ capacity is much smaller and constant (to avoid the extra cost of higher contracted power) than in Scenario $\boldsymbol{S}_{\boldsymbol{D}, \boldsymbol{r}, \boldsymbol{n}}$. Indeed, demand response (thermal production and a percentage of the daily electricity load) reduces the total amount of energy bought at peak hours and the total contracted power.

- Scenario $\boldsymbol{S}_{D, R, N}$ includes into the optimization model all DER systems and network thermal constraints. In comparison to Scenario $\boldsymbol{S}_{D, r, N}$, the behaviour of power flows in the network is slightly more complex due to the demand response mechanisms, yet it also lays within the thermal limits of the power lines.
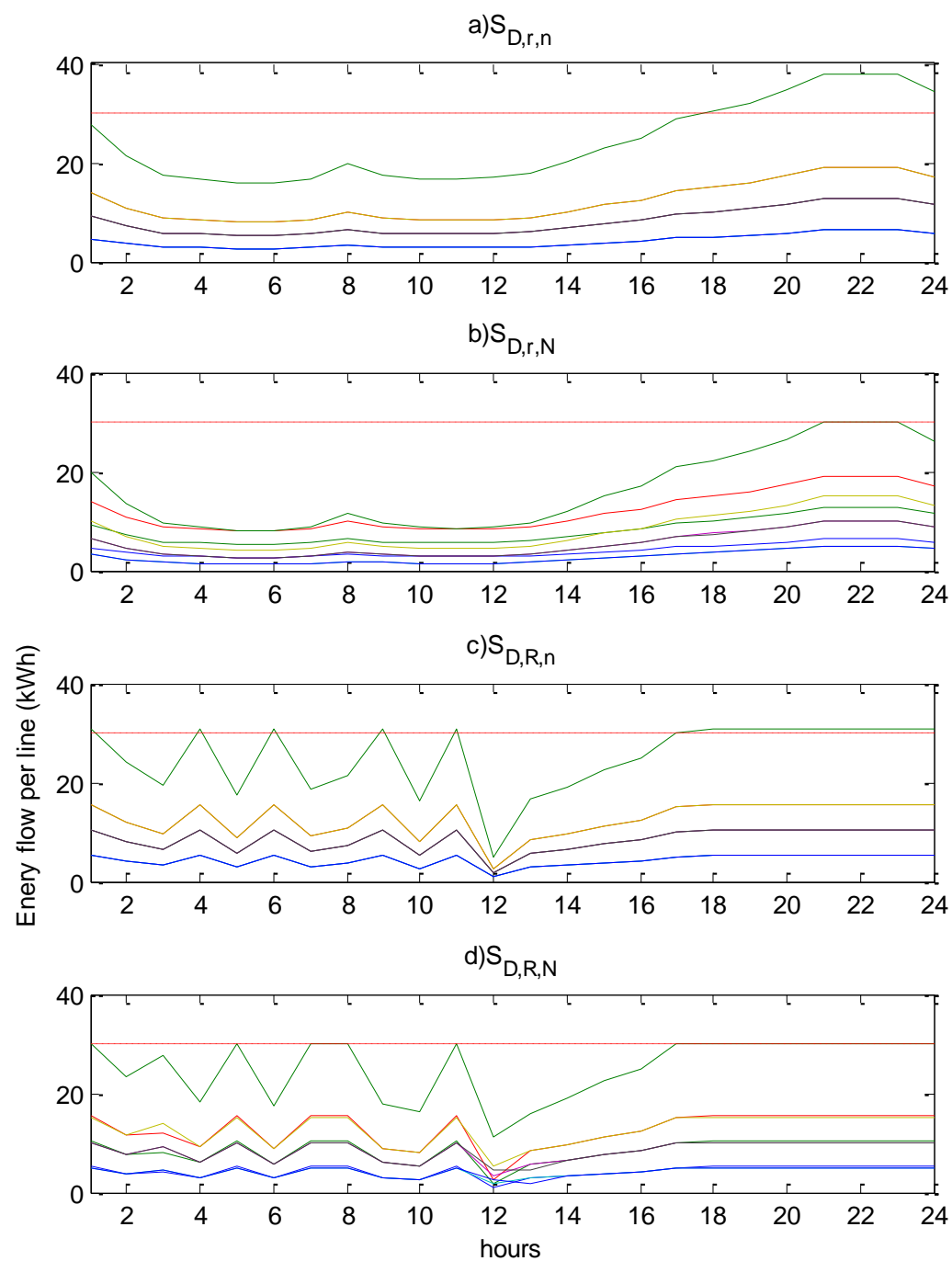

FIG. 11. LOAD FLOW ANALYSIS DETAIL FOR THE REPRESENTATIVE DAY OF DECEMBER (CASE STUDY A).

The reinforcement costs for each scenario has been computed using equation (51). This is to evaluate the importance of considering network constraints in the optimization model. 
As mentioned in section 4.2.1, the cost considered for the reinforcement of the power lines is $6.8 € / \mathrm{m}$ [73]. Line lengths are in Table 13, and for both Scenarios $\boldsymbol{S}_{\boldsymbol{D}, \boldsymbol{r}, \boldsymbol{n}}$ and $\boldsymbol{S}_{\boldsymbol{D}, \boldsymbol{R}, \boldsymbol{n}, \text {, the line }}$ to be reinforced is line $\boldsymbol{I}$.

The global benefits of the different solutions analysed are summarized in the total costs values presented in Table 22. Comparing to the base Scenario $\boldsymbol{S}_{\boldsymbol{d}, \boldsymbol{r}, \boldsymbol{n}}$, the inclusion of distributed generation provides savings of $9.44 \%$ when the network constraints are not taken into account with around $0.2 \%$ of increased cost for reinforcements. In contrast savings of $9.16 \%$ are achieved when the network is considered in the optimization model. These small differences suggest that it may be better to just reinforce the lines than the added complexity and additional costs of installing communications systems to measure and control the real-time network status and equipment to manage the DG accordingly.

TABLE 22. TOTAL COSTS IN CASE STUDY A.

\begin{tabular}{c|ccccccc} 
& $\begin{array}{c}\mathbf{S}_{\mathbf{d}, \mathbf{r}, \mathbf{n}} \\
\text { (base) }\end{array}$ & $\mathbf{S}_{\mathbf{D}, \mathbf{r}, \mathbf{n}}$ & $\begin{array}{c}\mathbf{S}_{\mathbf{D}, \mathbf{r}, \mathbf{n}}+ \\
\text { reinf. }\end{array}$ & $\mathbf{S}_{\mathbf{D}, \mathbf{r}, \mathbf{N}}$ & $\mathbf{S}_{\mathbf{D}, \mathbf{R}, \mathbf{n}}$ & $\begin{array}{c}\mathbf{S}_{\mathbf{D}, \mathbf{R}, \mathbf{n}}+ \\
\text { reinf. }\end{array}$ & $\mathbf{S}_{\mathbf{D}, \mathbf{R}, \mathbf{N}}$ \\
\hline $\begin{array}{c}\text { Value } \\
\text { (k€) }\end{array}$ & 895.806 & 811.208 & 812.916 & 813.737 & 742.384 & 744.092 & 742.53 \\
Benefit & 0 & $9.44 \%$ & $9.25 \%$ & $9.16 \%$ & $17.13 \%$ & $16.94 \%$ & $17.11 \%$
\end{tabular}

Regarding the scenarios that also includes demand response, the benefit increases to $17.13 \%$ with a similar reinforcement cost of around $0.2 \%$. The scenario considering network thermal constraints gives almost the same benefits than in $\boldsymbol{S}_{D, R, n}$ without the reinforcement costs. It is important to note that the obtained results for $\boldsymbol{S}_{\boldsymbol{D}, \boldsymbol{r}, N}$ and $\boldsymbol{S}_{\boldsymbol{D}, \boldsymbol{R}, \boldsymbol{N}}$ are very likely to be overvalued, as the real implementation of such coordinated control of network and RES systems could represent considerable costs, reducing the expected benefits.

\subsubsection{CASE STUDY B}

In the second case study more power lines are included, for a total of 16 . Similar to case study A, the load for each node is established to be equal to 5 houses.

The total installed distributed generation of PV, HP and storage systems is listed in Table 23. Similarly to case study A, the installed capacity in scenarios without network constraints depends solely on the energy requirements of the house; while in $S_{D, r, N}$, the location of the house within the network affects that decision, being the houses in more saturated lines the ones with a slightly higher capacity installed. It is important to remark that for this case study, just like in case study A, battery storage investments were only profitable in scenarios $S_{D, r, n}$ and $S_{D, r, N}$. 
TABLE 23. TOTAL INSTALLED CAPACITY AND CONTRACTED POWER IN CASE STUDY B (KW).

\begin{tabular}{c|ccccc} 
& $\begin{array}{c}\mathbf{S}_{\mathbf{d}, \mathbf{r}, \mathbf{n}} \\
\text { (base) }\end{array}$ & $\mathbf{S}_{\mathbf{D}, \mathbf{r}, \mathbf{n}}$ & $\mathbf{S}_{\mathbf{D}, \mathbf{r}, \mathbf{N}}$ & $\mathbf{S}_{\mathbf{D}, \mathbf{R}, \mathbf{n}}$ & $\mathbf{S}_{\mathbf{D}, \mathbf{R}, \mathbf{N}}$ \\
\hline $\mathrm{PV}$ & 0 & 64.944 & 64.932 & 85.536 & 85.536 \\
$\mathrm{HP}$ & 0 & 24.032 & 18.032 & 28.848 & 28.848 \\
$\begin{array}{c}\text { Battery } \\
\begin{array}{c}\text { Contracted } \\
\text { electric power }\end{array}\end{array}$ & 0 & 5.68 & 5.655 & 0 & 0 \\
$\begin{array}{c}\text { Contracted } \\
\text { thermal power }\end{array}$ & 80.4 & 101.1 & 85.4 & 81.9 & 80.4 \\
& 85.1 & 21.2 & 67.1 & 8.4 & 8.4
\end{tabular}

For the comparison between scenarios, the resulting total costs are summarised in Table 24. The load flow analysis for scenario $\boldsymbol{S}_{\boldsymbol{D}, \boldsymbol{r}, \boldsymbol{n}}$, (which considers distributed generation) shows that the network requires the reinforcement of lines $\boldsymbol{H}, \boldsymbol{I}$ and $\boldsymbol{P}$ (see Fig. 8). In scenario $\boldsymbol{S}_{D, R, n}$ which includes DER systems but no network constraints, the behaviour is similar to the one in the previous case study. With the added capability of demand response, the network topology and the behaviour of loads result in smaller violations in the maximum thermal capacity of power lines. Hence, only lines $\boldsymbol{I}$ and $\boldsymbol{P}$ need to be reinforced to cope with this operation.

TABLE 24. TOTAL COSTS IN CASE STUDY B.

\begin{tabular}{c|ccccccc} 
& $\begin{array}{c}\mathbf{S}_{\mathbf{d}, \mathbf{r}, \mathbf{n}} \\
\text { (base) }\end{array}$ & $\mathbf{S}_{\mathbf{D}, \mathbf{r}, \mathbf{n}}$ & $\begin{array}{c}\mathbf{S}_{\mathbf{D}, \mathbf{r}, \mathbf{n}}+ \\
\text { reinf. }\end{array}$ & $\mathbf{S}_{\mathbf{D}, \mathbf{r}, \mathbf{N}}$ & $\mathbf{S}_{\mathbf{D}, \mathbf{R}, \mathbf{n}}$ & $\begin{array}{c}\mathbf{S}_{\mathbf{D}, \mathbf{R}, \mathbf{n}}+ \\
\text { reinf. }\end{array}$ & $\mathbf{S}_{\mathbf{D}, \mathbf{R}, \mathbf{N}}$ \\
\hline $\begin{array}{c}\text { Value } \\
\text { (k€) }\end{array}$ & 1592.55 & 1442.15 & 1443.85 & 1447.21 & 1319.79 & 1320.86 & 1319.95 \\
Benefit & 0 & $9.44 \%$ & $9.34 \%$ & $9.13 \%$ & $17.13 \%$ & $17.06 \%$ & $17.12 \%$
\end{tabular}

The results in these scenarios are very similar to those of case study A. For the scenario including distributed generation, a $9.44 \%$ of savings is achieved with a decrease of approximately $0.1 \%$ in the benefits if the reinforcement costs are considered. For the same system but including network thermal constraints, the total savings are $9.13 \%$. On the other hand, scenario $S_{D, R, n}$ with all DER available gives $17.13 \%$ of savings and an added cost of $0.07 \%$ for network reinforcements; while, scenario 5 provides a total benefit of $17.12 \%$, which is quite similar to the benefits of scenario $S_{D, R, n}$. Once more, it can be noted that the difference between considering or not the network thermal constraints is not significant. In addition, the benefits of scenario $S_{D, R, N}$ would decrease if coordinated control costs are taken into account.

\subsubsection{CASE STUDY C}

Lastly, case study C presents a different organization to see the effects of DER in a network with more main branches and more balanced. In this case, each node of the district includes the energy consumption patterns of 7.5 houses. The load flow analysis for the scenarios of case study $\mathrm{C}$ shows that many power lines in this network have similar energy flows. For scenarios $\boldsymbol{S}_{\boldsymbol{D}, \boldsymbol{r}, \boldsymbol{n}}$ and $\boldsymbol{S}_{\boldsymbol{D}, \boldsymbol{R}, \boldsymbol{n}}$, power lines $\boldsymbol{D}, \boldsymbol{H}, \boldsymbol{L}$ and $\boldsymbol{P}$ need to be reinforced (see Fig. 9). 
For this case study:

- Planning of DER systems continues with the same trend of previous cases (see Table 25), with PV and HP system are installed in all DER scenarios, and battery systems have been only implemented in $\boldsymbol{S}_{D, r, n}$ and $\boldsymbol{S}_{D, r, N}$.

- However, the results in HP power differ from previous cases, not only in total installed capacity (which is larger than case studies A and B) but in the distribution of the systems, as all nodes of the network implement the same HP installed capacity. This result can be attributed to the more balanced network proposed in this case study.

TABLE 25. TOTAL INSTALLED CAPACITY AND CONTRACTED POWER IN CASE STUDY C (KW).

\begin{tabular}{c|ccccc} 
& $\mathbf{S}_{\mathbf{d}, \mathbf{r}, \mathbf{n}}$ (base) & $\mathbf{S}_{\mathbf{D}, \mathbf{r}, \mathbf{n}}$ & $\mathbf{S}_{\mathbf{D}, \mathbf{r}, \mathbf{N}}$ & $\mathbf{S}_{\mathbf{D}, \mathbf{R}, \mathbf{n}}$ & $\mathbf{S}_{\mathbf{D}, \mathbf{R}, \mathbf{N}}$ \\
\hline PV & 0 & 97.408 & 97.6 & 128.304 & 128.304 \\
HP & 0 & 36.048 & 24.032 & 43.264 & 43.264 \\
$\begin{array}{c}\text { Battery } \\
\begin{array}{c}\text { Contracted } \\
\text { electric power }\end{array}\end{array}$ & 120.8 & 151.6 & 120 & 122.8 & 119.8 \\
$\begin{array}{c}\text { Contracted } \\
\text { thermal power }\end{array}$ & 136.1 & 31.8 & 116.2 & 12.6 & 12.6
\end{tabular}

Table 26 shows that the percentage of benefits has increased in comparison to previous cases. This can be attributed to the higher number of stressed power lines and the more balanced network.

TABLE 26. TOTAL COSTS IN CASE STUDY C.

\begin{tabular}{c|ccccccc} 
& $\begin{array}{c}\mathbf{S}_{\mathbf{d}, \mathbf{r}, \mathbf{n}} \\
\text { (base) }\end{array}$ & $\mathbf{S}_{\mathbf{D}, \mathbf{r}, \mathbf{n}}$ & $\begin{array}{c}\mathbf{S}_{\mathbf{D}, \mathbf{r}, \mathbf{n}}+ \\
\text { reinf. }\end{array}$ & $\mathbf{S}_{\mathbf{D}, \mathbf{r}, \mathbf{N}}$ & $\mathbf{S}_{\mathbf{D}, \mathbf{R}, \mathbf{n}}$ & $\begin{array}{c}\mathbf{S}_{\mathbf{D}, \mathbf{R}, \mathbf{n}}+ \\
\text { reinf. }\end{array}$ & $\mathbf{S}_{\mathbf{D}, \mathbf{R}, \mathbf{N}}$ \\
\hline $\begin{array}{c}\text { Value } \\
\text { (k€) }\end{array}$ & 2441.22 & 2139.95 & 2142.07 & 2150.07 & 1954.02 & 1956.14 & 1954.33 \\
Benefit & 0 & $12.34 \%$ & $12.25 \%$ & $11.93 \%$ & $19.96 \%$ & $19.87 \%$ & $19.94 \%$
\end{tabular}

Lastly, for the sake of comparison, the total benefits for all case studies are listed in Table 27. The reviewed networks included 9 and 16 nodes for case studies A and B, respectively, whereas case study $\mathrm{C}$ also presents a 16 nodes network, but organized in 4 more balanced branches. From the table below, it can be seen that the size of the network is not relevant when the load distribution in the network is similar, as in cases A and B. In contrast, case study $\mathrm{C}$ presents a different distribution of loads, achieving around 3\% more benefits with respect to the base scenario without DER. This extra profit can be attributed to the loads distributed more evenly in the network. 
TABLE 27. SUMMARY OF BENEFITS FOR ALL CASE STUDIES.

\begin{tabular}{c|ccccccc}
$\begin{array}{c}\text { Case } \\
\text { study }\end{array}$ & $\begin{array}{c}\mathbf{S}_{\mathbf{d}, \mathbf{r}, \mathbf{n}} \\
\text { (base) }\end{array}$ & $\mathbf{S}_{\mathbf{D}, \mathbf{r}, \mathbf{n}}$ & $\begin{array}{c}\mathbf{S}_{\mathbf{D}, \mathbf{r}, \mathbf{n}}+ \\
\text { reinf. }\end{array}$ & $\mathbf{S}_{\mathbf{D}, \mathbf{r}, \mathbf{N}}$ & $\mathbf{S}_{\mathbf{D}, \mathbf{R}, \mathbf{n}}$ & $\begin{array}{c}\mathbf{S}_{\mathbf{D}, \mathbf{R}, \mathbf{n}}+ \\
\text { reinf. }\end{array}$ & $\mathbf{S}_{\mathbf{D}, \mathbf{R}, \mathbf{N}}$ \\
\hline $\mathrm{A}$ & 0 & $9.44 \%$ & $9.25 \%$ & $9.16 \%$ & $17.13 \%$ & $16.94 \%$ & $17.11 \%$ \\
$\mathrm{~B}$ & 0 & $9.44 \%$ & $9.34 \%$ & $9.13 \%$ & $17.13 \%$ & $17.06 \%$ & $17.12 \%$ \\
$\mathrm{C}$ & 0 & $12.34 \%$ & $12.25 \%$ & $11.93 \%$ & $19.96 \%$ & $19.87 \%$ & $19.94 \%$
\end{tabular}

\subsubsection{DISCUSSION OF RESULTS}

From the results obtained, it is important to remark that:

- As seen in Table 27, the network size does not seem to affect significantly the expected benefits from DER systems (around 17\% for both case studies A and B), but different network topologies seem to have different results (around 20\% of benefits for case study C). Nevertheless, the difference between considering or not network thermal constraints is similar for all case studies analysed (less than $0.2 \%$ ), and it seems therefore sensible not to consider network thermal constraints, even on other networks topologies but with similar energy tariffs and reinforcement costs.

- Conventional residential tariffs include not only energy prices but also contracted power costs, which is a mechanism to avoid, power line saturation. This can be seen in Fig. 11c, where network constraints are not considered but the resulting operation of the loads barely increases the original power. This shows that the optimisation problem limits investments to avoid increasing the contracted power and its corresponding extra costs. This explains why the impact of considering or not the network constraints in the scenarios where demand response is available, is not so significant. However, other cases could present different outcomes. For instance:

- When DG systems (such as PV) are not accompanied with demand response mechanisms or storage systems, the increase of peak load when not considering network thermal constraints is likely to be higher, as there is less flexibility from the demand side (see, for example, Fig. 11a in comparison with Fig. 11c).

- With other type of tariffs, where the power component of the tariff is smaller, in comparison with the energy component (the optimisation problem will focus more on managing the resources to reduce energy use, and less on reducing power peaks).

Finally, these results suggest that, when considering a tariff with a contracted power component, it seem sensible not to consider a network model in the long-term planning of DER systems, as the tariff itself limits power peaks, avoiding power line violations. Note that in this thesis, all the analyses consider a contracted power component, so the network (from a thermal constraints perspective) could be disregarded.

- Furthermore, note that the network reinforcement costs are relatively small (around $0.2 \%$ relative to the total costs). So, in some cases, the network thermal constraints could be straightforwardly ignored, and the network just reinforced 
when needed. Nevertheless, we consider that the analysis developed here is relevant for:

- New business models where an aggregator or retailer manage DER systems and residential loads. Certainly, the cost of the network is not large, but if the profit margin of the aggregator is also small, the extra reinforcement costs could be relevant in the aggregator's planning and operation process.

- To be used as a starting point to analyse network constraints in other contexts, with different energy tariffs, more saturated networks and/or higher reinforcement costs. In such cases, the decision of not taking into account network thermal constraints might not be as straightforward.

- Lastly, it is important to remark that there are other network problems besides saturated power lines. In particular, voltage variation due to DER presence have been remarked as an important challenge for network operation [177]. Certainly, distributed generation, such as wind turbines or PV panels, tend to increase voltage levels. Conversely, extra electric load in the grid, such as HP systems or EVs, could create voltage dips. These voltage issues are an important concern as they reduce the overall efficiency of the electric network, and can potentially damage the electrical equipment connected to the grid [184]. Several solutions have been proposed in the literature to alleviate these issues. For instance:

- The use of residential battery storage systems and demand response, to balance locally supply and demand, mitigating the voltage variation problems created by distributed generation [171].

- The implementation of reactive power control on the inverters connecting DG with the grid [176].

- Network reinforcements. In [185] it is remarked that upgrading the network could alleviate the voltage problems. The network reinforcements required involve the use of larger diameter cables, which also have smaller resistance. The lower resistance decreases the losses and the same amount of distributed resources cause smaller overall currents and voltage drops [185].

Considering that these issues could be addressed locally with adequate power electronics or with the DER systems available (a real-time operation problem), and considering the extra complexity required in the model to address this issue (i.e. modelling voltages, adding an AC load flow and increasing the time resolution), only the network thermal constraints has been considered in this analysis. Nevertheless, note that by solving the network constraint problem, the voltage issues could also be mitigated by selecting adequate network reinforcements that can solve both the power limit violations and potential voltage variation at the same time.

\subsection{ConClusions}

Three case studies have been analysed, each one proposing a different low-voltage district network. These case studies have been selected because of their variety, and with the aim of representing typical urban network topologies. The results obtained suggest that the size of the network does not affect importantly the percentage of expected benefits of DER systems, when the structure of the network is similar. Indeed, it can be seen that the 
household benefits of distributed energy resources systems can be around $10 \%$ when no demand response is implemented, and near $20 \%$ when it is. In addition, the analysis also suggests that the distribution of loads in the network has an impact on the share of profits. For instance, the network with a higher number of saturated power lines showed around 3\% more benefits from DER systems than the cases with less saturated lines.

In the case studies analysed, it is evident that, by including network thermal constraints in the optimization model, the violation of the limits of the power lines can be avoided while still taking advantage of DER systems with a slight decrease of the expected benefits. However, the comparison of this reduction on the total benefits to the extra costs of introducing network reinforcements where needed (considering only the low voltage network) shows that the difference between them is not significant, suggesting that line reinforcements are a better solution than including network constraints.

Although it has been discussed how energy tariffs and the power line reinforcement costs are important parameters that could affect significantly the outcomes of this analysis, the results show that the network topology does not seem to be such a determining factor (as the power tariffs affect the planning and operation independently from the network topology). Hence, the outcomes of the case studies presented could be used as a first approach for other networks with similar cost scenarios (line reinforcement, energy tariffs and DER costs similar to the ones considered here), provided that no more detailed analysis were available.

As already mentioned, this study does not consider other possible network problems such as voltage and frequency deviations. One reason for this is that these problems tend to be more relevant in the real-time network operation and not as much in the long-term planning process of such systems. Nevertheless, these power quality issues might appear due to DER implementation and could also be addressed with network reinforcements, or locally with the available DER systems and with reactive power control done by the inverters. Hence, the outcomes of this analysis provide valuable insight on the network problem in DER planning.

Finally, operating the installed DER systems respecting the network constraints would imply complex communication and control systems, and herein additional costs. Therefore, considering these additional costs, the non-significant differences between limiting DER investments and reinforcing the grid when needed, and also considering that all the analysis developed in this thesis include a contracted power tariff (reducing the need of considering the network), the smart city model developed will follow the approach of not considering network constraints in the planning and operation of systems. It is considered that the simpler optimization problem does not compromise the overall quality of the results, and allows to include extra complexity in other relevant features of the model. 


\section{5}

\section{ASSESSING THE IMPACT OF}

AGGREGATED DER SYSTEMS IN THE ENERGY MARKET

This chapter continues with the exploration of model considerations and restrictions task, corresponding to the smart city energy model methodology described in section 1.3. focusing on hypothesis 2 , and dealing with the impact of the aggregation size on the energy market and on the planning and operation of the considered DER systems.

To explore this, a model for aggregated DER systems planning is proposed, considering its participation in the electricity market and its impact on the market price. A price-maker approach based on representing the market competitors with residual demand curves is followed, and the impact on the price is assessed to help in the decision of using price-maker or price-taker approaches depending on the size of the aggregated resources. Note that despite the amount of research available about DER aggregation, most work focus on operation only in the short term, very few consider direct transactions with the market in their planning process, and most of them follow a price-taker approach. Hence, the main contribution of this chapter is the assessment of when is recommendable to follow a price-maker approach and when a price-taker one could be acceptable, in the planning of DER systems.

The results suggest that the impact on electricity prices is relevant even for relatively small aggregations. However, for very small aggregations (less than 50000 houses), the impact on price is not as significant and might not be necessary to include this extra complexity in the programming problem. Therefore, the aggregator or DER system planner should decide to consider or not this price-maker approach according to the amount of aggregated resources.

The contents of this chapter draws heavily from the journal article: C. F. Calvillo, A. SánchezMiralles, J. Villar, and F. Martín, "Optimal Planning and Operation of Aggregated Distributed Energy Resources with Market Participation," Applied Energy, vol. 182, pp. 340-357, Nov. 2016. 


\subsection{INTRODUCTION}

DER systems owners (or "prosumers") can benefit not only from the energy costs reductions provided by the DER systems, but also from actively participating in the energy markets. Having access to the market prices, the prosumers can prepare better strategies to buy or sell energy or other ancillary services, and how to best manage their energy resources. Normally, the prosumers don't have enough size to participate directly in energy markets (due to the existing entry barriers, [186]), and thus the importance of the aggregator to manage the DER systems and interact with the market [13], [43].

In addition, the participation in the market of this aggregated resources can be modelled following price-taker or price-maker approaches. Under a price-taker approach, the market participant is considered unable to significantly affect the market price when changing its cleared energy or its offering strategy, and corresponds normally to small players. Computations for this participants can assume constant market prices independently of their strategy. In the price-maker approach it is considered that the market participant affects the market price by clearing more or less energy or by changing its offering strategy, and computation must take into account this impact on the price [187]. In DER systems planning, the common practice is to follow a price-taker approach, as it is a simpler problem to solve and can provide, in many cases, sensible results, due to the small size of the aggregated DER systems. However, with larger aggregation levels, the aggregator's actions could have an important impact on the market, changing energy prices and possibly making the price-taker approach inaccurate.

In this sense, this chapter, as mentioned in the methodological proposal of 1.3, is intended to provide insight on the benefits of aggregation and the potential need of following a pricemaker approach in the planning and operation of DER systems.

The aggregation of distributed energy resources can be done in a variety of ways, such as Virtual Power Plants (VPP, composed by several micro generators, loads and flexible storage capacities not necessarily geographically close to each other [188]), microgrids (similar to VPPs, with the difference that loads and resources are geographically concentrated, such as in residential districts or university campus, and can operate connected or isolated from the grid [83]) or mobile storage or loads in the form of electrical vehicles (EV) fleets.

In this chapter, the aggregator is the agent (physical or not) responsible of managing a set of resources, such as a microgrid, a VPP, an EV fleet or just a group of clients. This aggregator could be a retailer, a distribution company, or another market participant. Regulatory particularities of such agents have not been addressed here as they fall outside the scope of this thesis. Some representative examples of research works found in the literature, focusing in aggregation of resources with market participation have been summarized in Table 28. 
TABLE 28. SUMMARY OF RESOURCE AGGREGATION MODELS WITH MARKET PARTICIPATION.

\begin{tabular}{|c|c|c|c|c|c|c|}
\hline Reference & $\begin{array}{l}\text { Type of } \\
\text { aggregation }\end{array}$ & Methodology & $\begin{array}{l}\text { Market } \\
\text { participation }\end{array}$ & $\begin{array}{l}\text { Time } \\
\text { scope }\end{array}$ & Focus & Approach \\
\hline [188] & VPP & $\begin{array}{l}\text { Stochastic } \\
\text { MILP }\end{array}$ & $\begin{array}{l}\text { Day-ahead } \\
\text { and } \\
\text { balancing }\end{array}$ & $\begin{array}{l}\text { Short- } \\
\text { term }\end{array}$ & Operation & Price-taker \\
\hline [189] & VPP & MILP & $\begin{array}{l}\text { Bilateral } \\
\text { contracts }\end{array}$ & $\begin{array}{l}\text { Short- } \\
\text { term }\end{array}$ & Operation & Price-taker \\
\hline [190] & VPP & Montecarlo & Balancing & $\begin{array}{l}\text { Short- } \\
\text { term }\end{array}$ & Operation & Price-taker \\
\hline [191] & Microgrid & $\begin{array}{l}\text { Stochastic } \\
\text { MILP }\end{array}$ & Day-ahead & $\begin{array}{l}\text { Short- } \\
\text { term }\end{array}$ & Operation & Price-taker \\
\hline [192] & $\begin{array}{l}\text { Microgrid, } \\
\text { EV fleet }\end{array}$ & MILP & Day-ahead & $\begin{array}{l}\text { Short- } \\
\text { term }\end{array}$ & Operation & Price-taker \\
\hline [193] & Microgrid & MPEC & Balancing & $\begin{array}{l}\text { Short- } \\
\text { term }\end{array}$ & Operation & Price-taker \\
\hline [194] & $\begin{array}{l}\text { Microgrid, } \\
\text { EV fleet }\end{array}$ & Tabu search & $\begin{array}{l}\text { Internal } \\
\text { market }\end{array}$ & $\begin{array}{l}\text { Short- } \\
\text { term }\end{array}$ & Operation & Price-maker \\
\hline [160] & Microgrid & MCP & $\begin{array}{l}\text { Internal } \\
\text { market }\end{array}$ & $\begin{array}{l}\text { Medium- } \\
\text { term }\end{array}$ & Planning & Price-maker \\
\hline [187] & $\begin{array}{l}\text { Retailer } \\
\text { (loads) }\end{array}$ & $\begin{array}{l}\text { Genetic } \\
\text { algorithm }\end{array}$ & $\begin{array}{l}\text { Day-ahead } \\
\text { and } \\
\text { intradays }\end{array}$ & $\begin{array}{l}\text { Short- } \\
\text { term }\end{array}$ & Operation & Price-taker \\
\hline [195] & VPP & NLP & Day-ahead & $\begin{array}{l}\text { Short- } \\
\text { term }\end{array}$ & Operation & $\begin{array}{l}\text { Price-taker } \\
\text { price-maker }\end{array}$ \\
\hline [196] & VPP & MILP & Day-ahead & $\begin{array}{l}\text { Short- } \\
\text { term }\end{array}$ & Operation & Price-maker \\
\hline [197] & VPP & EPEC & Day-ahead & $\begin{array}{l}\text { Short- } \\
\text { term }\end{array}$ & Operation & Price-maker \\
\hline
\end{tabular}

\subsubsection{EXAMPLES OF PRICE-TAKER MODELS FOR AGGREGATED ENERGY RESOURCES}

As shown in Table 28, there are several price-taker examples in the literature, implementing different types of aggregation. An example of a VPP model has been proposed in [188], composed by a two-stage stochastic mixed-integer linear programming model which maximizes the virtual power plant expected profit. This model buys and sells energy from the day-ahead and balancing markets as a price-taker agent. Similarly, a mixed-integer linear programming model based on robust optimization approach has been proposed in [189] to reduce the risk of not meeting bilaterally contracted energies by a VPP. Conversely, authors in [190] analyse the integration of wind power into the grid by using VPPs, focusing on balancing wind power and energy costs with micro-CHP (combined heat and power systems).

Examples of Microgrids managed by aggregators, following a price-taker approach, can be found in [191] and [192]. The former proposes a stochastic problem for the optimal operation of a microgrid, implementing several DER systems, with the objective of placing optimal hourly bids in the day-ahead market. The latter presents an aggregator that manages distributed generation and a smart parking lot with 200 EVs. The main objective of the model they propose was to compute the optimal day-ahead energy schedule of the microgrid and the EVs that minimizes the operation costs. Both models follow a price-taker approach and involve only the operation of DER systems in the short term (1 day). Another example can be found in [193], where an aggregator works with a wind power producer, 
and uses demand-response to cope with the power production uncertainty and market violations. To solve this problem, single-level mathematical program with equilibrium constraints (MPEC) is proposed.

\subsubsection{EXAMPLES OF PRICE-MAKER MODELS FOR AGGREGATED ENERGY RESOURCES}

Other research works implement price-maker approaches in their planning or operation problems. For instance, in [194] an aggregator manages loads, distributed generation (DG) and EVs of a district with the particularity that the customers have elastic demand curves as linear functions of the electricity price, leading to an additional internal market between the aggregator and its prosumers. Tabu search [198] has been used to solve the proposed non-linear problem, and the scope of the model is to find the optimal scheduling for the external day-ahead energy markets (which is modelled exogenously, being the aggregator a price-taker), given the energy usage expected from the internal market clearing (where the participants of this internal market are price-makers). Similarly, a planning and operation of isolated microgrids is proposed in [160], where an internal market is implemented and the market price is solved using a mix complementarity problem (MCP). Note that in this two research works, the considered microgrid are very small to have a noticeable impact in the energy markets (less than 100 households).

In [195], pumped storage hydro has been used to balance wind power generation in the electricity markets, following both price-taker and price-maker approaches, using a nonlinear optimization problem. To analyse the effect on prices and find the market clearing price, the authors use residual demand curves. Also, the authors remark that the operation of the considered systems and the participation in the market change considerably due to the approach taken. Other price-maker approaches can be found in [197] and [196], where energy storage technologies have been used for energy arbitrage, the latter also analysing the particular strategic behaviours of different types of storage systems. In both these papers, authors use different supply and demand curves to compute the market clearing price. Note that these examples involve larger loads and generators (of several hundred MW of power), and thus, can potentially have important impacts on the energy markets clearing prices.

Despite the amount of research available about DER aggregation, as it can be clearly seen in Table 28, most work focus on operation only in the short term. Moreover, from those considering investment planning, very few consider direct transactions with the market in their planning process, and most of them follow a price-taker approach (the problem formulation might be inexact and might provide misleading results). In addition, stochastic optimization models are rare in this kind of application. Hence, the work proposed in this chapter intends to fulfil this gap in the literature proposing a stochastic optimal planning problem of aggregated DER systems with market participation, following a price-maker approach. To the best of the author's knowledge, such a model has not been proposed in the literature.

The goal of this study is to propose a price-maker model for DER systems planning in a district (which can be considered either a microgrid or a VPP) operated by an aggregator that participates in the electricity market. The importance of following a price-maker approach in comparison with a price-taker one is analysed by modelling and assessing the impact of the aggregator's actions on the final electricity price. 
Two programming problems have been proposed to analyse different approaches in the planning stage: a deterministic Price-maker model, and a stochastic Price-maker model to cope with market uncertainty. The impact of the aggregator on the market has been simulated by clearing the aggregator's energy (to sell or to buy) against a set of residual demand curves (RDC) [187] representing the different scenarios analysed. Solar photovoltaic panels (PV) and air-source heat pumps (HP) have been selected as representative DG technologies for electric and thermal energy production. For the energy storage, conventional battery systems have been considered.

It is important to remark that the proposed methodology does not imply any market modification but only provides a better way to compute the interaction of the aggregator of DER systems with the market, providing a better estimation of the final market price, in comparison with the simpler but less realistic price-taker models for large aggregations.

\subsubsection{MODIFICATIONS OF THE SMART CITY ENERGY MODEL FOR THIS ANALYSIS}

The optimization model proposed is a mixed-integer linear programming one, and its objective is to maximize the profit of an aggregator that has to decide the investments and the operation of a set of distributed energy resources.

The particular assumptions and considerations for this analysis are summarized below:

- The residential loads at the district are modelled with 4 different consumption profiles. With the objective of replicating the Spanish context, these profiles have been selected as they represent the typical residential clients in Spain (see section 5.2.1).

- The residential clients are managed by an aggregator that can buy and sell energy directly from the market, to make possible for the residential clients to overcome market entry barriers (such as minimum size), and be able to actively participate in the electricity market.

- Different levels of aggregation have been considered, ranging from 100 thousand houses to 8 million houses. This is to analyse how the size of aggregated resources affects the electricity prices and the expected benefits of DER systems. Note that network losses have not been considered in this study, assuming implicitly that all energy exchanges among consumers are done locally, without accessing the distribution grid. Specific distribution costs have also been assumed to be included in the network cost component considered in addition to the electric energy costs as in equation (53) (see also section 5.2.1 for more details on this).

- The Spanish electricity market is composed of the wholesale market, the intraday markets (a time scheme of such sessions can be found in [187]), the balancing market and the ancillary service markets. Due to the long-term scope of this study, and considering that most energy is traded in the day-ahead session, the proposed model considers only the participation in the day-ahead market. In addition, and for the sake of simplicity, complex offers and other transversal conditions (linking the offers of different hours) have not been considered in this analysis.

- Three case studies are proposed for this analysis, representing different market scenarios (see section 5.2.2 for more detail on the creation of these scenarios). The objective of these case studies is to assess the impact of the market scenario 
approach on the planning and operation of DER systems and the energy price changes (see section 5.3.2.1 for further discussion on the impact of the market scenarios on the operation of the aggregated resources).

- Each scenario has been modelled with a set of market residual demand curves. This is a very common approach for representing the competitors' behaviour, and is frequently used by market participants to formulate effective oligopolistic bidding strategies [199]. It has also been considered that other market players do not change their strategy based on our aggregator's actions. Although this is a simplified market representation, it still provides valuable insight on the effects of DER system aggregation on the market, while maintaining the optimisation model of a manageable size and complexity.

- The DER resources considered are HP, PV, and Batteries. In addition to demand response schemes.

- Reliability issues and the economic interactions client-retailer (business models) have not been addressed in this study, as they fall outside the scope of this thesis. Nevertheless, there is an implicit business model since the objective of the aggregator managing the residential loads is to minimise the total costs for his clients, under a tariff structure similar to current Spanish one, and without additional charges for energy exchanges among costumers. Note that the costs (including DER investments, energy and power costs, etc.) and benefits obtained in this analysis relate to the residential clients, and specific economic benefits of the aggregator have not been modelled.

The MILP optimization model for this study, includes the constraints described in sections 3.2.1, 3.2.2, 3.2.3, 3.2.4 (removing the EV and metro parts), and 3.2.5 (without the EV and Metro part). As this is a stochastic price-maker problem, the following changes are also implemented in the objective function. For the sake of brevity, only the stochastic pricemaker modifications are described here, as the deterministic price-maker is identical but with only one scenario in equations (53) - (65).

The objective function for the proposed model is the following:

$$
\begin{gathered}
\min \{v \operatorname{CostDistE} E+v \operatorname{CostDistPowE}+v \operatorname{CostPV}+v O M P V+v \operatorname{CostBat}+v \operatorname{CostHP} \\
+v O M H P+v \operatorname{CostET}+v \operatorname{CostPowT}+v \operatorname{CostDR}\}
\end{gathered}
$$

With all the elements similar as the ones presented in section 3.2.6, except the following that replace (35) to (38), with (53) to (56), respectively:

$$
\begin{aligned}
v \operatorname{CostDistEE}= & \sum_{y}\left(p \operatorname{Cost} E_{y}\right. \\
& * \sum_{s} \sum_{m}\left(p \operatorname{Days}_{m}\right. \\
& \left.\left.* \sum_{h}\left(\text { Probs }_{s, m, h} *\left(\text { vElectric } \operatorname{Cost}_{s, m, h}+\text { vGridCostE }_{s, m, h}\right)\right)\right)\right) \\
v \operatorname{CostDistPowE}= & \sum_{y}\left(p \operatorname{Cost}_{y} * \text { pFixEpow } * \sum_{s} \sum_{c}\left(\text { probAvg }_{s} * v \text { PowElect }_{s, c}\right)\right)
\end{aligned}
$$




$$
\begin{aligned}
& v \operatorname{CostET}=\sum_{y}\left(\operatorname{postT}_{y} * \sum_{s} \sum_{c} \sum_{m}\left(\text { pProbAvg }_{s} * \text { pDaysM }_{m} * \text { vThBuy }_{s, c, m}\right)\right) \\
& v \text { CostPowT }=\text { pLifespan } * \text { pNumHouses } * \text { pHouseMultiplier } * \text { pFixTpow }
\end{aligned}
$$

The price-maker formulation is completed with the constraints (57) and (58). These electricity cost constraints have been used to calculate the electric energy costs from the market price, using a piecewise linear approximation, avoiding the non-linearity of this problem. First, (57) has been used to separate the positive and negative parts of the energy transactions with the grid. This is to pay the equivalent share of network usage when buying energy, considering that this cost is to be paid by the buyer and not the seller of energy, as formulated in (58).

$$
\begin{aligned}
& \text { vGridEnTotalPos } s_{s, m, h}-\text { vGridEnTotalNe } g_{s, m, h}=\sum_{c} \text { vGridEnTr }_{s, c, m, h} \\
& \text { vGridCostE } E_{s, m, h}=\text { GGidTariffEE } * v \text { GridEnTotalPos } \\
& s, m, h
\end{aligned}
$$

\subsubsection{PIECEWISE LINEAR FUNCTION CONSTRAINTS:}

The piecewise linear function approximation of the energy cost curves have been modelled as described in [200]. The piecewise function is characterized by the points connecting the linear segments (" $\mathrm{x}, \mathrm{y}$ " points described with $\mathrm{pXparameter}$ and pYparameter). In this study, 23 points have been used to model the 22 considered segments for the energy cost curve approximation. The detailed process for the piecewise linear function approximation can be found in section 5.2.2.

The positive auxiliary variable $\lambda$ has been used in (59) to compute the electricity cost as a linear combination of energy cost values of the considered points (pYparameter) previously described. Similarly, the energy value of the piecewise linear function is translated to a linear combination of the pXparameter values, as shown in (60).

$$
\begin{aligned}
& \text { vElectricCost }_{s, m, h}=\sum_{p}\left(\lambda_{s, p, m, h} * \text { pYparameter }_{s, p, m, h}\right) \\
& \text { vGridEnTotalPos }_{s, m, h}-\text { vGridEnTotalNeg }_{s, m, h}=\sum_{p}\left(\lambda_{s, p, m, h} * \text { pXparameter }_{s, p, m, h}\right)
\end{aligned}
$$

It is important to remark that the sum of all $\lambda$ variables cannot be greater than 1 , as shown in (61). However, to avoid being in more than one segment of the piecewise function, the binary variable $\chi$ is used (also, the sum of all $\chi$ cannot be greater than one, and thus, only the $\chi$ of one of the segments will be equal to 1 and the rest will be 0 , as shown in (65)). This binary variable makes the optimization problem a mixed integer programming one. The constraints (62) - (65) complete the piecewise linear function formulation, allowing the $\lambda$ variables to be greater than 0 if the binary variable is 1 (the active segment of the piecewise linear function), and to be zero otherwise. A more detailed explanation of this piecewise approximation can be found in [200].

$$
\begin{aligned}
& \sum_{p} \lambda_{s, p, m, h}=1 \\
& \lambda_{s, p=1, m, h} \leq \chi_{s, s e g=1, m, h}
\end{aligned}
$$


$\lambda_{s, \text { seg,m,h}} \leq \chi_{s, \text { seg-1,m,h }}+\chi_{s, \text { seg }, m, h} \forall$ seg $\in[2,21]$

$\lambda_{s, p=23, m, h} \leq \chi_{s, s e g=22, m, h}$

$\sum_{s e g} \chi_{s, s e g, m, h}=1$

\subsection{Model SCEnarios and CASE Studies}

\subsubsection{CASE STUDY DESCRIPTION AND PARAMETERS}

Three case studies with different DER planning approaches have been analysed:

- $\quad$ Case study A: Price-maker with deterministic approach (average scenario).

- Case study B: Price-maker with deterministic approach (most likely scenario).

- Case study C: Price-maker with stochastic approach based on three scenarios.

For all cases different sizes of aggregated districts have been analysed. To adequately simulate a district different types of domestic energy users have been considered. According to [180] residential clients in Spain can be classified in four kinds depending on the age of the head of the family (HF) or the presence of young children in the household: head of the family with less than 35 years, head of the family between 35 and 65 years old, head of the family with more than 65 years, and family with children younger than 14 years old. Fig. 12 and Fig. 13 show the typical electricity demand curves for every type of client in summer and winter seasons, calculated as an average of historical data up to year 1998 [180].

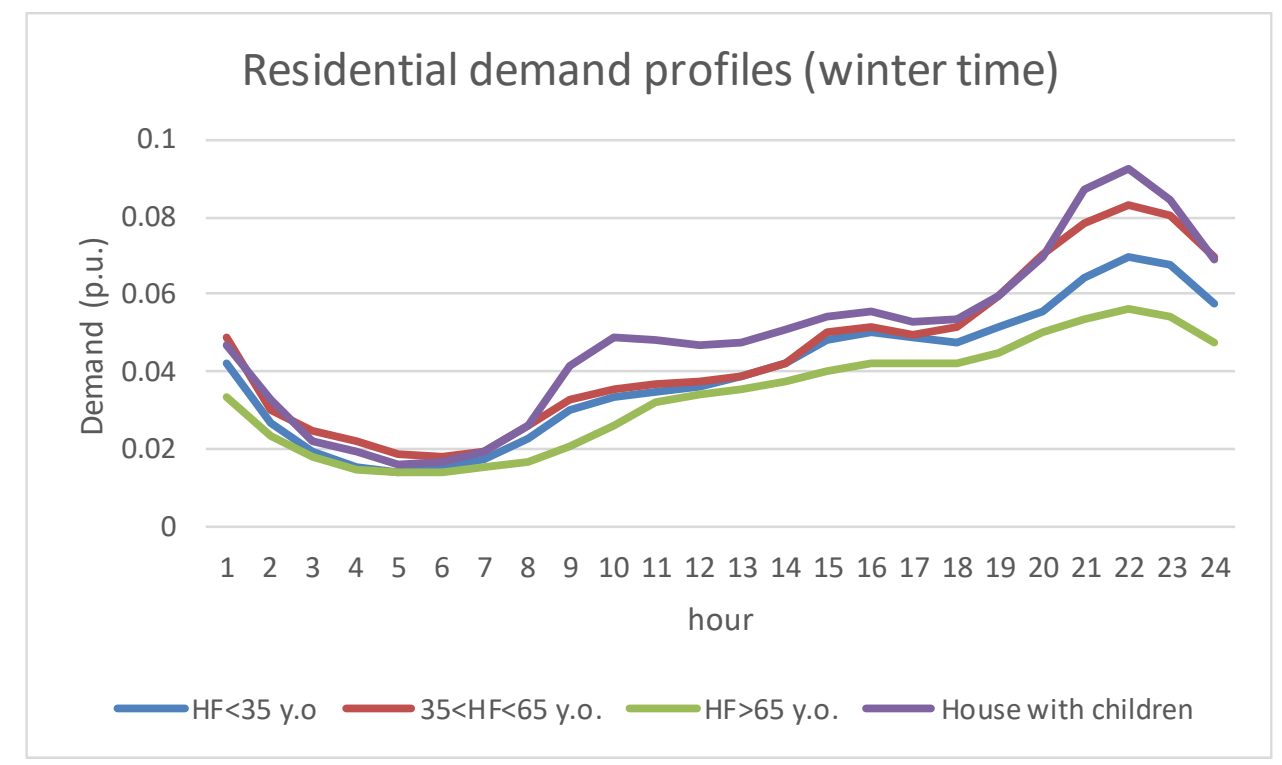

FIG. 12. NORMALIZED DEMAND CURVES FOR WINTER TIME. 


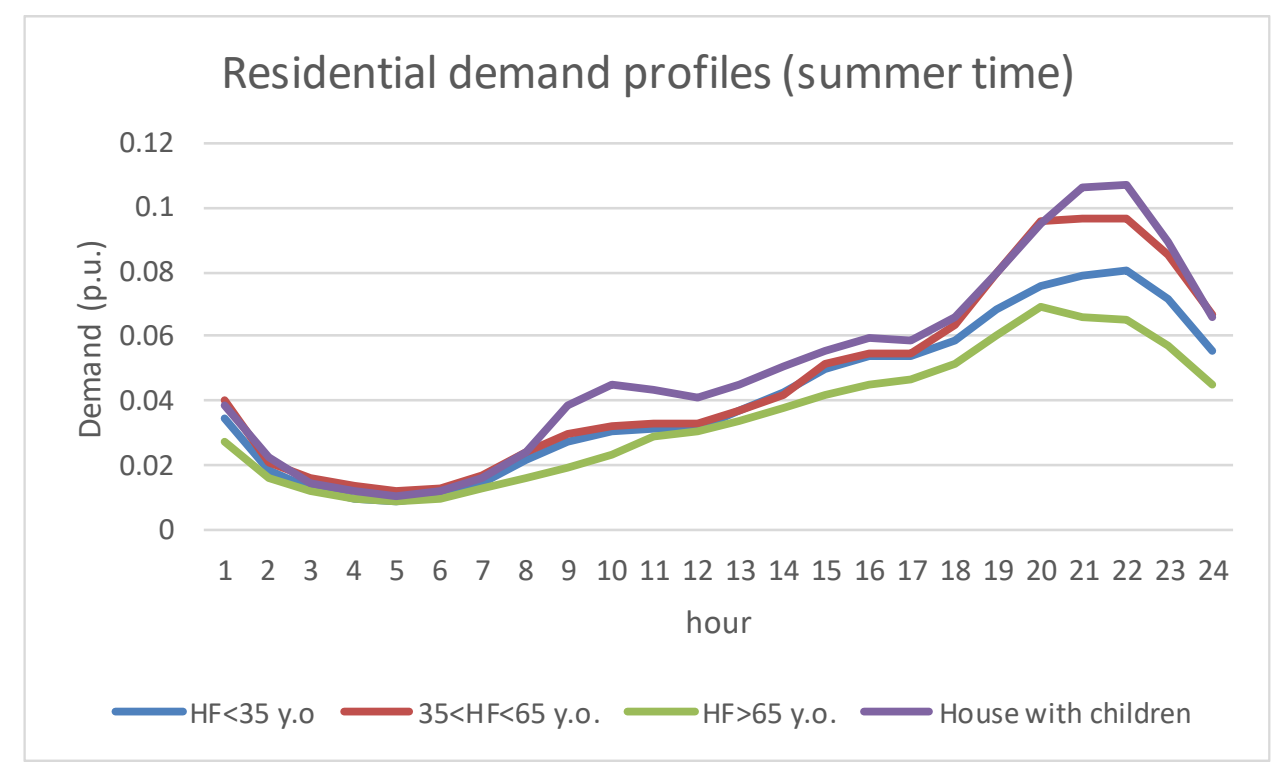

FIG. 13. NORMALIZED DEMAND CURVES FOR SUMMER TIME.

Table 29 summarizes the annual energy consumption per client type and the difference with respect to the Spanish residential average value per household [179]. The monthly energy demand throughout a year is represented in Fig. 14 [180].

For thermal energy, it has been considered that most residential customers have a hot water tank or other means of thermal storage, so there is no an hourly demand curve. However, constraint (15) has been added to have a minimum thermal production during peak hours, to avoid concentrating all the thermal energy in a few off-peak hours when is less likely to be used. Moreover, and due to lack of more detailed data, it has been assumed that the total thermal use follows the same monthly percentage pattern of Fig. 14.

TABLE 29. TOTAL ANNUAL ENERGY CONSUMPTION PER CLIENT TYPE.

\begin{tabular}{|c|c|c|c|}
\hline Type of client & $\begin{array}{l}\text { Comparison } \\
\text { with average } \\
\text { value }\end{array}$ & $\begin{array}{l}\text { Annual } \\
\text { Thermal (kWh) }\end{array}$ & $\begin{array}{l}\text { Annual } \\
\text { Electric }(\mathbf{k W h})\end{array}$ \\
\hline $\mathrm{HF}<35$ у.о. & $-5 \%$ & 6054.9747 & 3507.0613 \\
\hline $35 \leq \mathrm{HF}<65$ y.o. & $8 \%$ & 6871.7046 & 3980.1140 \\
\hline$H F \geq 65$ y.o. & $-19 \%$ & 5174.3962 & 2997.0274 \\
\hline $\begin{array}{l}\text { House with } \\
\text { children }\end{array}$ & $16 \%$ & 7422.3987 & 4299.0778 \\
\hline
\end{tabular}




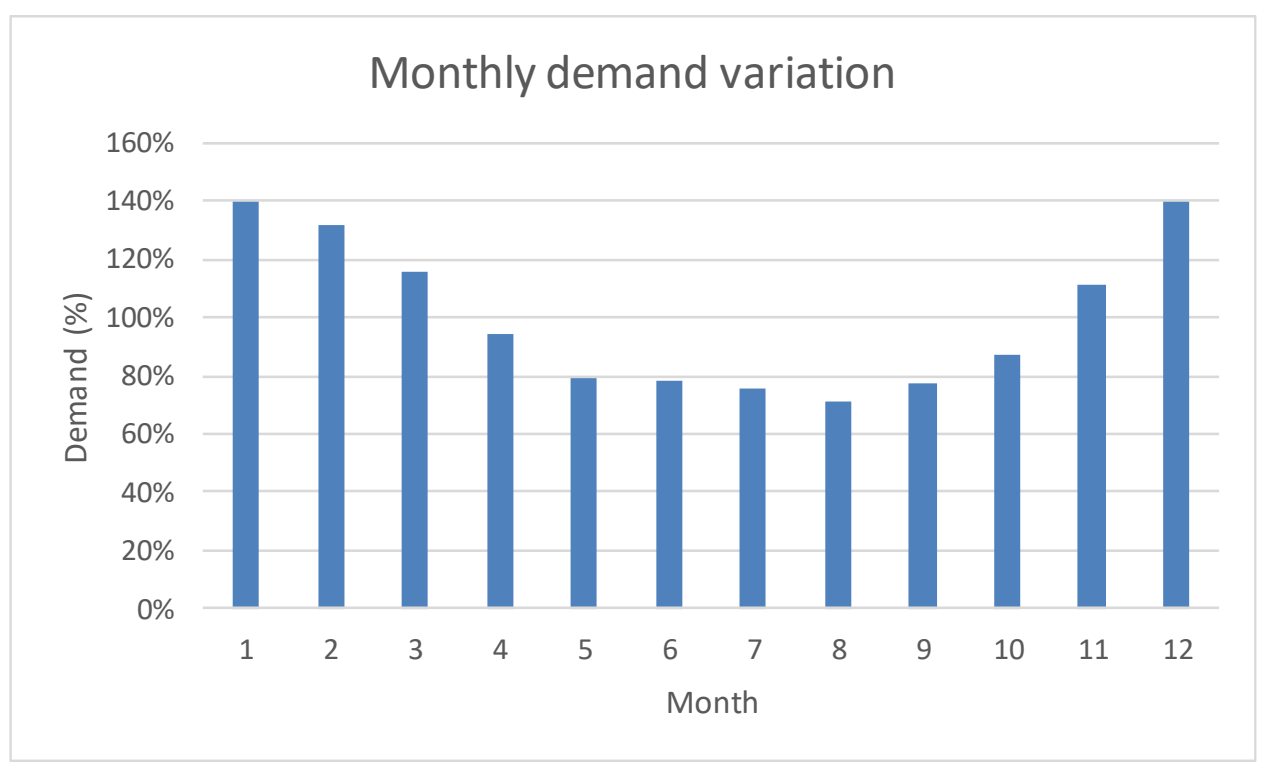

FIG. 14. MONTHLY DEMAND VARIATION FOR THE RESIDENTIAL ELECTRIC SECTOR IN SPAIN

In this study, the solar characteristics of Madrid, Spain, have been considered, and solar production has been calculated with hourly DNI data from [152]. Table 30 and Table 31 summarise other required parameters. Table 30, with data taken from [181], presents the access tariffs to be paid by each household (due to the contracted power), the thermal energy cost (in the form of natural gas) and the electric energy cost for network operation and maintenance, to be paid in addition to the cost of the energy bought from the market (according to [201], the network cost and taxes represents about $60 \%$ of the tariff). The electricity prices will be an output of the model, so they are not included here.

Table 31 shows the investment, maintenance and operation costs, and performance parameters (including losses) of the considered distributed energy resources (taken from [10], [202] and [203], losses from [152], [160] and [204]). Battery charge and discharge efficiency has been set to 95\% [10]. The coefficient of performance (COP) of the heat pump has been assumed in 2.5 units, considered as an average COP throughout the year [205]. Indeed, the COP of HP system varies constantly as a function of the difference between indoor-outdoor temperatures, and thus, the approximation used is expected to have an error in real-time operation (in summer time the COP is likely to be smaller, and in winter time the COP is likely to be larger). However, given the long-term scope of this study, it is considered that the average value used is enough to deliver sensible results. Other works with similar COP range can be found in [160], [164] and [165].

The pDemandShift parameter has been calculated considering the appliances that can be more easily shifted in time. According to [179], the washing machine, dryer and dish washer represent the $13.3 \%$ of the total electric consumption of a typical Spanish household; hence, the pDemandShift parameter has been established to a maximum $13 \%$ of total daily load. A fixed cost $p D$ RequipCost of $250 € /$ house represents the cost of the control devices needed for implementing demand response control systems [182]. 
TABLE 30. POWER TARIFFS AND THERMAL ENERGY PRICING.

\begin{tabular}{l|c} 
Access tariffs (Power) & Price \\
\hline Electric (Annual) & $38043(€ / \mathrm{MW})$ \\
Thermal (Annual) & $106.08(€ /$ Client) \\
\hline Natural gas tariff: & $74.3(€ / \mathrm{MWh})$ \\
\hline Network costs share: & $44.02(€ / \mathrm{MWh})$ \\
\hline
\end{tabular}

TABLE 31. TECHNOLOGY COSTS AND EXPECTED ENERGY LOSSES.

\begin{tabular}{l|lll} 
Technology & Inst. Cost $(\boldsymbol{€} / \mathbf{W})$ & $\begin{array}{l}\text { O\&Mfix } \\
\text { per annum) }\end{array}$ & Losses (\%) \\
\hline PV & 2.15 & 30.93 & 24 (electric) \\
HP (COP=2.5) & 2.94 & 100.1 & 15 (thermal) \\
Battery & $0.36(€ / W h)$ & - & 10 (electric)
\end{tabular}

\subsubsection{SCENARIO DESCRIPTION}

The scenarios proposed consist of residual demand curves (RDC) used by the aggregator to assess its impact on the market price when selling or buying energy at each hour he optimizes its energy transactions. In a simple way, a residual demand curve of a market participant is a function that represents the market competitors' behaviour by relating the market clearing price to the quantity sold by the participant in that hour. It is obtained by adding up the demand curves of the competitors and subtracting their supply curves, or equivalently, by removing the market participant own aggregated supply curve from the total aggregated residual demand curve of the market [206]. It is a well-known approach for representing the competitors' behaviour, and is commonly used by market participants to formulate effective oligopolistic strategies [199]. The RDC for the representative days used to model year 2013 have been computed from real market data taken from [207] and [208], and used in all residual demand curve scenarios. For the sake of simplicity, complex offers and other transversal conditions (linking the offers of different hours) have not been considered in this analysis.

In the deterministic problem 288 representative residual demand curves have been computed, corresponding to one representative curve per hour, 24 hours per day and 12 representative days for the year. For the stochastic case, three sets of 288 curves have been created (i.e. 3 scenarios per hour). Then, an energy cost curve (see section 5.2.2.1) has been computed for every residual demand curve considered and a piecewise linear approximation has been carried out to implement them in the optimization model, [209]. It is important to remark that both the calculation of the energy cost curve and the use of a piecewise linear approximation have been implemented to avoid the non-linearity of this kind of model (the minimization of the energy costs depends on the energy transaction and the energy price, which is also function of the energy, making it a non-linear problem) and having a mixed-integer linear programming one. 
This process can be described as follows:

1. For a particular month, all the residual demand curves of the same hour, but of different days of the same month, have been grouped. For instance, for January at $10 \mathrm{~h} 00$ there are 31 curves. In the deterministic cases, no distinction has been made between working days and holidays; however, the stochastic approach creates different groups of days.

2. Using the K-means clustering algorithm implemented in MATLAB [210], a representative curve has been created ( 3 representatives for the stochastic case) for each hour of each representative day of each month. This clustering methodology has been used effectively to create RDC scenarios, as shown in [211].

3. With the representative demand curve of each cluster, the energy cost curve has been computed by multiplying all the energy values by its corresponding price. This pre-processing has been developed to avoid nonlinearities in the programming problem, as proposed in [209].

4. The piecewise linear approximation has been carried out using the Recursive Douglas-Peucker Polyline Simplification algorithm, implemented in MATLAB [212]. The tolerance parameter has been fine-tuned to create 22 segments for the piecewise linear function, putting especial emphasis in the area where the clearing is more likely to occur. This clearing area changes according to the amount of aggregated resources (a larger district will have larger transactions in the market, and thus, a larger energy ranges), but it will normally be centred on zero as the aggregator is likely to sell or buy energy (positive and negative values) at different hours. This procedure is repeated for all the 288 hours considered representative of the whole year.

\subsubsection{Average scenario for the deterministic model (Case study A).}

For this case study, the process described above has been applied and a unique average representative has been computed from all the residual demand curves of a particular hour in that month. Fig. 15 shows the curves for all the month of January at $10 \mathrm{~h}$, and their representative curve (dashed red line). 


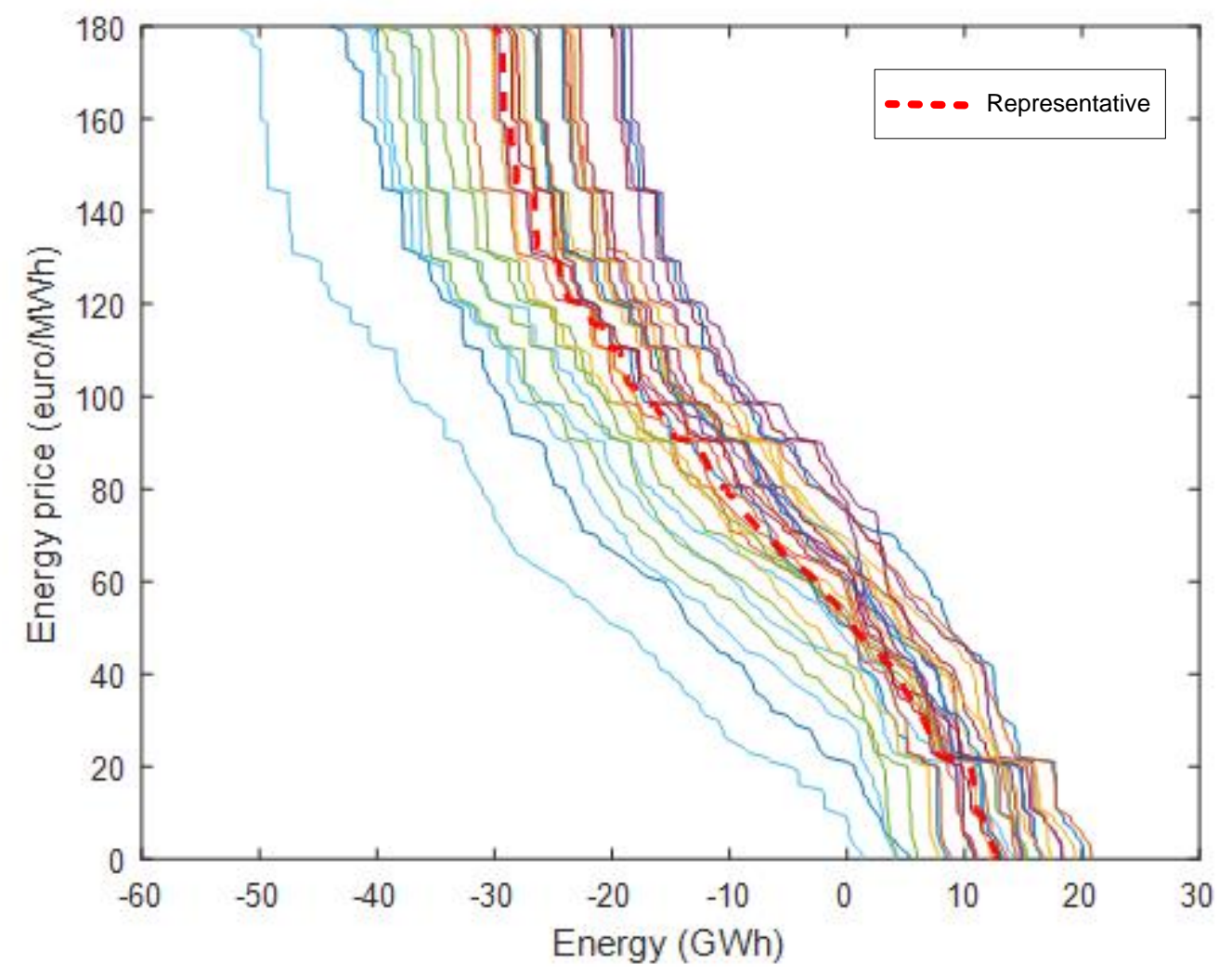

FIG. 15. RESIDUAL DEMAND CURVES OF ALL DAYS OF JANUARY AT HOUR 10 AND THE COMPUTED REPRESENTATIVE CURVE.

For all the representatives obtained with the abovementioned process, the energy cost curve has been computed, by multiplying the energy quantity times its price, and the piecewise linear approximation has been applied. Fig. 16 shows an example of the piecewise linear functions obtained (dashed line in red) for the corresponding energy cost curve (solid line in blue). Positive costs are for buying energy, while negative costs represent profits for selling energy. 


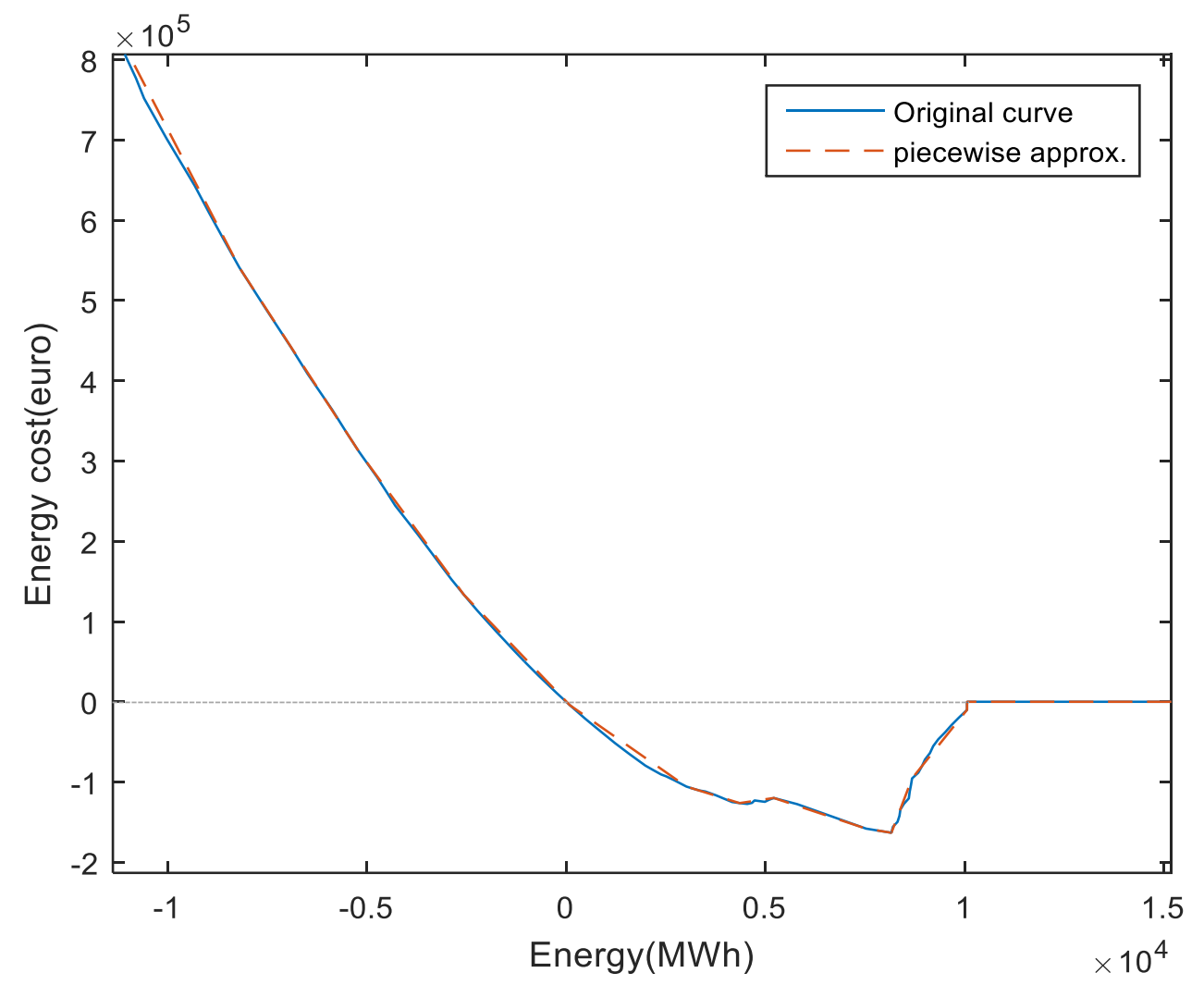

FIG. 16. PIECEWISE LINEAR APPROXIMATION OF THE ENERGY COST CURVE (CASE STUDY A, JANUARY 8H00).

\subsubsection{The most likely scenario (Case study B) and three scenarios for the stochastic model (Case study C).}

Case study B has been proposed to analyse the aggregated system with market values that are likely to occur. This approach gives relevant information that might be lost in the average scenario considered previously, as the clustering in a single representative behaves as an average of all the samples, and tends to over-smooth the residual demand curve. Case study $\mathrm{C}$, on the other hand, tries to model the uncertainty of the markets by following a stochastic approach.

The stochastic scenarios have been modelled, using the same clustering procedure described previously, but clustering similar days of each month and no individual hours. So the three cluster representatives could be considered to represent typical days of that month. In other words, scenarios 1, 2 and 3, could be considered to represent typical days with "low", "medium" and "high" prices. Therefore, instead of one set of residual demand curves, modelling the average day in case study A, now three representative curves have been created, and thus 288 sets of three curves have been produced to represent these three typical days.

The selection of only three scenarios for the stochastic model has been done, firstly, due to computational constraints as the number of binary variables in the problem make it difficult to solve and time consuming, secondly, because the three scenarios provides good 
approximation of the reality, according to the silhouette clustering validation method [213]. This method permits to assess how well represented are the residual demand curves by the three representatives created. The results of this test, carried out in MATLAB, gives a Silhouette value of 0.67 , which can be translated to $83.37 \%$ of correctness in the clustering representatives. Note that the silhouette value ranges from -1 to +1 . A high value indicates that the sample is well-matched to its own cluster, and poorly-matched to neighbouring clusters (the clusters are different enough). Hence, considering the average silhouette value obtained, the clustering solution can be considered is appropriate [214].

Fig. 17 exemplifies a set of energy cost curves with their corresponding piecewise linear functions approximations. These cost curves remain at zero cost from a certain energy value, as there is no more demand for energy in the system for the extra generation, reducing the electricity price to zero (see Fig. 15). In other words, the energy price falls when more energy is sold to the system (more offer than demand). If the extra availability of energy continues, and there is not an increase in demand, the price of energy falls to 0 $€ / M W h$, making the energy costs to be $0 €$ as well (see the horizontal axis in Fig. 16 or in Fig. 17).

While case C uses the three curves per hour, case B only uses the one with greater probability corresponding to the representative of the largest cluster. The probability of each scenario has been calculated as the proportion of samples (days) classified in each cluster regarding the total number of samples (number of days in each month) [211].

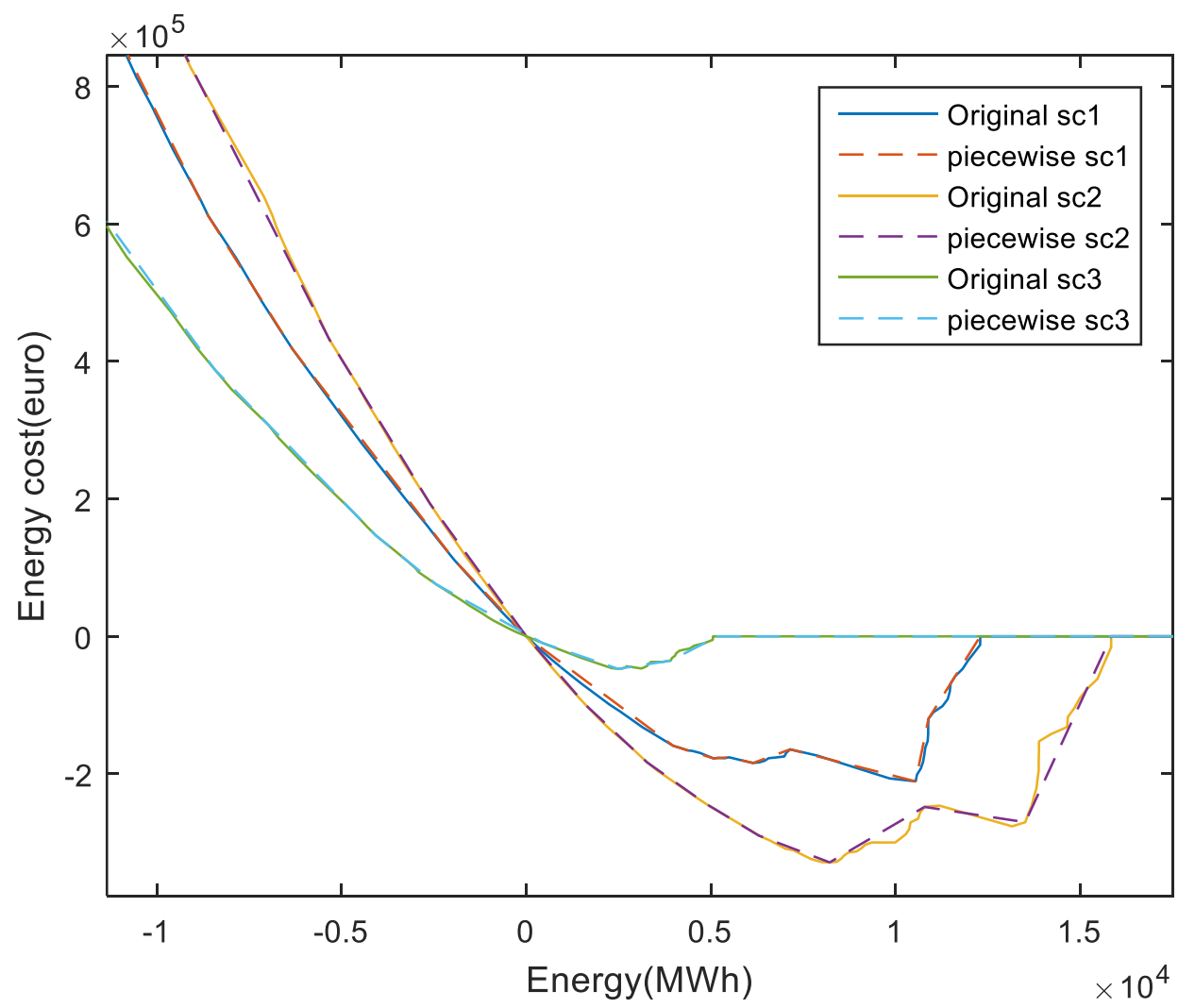

FIG. 17. PIECEWISE LINEAR APPROXIMATION OF THE ENERGY COST CURVES (CASE STUDY B AND C, JANUARY 10H00). 


\subsubsection{Residual demand curve adjustment for different loads.}

The residual demand curves obtained from [207] and [208] include the total generation and demand of the Spanish system, and the resulting market price (the price of the energy at that particular hour) falls at energy $=0 \mathrm{MWh}$ (equilibrium between generation and demand of all the system). Therefore, the proposed aggregator needs to take out the original load of the considered district from such curves before placing offers in the electricity market. Otherwise, it will be like if the considered aggregated clients have been added to the system, artificially increasing the total system demand.

To correct this problem, a similar methodology as in [199] and [215] has been applied, so the original unmanaged load of the considered group of aggregated clients is removed from the residual demand curves, by shifting the curves to the left in the same number of units of energy as the demand removed. Fig. 18, shows an example of such curve shift, where the blue solid line represents the original curve and the red curve is the adjusted one. In Fig. 19, the original (blue) and adjusted (red) energy cost curves are shown. It can be seen that removing load (moving the residual demand curve to the left) makes the price to decrease (the crossing with zero energy falls at a lower price), which implies lower energy costs when the energy is bought from the grid (red curve in Fig. 19). If there is no energy management and the same amount of energy is bought from the grid (as the original case), the red line will be shifted back to where the blue line is, getting the original market price for that hour.

Note that this curve adjustment not only makes the energy price lower for buying energy, but also produces lower income for selling energy (the curve is shifted further to the left, reducing more the market price), logically affecting the strategies taken by the aggregator.

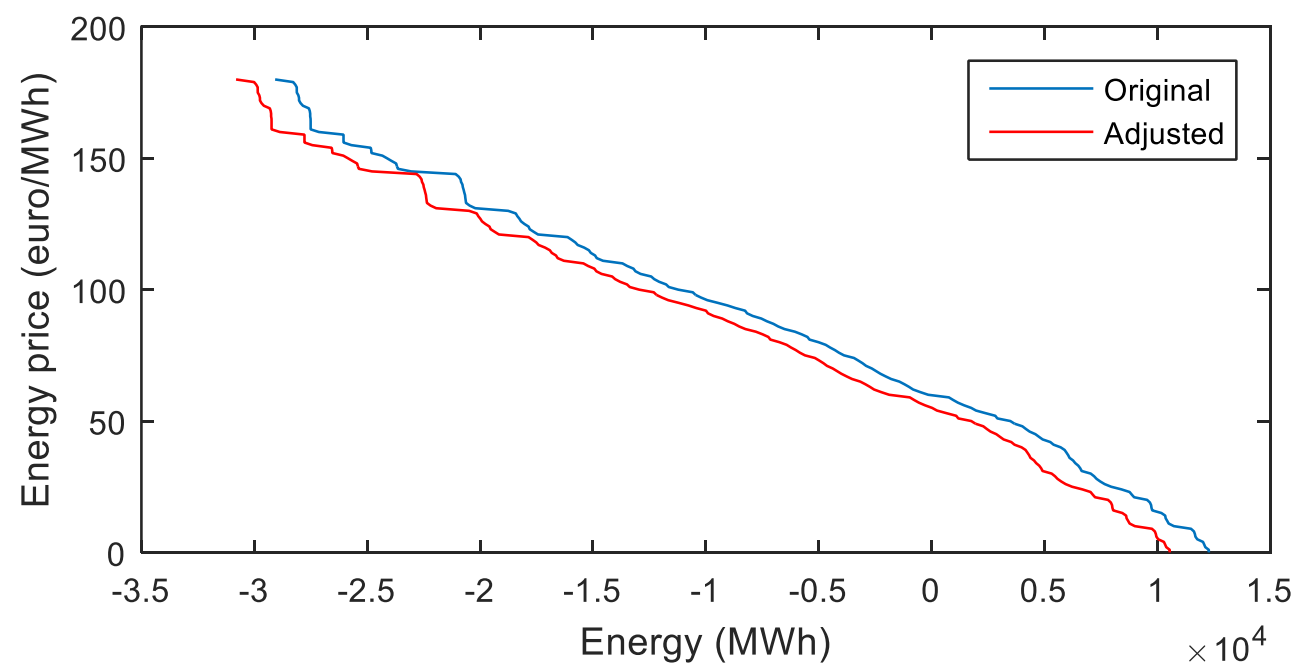

FIG. 18. ADJUSTED RESIDUAL DEMAND CURVE (JANUARY 10H00). 


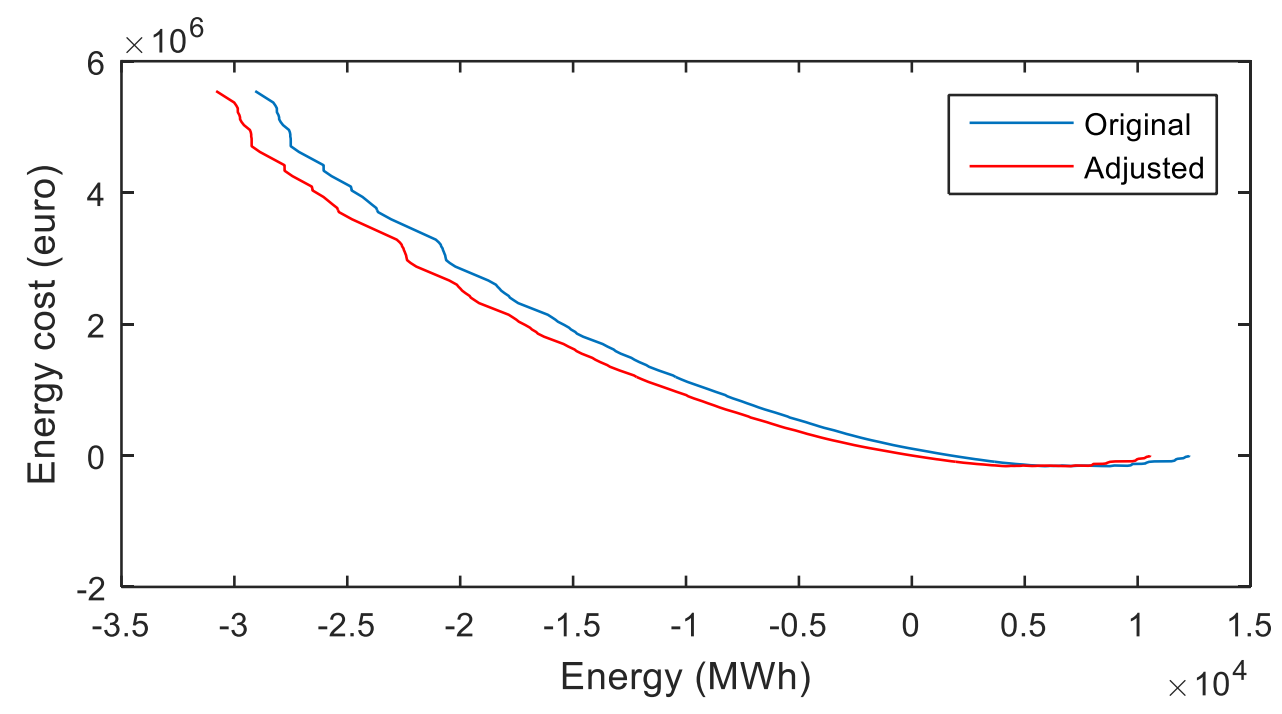

FIG. 19. ADJUSTED ENERGY COST CURVE (JANUARY 10H00).

\subsection{RESULTS AND DISCUSSION}

This section presents the results of the optimization models proposed, and the effect of the amount of aggregated resources is analysed. For the sake of comparison, the results of the three case studies have been grouped and discussed in section 5.3.1. then, section 5.3.2 presents examples of the aggregated resources operation for the different scenarios and aggregation levels. It is important to remark that, as network constraints have not been included, the optimal DER planning solely depends on the type of client, and not on its location in the network [11].

\subsubsection{RESULT DISCUSSION AND CASE STUDY COMPARISON}

Different district sizes have been considered for this analysis, taking the 4 household types, described in section 5.2.1 as the base load. For instance, a district with 100000 clients is disaggregated into 25000 clients per each client type. To have a better understanding of the magnitude of the districts in comparison to the total market size, the respective market shares for all considered districts has been calculated with (66) as the mean of the hourly market shares. The hourly market share has been computed as the original demand (without implementing any DER or management of any sort) of the considered district at a particular hour of a month, over the average demand of the Spanish system at the same hour, considering all the days of that month. This has been repeated for all months, and a final average is computed. The maximum number of clients implementing DER systems considered in this study is 8 million, which corresponds to around $15 \%$ of the total demand of the Spanish system. Then, assuming that the demand consists only of domestic and industrial clients (neglecting pump-storage units, auxiliary services, etc.), the rest of the system demand goes to other residential clients (approx. 25\%) and to industrial and commercial clients (approx. 60\%, see Fig. 20), which is coherent with the number of clients participating in the liberalised energy market [216]. 
marketShare $=\frac{\sum_{m} \sum_{h}\left(\frac{\text { vOriginalDemand }_{m, h}}{\text { pAvgSystDemand }}, \mathrm{m}, h\right.}{m * h}$

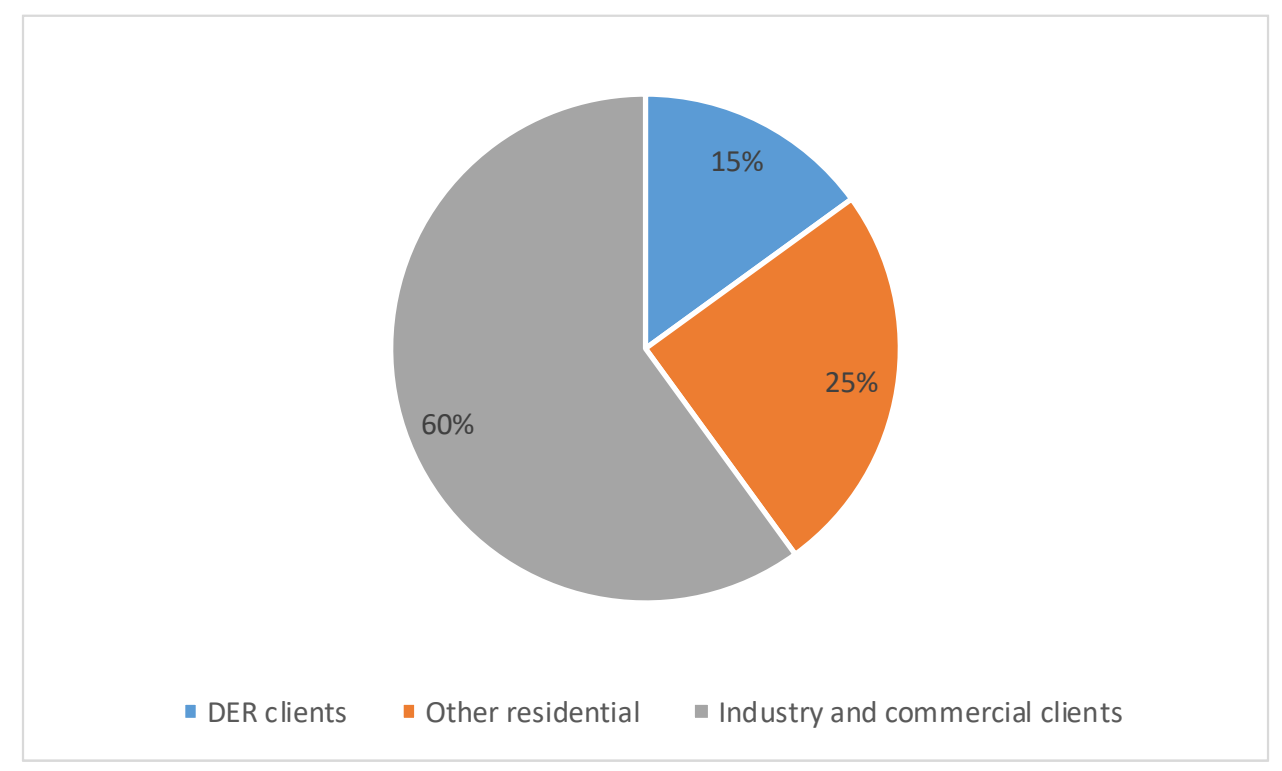

FIG. 20. APPROXIMATE DEMAND DISTRIBUTION OF THE SPANISH SYSTEM.

The average change on electricity prices due to the aggregator actions and the impact on the electric energy costs in the considered districts have been computed as well. The average price change and the absolute price change have been computed with (67) and (68) respectively, where the average of the original prices has been computed with (69). Also, the average energy weighted system price change is calculated with (70) - (72). The change in electricity costs is calculated with (73).

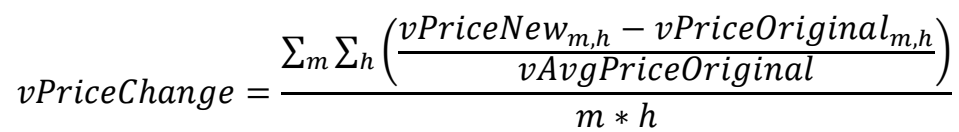

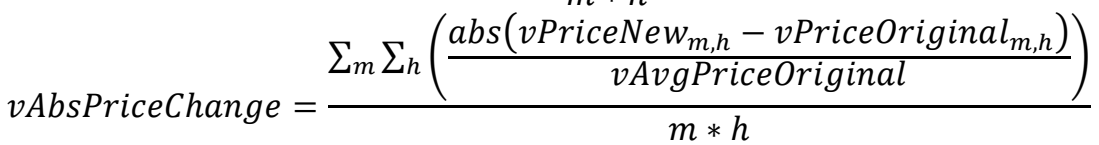

$$
\begin{aligned}
& \text { vAvgPriceOriginal }=\frac{\sum_{m} \sum_{h}\left(\text { vPriceOriginal }_{m, h}\right)}{m * h} \\
& v \text { WaveragePriceNew }=\frac{\sum_{m} \sum_{h}\left(\text { vPriceNew }_{m, h} * \text { vSystemEnergyNew }_{m, h}\right)}{\sum_{m} \sum_{h}\left(\text { vSystemEnergyNew } \text { S }_{m, h}\right)} \\
& v \text { WaveragePriceOriginal }=\frac{\sum_{m} \sum_{h}\left(\text { vPriceOriginal }_{m, h} * \text { vSystemEnergyOriginal }_{m, h}\right)}{\sum_{m} \sum_{h}\left(\text { vSystemEnergyOriginal }_{m, h}\right)} \\
& \text { vSystemPriceChange }=\frac{v \text { WaveragePriceNew }- \text { vWaveragePriceOriginal }}{v \text { WaveragePriceOriginal }} * 100
\end{aligned}
$$

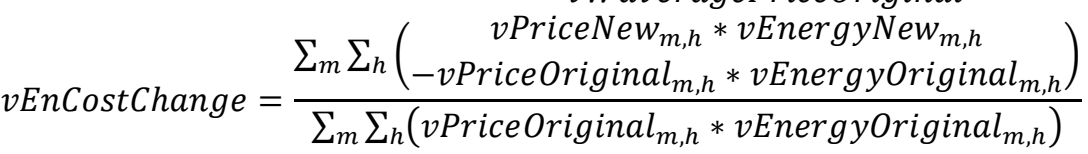

The results of the analysed case studies are presented in Table 32 and Table 33. In case study A, the former table shows how the installed capacity of the PV and HP grew almost 
linearly with the number of houses, yet the battery has been very little or not implemented in most cases, since the prices differences after load management have not been enough to compensate batteries investment prices. The system total costs (Table 33), including energy and DER costs (calculated with (52)), presented a similar linear pattern, with lower slope, than the PV and HP installed capacity, meaning that the aggregator's economic benefits of managing larger districts are greater than the increased costs of a greater amount of loads and distributed resources.

TABLE 32. DER INSTALLED CAPACITY FOR ALL CASE STUDIES.

\begin{tabular}{cc|ccccccccc}
$\begin{array}{c}\text { Number } \\
\text { of clients }\end{array}$ & $\begin{array}{c}\text { Market } \\
\text { share }\end{array}$ & \multicolumn{3}{|c}{ PV (MW) } & \multicolumn{4}{c}{ Battery (MWh) } & \multicolumn{3}{c}{ HP (MW) } \\
(millions) & $\mathbf{( \% )}$ & $\mathbf{A}$ & $\mathbf{B}$ & $\mathbf{C}$ & $\mathbf{A}$ & $\mathbf{B}$ & $\mathbf{C}$ & $\mathbf{A}$ & $\mathbf{B}$ & $\mathbf{C}$ \\
\hline 0.04 & $0.076 \%$ & 110 & 124 & 114 & 0 & 0 & 38 & 17 & 17 & 16 \\
0.1 & $0.19 \%$ & 279 & 327 & 251 & 9 & 0 & 84 & 42 & 43 & 38 \\
0.2 & $0.38 \%$ & 540 & 635 & 527 & 16 & 0 & 177 & 83 & 86 & 76 \\
0.4 & $0.76 \%$ & 1053 & 1234 & 1106 & 27 & 0 & 371 & 167 & 171 & 149 \\
1 & $1.9 \%$ & 2621 & 3028 & 2102 & 65 & 0 & 705 & 412 & 426 & 383 \\
2 & $3.8 \%$ & 5227 & 5954 & 3889 & 10 & 0 & 1305 & 834 & 856 & 700 \\
4 & $7.6 \%$ & 9651 & 10469 & 7583 & 11 & 0 & 2545 & 1667 & 1667 & 1458 \\
8 & $15.2 \%$ & 17662 & 18185 & 14227 & 0 & 0 & 4775 & 3335 & 3335 & 2974
\end{tabular}

TABLE 33. TOTAL SYSTEM COST (ENERGY, DER INVESTMENTS AND O\&M) FOR ALL CASE STUDIES.

\begin{tabular}{cc|rrr}
$\begin{array}{c}\text { Number } \\
\text { of clients } \\
\text { (millions) }\end{array}$ & $\begin{array}{c}\text { Market } \\
\text { share }\end{array}$ & \multicolumn{3}{|c}{ Total costs (M€) } \\
\hline 0.04 & $0.076 \%$ & 760.77 & 759.8 & 684.1 \\
0.1 & $0.19 \%$ & 1824.15 & 1870.3 & 1636.9 \\
0.2 & $0.38 \%$ & 3635.94 & 3726.2 & 3186.7 \\
0.4 & $0.76 \%$ & 7277.55 & 7440.1 & 6162.1 \\
1 & $1.9 \%$ & 18083.2 & 18237.1 & 14268.7 \\
2 & $3.8 \%$ & 36192.1 & 36574.5 & 28586.1 \\
4 & $7.6 \%$ & 72952.13 & 73576.4 & 60931.8 \\
8 & $15.2 \%$ & 147378.07 & 149218.5 & 131383.9
\end{tabular}

In case study B, battery storage has not been implemented in any of the district sizes considered while the entire DER installed capacity grew with the number of clients. The difference in prices during the day, especially at winter time, makes load shifting more profitable, but they are not large enough to invest in battery systems. Regarding the total 
system costs (Table 33), Case B values were slightly greater than those of Case A. This increment is a result of both the slightly higher average price and the slightly higher prices at the off-peak hours of case study B.

Focusing on Case $\mathrm{C}$, it can be seen that in comparison with the deterministic cases, the HP installed capacity was slightly smaller, especially in big districts. In addition, the PV capacity was smaller for all district sizes, especially in the larger districts. However, the main difference is in the battery systems that increased significantly for all the analysed district sizes. This has been due to the greater variability and difference in prices provided by the stochastic scenarios, (see section 5.3.2, in particular Fig. 27 and Fig. 28). Lastly, the total system costs were slightly smaller (especially with medium to large amounts of aggregated resources) than in the previous cases. Once again, this last phenomenon has been produced by taking advantage of the larger price variability to do more load shifting, and the lower minimum price to buy cheaper energy (see Fig. 27), in comparison with case studies A and B.

Note that the electricity price scenarios of the stochastic case are likely to represent the reality better than the deterministic scenarios (case studies A and B), as the latter do not represent adequately all the price range and variability due to the averaging made while building the representatives (see section 5.2.2). This is an important element to consider, as the DER planning changes considerably from case study $\mathrm{C}$ to case studies A and B (more than $20 \%$ less PV, and around 10\% less HP, see Table 32), especially for the battery system installed capacity (in cases A and B, battery systems is almost inexistent, see Table 32).Note also that more scenarios in the stochastic case are likely to represent even better the variability of energy prices, but with the drawback of extra complexity in the optimization problem.

Table 34 shows the average change on electricity prices due to the aggregator transactions in the market and the repercussion on the electric energy costs of the system (calculated with (67) - (73)). The average price change shows the overall tendency on the electricity prices (if the prices decrease or increase in average). However, this value might not give all the information, as a certain average value could be computed in many ways. For instance, an average price change of $0 \%$ might be caused by a lack of change at all hours, or by a $5 \%$ price increment in half of the hours, followed by a $5 \%$ decrement in the remaining hours. Hence, the absolute average value is computed to add more information on the size and direction (increment or decrement) of the price changes.

From Table 34 and the aggregator's operation figures (see section 5.3.2), it can be seen that the DER systems considered reduce the overall electricity consumption (between 32 and $68 \%$ depending on the district size and the case study), reducing the electricity price for all district sizes (up to $8 \%$ in average). However, it is evident that the price change is more significant for larger district sizes, as the market share is larger.

Note that all market participants affect the market price since they move the clearing point on the RDC, and if the slopes of the RDC faced are large, even small agents can have large impacts on the price (as proved in [217] and [218]). 
It is important to remark that the adequate computation of the price-taker error is not straightforward as it requires several considerations:

- It is needed, at least, to create two more models.

- One of the models would be a price-taker with fixed energy prices, where the resulting planning and operation of the energy resources are saved (the energy prices and costs will be erroneous with respect to reality).

- The second model would be a price-maker one, that takes the planning and operation from the "price-taker", evaluating the change on prices according to this operation. This second model would be different than the one presented here, as it does not decide on the planning and operation of DER systems, and just evaluates the price changes.

- The second model would give the new energy prices and costs, and thus, by comparing with the price-taker results, an error can be estimated.

For the sake of brevity, such computation is not developed in this thesis. Nevertheless, it can be seen that for large DER aggregations, a price-taker approach could have a significant error and provide inaccurate results, as the planning would be done for a particular price, which could be different from the real one (see the electricity prices changes in Table 34). However, for smaller aggregations a price-taker approach could be acceptable. In this particular study, it seems that for less than 100000 houses (hourly transactions of less than $50 \mathrm{MWh}$ in average), a price-taker approach could give sensible results (the average error would be lower than $0.15 \%$ ), but in a different system with other price curves the results might differ considerably.

TABLE 34. EFFECT ON ELECTRICITY PRICES FOR ALL CASE STUDIES.

\begin{tabular}{|c|c|c|c|c|c|c|c|c|}
\hline $\begin{array}{l}\text { Number } \\
\text { of clients } \\
\text { (millions) }\end{array}$ & $\begin{array}{c}\text { Market } \\
\text { share } \\
(\%)\end{array}$ & Averag & price ch & ge (\%) & Averag & $\begin{array}{c}\text { abs. price } \\
\text { (\%) } \\
\text { B }\end{array}$ & change & $\begin{array}{c}\text { Average } \\
\text { system } \\
\text { price } \\
\text { change (\%) }\end{array}$ \\
\hline 0.04 & $0.076 \%$ & $-0.05 \%$ & $-0.05 \%$ & $-0.06 \%$ & $0.10 \%$ & $0.09 \%$ & $0.17 \%$ & $-0.07 \%$ \\
\hline 0.1 & $0.19 \%$ & $-0.12 \%$ & $-0.15 \%$ & $-0.12 \%$ & $0.25 \%$ & $0.23 \%$ & $0.37 \%$ & $-0.14 \%$ \\
\hline 0.2 & $0.38 \%$ & $-0.22 \%$ & $-0.28 \%$ & $-0.19 \%$ & $0.49 \%$ & $0.46 \%$ & $0.72 \%$ & $-0.26 \%$ \\
\hline 0.4 & $0.76 \%$ & $-0.42 \%$ & $-0.55 \%$ & $-0.34 \%$ & $1.02 \%$ & $0.90 \%$ & $1.33 \%$ & $-0.50 \%$ \\
\hline 1 & $1.9 \%$ & $-1.00 \%$ & $-1.39 \%$ & $-0.73 \%$ & $2.35 \%$ & $2.26 \%$ & $3.28 \%$ & $-1.20 \%$ \\
\hline 2 & $3.8 \%$ & $-2.19 \%$ & $-2.73 \%$ & $-1.40 \%$ & $4.83 \%$ & $4.61 \%$ & $6.80 \%$ & $-2.59 \%$ \\
\hline 4 & $7.6 \%$ & $-4.15 \%$ & $-4.71 \%$ & $-2.85 \%$ & $8.81 \%$ & $8.32 \%$ & $12.78 \%$ & $-4.81 \%$ \\
\hline 8 & $15.2 \%$ & $-7.94 \%$ & $-8.40 \%$ & $-6.40 \%$ & $16.07 \%$ & $14.93 \%$ & $23.01 \%$ & $-8.88 \%$ \\
\hline
\end{tabular}

Comparing the change on electricity prices (see Table 34), it seems that the average price change in case study $\mathrm{C}$ is small in comparison with case studies $\mathrm{A}$ and $\mathrm{B}$, at certain district sizes; however, the absolute change showed larger price changes, especially with the larger district sizes, that can be above $23 \%$. In other words, in case study $\mathrm{C}$ the price decrements 
have been more compensated with the prices increments, unlike the other cases that produced more decrements than increments on the electricity price. This effect can also be seen in the operation of the systems shown in section 5.3.2.

Table 35 shows the average changes in electric energy costs of the district (calculated with (73)). The savings in case study A were lower than in case study B for all district sizes, mainly caused by the higher average prices in case study B (see section 5.3.2). Regarding case study $C$, the average savings in electric energy costs for all district sizes were $64 \%$ approximately (see Table 35, right column). It is important to remark that, for all case studies, the electric energy cost reduction is greater for smaller number of clients and this amount decreases as the number of clients increases. This is caused, on the one hand, by the overall lower prices (produced with larger district sizes) that generate a lower profit for selling energy (for smaller districts, the price for selling energy is higher because less energy has been bought from the market and the adjustment of the RDC is smaller, see section 5.2.2). On the other hand, the benefit of buying energy at off-peak times reduces with flatter price curves (see section 5.3.2). Note that the savings in electricity costs might not be representative of the savings on total costs, as other aggregator costs (investment in DER systems, maintenance, etc.) must also be taken into account.

TABLE 35. EFFECT ON ELECTRIC ENERGY COST FOR ALL CASE STUDIES.

\begin{tabular}{cc|ccc}
$\begin{array}{c}\text { Number } \\
\text { of clients } \\
\text { (millions) }\end{array}$ & $\begin{array}{c}\text { Market } \\
\text { share }\end{array}$ & \multicolumn{3}{|c}{ Electric Energy Cost change (\%) } \\
\hline 0.04 & $0.076 \%$ & $-65.71 \%$ & $-84.92 \%$ & $-105.1 \%$ \\
0.1 & $0.19 \%$ & $-66.18 \%$ & $-92.48 \%$ & $-90.1 \%$ \\
0.2 & $0.38 \%$ & $-63.21 \%$ & $-88.19 \%$ & $-85.0 \%$ \\
0.4 & $0.76 \%$ & $-59.58 \%$ & $-84.06 \%$ & $-72.4 \%$ \\
1 & $1.9 \%$ & $-58.29 \%$ & $-78.71 \%$ & $-58.2 \%$ \\
2 & $3.8 \%$ & $-56.12 \%$ & $-75.40 \%$ & $-48.7 \%$ \\
4 & $7.6 \%$ & $-46.84 \%$ & $-60.92 \%$ & $-37.1 \%$ \\
8 & $15.2 \%$ & $-35.95 \%$ & $-45.95 \%$ & $-25.4 \%$
\end{tabular}

Indeed, the aggregator's actions in the market impact the electricity prices for the whole system (see Table 34), which affects the electricity costs of not only the DER owners but of the other market participants as well. Table 36 and Table 37 show the estimated electricity costs of all market participants in the Spanish system and the equivalent weighted average energy price (calculated with (70)), grouped in residential DER owners, normal residential clients (without DER) and industrial clients, and under the pricing scenarios of case study A (see section 5.2.2.1). These costs and average prices have been estimated, considering the approximate total demand shares per user types in Fig. 20 and taking average load profiles from real market data from [207] and [208]. From these tables, it can be seen that: 
- As expected, the prosumers managed by an aggregator present the largest energy costs reductions (up to 66\%) because the make an optimal use of their resources and of the hourly price fluctuations.

- The average decrease of energy prices caused by the aggregator's actions since less demand goes to the market (see Table 34), also benefit the other consumers in the system as they are buying cheaper energy (in average, up to 9.5\%), even if they do not change their consumption profiles.

- The benefits for the different type of clients is not the same, as each client has different energy use profiles. For instance, the industrial consumers achieve up to $8.88 \%$ reduction, which is around $1 \%$ less than the residential consumers without DER.

Note that this is a simple estimation, which has been made considering average values, and assuming that the other market players do not change their behaviour. Also, note that a more in depth analysis is not developed here, as it falls outside the scope of the thesis.

TABLE 36. IMPACTS OF ELECTRIC ENERGY COSTS FOR ALL MARKET PARTICIPANS (ENERGY PRICES OF CASE STUDY A)

\begin{tabular}{cc|cccc}
$\begin{array}{c}\text { Number } \\
\text { of clients } \\
\text { (millions) }\end{array}$ & $\begin{array}{c}\text { Market } \\
\text { share }\end{array}$ & \multicolumn{4}{|c}{ Average electricity costs change (M€/Year) } \\
\hline 0.04 & $0.076 \%$ & $-65.71 \%$ & $-0.054 \%$ & $-0.053 \%$ & $-0.06 \%$ \\
0.1 & $0.19 \%$ & $-66.18 \%$ & $-0.14 \%$ & $-0.14 \%$ & $-0.15 \%$ \\
0.2 & $0.38 \%$ & $-63.21 \%$ & $-0.27 \%$ & $-0.26 \%$ & $-0.27 \%$ \\
0.4 & $0.76 \%$ & $-59.58 \%$ & $-0.53 \%$ & $-0.51 \%$ & $-0.53 \%$ \\
1 & $1.9 \%$ & $-58.29 \%$ & $-1.26 \%$ & $-1.19 \%$ & $-1.23 \%$ \\
2 & $3.8 \%$ & $-56.12 \%$ & $-2.72 \%$ & $-2.58 \%$ & $-2.90 \%$ \\
4 & $7.6 \%$ & $-46.84 \%$ & $-5.14 \%$ & $-4.79 \%$ & $-5.74 \%$ \\
8 & $15.2 \%$ & $-35.95 \%$ & $-9.50 \%$ & $-8.88 \%$ & $-12.21 \%$ \\
& & & & & \\
& & & & & \\
DER & & & & \\
\end{tabular}


TABLE 37. AVERAGE WEIGHTED ENERGY PRICES FOR ALL MARKET PARTICIPANS (ENERGY

PRICES OF CASE STUDY A)

\begin{tabular}{cc|cccc}
$\begin{array}{c}\text { Number } \\
\text { of clients } \\
\text { (millions) }\end{array}$ & $\begin{array}{c}\text { Market } \\
\text { share }\end{array}$ & \multicolumn{4}{|c}{ Average weighted energy prices ( $€$ /MWh) } \\
& (\%) & Residential & Residential & & \\
DER & No DER & Industry & System \\
\hline & Original & 45.12 & 45.12 & 41.77 & 42.06 \\
0.04 & $0.076 \%$ & 37.69 & 45.10 & 41.74 & 42.03 \\
0.1 & $0.19 \%$ & 38.08 & 45.06 & 41.71 & 41.99 \\
0.2 & $0.38 \%$ & 38.28 & 45.00 & 41.66 & 41.93 \\
0.4 & $0.76 \%$ & 38.85 & 44.86 & 41.56 & 41.81 \\
1 & $1.9 \%$ & 40.35 & 44.55 & 41.27 & 41.49 \\
2 & $3.8 \%$ & 42.24 & 43.89 & 40.69 & 40.89 \\
4 & $7.6 \%$ & 43.75 & 42.80 & 39.76 & 39.99 \\
8 & $15.2 \%$ & 45.44 & 40.84 & 38.06 & 38.65
\end{tabular}

To further analyse the effect of the size of the aggregated resources, Table 38 shows the total costs (including energy and DER system costs) per house at the end of the project lifespan (20 years) for the different district sizes and its equivalent market shares.

TABLE 38. TOTAL COSTS PER HOUSEHOLD (INCLUDING DER INVESTMENTS).

\begin{tabular}{|c|c|c|c|c|}
\hline $\begin{array}{l}\text { Number of } \\
\text { clients } \\
\text { (millions) }\end{array}$ & $\begin{array}{c}\text { Market } \\
\text { share } \\
(\%)\end{array}$ & $\begin{array}{c}\text { Case study } \\
\begin{array}{c}\text { A } \\
(k €)\end{array}\end{array}$ & $\begin{array}{c}\text { Case study } \\
\text { B } \\
(\mathrm{k} €)\end{array}$ & $\begin{array}{c}\text { Case study } \\
\text { C } \\
(\mathrm{k} €)\end{array}$ \\
\hline 0.04 & $0.076 \%$ & 19.02 & 19.00 & 17.10 \\
\hline 0.1 & $0.19 \%$ & 18.24 & 18.70 & 16.37 \\
\hline 0.2 & $0.38 \%$ & 18.18 & 18.63 & 15.93 \\
\hline 0.4 & $0.76 \%$ & 18.19 & 18.60 & 15.41 \\
\hline 1 & $1.9 \%$ & 18.08 & 18.24 & 14.27 \\
\hline 2 & $3.8 \%$ & 18.10 & 18.29 & 14.29 \\
\hline 4 & $7.6 \%$ & 18.24 & 18.39 & 15.23 \\
\hline 8 & $15.2 \%$ & 18.42 & 18.65 & 16.42 \\
\hline
\end{tabular}

Case studies A and B had larger costs per household in comparison with case study C. This can be explained by the larger variability of prices on the stochastic scenarios, taking more advantage from DER systems and load shifting. The total system costs per house decreased as the number of aggregated resources increased (the aggregator had greater market share and a larger amount of manageable resources), up to a point when a minimum cost has been reached (around 1 - 2 million of clients), then the costs increased slightly. Once again, this phenomenon can be explained by the overall lower prices and flatter price curves, where 
the aggregator benefited from buying energy cheaper, but his income of selling energy has been affected at the same time (the price is cheaper and the income is lower). Hence, an optimal point has been achieved where the aggregator found the best compromise in costs and profits, as can be seen in Fig. 21.

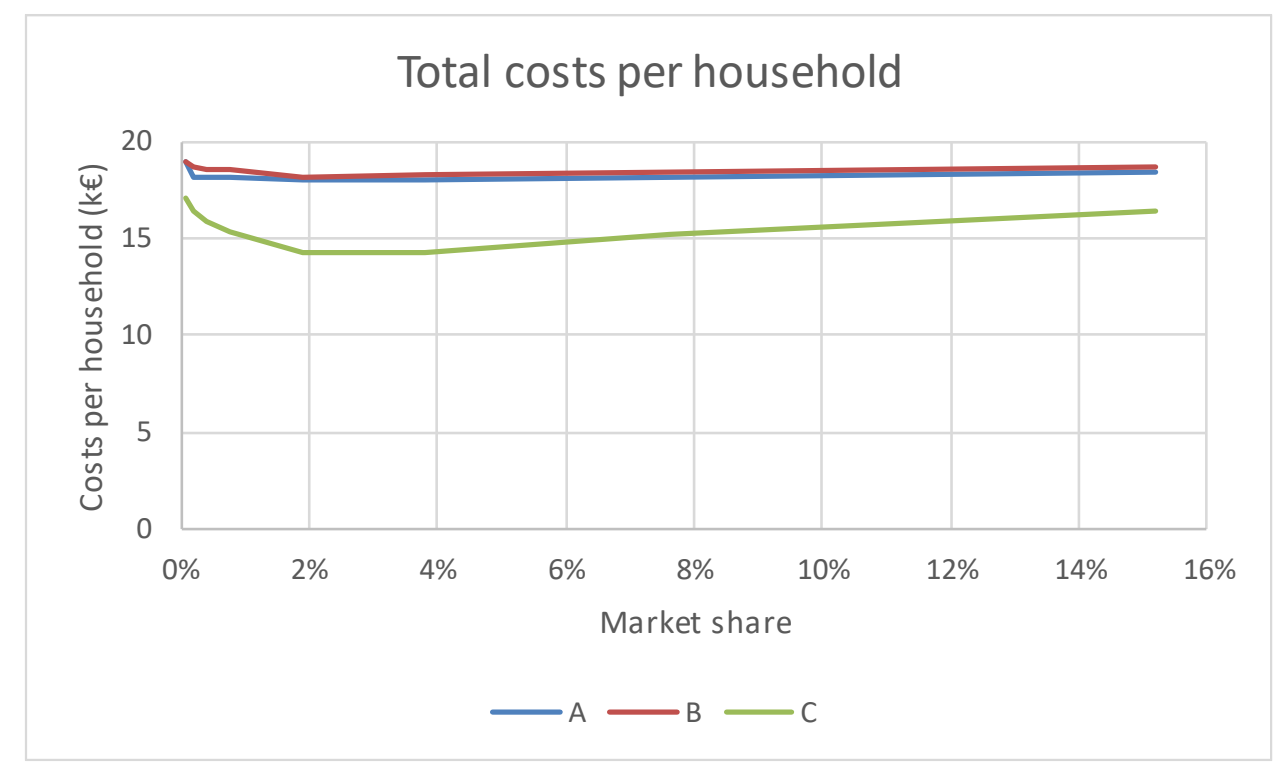

FIG. 21. TOTAL COSTS PER HOUSEHOLD (AT THE END OF THE 20 YEARS PROJECT LIFESPAN).

Additionally, the total costs of the proposed systems have been compared with a base case following a business-as-usual approach (not implementing any DER systems). The base case total cost has been calculated with (52) but with DER capacity and related costs equal to zero (the only terms considered are $v \operatorname{CostEE}, v \operatorname{CostET}, v \operatorname{CostPowE}$ and $v \operatorname{CostPowT}$ ). Hence, this comparison served to assess the benefits of the optimal management of loads and DER systems under different aggregation scales. To create a fair assessment, each case study has been compared with its own base case (equal input parameters) without implementing any distributed energy resources, as described in (74). The results of such comparisons can be found in Table 39 and have been illustrated in Fig. 22. It can be seen that, similarly to previous analysis, the profitability is maximum around a market share of $3-4 \%$, where the savings achieved are $31 \%, 28 \%$ and $40 \%$ for case studies A, B and C, respectively.

$$
\text { totalSavings }=\frac{\text { vTotalCostBaseCase }- \text { vTotalCostNew }}{\text { vTotalCostBaseCase }}
$$

The results presented in both Table 38 and Table 39 suggest that an aggregator can benefit significantly from participating in the market, even with a relatively small market share (less than 1\%). 
EACH CASE STUDY.

\begin{tabular}{|c|c|c|c|c|}
\hline $\begin{array}{c}\text { Number of } \\
\text { clients } \\
\text { (millions) }\end{array}$ & $\begin{array}{c}\text { Market } \\
\text { share } \\
(\%)\end{array}$ & $\begin{array}{c}\text { Case study } \\
\text { A } \\
\text { (\%) }\end{array}$ & $\begin{array}{c}\text { Case study } \\
\text { B } \\
(\%)\end{array}$ & $\begin{array}{c}\text { Case study } \\
\text { C } \\
(\%)\end{array}$ \\
\hline 0.04 & $0.076 \%$ & $27.9 \%$ & $24.8 \%$ & $27.5 \%$ \\
\hline 0.1 & $0.19 \%$ & $30.9 \%$ & $25.9 \%$ & $30.6 \%$ \\
\hline 0.2 & $0.38 \%$ & $31.1 \%$ & $26.2 \%$ & $32.5 \%$ \\
\hline 0.4 & $0.76 \%$ & $31.0 \%$ & $26.3 \%$ & $34.7 \%$ \\
\hline 1 & $1.9 \%$ & $31.5 \%$ & $27.8 \%$ & $39.5 \%$ \\
\hline 2 & $3.8 \%$ & $31.4 \%$ & $27.6 \%$ & $39.4 \%$ \\
\hline 4 & $7.6 \%$ & $30.9 \%$ & $27.1 \%$ & $35.5 \%$ \\
\hline 8 & $15.2 \%$ & $30.2 \%$ & $26.1 \%$ & $30.4 \%$ \\
\hline
\end{tabular}

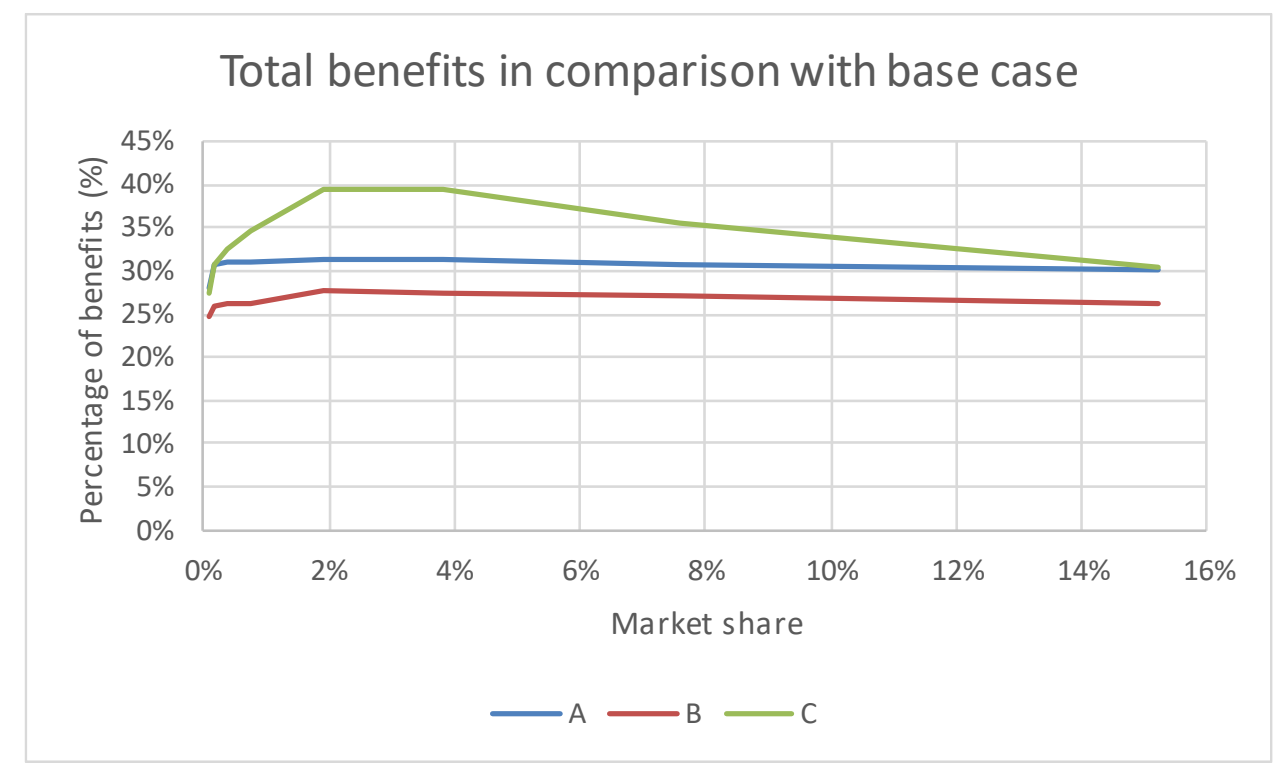

FIG. 22. PERCENTAGE OF ECONOMIC BENEFITS IN COMPARISON WITH THE BASE CASE.

Lastly, to analyse the effect of the volume of the aggregated resources, the total cost per client (taken from Table 38) at all district sizes has been compared with the cost at the smallest considered district, as in (75). This index shows more clearly the impact of market share into the final costs.

Table 40 summarizes such effects for the three case studies. It can be seen that the benefit can get up to $16 \%$ in costs savings with a market share of around $2 \%$ in case study $\mathrm{C}$. However, the deterministic cases did not show such a large benefit. This phenomenon occurred because the lower variability on prices in case studies A and B, provided less incentives to exercise market power and DER system management, having less overall DER installed capacity and less load shifting. Thus, adequately representing the price variability 
seems very relevant for more accurate results, that in addition, highlight the benefits of DER systems with respect to the business as usual alternative.

$$
\text { savingsPerClient }=\frac{v \text { CostClientSmallestDistrict }-v \text { CostClientNewDistrict }}{v \text { CostClientSmallestDistrict }}
$$

TABLE 40. PERCENTAGE OF SAVINGS PER HOUSE IN COMPARISON WITH THE SMALLEST

DISTRICT.

\begin{tabular}{|c|c|c|c|c|}
\hline $\begin{array}{l}\text { Number of } \\
\text { clients } \\
\text { (millions) }\end{array}$ & $\begin{array}{c}\text { Market } \\
\text { share } \\
(\%)\end{array}$ & $\begin{array}{c}\text { Case study } \\
\text { A } \\
(\%)\end{array}$ & $\begin{array}{c}\text { Case study } \\
\text { B } \\
(\%)\end{array}$ & $\begin{array}{c}\text { Case study } \\
\text { C } \\
(\%)\end{array}$ \\
\hline 0.04 & $0.076 \%$ & $0 \%$ & $0 \%$ & $0 \%$ \\
\hline 0.1 & $0.19 \%$ & $4.09 \%$ & $1.54 \%$ & $4.28 \%$ \\
\hline 0.2 & $0.38 \%$ & $4.41 \%$ & $1.92 \%$ & $6.83 \%$ \\
\hline 0.4 & $0.76 \%$ & $4.34 \%$ & $2.08 \%$ & $9.92 \%$ \\
\hline 1 & $1.9 \%$ & $4.92 \%$ & $3.99 \%$ & $16.57 \%$ \\
\hline 2 & $3.8 \%$ & $4.85 \%$ & $3.73 \%$ & $16.42 \%$ \\
\hline 4 & $7.6 \%$ & $4.11 \%$ & $3.16 \%$ & $10.93 \%$ \\
\hline 8 & $15.2 \%$ & $3.14 \%$ & $1.80 \%$ & $3.97 \%$ \\
\hline
\end{tabular}

\subsubsection{AGGREGATED SYSTEM BEHAVIOUR FOR ALL STUDY CASES}

The first model implemented is the deterministic one that considers the average residual demand curve of each hour of each day (Case study A). Fig. 23 and Fig. 24 show the electric energy transaction from the grid of the considered clients implementing DER systems (net demand from the grid, considering consumption, generation and management of resources) and its effect on electricity prices. For the sake of brevity, only two out of the twelve representative days have been shown (one for winter and one for summer), and three district sizes (which could be considered: small, medium and large, corresponding to sizes 40000,1000000 and 8000000 houses, respectively). For the winter day, the original energy price (blue line, Fig. 23) has lower prices in the early morning (off-peak time) and higher prices from $16 \mathrm{~h}$ to $24 \mathrm{~h}$ (peak time). As expected, it can be seen that the energy price changes more for the larger district (red line), and the price barely changes in the smaller district (see Fig. 23, the red line is over the blue line). 
a) $\mathbf{4 0}$ thousand houses

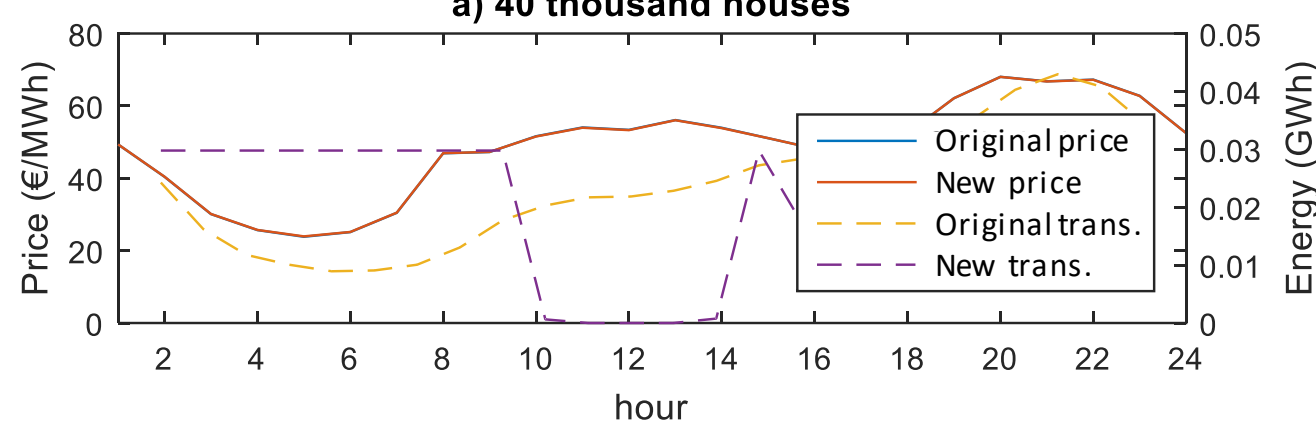

b) 1 million houses

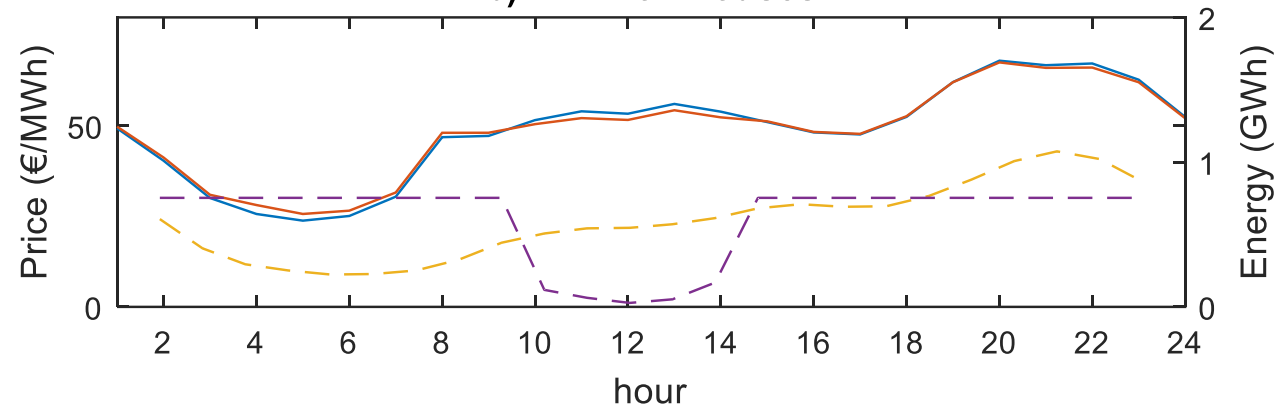

c) 8 million houses

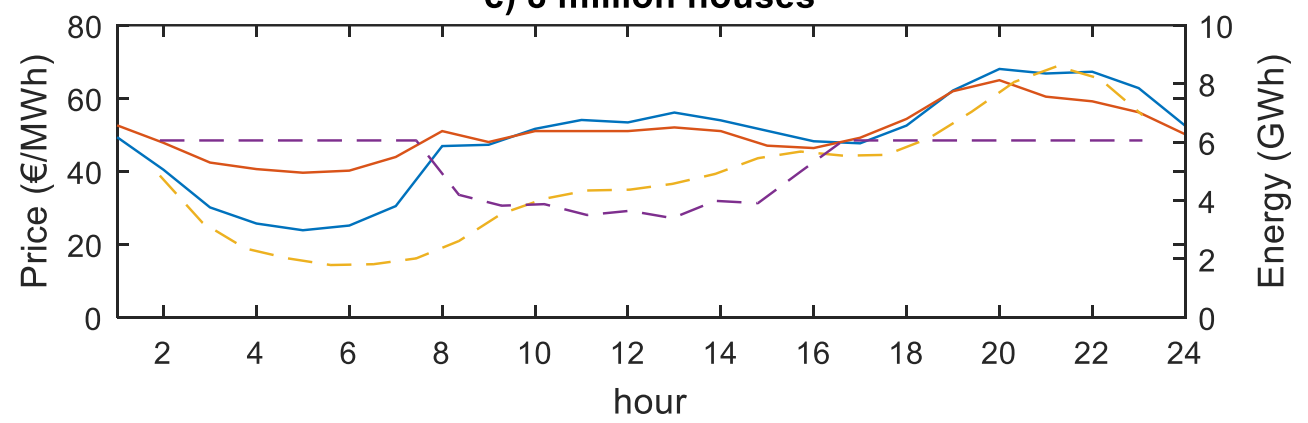

FIG. 23. AGGREGATOR ENERGY TRANSACTIONS AND EFFECT ON ENERGY PRICE FOR THE REPRESENTATIVE DAY OF JANUARY (CASE STUDY A), A) FOR 40000, B) 1000000 AND C) 8000000 HOUSES.

In the representative summer day, the original price curve (blue line, Fig. 24) is flatter than its equivalent at winter. However, the behaviour of the aggregator is similar, reducing energy transactions at the middle of the day thanks to the PV production (see the installed capacities in Table 32), and shifting load to such sunny hours. The new energy price (red line, Fig. 24) is lower, especially at the sunny hours (mainly $8-18 \mathrm{~h}$ ). 
a) $\mathbf{4 0}$ thousand houses

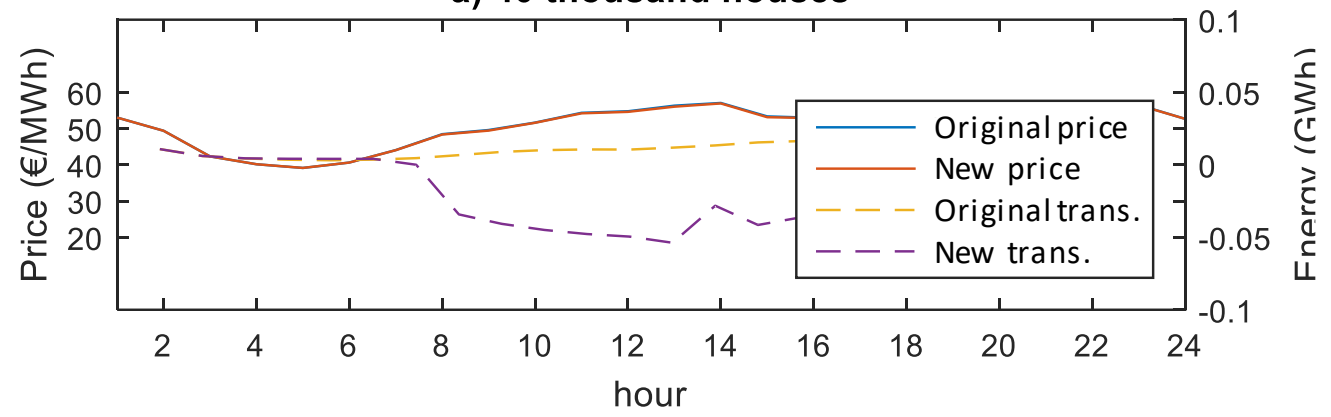

b) 1 million houses

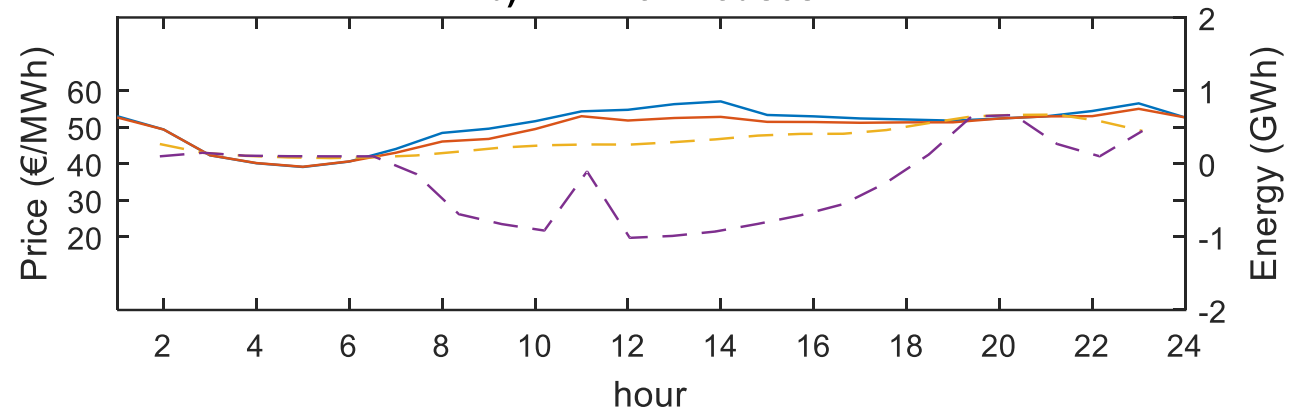

c) 8 million houses

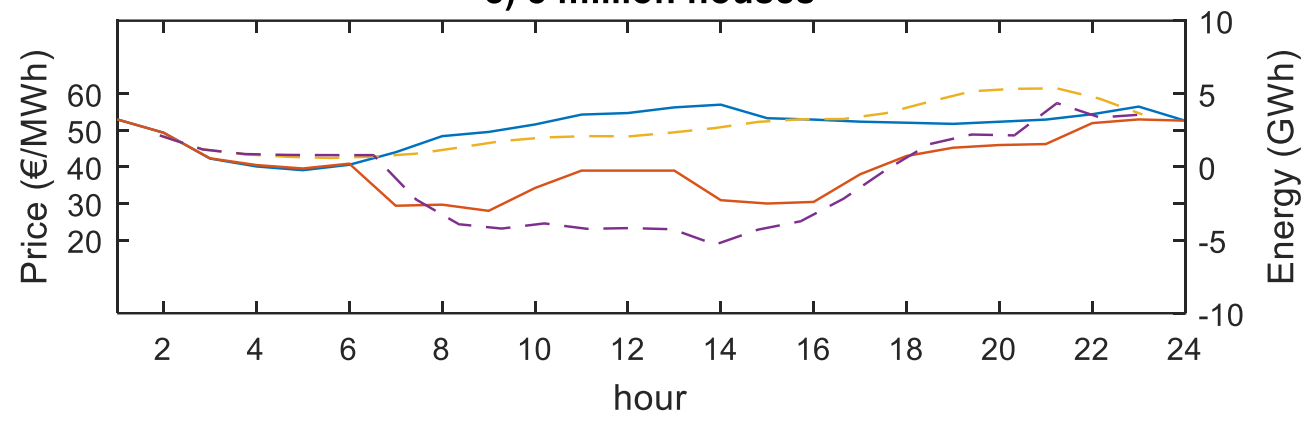

FIG. 24. AGGREGATOR ENERGY TRANSACTIONS AND EFFECT ON ENERGY PRICE FOR THE REPRESENTATIVE DAY OF JULY (CASE STUDY A), A) FOR 40000, B) 1000000 AND C) 8000000 HOUSES.

The behaviour of the aggregated systems for case study B is shown in Fig. 25 and Fig. 26. In this case study, it has been used the representative energy cost curve from the largest cluster out of the three computed at each hour.

The aggregator takes advantage of the larger difference between off-peak and peak time electricity prices (23-78€/MWh in Fig. 25, in comparison with $24-68 € / M W h$ of case A in Fig. 23), promoting more load shifting than in case study A. Moreover, the price at sunny hours is slightly higher in this case study (over $60 € / M W h$ at $14 \mathrm{~h}$ in Fig. 26, in comparison with $57 € / M W h$ at $14 \mathrm{~h}$ in Fig. 24), encouraging the aggregator to sell energy during such hours, especially in summer months as can be seen in Fig. 26. 
a) $\mathbf{4 0}$ thousand houses

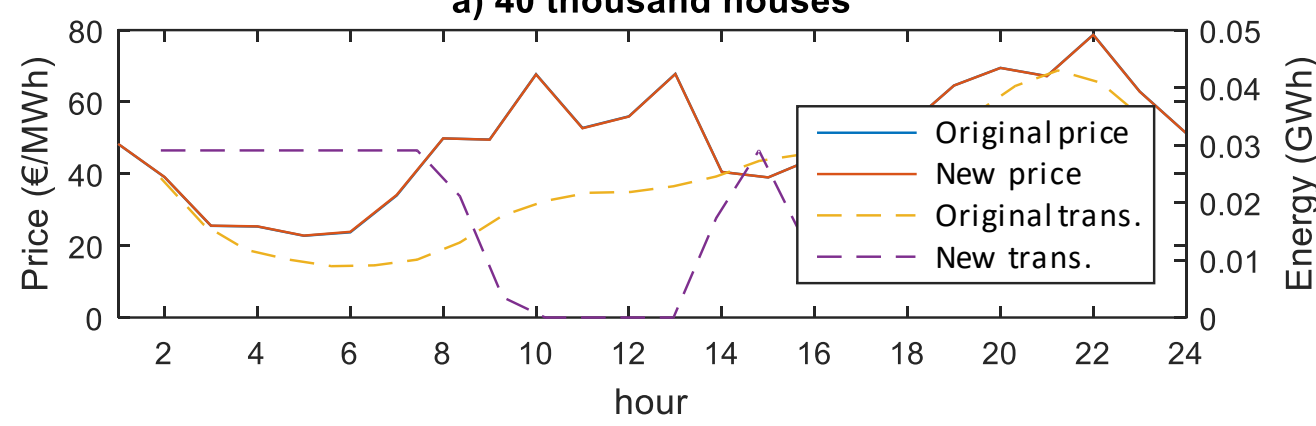

b) 1 million houses

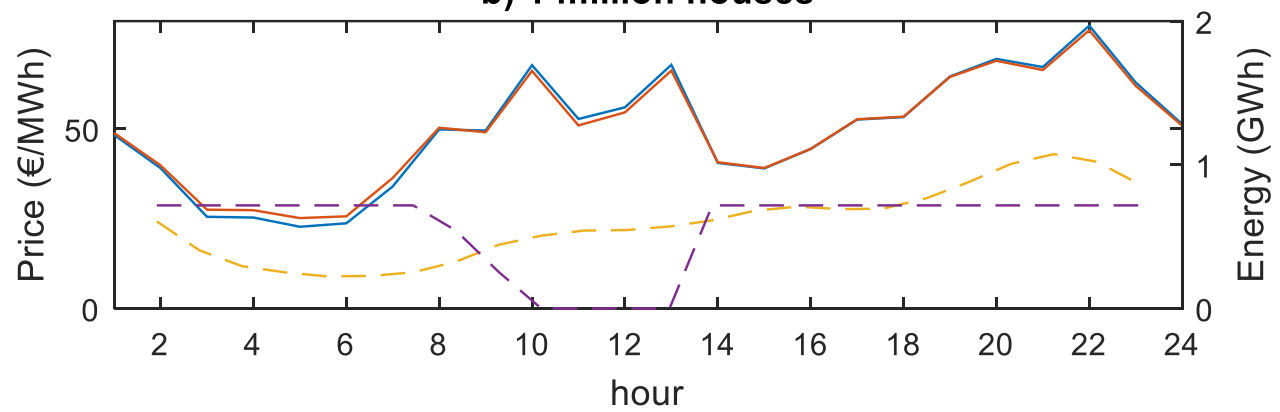

c) 8 million houses

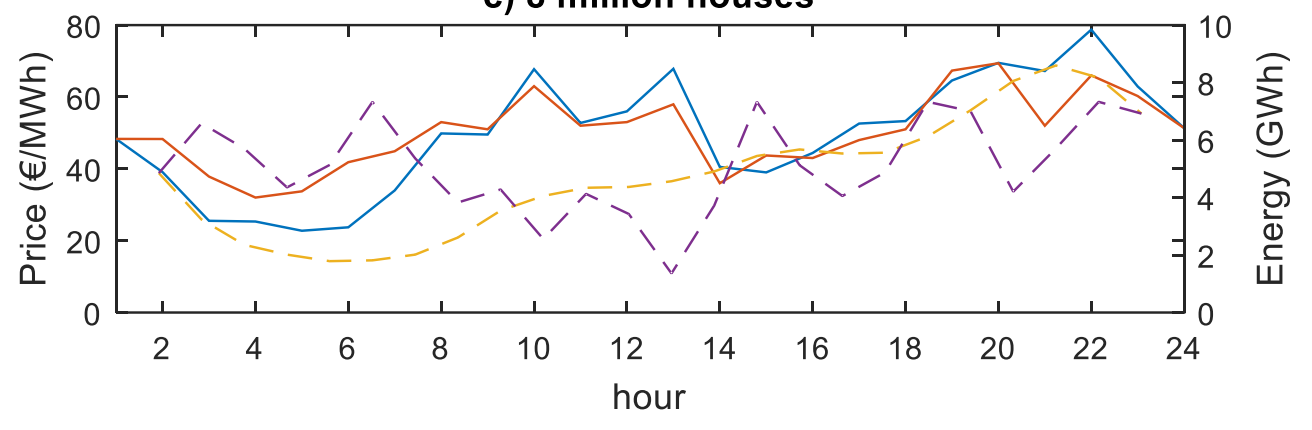

FIG. 25. AGGREGATOR ENERGY TRANSACTIONS AND EFFECT ON ENERGY PRICE FOR THE REPRESENTATIVE DAY OF JANUARY (CASE STUDY B), A) FOR 40000, B) 1000000 AND C) 8000000 HOUSES. 
a) $\mathbf{4 0}$ thousand houses

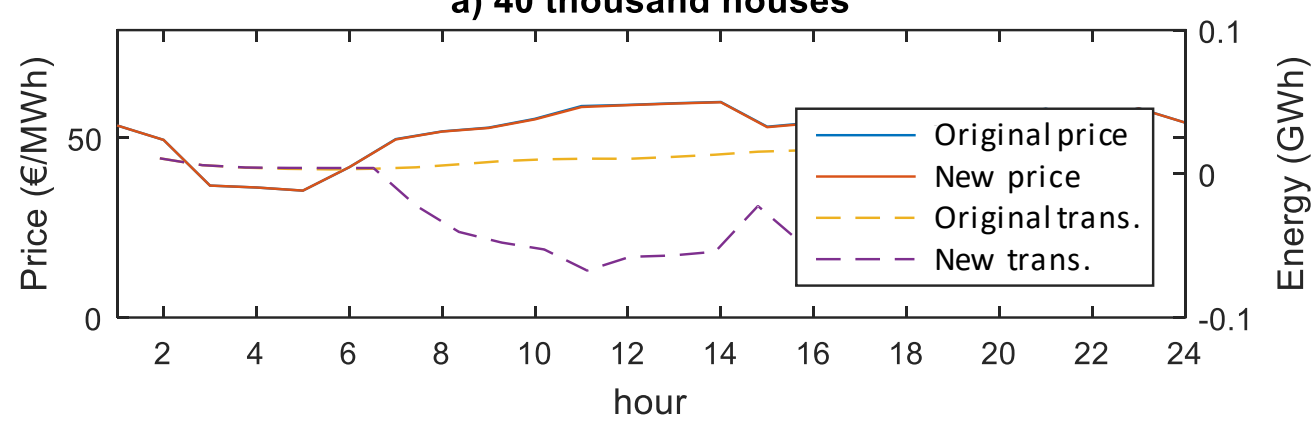

b) 1 million houses

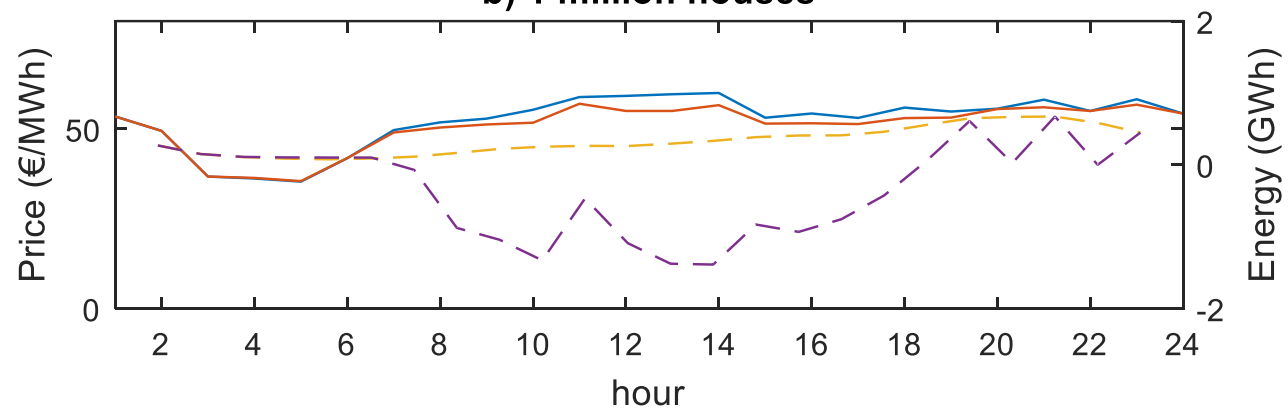

c) 8 million houses

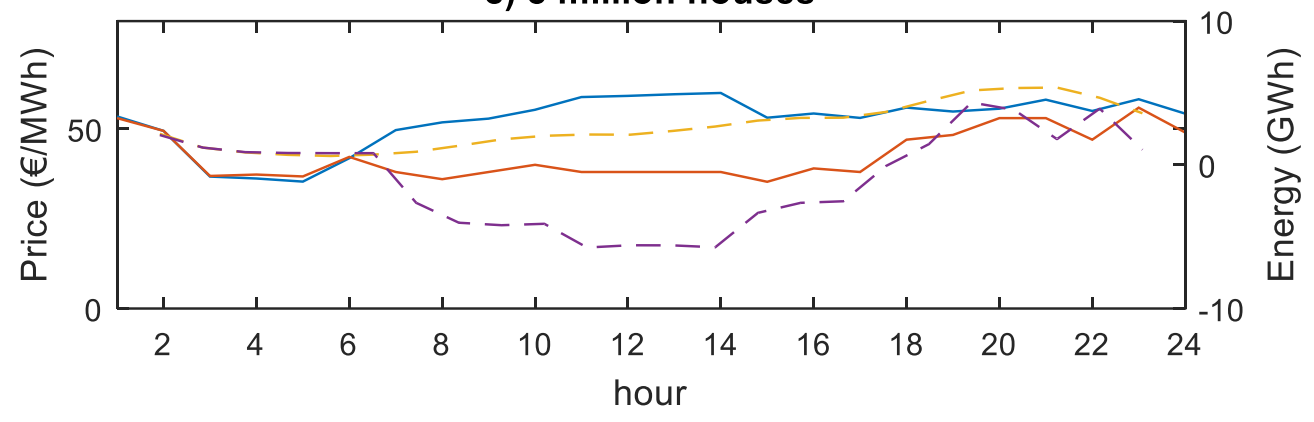

FIG. 26. AGGREGATOR ENERGY TRANSACTIONS AND EFFECT ON ENERGY PRICE FOR THE REPRESENTATIVE DAY OF JULY (CASE STUDY B), A) FOR 40000, B) 1000000 AND C) 8000000 HOUSES.

The third case study implements the stochastic model with 3 scenarios per hour. Fig. 27 shows the aggregator behaviour for the three scenarios at winter time for one million houses. The main characteristics of these scenarios are:

- The scenarios have even larger variability and price differences in comparison with previous case studies, with prices ranging from 0 to $80 € / \mathrm{MWh}$ approximately. Hence, the stochastic scenarios represent better the price range that is artificially reduced in the deterministic ones due to the averaging process (for instance, cases related to weekends are averaged out with the working days, reducing peaks and valleys in the price curves).

- The stochastic scenarios are synthetically formed using k-means clustering (see section 5.2.2), and even if they do not follow a certain predefined classification, they represent typical days. In other words, scenarios 1, 2 and 3, could represent days with "high", "medium" and "low" prices, respectively. 
- This price variability provokes the district to install more battery capacity in the stochastic case (see Table 32), so the aggregator can buy more energy at the early hours of the day with lower or even null prices, to store it and use it (or sell it) when prices are higher.

- The price variability also provokes more dynamic market behaviour in comparison to case studies A and B, with more energy buying and selling at different hours of the day. However, the main market strategy remains the same: buying energy when the prices are lower, and not buying energy (or even selling) in hours with high prices or with high solar production.

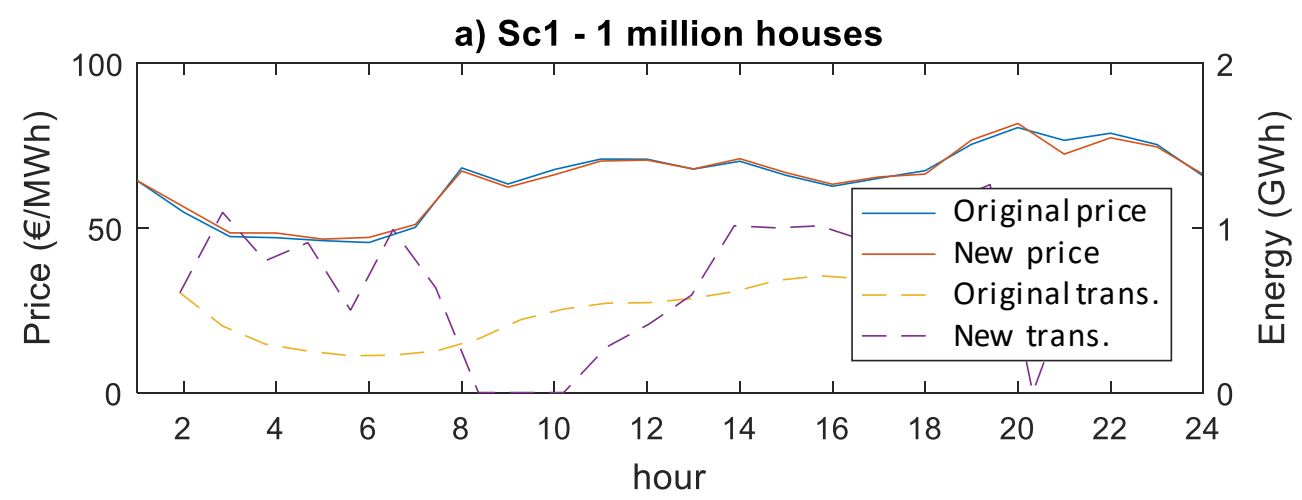

b) Sc2 - 1 million houses

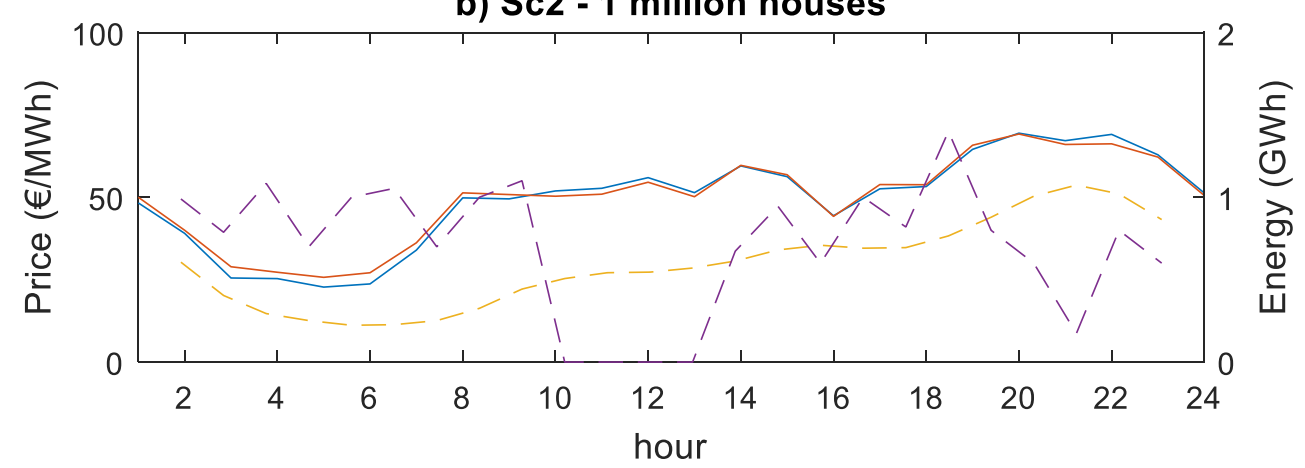

c) Sc3 - 1 million houses

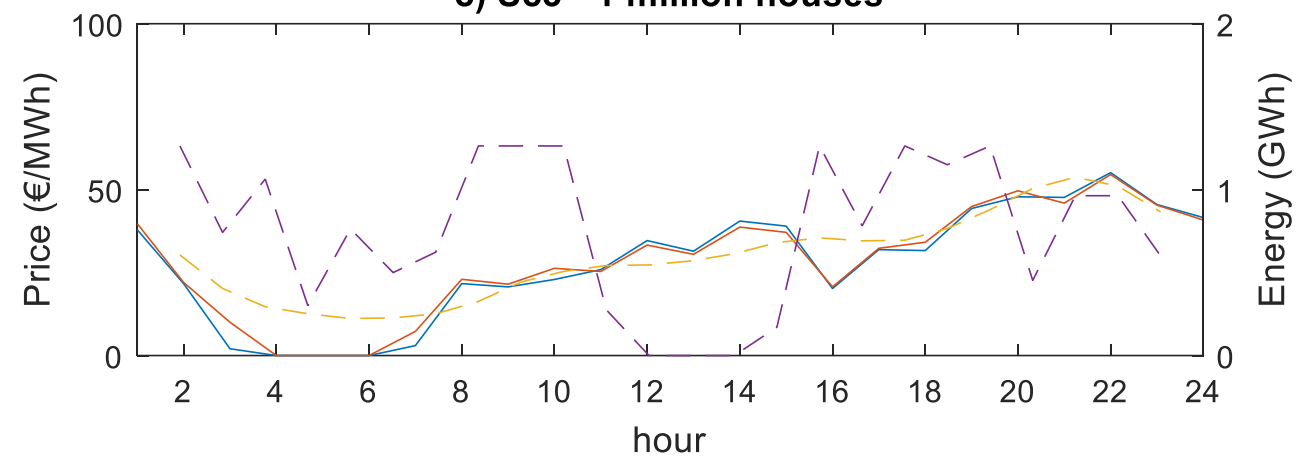

FIG. 27. AGGREGATOR ENERGY TRANSACTIONS AND EFFECT ON ENERGY PRICE FOR THE REPRESENTATIVE DAY OF JANUARY (CASE STUDY C), A) FOR SC1, B) SC2 AND C) SC3, ALL WITH 1000000 HOUSES. 
The aggregator operation on the representative summer day is depicted in Fig. 28, again with a district size of 1 million houses. The first figure (a) shows that the original price curve is flatter than in winter (see Fig. 27a), and thus, there is not much load shifting throughout the day and most of the energy produced by the PV systems has been sold back to the grid. Scenario 2 (Fig. 28b) presents a slightly larger variability in prices. This produces more load shifting and selling energy back to the grid when the electricity price is higher. Lastly, scenario 3 (c) has a slightly flatter price curve, and the aggregator strategy is similar than in scenario 1. It can be noted that the aggregator strategy overall tends to decrease the electricity price in summer time, by selling energy back to the grid.

a) Sc1 - 1 million houses

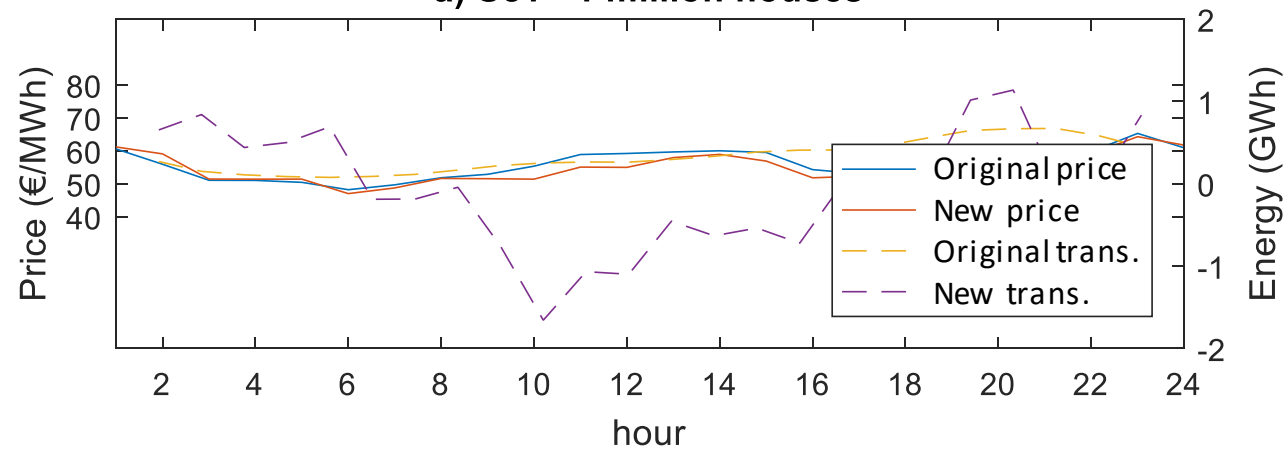

b) Sc2 - 1 million houses

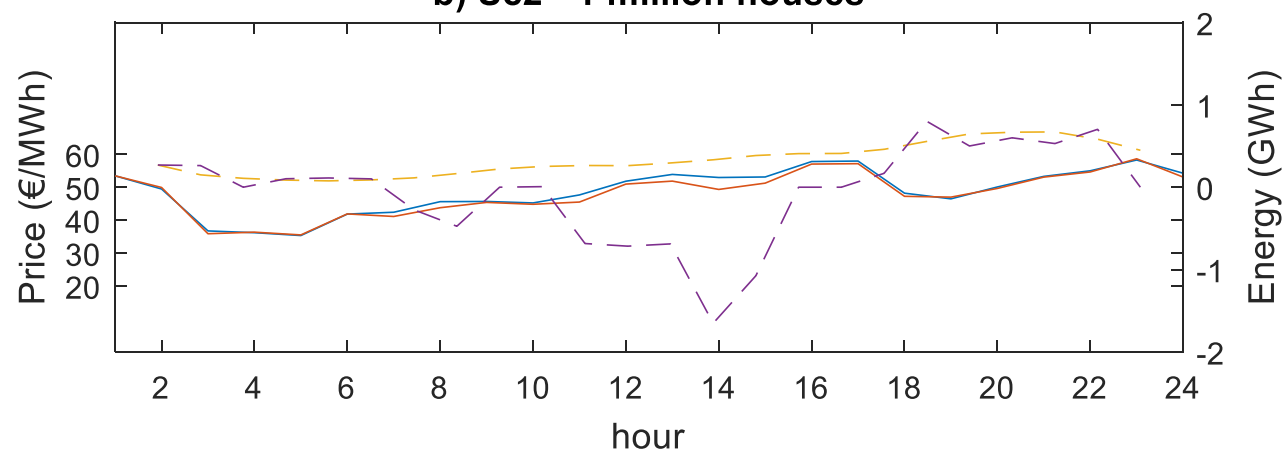

c) Sc3 - 1 million houses

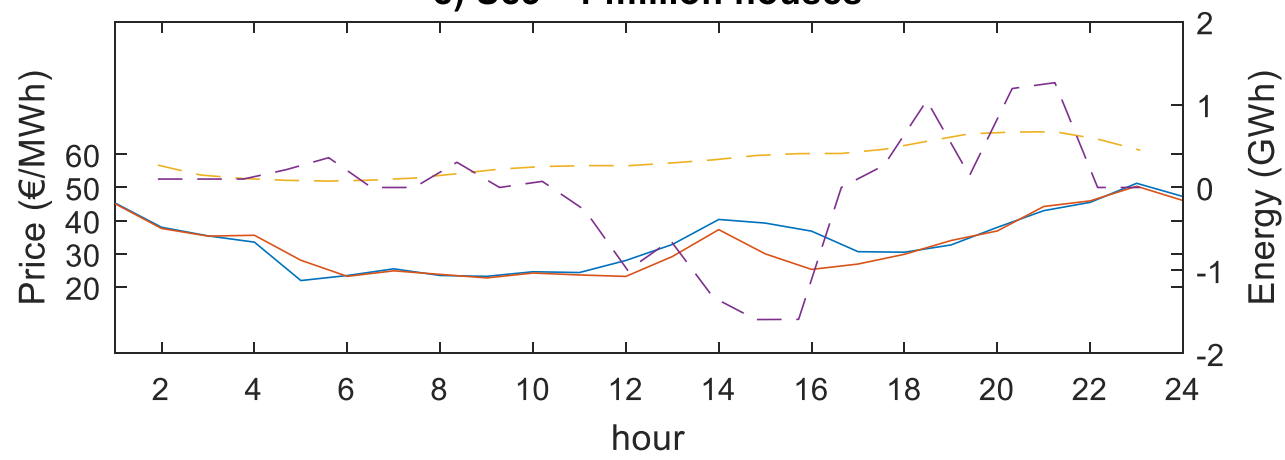

FIG. 28. AGGREGATOR ENERGY TRANSACTIONS AND EFFECT ON ENERGY PRICE FOR THE REPRESENTATIVE DAY OF JULY (CASE STUDY C), A) FOR SC1, B) SC2 AND C) SC3, ALL WITH 1000000 HOUSES. 


\subsubsection{Remarks and discussion of system operation}

As shown in the above figures, the aggregator behaves similarly in all case studies: on the one hand, it reduces the energy bought from the market at the middle of the day, when the PV production is larger; on the other hand, it shifts load from the peak hours to the off-peak ones, using the battery storage and/or the demand response strategy. This load shifting makes the electricity price curve flatter (red line), increasing the price of the off-peak hours (due to a greater demand) and decreasing the price at peak hours (due to a lower demand), with a net cost reduction for the aggregator. Since load shifting reduces prices variability, batteries are only installed when load shifting still allows for some prices differences that make battery investments profitable, and it can be seen that the price change increases with the amount of aggregated resources (up to $8 \%$ in average for the number of houses considered, see Table 34).

As mentioned before, the stochastic scenarios have been created using the k-means clustering technique (see section 5.2.2). These stochastic scenarios representing different types of days, reproduce better real prices, as well as their range and variability, which are artificially reduced in the deterministic cases due to the averaging process. Therefore, the energy transactions with the grid present more energy buying and selling throughout the day (see Fig. 27 and Fig. 28), taking advantage of the larger prices differences.

Lastly, it should be noted that the range of benefits and price changes obtained in this analysis are particular to the selected market data and energy systems considered. For instance, other markets with higher overall prices are likely to present larger benefits from DER systems aggregation (and vice versa). Also, other contexts with market profiles showing larger price differences between off-peak and peak times, could promote more load shifting and more battery capacity, so the results should not be taken as general to all energy systems. Nevertheless, the analysis developed provides insight on the best type of modelling approaches to be used according to the considered systems and aggregation size.

\subsection{CONCLUDING REMARKS}

This chapter presents two different optimization models corresponding to three different approaches (stochastic, deterministic with the average scenario and deterministic with the most likely scenario out of the stochastic ones) for planning and operating distributed energy resources managed by a price-maker aggregator, participating in the electricity market.

From the numerical results, it can be concluded that the aggregation of distributed energy resources can be very profitable for both aggregator and prosumers. With relatively small market shares (1\% - 2\%), the economic benefits of such approach can get up to $40 \%$ with respect to the case of not installing DER systems and managing load. It is important to remark that these economic benefits are for the aggregator or retailer participating in the market. However, it is sensible to consider that these benefits could be translated to a large extent to the final prosumer as well.

Indeed, the aggregator's price-maker approach is not commonly found in the literature, as it represents a more complex non-linear and/or mixed-integer problem to solve (mainly addressed by metaheuristic methods), and very often this approaches focuses on small aggregators. However, it can be seen in the analysis developed that the market price change 
is related to the size of the aggregator, and that this price change affects both the costs of buying energy and the profit of selling energy at a wholesale level. Therefore, even for relatively small aggregations, the impact on electricity prices can be relevant and is better to be considered in order to find optimal strategies.

Comparing the models presented in this chapter, the deterministic case studies proposed delivered similar results in the final costs. However, there is an important difference with the stochastic approach in both planning and overall costs. For instance, the stochastic model implemented battery systems for all district sizes and the deterministic models did not. These difference imply:

- That case study C presents lower costs because it represents the reality of energy prices better.

- Therefore, the planning of DER investments in case $\mathrm{C}$ is likely to be more adequate in real terms, than the planning of cases A and B.

- Also, it can be expected that the planning of case study $C$ will deliver in real life better economic benefits, in particular considering that it includes battery investments taking advantage of the larger price ranges and variability that can be found in real energy markets.

- Note that the extra economic benefit provided by the larger price variability is not seen in the scenarios of case studies A and B (due to the averaging made in the clustering process), showing the importance of the modelling approach taken and the relevance of adequately representing prices variability in the DER planning process.

Lastly, taking into account the results of the study developed in this chapter. It is sensible to consider a price-maker approach for the smart city energy model developed in this thesis. In addition, a stochastic model should be considered (even if the deterministic case is also included), as the planning results seems to be more robust and more adequate to obtain the maximum benefits in a real smart city implementation. 


\section{6}

\section{ANALYSIS OF SYNERGIES BETWEEN DER AND TRANSPORT SYSTEMS}

This chapter continues with the exploration of model considerations and restrictions task, corresponding to the smart city energy model methodology described in section 1.3. The study developed in this chapter focuses on hypothesis 3, related to the analysis of the synergies between DER systems and other energy systems such as transport, when they are interconnected and a joint management is carried out.

The highly interconnected and monitored environment of the smart city is explored, using a linear programming version of the smart city energy model, looking for synergies among systems such as different distributed energy resources and transports. This model has been formulated to find the optimal planning of distributed energy resources (DER) systems to supply generation and storage for a district with electric vehicles (EV). An electrical substation of the metro system is also modelled, and it is electrically connected to the district, so it becomes possible to store the metro regenerative braking energy into EVs' batteries to be used later for other trains or for the EVs themselves. Economic benefits of the interconnection of these systems is assessed and the impact of the EV penetration level is analysed. Therefore, the main contributions of this chapter are the assessment of synergies of the interconnection of these systems and the detailed analysis of the impact of different EV penetration levels. Outcomes of this study show important economic benefits for the overall system, especially reducing the metro energy costs, even with a relatively small numbers of EVs.

The contents of this chapter draws heavily from the journal article: C. F. Calvillo, A. SánchezMiralles, and J. Villar, "Synergies of Electric Urban Transport Systems and Distributed Energy Resources in Smart Cities," IEEE Transactions on Intelligent Transportation Systems, (accepted for publication). 
And from: C. F. Calvillo, A. Sánchez-Miralles, J. Villar, and F. Martín, "Impact of EV Penetration in the Interconnected Urban Environment of a Smart City," Energy, (under review).

\subsection{INTRODUCTION}

The smart city looks for new solutions to many urban challenges (environmental, social and economic) resulting from the interconnection, integrated optimization and operation of systems like transports, waste and energy management, to profit from its potential synergies. However, these synergies are not always evident and should be investigated to obtain the maximum benefit [10]. As mentioned in the methodological proposal of 1.3, this chapter tries to provide insight on the potential synergies between different energy systems in an interconnected smart city environment.

Fast, efficient and clean mobility and transport systems inside cities are one of the main challenges commonly addressed by local governments, due to the large energy requirements and the significant impact on air pollution and other associated externalities (such as health costs) [105]. With the aim of cleaner and more efficient transport systems, alternatives to conventional transport systems are being investigated and promoted [131]. Among these alternatives, electric vehicles (EV) are one of the most popular and have deserved many research efforts. For example, EV charging strategies have been addressed in [64], where a review of smart charging systems is presented, the use of EVs as storage has been addressed in [69] and [68], or its impact on the grid and its use as a tool to foster the introduction of renewable energy in [219] and [65].

Many approaches to mobility look for increasing efficiency in current transport systems. For example, efficiency on urban rail systems has been object of many efforts and has been commonly addressed in the literature. In this context, a review of energy efficiency solutions has been presented in [122], identifying five main groups of action: traction efficiency, efficient driving, comfort functions, regenerative braking, and smart measurement and management.

From the urban rail systems, the metro (metropolitan trains) is one of the most used. Considering the numerous and frequent stops of the metro trains, regenerative braking can potentially provide important energy savings [58]. To maximize the use of braking energy, three main strategies have been commonly proposed. The first one is the optimal design of the train schedules to synchronize the braking of trains arriving to a station with the departing of other trains within the same electrical sections, allowing accelerating trains to use the braking recovered energy without the need of storage. An example of this solution has been presented in [135], where a programming problem has been proposed to find an optimal schedule in a real metro system application. The second approach consists in using energy storage systems to store the braking energy. This solution has the benefit of not needing complex train synchronization, maximizing the energy recovery, but has higher costs due to the extra storage infrastructure. The main storage technologies for both onboard and wayside applications have been reviewed in [58]. Lastly, the third approach consists in using reversible substations able to return the braking energy back to the grid. An example of this solution can be found in [220]. 
The connection of transport systems with urban districts and distributed energy resources has been barely addressed in the literature. Some pilot projects such as [123] have proven possible the connection metro-EV, motivating further research on this and other similar schemes. Hence, one of the main contributions of the study developed in this chapter is the quantitative analysis of the synergies and economic benefits of an interconnected urban environment with distributed energy resources (DER), private electric vehicles and electric public transport (metro). In addition to the assessment of impacts of the EV penetration level and the district load size. This analysis provides insight on the potential synergies of these systems, suggesting new possibilities of coordinated management on smart city environments.

A linear programming version of the smart city energy model (described in section 3) has been proposed for this analysis, modelling a residential district with different energy load curves and DER systems, such as PV panels, air-source heat pumps, stationary batteries and demand response systems. A set of EVs with different daily usage patterns, and the regenerative braking and electric energy consumption of metro trains connected to an electrical substation have also been modelled. The residential area selected is a real Madrilenian district where typical residential load profiles have been considered. Consumption and generation profiles of metro trains have been estimated using average values of real train data (taken from [221]) and approximated distances and trip times of Madrid's metro. PV production has been calculated using typical solar irradiation values of Madrid, and Spanish residential and commercial energy tariffs have been used. The outcomes of the model include the optimal investment planning and operation of the DER systems, according to the metro running patterns and EV usage profiles. Economic benefits in energy and power costs have also been assessed for both the metro substation and the residential district considered.

Three main analyses are carried out in this chapter:

1. The assessment of the synergies of the systems considered, including an analysis of the share of economic benefits between the participants.

2. The analysis of impacts on the DER planning process, according to district size and number of EVs.

3. The assessment of the effects of large EV penetration levels, looking for the EV saturation point at which the system does not benefit further with more EV storage.

For the first analysis, and to assess independently the importance of the connection EVmetro and the implementation of DER systems, four case studies are analysed.

- A base case with independent metro and EV operation, and district loads without DER.

- A second case optimizing EVs and metro together but still no DER.

- A third case implementing DER systems but optimizing separately metro and EVs, removing their electrical connection.

- Lastly, the complete case that optimizes metro and EVs, together, and computes the optimal DER systems investments. 
The second analysis consist in the assessment of synergies of the systems considered depending on the district size and on the number of EVs, focusing on the impacts on DER planning and operation. Considering the complete model with DER and the EV-metro connection, three different district sizes and five different numbers of EVs are analysed.

The third analysis consists in the assessment of the impact of large EV penetration levels, looking for the EV saturation point at which the system does not benefit further with more EV storage. In addition, the effect on DER investments and the share of economic benefits between the participants has been discussed.

\subsubsection{MODIFICATIONS OF THE SMART CITY ENERGY MODEL FOR THIS ANALYSIS}

The version of the smart city energy model used in this analysis follows the description of the smart city energy model made in chapter 3 . The model includes the electric substation of a metro electrical section connected to the grid, supplying energy to the trains and other metro related systems. The substation is also connected to the parking where EVs can be parked and used as storage for regenerated braking energy. The parking is also connected to the grid and to an energy district. This district represents a neighbourhood or an area of the city with household loads and DER systems. Note that the elements forming this metroEV connection are considered to be already implemented in the system, and thus, they are not explicitly modelled in the optimisation problem.

The block diagram of the model is shown in Fig. 29. Black lines represent electric energy connections and the arrows illustrate the energy flow directions. Blue squares represent loads or generators, the three interconnected systems are the brown squares, and the electric grid is represented as a red square. This general model can be particularized for several case studies by combining the possibility of not implementing DER systems (deleting (2) in Fig. 29), separately optimizing EVs and metro operation (removing connection (1) in Fig. 29), or limiting the energy transfer between the metro and EV (constraining the connection (1) in Fig. 29). The linear programming model proposed, includes the constraints described in sections 3.2.1, 3.2.2, 3.2.3, 3.2.4, 3.2.5 and 3.2.6.

It is important to remark that the number of houses at the district, the number of EVs and the load profiles of the metro are inputs to the model (see section 6.2 for a more detailed description of these input parameters), whereas the operation schedule of these systems and the DER capacity planning are output variables, obtained from the optimisation problem. 


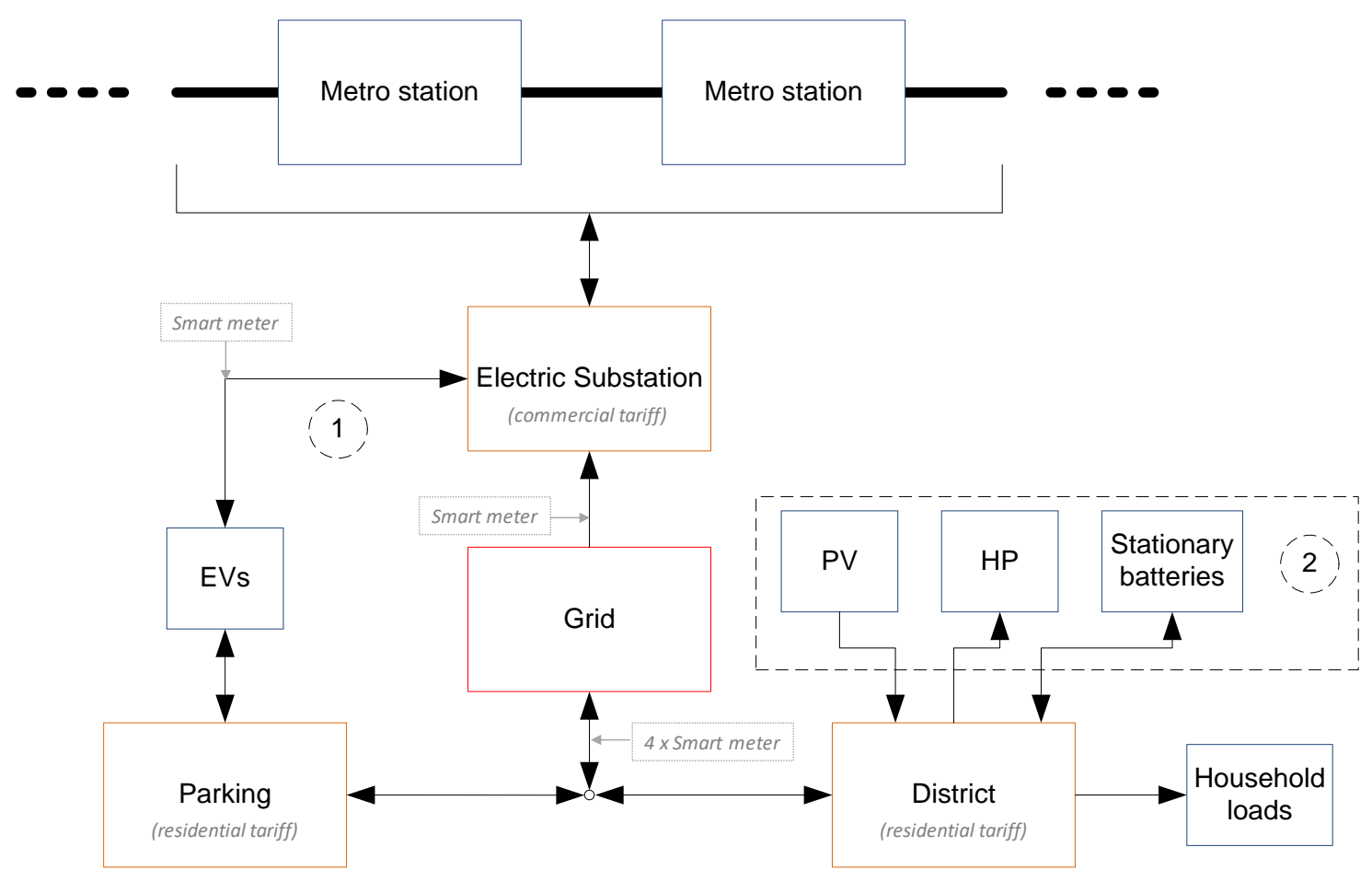

FIG. 29. BLOCK DIAGRAM OF THE PROPOSED SYSTEM.

The particular assumptions and considerations for the analysis in this chapter are summarized below:

- Similar to the analysis in chapter 5, the residential loads at the district have been modelled with 4 different consumption profiles representing typical residential clients in Spain. These profiles have been selected with the objective of replicating a Spanish city context (see section 5.2.1).

- The EV availability profiles have been based in two types of users: residents and visitors, which share the use of the selected parking lot (see section 6.2.2 for more details on the EV parameters).

- The metro system has been modelled taking into account metro de Madrid's trip times, according to current metro schedules, and using average energy consumption per distance and trip time values from [221] (see section 6.2.1 for more details on the metro modelling parameters). Note that, due to data availability and confidentiality issues, it has not been possible to compute a more accurate approximation of the metro energy profiles. However, we believe that the approximation developed can provide valuable insight on the potential synergies with other systems. Moreover, to analyse the impact of different metro energy values and to discuss the applicability of these results on other contexts, a simplified sensitivity analysis has been developed in section 6.3.2.1.

- The considered systems and the electrical connections of this setup are shown in Fig. 29 (connections represented with black lines, and the arrows show the energy flow directions).

- The district clients and EV drivers use a conventional time-of-use residential tariff, with an energy and a power cost component (see section 6.2.4 for more details on this tariff). Similar to previous case studies, these types of tariffs have been selected 
as they are commonly found in the Spanish context, aligning with the objective of replicating a Spanish smart city.

- It has been considered that the metro system uses a time-of-use commercial tariff with three time periods: peak, mid-peak and off-peak. Unfortunately, there is no publicly available data on Metro de Madrid's energy transactions. Therefore, this commercial tariff has been selected as it is designed for small industries and enterprises in Spain, using similar amounts of energy (see section 6.2.4 for more details on this tariff).

- There are 6 energy meters in this setup, four for the district (one per residential client type) and the parking lot, one for the metro electrical substation, and one for the connection between the EV's and the metro system (see Fig. 29). The location of these meters is relevant for monitoring purposes, and to charge the energy use of the different systems with the adequate tariff.

- HP, PV and Batteries are the only DER resources considered, in addition to demand response.

\subsection{CASE STUDY DESCRIPTION AND PARAMETERS}

\subsubsection{SUBSTATION ENERGY PROFILES}

Line 3 of Metro de Madrid has been selected for this study due to its high passenger load [222]. It has 18 metro stations served by 6 electrical substations [135], [223]. Since substation's exact location is not publicly available, it has been assumed that they are uniformly located throughout the metro line, i.e. one substation every three metro stations. In this study, a section of metro line 3 (starting from Villaverde Alto to Ciudad de los Ángeles stations, see Fig. 30 taken from [224, p. 3]) has been selected due to its proximity to residential districts and public parking. It is also assumed that one substation at the beginning of metro line 3 serves energy to Villaverde Alto, San Cristóbal, Villaverde BajoCruce, and partly to the Ciudad de los Ángeles stations, where a second substation is likely to be located.

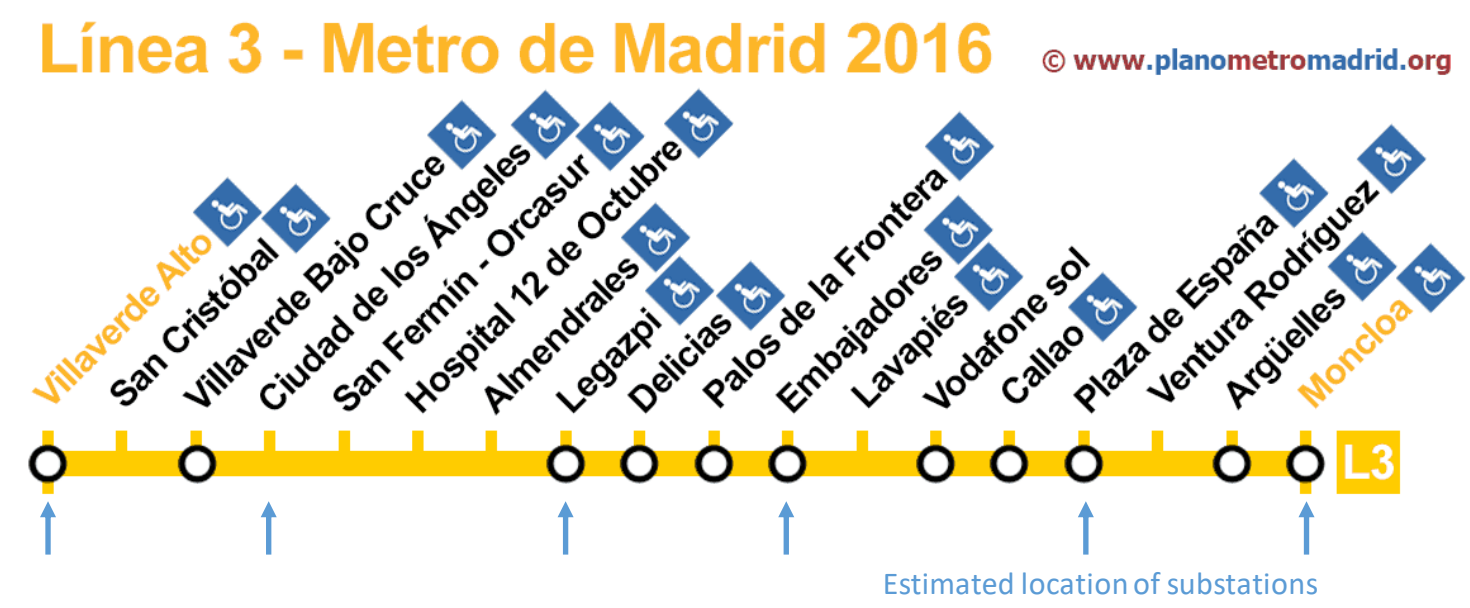

FIG. 30. STATION PLAN OF MADRID'S METRO LINE 3.

Using the metro line 3 interstation distances (estimated with google maps, [133]) and trip times (taken from current metro schedules, [225]), and considering the average energy 
consumption per distance and per trip time values from [221], the train traction energy has been calculated for the selected section of metro line 3. The regenerative braking energy has been computed considering that only $1 / 3$ of the train traction energy can be reused [58], and the total electric load of the train has been calculated by adding $20 \%$ of traction energy for the non-traction loads (illumination, ventilation, opening and closing doors, etc.) [58].

Table 41 shows the energy usage and regenerated braking energy obtained by the trains operating between Villaverde Alto and Ciudad de los Ángeles stations (including the nontraction energy). It has been considered that the same energy is required in both directions. Moreover, catenary lines of the trains are normally connected to two electrical substations, and the energy to feed the train can come from both. Unfortunately, since detailed information on tracks and electrical connections is not available, it has been considered that the energy required by the trains is equally shared between the two substations.

TABLE 41. CONSUMED AND REGENERATED ENERGY PER TRAIN AND JOURNEY, BETWEEN THE VILLAVERDE ALTO AND C. DE LOS ANGELES METRO STATIONS.

\begin{tabular}{c|ccc} 
& Traction & Non-traction & Total \\
\hline $\begin{array}{c}\text { Consumed energy (kWh) } \\
\begin{array}{c}\text { Regenerated energy } \\
(\mathrm{kWh})\end{array}\end{array}$ & 45 & 9 & 54 \\
& 15 & - & 15
\end{tabular}

It is important to remark that the usable regenerated energy can be used for different purposes. For instance, it can be used when possible to supply to other departing trains or for other non-traction loads both in the trains and stations. According to the analysis developed in [226], it has been considered that from all the usable energy $43 \%$ goes to other trains and station loads, $50 \%$ to the external EV systems, and $7 \%$ to additional electrical losses.

Metro systems are normally scheduled either following a timetable or in time intervals (a train passes through a station every certain amount of time). Metro de Madrid implements time intervals, whose length depends on the day of the week and the hour. Considering the average time intervals of metro line 3 during a standard weekday (Monday to Thursday) provided in [225], Fig. 31 shows the computed energy profiles for the selected electrical substation, taking into account the energy values of Table 41, and the considerations previously discussed. It also takes into account the considerations of the regenerated energy distribution mentioned before. Hence, in Fig. 31, the total required energy includes traction and non-traction loads of the trains, the net required energy is equal to the total required energy minus $43 \%$ of the regenerated energy, the usable regenerative energy is computed as $1 / 3$ of the trains' traction energy minus $7 \%$ of losses, and the regenerative energy to EVs is $50 \%$ of the total regenerated energy. 


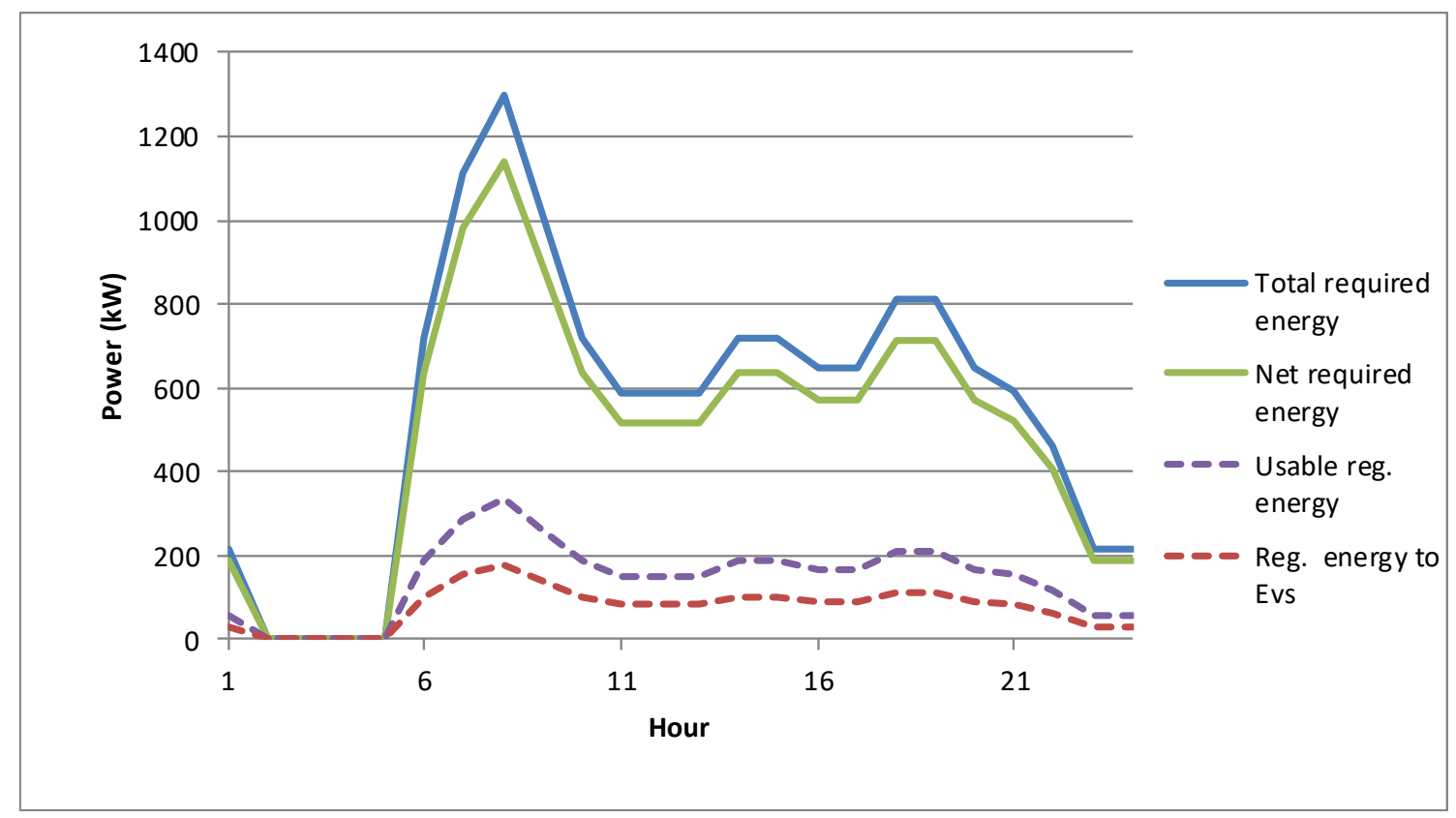

FIG. 31. VILLAVERDE ALTO SUBSTATION ELECTRIC ENERGY PROFILES.

\subsubsection{EV AVAILABILITY}

Villaverde district has 5 public parking lots for residents [227]. Among them, San Aureliano has been selected as the parking for EVs due to its relatively large capacity (194 parking spots) and its proximity to the electrical substation chosen for this study.

The normal practice in a Madrilenian residential neighbourhood during the week days is that the residents leave to work in the morning, around $6 \mathrm{~h} 00-8 \mathrm{~h} 00$, and come back home around $17 \mathrm{~h} 00-19 \mathrm{~h} 00$. It is also common that many people living in suburbs away of the city centre arrive in their cars to parking lots close to metro or commuter train stations, occupying the residents' empty places, and continue their journey in public transport systems. Therefore, both EV users, district residents and visitors, have been modelled (see Fig. 32). Residents' EVs are fully available as storage systems until $5 \mathrm{~h} 00$ when they start to move to work, causing a slow decrease in EV storage availability. Conversely, the visitors start to arrive to the parking at $6 \mathrm{~h} 00$ and leave from $16 \mathrm{~h} 00$, liberating the places for the residents. Following the recommendations given by most manufacturers to extend battery life [228], it has been established a minimum SOC of $20 \%$ at all times the car is parked, and complying with the requirement of EV users, a minimum SOC of $80 \%$ has been set for the time the car leaves the parking. It has been also considered that the EV arrives to the parking with a SOC level of $40 \%$ (i.e. the energy required for the journey is $40 \%$ of the total $\mathrm{EV}$ capacity) [229], [230]. It has been considered that the total storage capacity of each EV is 19 $\mathrm{kWh}[231]$. 


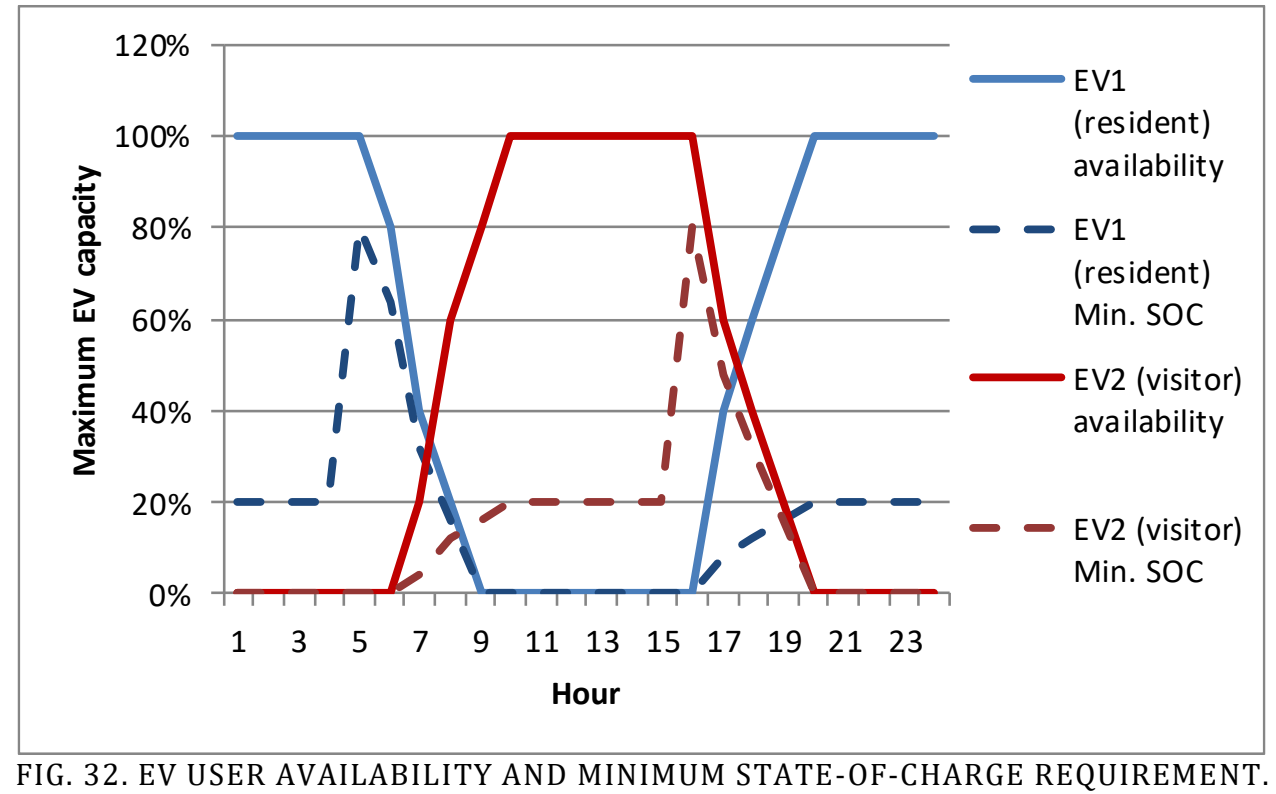

\subsubsection{DER CHARACTERISTICS AND DISTRICT ENERGY PROFILES}

The distributed energy resources considered for the district (apart from the EV) are photovoltaic (PV) panels, air-source heat pump (HP), stationary batteries and demand response systems. These systems have been modelled with the same parameters and considerations described in section 5.2.1 (see Table 31), and for the sake of brevity, they are not repeated here.

Similarly, it is considered in this study that the residential customers at the district follow the same energy consumption behaviour of the four types of residential clients described in section 5.2.1 (see Fig. 12 - in Fig. 14 and Table 29).

\subsubsection{ENERGY PRICE PARAMETERS}

A time-of-use tariff has been used for the households' electricity consumption including EV charging, while thermal energy has been priced with a static tariff. Table 42 presents the energy tariffs selected (from [232], [233]). It has been assumed that the prosumer can sell electricity back to the grid at a fixed price of $0.0421 € / \mathrm{kWh}$, ignoring the network costs and the time discrimination. In other words, this sell price is calculated considering that approximately $40 \%$ of the electricity tariff correspond to energy costs and the rest goes to taxes and network costs [234]. So, the assumed sell price corresponds only to the value of the energy sold and not to network costs or taxes. 
TABLE 42. RESIDENTIAL ENERGY TARIFFS AND TIME SCHEDULES.

\begin{tabular}{c|ccc} 
& Peak & Mid-peak & Off-peak \\
\hline Electric energy $(€ / \mathrm{kWh})$ & 0.1632 & 0.0843 & 0.0564 \\
Electric Power $(€ / \mathrm{kW})$ & & 49.28617 & \\
Time schedule & $13-23 \mathrm{~h}$ & $7-13,23-1 \mathrm{~h}$ & $1-7 \mathrm{~h}$ \\
\hline Natural gas variable $(€ / \mathrm{kWh})$ & & 0.0568 & \\
Natural gas fixed $(€ /$ year $)$ & & 52.32 &
\end{tabular}

Detailed information of Metro de Madrid energy transactions is not publicly available. However, reference [235] shows an example of a contract between Metro de Madrid and two Spanish retailers buying electric energy at prices ranging from 0.08 to $0.10 € / \mathrm{kWh}$. Therefore, it seems sensible to consider that the metro has a commercial high voltage tariff, like the one presented in [232], with a time-of-use discrimination for both energy and power, and different time schedules for winter and summer months. Table 43 summarizes the selected tariff values for the metro system.

TABLE 43. METRO ENERGY TARIFFS AND TIME SCHEDULES.

\begin{tabular}{c|ccc} 
& Peak & Mid-peak & Off-peak \\
\hline Energy $(€ / \mathrm{kWh})$ & 0.126623 & 0.109203 & 0.080358 \\
Power $(€ / \mathrm{kW})$ & 59.47529 & 36.67681 & 8.410411 \\
Schedule winter & $17-23 \mathrm{~h}$ & $8-17 \mathrm{~h} \& 23 \mathrm{~h}$ & $0-8 \mathrm{~h}$ \\
Schedule summer & $10-16 \mathrm{~h}$ & $8-10 \mathrm{~h} \& 16-0 \mathrm{~h}$ & $0-8 \mathrm{~h}$
\end{tabular}

\subsubsection{CASE STUDIES DESCRIPTION}

For the sake of clarity, the case studies have been labelled with the abbreviation CS for Case Study, a sub-index that refers to the number of houses per house type considered in the district, and a second sub-index with three letters that refers to the selected options. Upper case $\mathbf{D}$ stands for DER systems installation, while lower case $\mathbf{d}$ stands for no DER systems installation; upper case $\mathbf{C}$ stands for the connection between metro and $\mathrm{EV}$, while lower case c stands for the absence of such connection; and upper case $\mathbf{L}$ energy unconstrained metroEV connection while lower case $\mathbf{l}$ stands for the limited metro-EV energy transfers. Note that these options imply different model alternatives as seen in section 6.1.1. For instance, $\mathbf{C S}_{\text {500DCL }}$ refers to the full model described in Fig. 29, with a district size of 500x4 houses (i.e. 500 houses per household type) implementing DER and with complete connection metroEV (no limiting the energy transfers), while $\mathbf{C S}_{\mathbf{2 5 0 d C L}}$ correspond to $250 \times 4$ houses without DER implementation but with full metro-EV connection. Table 44 summarises the variants of the model considered in this chapter. 
TABLE 44. SUMMARY OF CASE STUDIES CONSIDERED.

\begin{tabular}{l|l} 
Case study & Description \\
\hline $\mathbf{C S}_{\mathbf{D C L}}$ & $\begin{array}{l}\text { DER systems implemented and free connection metro-EV } \\
\text { DER systems not implemented, but with free connection } \\
\text { metro-EV } \\
\mathbf{C S}_{\mathbf{d C L}}\end{array}$ \\
$\mathbf{C S}_{\mathbf{D C l}}$ & $\begin{array}{l}\text { DER systems implemented, but with limited metro-EV } \\
\text { power flow (the metro cannot receive more energy than } \\
\text { sent to the EVs each day) } \\
\text { DER systems implemented, but without the metro-EV } \\
\text { connection (no energy transfers) } \\
\mathbf{C S}_{\mathbf{D c L}}\end{array}$ \\
$\mathbf{C S}_{\mathbf{d c L}}$ & $\begin{array}{l}\text { Neither the DER systems nor the metro-EV connection are } \\
\text { implemented ("business-as-usual” base case) }\end{array}$
\end{tabular}

The case studies proposed in this chapter and developed in the following subsections have three main objectives:

- To analyse the effect of the number of available EVs within the selected parking lot and of the size of the district on the DER investment decisions and the total district energy costs.

- To assess the synergies between district, EVs and metro trains, with and without DER investments.

- To find and understand the saturation level where the considered system does not benefit further from more EV storage.

\subsection{RESULTS AND DISCUSSION}

\subsubsection{ANALYSIS OF THE EFFECT OF EV PENETRATION AND DISTRICT SIZE.}

According to [236], there are 43109 inhabitants in San Andrés neighbourhood of Villaverde. For this first objective, three scenarios have been considered corresponding to three district sizes, assuming that only a partial share of the inhabitants chose to participate in DER installation (but fully implementing DER systems with unrestricted metro-EV connection, corresponding to sub-indexes DCL). Following the four types of households described in section 5.2.1, the three case studies are: 4 house types $\times 250$ houses per type, $4 \times 500$ and 4 x 1000 (which are possible to fit in the Villaverde district). For these three district sizes, different numbers of EVs going from 25 to 194 EVs have been considered, 194 being the maximum capacity of the selected parking lot. For all cases optimal DER investments are determined by minimizing the total system costs including DER investment costs and the operating costs of metro, districts and EV as defined in (34). 
The resulting installed capacity of DER systems for the three district sizes has been illustrated in Fig. 33. By analysing the results, the following considerations can be made.

- The investments in the DER systems considered increase almost linearly with the district size: for instance, $\mathbf{C S}_{\text {500DCL }}$ installs around $60 \%$ more PV systems than $\mathbf{C S}_{\mathbf{2 5 0 D C L}}$,

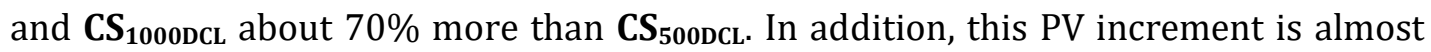
independent of the number of EVs. This is due to the fact that, in this study, the PV system is an important supplier of electricity for the district and the EV electric demand is very small in comparison with the household electricity demand. Note, as shown in Fig. 31, that the metro load is larger than the EV load and has a profile that takes advantage of the sunny hours, increasing the amount of PV capacity to install. However, when the district load becomes large enough (in relation with the metro and EV loads), the PV capacity increases almost linearly with the district size.

- The heat pump investments are barely affected by the EV numbers. Indeed, the change is negligible, less than $0.1 \%$, and is due to the small change in PV production for the extra EV electric load, which is something expected since EV load is purely electric and does not need any thermal production from the HP system.

- Battery systems investments depend on both, the district size and the number of EVs. Larger districts profit from more battery installation, but larger amount of EVs provides "free" storage capacity decreasing batteries investments needs. The rate of substitution of battery by EV storage is around $60 \%$ (for each $\mathrm{kWh}$ of extra EV storage, the battery system decreases its capacity in $0.6 \mathrm{kWh}$ ), which is a measure of the available extra storage that EVs are able to provide to the district, conditioned by their availability constraints (see Fig. 32). Different EV availability profiles are likely to produce different substitution ratios.

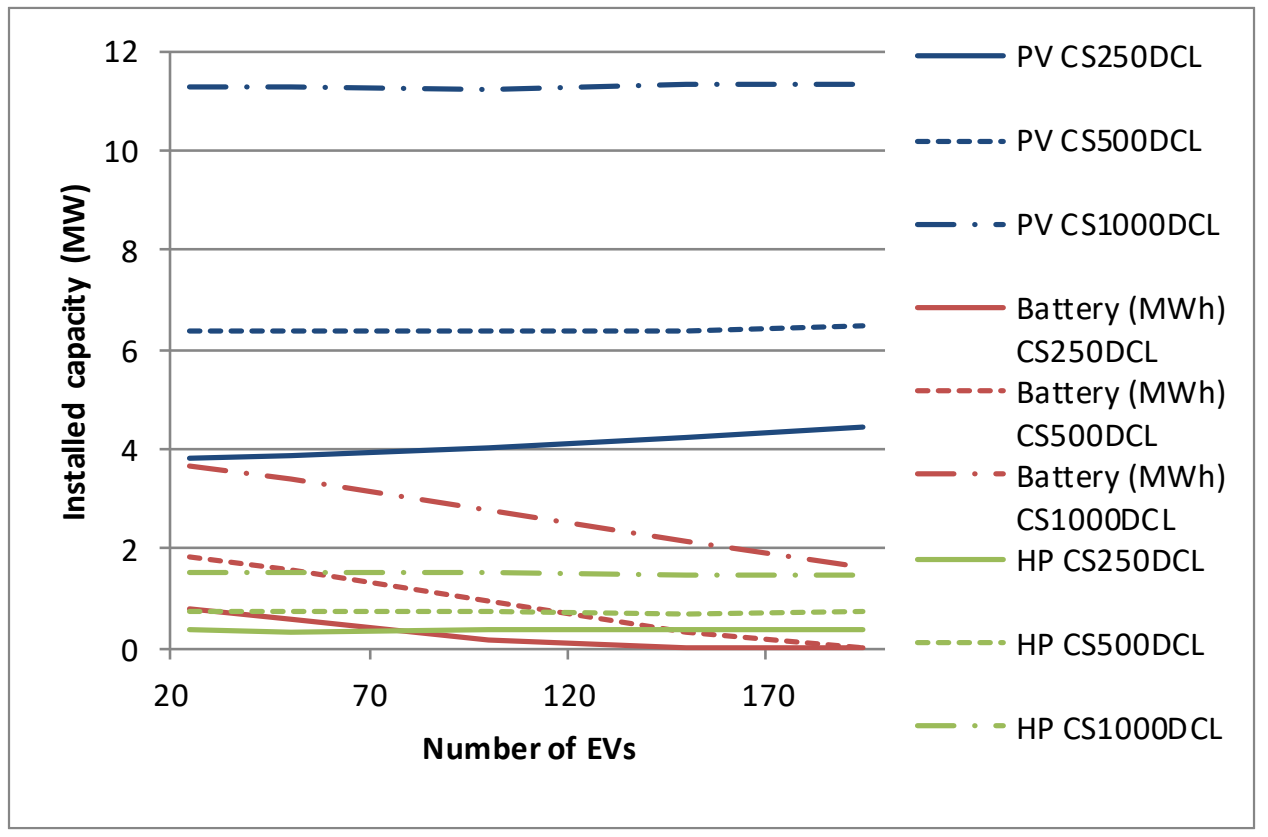

FIG. 33. INSTALLED CAPACITY OF DER SYSTEMS FOR DIFFERENT DISTRICT SIZES, AND WITH FULL CONNECTION METRO-EV. 
The average annual electric power and energy costs for the metro are shown in Fig. 34. Power and energy metro costs increase slightly with low numbers of EVs, up to around 50, due to the fact that it is more profitable for the whole system if the district uses this EV storage instead of the metro. However, for larger numbers of EVs, the additional EV storage can be used by the metro, which then reduces significantly its costs. This is especially noticeable for $\mathbf{C S}_{250 \mathrm{DCL}}$, where the savings in energy and power costs can go up to $44 \%$ comparing the case of 25 EVs with 194 EVs. Conversely, $\mathbf{C S}_{\mathbf{1 0 0 0 D C L}}$ shows a smaller benefit of $15 \%$ for power and $9 \%$ for energy costs (from 25 to $194 \mathrm{EVs}$ ). In these scenarios with larger districts sizes, the higher energy requirements of the households represent a larger cost than the metro in the objective function, so the cost minimization directs more EV storage capacity to the district (to store PV energy and provide load shifting), leaving less capacity for the metro.

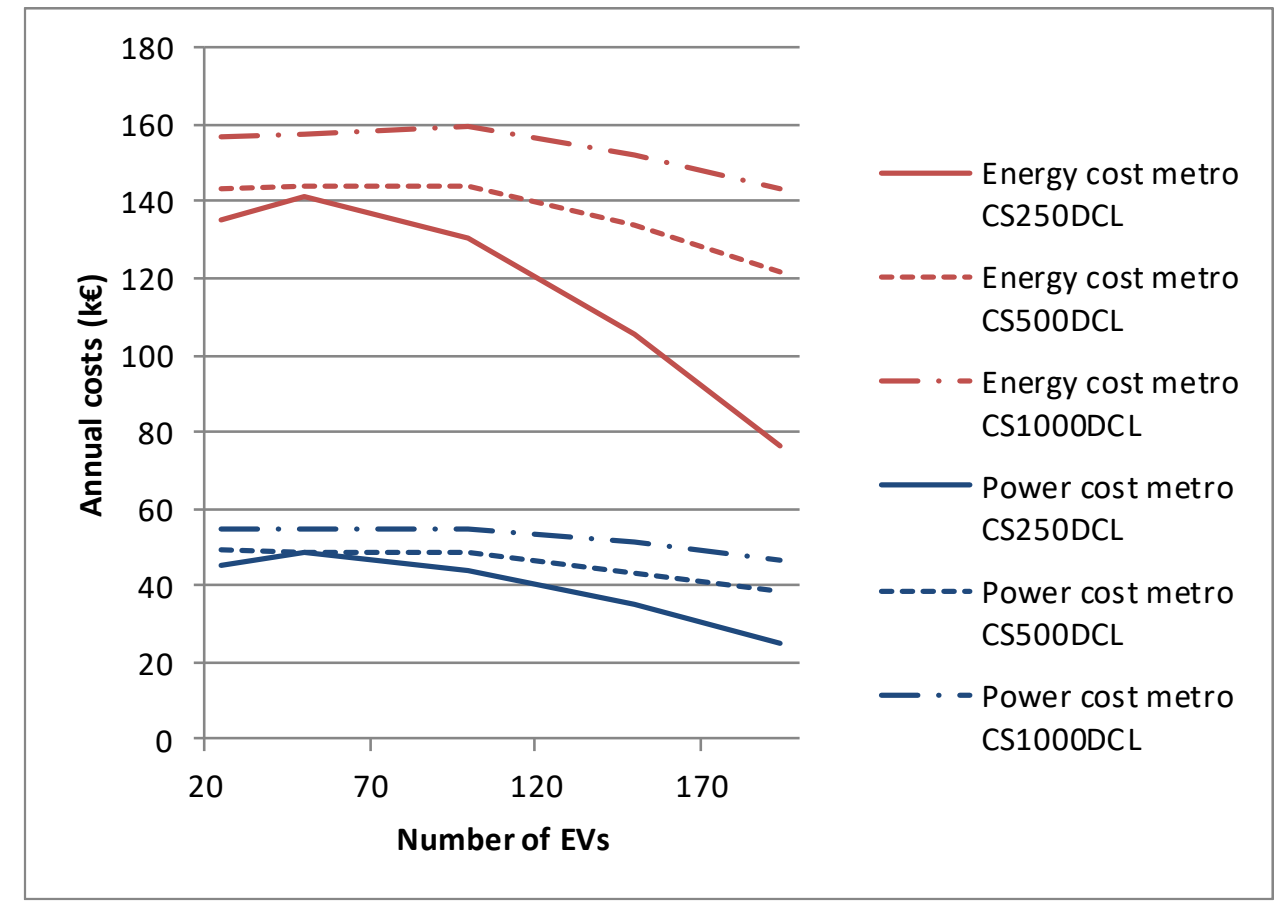

FIG. 34. ANNUAL ELECTRIC ENERGY AND POWER COSTS FOR THE METRO SUBSTATION.

The detail of the power contracted by the metro considering the three tariff periods is shown in Fig. 35. The effect of the EV storage can be seen in the important reduction in the contracted power for mid-peak and peak hours, but the benefit is smaller with bigger districts. Indeed, the largest reductions $(41 \%$ and $53 \%$ at peak and mid-peak hours respectively) occur for $\mathbf{C S}_{\text {250DCL. }}$ On the other hand, $\mathbf{C S}_{\text {500DCL }}$ and $\mathbf{C S}_{\mathbf{1 0 0 0 D C L}}$ present a similar behaviour at peak hours (38\% savings in $\mathbf{C S}_{\mathbf{5 0 0 D C L}}$ and $28 \%$ in $\mathbf{C S}_{\mathbf{1 0 0 0 D C L}}$ ), but at mid-peak time the decrement is considerably smaller (less than $3 \%$ ). Once again, the larger loads of the larger districts represent larger costs in the objective function, and it is more profitable for the district to use the additional storage capacity of the EVs at peak and mid-peak hours to reduce the total system costs. The lack of change at off-peak hours (see the overlapping green lines in Fig. 35) is caused by the low train transit at this time, and the low EV availability around 6am when users drive to work. In other words, with the current EV availability and metro profiles, the metro (and the system overall) does not benefit from additional EV storage at off-peak time. 


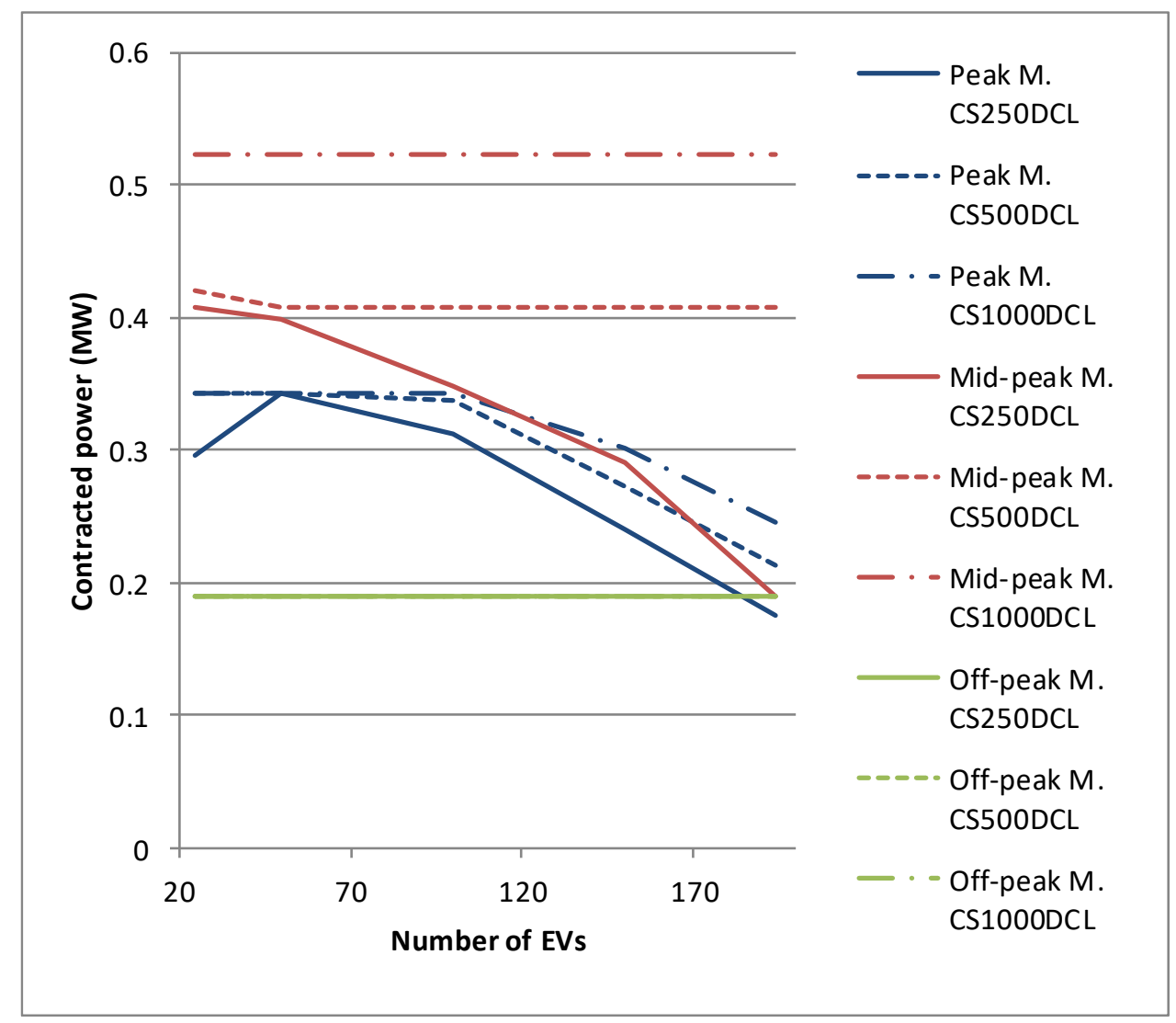

FIG. 35. METRO ELECTRICAL SUBSTATION CONTRACTED POWER.

The average annual electric power and energy costs for the district, including EVs consumption, are shown in Fig. 36. The electricity costs increase slightly with EVs due to the additional EV energy requirements, leading to $11-19 \%$ increments, or equivalently $1.5-3$ million euros for the whole 20-year period, corresponding to approximately $743 €$ per extra $\mathrm{EV}$ and per year in $\mathbf{C S}_{\text {1000DcL }}$ (note that and independent not connected EV would costs approx. $775 €$ per year). Looking at the total costs (including metro, district, DER and EV costs, see Fig. 37), a similar increment can be seen.

However, if EVs charging and EV battery replacement costs are removed, since EVs deployment respond to other objectives and requirements, it is possible to see more clearly the effect of the synergies provided by both the extra storage and the interconnectivity of systems. As can be seen in Fig. 37, the savings in total costs (without EV costs) are around 2 - 6\%. Comparing this savings to those of the metro system (up to $44 \%$ in $\mathbf{C S}_{250 \mathrm{DCL}}$ ), it is possible to see that the metro benefits considerably more from EVs than the district (see Fig. 34). This is caused by the fact that the overall costs are minimized when the metro uses the EV energy (from $50 \mathrm{EVs}$ ) charged with the PV production and the cheaper off-peak energy from the district (which is a smaller share of the overall costs at those hours). 


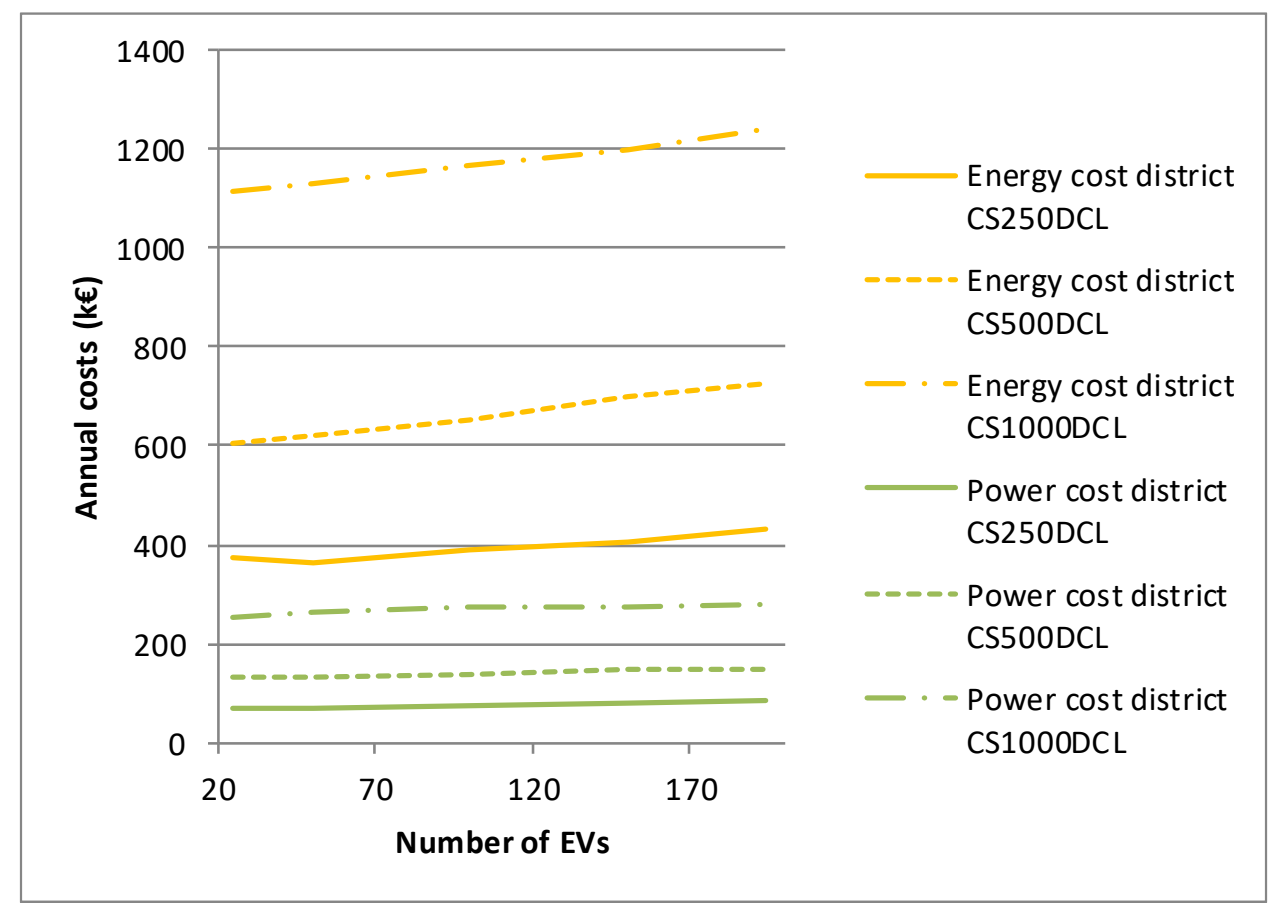

FIG. 36. TOTAL ELECTRIC ENERGY COSTS FOR THE DISTRICT.

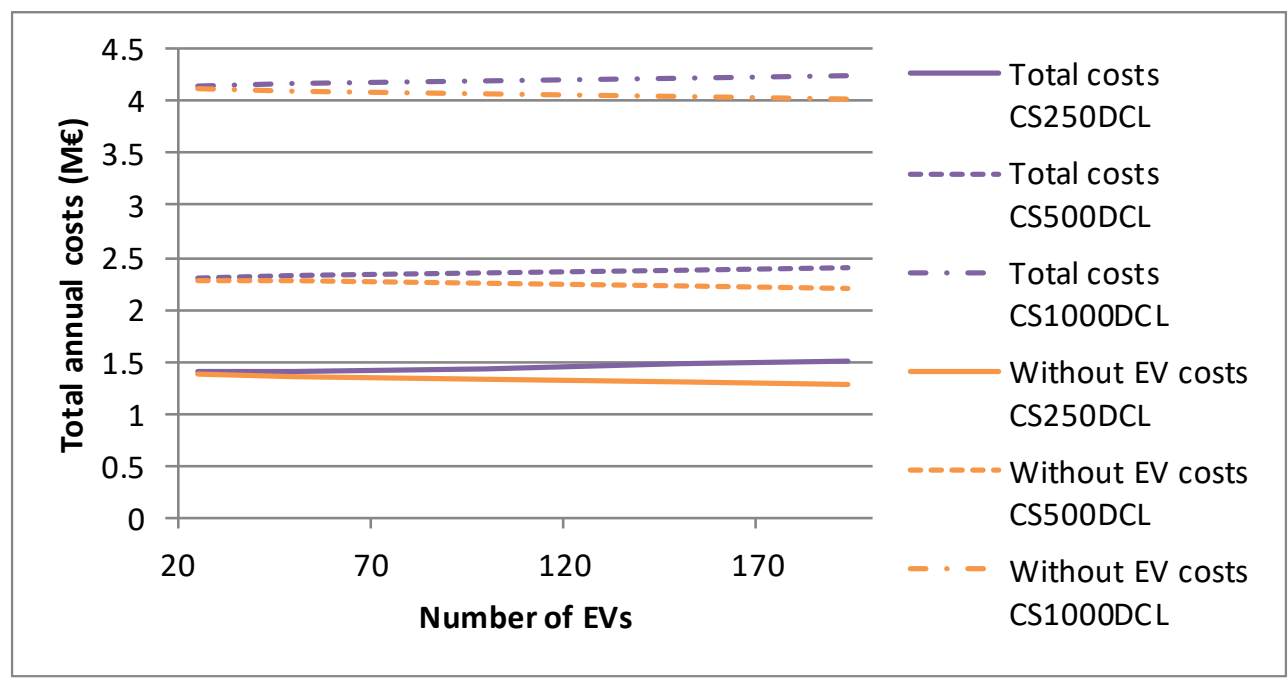

FIG. 37. TOTAL ANNUAL COSTS FOR ALL THE CONSIDERED SYSTEMS INCLUDING DER INVESTMENTS, AND WITHOUT EV COSTS.

Table 45 summarizes all the results shown in this section, taking the three case studies with the smaller number of EVs (25 vehicles) and comparing them with the scenario of 194 EVs, showing the changes in DER capacity and costs increments. Once again, it can be seen that in larger districts, the PV and HP systems are barely affected by the EV penetration (around of $2 \%$ of change in $\mathbf{C S}_{\mathbf{5 0 0 D C L}}$ and $\mathbf{C S}_{\mathbf{1 0 0 0 D C}}$, see Table 45 ), while the battery capacity are heavily impacted (up to a $100 \%$ change, see Table 45 ). Also, the metro cost reductions are more affected by the number of EVs than the district (especially in $\mathbf{C S}_{\mathbf{2 5 0 D C L}}$ ), as the metro system uses more the EV storage because it represents a larger share from the total costs. 


\begin{tabular}{c|ccc} 
& $\mathbf{C S}_{\text {250DCL }}$ & $\mathbf{C S}_{\text {500DCL }}$ & $\mathbf{C S}_{\mathbf{1 0 0 0 D C L}}$ \\
\hline PV & $17 \%$ & $2 \%$ & $1 \%$ \\
HP & $7 \%$ & $2 \%$ & $2 \%$ \\
Battery & $-100 \%$ & $-100 \%$ & $-56 \%$ \\
Metro costs & $-44 \%$ & $-17 \%$ & $-10 \%$ \\
District costs & $17 \%$ & $19 \%$ & $11 \%$ \\
Total costs & & & \\
(without EV costs) & & $-4 \%$ & $-2 \%$
\end{tabular}

\subsubsection{ASSESSMENT OF SYNERGIES BETWEEN SYSTEMS.}

To analyse the synergies that appear by interconnecting the considered systems, four case studies are proposed implementing three different versions of the model with a fixed district size (residential load) equivalent to 250 houses per house type, and the energy transfers between metro and EVs is not limited when such connection exist. Case study $\mathbf{C S}_{\mathbf{2 5 0 d c L}}$ is the business-as-usual base case (with no DER systems or EV-metro connection), and corresponds to the model depicted in Fig. 29, removing the connecting line (1) and the blocks grouped in (2). $\mathbf{C S}_{250 \mathrm{dcL}}$ implements the unlimited connection between the EVs and the metro electrical substation but without DER (see Fig. 29, removing the blocks grouped in 2). In case study $\mathbf{C S}_{\text {250DcL }}$ DER is implemented but with separate metro and EV optimization (removing their electrical connection), and $\mathbf{C S}_{\mathbf{2 5 0 D C L}}$ correspond to the complete model implementing DER systems and the joint optimization of EVs and the metro substation with the unlimited interconnection (see Fig. 29).

Table 46 shows the consumed energy costs (calculated with (35), (37) and (45)) and DER costs, (39) - (44). Table 47 shows the power costs, calculated with (36) and (46), and Table 48 show other system costs (thermal power, (38), and EV battery costs, (47)) and total costs (34), summing up all the costs. For $\mathbf{C S}_{\mathbf{d c L}}$, it can be seen how the costs for the district and the total costs increase with the number of EVs, due to the extra load of more EVs. For the metro substation, as the systems have not been interconnected, the cost has not been affected. 
TABLE 46. ENERGY COSTS FOR ALL CASE STUDIES (250X4 HOUSEHOLDS).

\begin{tabular}{|c|c|c|c|c|c|c|c|c|c|c|c|c|}
\hline \multirow{2}{*}{$\begin{array}{c}\text { Num. } \\
\text { of } \\
\text { EVs }\end{array}$} & \multicolumn{4}{|c|}{ Energy metro $(\mathrm{M} €)$} & \multicolumn{4}{|c|}{$\begin{array}{l}\text { Electric energy district } \\
\text { (M€) }\end{array}$} & \multicolumn{4}{|c|}{$\begin{array}{l}\text { Thermal energy district } \\
\text { (M€) }\end{array}$} \\
\hline & $\mathrm{CS}_{\mathrm{dcL}}$ & $\mathrm{CS}_{\mathrm{dCL}}$ & $\mathrm{CS}_{\mathrm{DcL}}$ & $\mathrm{CS}_{\mathrm{DCL}}$ & $\mathrm{CS}_{\mathrm{dcL}}$ & $\mathrm{CS}_{\mathrm{dCL}}$ & $\mathrm{CS}_{\mathrm{DcL}}$ & $\mathrm{CS}_{\mathrm{DCL}}$ & $\mathrm{CS}_{\mathrm{dcL}}$ & $\mathrm{CS}_{\mathrm{dCL}}$ & $\mathrm{CS}_{\mathrm{DcL}}$ & $\mathrm{CS}_{\mathrm{DCL}}$ \\
\hline 25 & 12.4 & 7.5 & 12.4 & 2.7 & 12.7 & 14.9 & 5.4 & 7.5 & 9.7 & 9.7 & 0.7 & 0.6 \\
\hline 50 & 12.4 & 7.9 & 12.4 & 2.8 & 12.9 & 14.8 & 5.7 & 7.3 & 9.7 & 9.7 & 0.6 & 0.6 \\
\hline 100 & 12.4 & 6.9 & 12.4 & 2.6 & 13.2 & 16.1 & 6.0 & 7.8 & 9.7 & 9.7 & 0.6 & 0.6 \\
\hline 150 & 12.4 & 6.3 & 12.4 & 2.1 & 13.5 & 17.0 & 6.1 & 8.1 & 9.7 & 9.7 & 0.6 & 0.5 \\
\hline 194 & 12.4 & 6.0 & 12.4 & 1.5 & 13.8 & 17.5 & 6.4 & 8.6 & 9.7 & 9.7 & 0.6 & 0.5 \\
\hline
\end{tabular}

TABLE 47. POWER COSTS FOR ALL CASE STUDIES (250X4 HOUSEHOLDS).

\begin{tabular}{|c|c|c|c|c|c|c|c|c|}
\hline \multirow[t]{2}{*}{$\begin{array}{l}\text { Number } \\
\text { of EVs }\end{array}$} & \multicolumn{4}{|c|}{$\begin{array}{l}\text { Electric power metro } \\
\text { (M€) }\end{array}$} & \multicolumn{4}{|c|}{ Electric power district (M€) } \\
\hline & $\mathrm{CS}_{\mathrm{dcL}}$ & $\mathrm{CS}_{\mathrm{dCL}}$ & $\mathrm{CS}_{\mathrm{DcL}}$ & $\mathrm{CS}_{\mathrm{DCL}}$ & $\mathrm{CS}_{\mathrm{dcL}}$ & $\mathrm{CS}_{\mathrm{dCL}}$ & $\mathrm{CS}_{\mathrm{DcL}}$ & $\mathrm{CS}_{\mathrm{DCL}}$ \\
\hline 25 & 2.45 & 1.48 & 2.45 & 0.91 & 1.19 & 1.13 & 1.30 & 1.37 \\
\hline 50 & 2.45 & 1.48 & 2.45 & 0.97 & 1.09 & 1.09 & 1.37 & 1.43 \\
\hline 100 & 2.45 & 1.30 & 2.45 & 0.87 & 1.34 & 1.30 & 1.44 & 1.52 \\
\hline 150 & 2.45 & 1.30 & 2.45 & 0.70 & 1.62 & 1.58 & 1.57 & 1.61 \\
\hline 194 & 2.45 & 1.30 & 2.45 & 0.50 & 1.86 & 1.82 & 1.68 & 1.70 \\
\hline
\end{tabular}

TABLE 48. DER AND TOTAL COST FOR ALL CASE STUDIES (250X4 HOUSEHOLDS).

\begin{tabular}{|c|c|c|c|c|c|c|c|c|c|}
\hline \multirow[t]{2}{*}{$\begin{array}{l}\text { Number } \\
\text { of EVs }\end{array}$} & \multicolumn{4}{|c|}{$\begin{array}{l}\text { DER invest. and maint. } \\
\text { (M€) }\end{array}$} & \multirow{2}{*}{$\begin{array}{c}\text { Other } \\
\text { costs (M€) } \\
\text { All case } \\
\text { studies }\end{array}$} & \multicolumn{4}{|c|}{ Total costs (M€) } \\
\hline & $\mathrm{CS}_{\mathrm{dcL}}$ & $\mathrm{CS}_{\mathrm{dCL}}$ & $\mathrm{CS}_{\mathrm{DcL}}$ & $\mathrm{CS}_{\mathrm{DCL}}$ & & $\mathrm{CS}_{\mathrm{dcL}}$ & $\mathrm{CS}_{\mathrm{dCL}}$ & $\mathrm{CS}_{\mathrm{DcL}}$ & $\mathrm{CS}_{\mathrm{DCL}}$ \\
\hline 25 & 0 & 0 & 9.77 & 13.36 & 1.56 & 39.94 & 36.21 & 33.58 & 27.94 \\
\hline 50 & 0 & 0 & 9.52 & 13.40 & 1.73 & 40.21 & 36.58 & 33.89 & 28.22 \\
\hline 100 & 0 & 0 & 9.52 & 13.37 & 2.07 & 41.09 & 37.35 & 34.53 & 28.81 \\
\hline 150 & 0 & 0 & 9.87 & 13.99 & 2.41 & 42.06 & 38.21 & 35.32 & 29.44 \\
\hline 194 & 0 & 0 & 9.87 & 14.50 & 2.71 & 42.91 & 39.02 & 36.10 & 30.03 \\
\hline
\end{tabular}

Looking at the results from the tables, it can be seen that:

- The connection metro-EV brings significant reductions to the metro system.

- This can be seen while comparing $\mathbf{C S}_{\mathbf{d c L}}$, with $\mathbf{C S}_{\mathbf{d c L}}$, where the power costs (see the left columns in Table 47) and energy costs (see the left columns in Table 46) for the metro system are considerably lower and decrease with the number of EVs.

$\circ$ Energy costs fall from $12.4 \mathrm{M} €$ in $\mathbf{C S}_{\mathbf{d c L}}$ to $7.5-6 \mathrm{M} €$ in $\mathbf{C S}_{\mathbf{d c L}}$ (see Table 46 ).

○ Power costs fall from 2.45M€ in $\mathbf{C S}_{\mathrm{dcL}}$ to $1.48-1.3 \mathrm{M} €$ in $\mathbf{C S}_{\mathbf{d C L}}$ (see Table 47).

- The average reduction is around $44 \%$, for both power and energy costs.

- This reduction has been caused by the extra storage capacity provided by more EVs, and the metro taking advantage of it, storing more regenerative braking energy.

- In $\mathbf{C S}_{\mathbf{D c L}}$, metro costs go back to those of the base case (see the left columns in Table 46 and Table 47).

- However, in $\mathbf{C S}_{\mathbf{D c L}}$ district energy costs decrease significantly due to the added distributed generation (consuming less energy from the grid), and the load shifting capacity. 
○ Energy costs fall from $12.7-13.8 \mathrm{M} €$ in $\mathbf{C S}_{\mathrm{dcL}}$ to $5.4-6.4 \mathrm{M} €$ in $\mathbf{C S}_{\mathbf{d C L}}$ (see the central columns in Table 46).

- Power costs fall from 1.19-1.86M€ in $\mathbf{C S}_{\mathrm{dcL}}$ to $1.3-1.68 \mathrm{M} €$ in $\mathbf{C S}_{\mathrm{dCL}}$ (see the central columns in Table 47).

- Around 50\% of total cost reduction for both power and energy costs.

- The costs of DER investments in $\mathbf{C S}_{\mathbf{D c L}}$ are compensated with the resulting operation, so the total costs are smaller than $\mathbf{C S}_{\mathbf{d C L}}$, and $\mathbf{C S}_{\mathbf{d c L}}$ (see right columns in Table 48).

- Total cost reduction of around $7 \%$ in comparison with $\mathbf{C S}_{\mathbf{d C L}}$.

- Total cost reduction of around $16 \%$ in comparison with $\mathbf{C S}_{\mathbf{d c L}}$.

- In $\mathbf{C S}_{\text {DCL }}$ DER investment and maintenance costs increase significantly (being nearly half of the total costs, see Table 48), but almost all other costs are lower than in previous cases.

- Especially for the thermal and electric energy costs for both metro and district systems.

- Metro energy costs fall from $12.4 \mathrm{M} €$ in $\mathbf{C S}_{\mathbf{d c L}}$, and $\mathbf{C S}_{\mathbf{D c L}}$, and from $7.5-6 \mathrm{M} €$ in $\mathbf{C S}_{\mathbf{d C L}}$ to $2.7-1.5 \mathrm{M} €$ in $\mathbf{C S}_{\mathbf{D C L}}$, for an average reduction of $81 \%$ and $66 \%$, respectively (see the left columns in Table 46) .

○ District thermal energy costs fall from $9.7 \mathrm{M} €$ in $\mathbf{C S}_{\mathbf{d c L}}$, and $\mathbf{C S}_{\mathbf{d C L}}$, to 0.6 $0.5 \mathrm{M} €$ in $\mathbf{C S}_{\mathbf{D C L}}$, for an average reduction of $94 \%$ (see the right columns in Table 46), showing that with the introduction of the HP system the thermal energy costs (from natural gas) almost disappear.

- The difference between $\mathbf{C S}_{\mathbf{D C L}}$ and $\mathbf{C S}_{\mathbf{D C L}}$ in thermal energy costs is negligible (see the right most columns in Table 46).

- District electric energy costs fall from $12.7-13.8 \mathrm{M} €$ in $\mathbf{C S}_{\mathbf{d c L}}$, and 12.7 $13.8 \mathrm{M} €$ in $\mathbf{C S}_{\mathbf{d C L}}$, to $7.5-8.6 \mathrm{M} €$ in $\mathbf{C S}_{\mathbf{D C L}}$, for an average reduction of $40 \%$ and $51 \%$, respectively (see the central columns in Table 46 ).

- This reduction is due to the higher energy flow from the renewable generation to both the district (including the EV load) and metro loads.

- However, the district electric energy costs increased from 5.4-6.4M€ in $\mathbf{C S}_{\text {DcL }}$ to 7.5 - 8.6M€ in $\mathbf{C S}_{\mathbf{D C L}}$, for an average increase of $32 \%$ (see the central columns in Table 46 ), suggesting that when the metro connection is available, the metro system also takes advantage from DER systems, reducing the benefit for the district.

- Looking at the system as a whole, the total costs (right columns in Table 48) give a clear overview of the maximum expected benefits of implementing the intermediate or the complete cases.

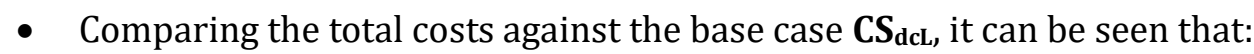

- Just the storage capabilities provided by the $\mathrm{EV}$ in $\mathbf{C S}_{\mathbf{d C L}}$, already give a considerable benefit (around 9\% in average, see right columns in Table 48) to the overall system, especially to the metro substation.

- The inclusion of DER systems in $\mathbf{C S}_{\text {DcL }}$ presents a slightly bigger cost reduction (around 16\% in average, see right columns in Table 48).

- Nevertheless, by including both elements in $\mathbf{C S}_{\mathbf{D C L}}$, an even larger benefit can be achieved (around 30\% in average, see right columns in Table 48) proving the existing synergies of approaching the problem globally. 
- It is also important to remark that $\mathbf{C S}_{\mathbf{D C L}}$ total benefits (30\%) are larger than the sum of $\mathbf{C S}_{\mathbf{d C L}}$ and $\mathbf{C S}_{\mathbf{D c L}}$ benefits (9\% and 16\%, respectively, which is $25 \%$ together), showing the importance of the joint optimization.

- Finally, the EV penetration level does not affect significantly the expected benefits, i.e. the cost of the EV load is relatively small in comparison to other loads, and the inclusion of EVs reduces the battery costs as well.

\subsubsection{Sensitivity analysis and discussion of results}

A sensitivity analysis on some of the main model parameters has been carried out, to provide insight on the potential applicability of the results in other contexts. The analysis consists in increasing or decreasing by $20 \%$ the metro energy profiles (shown in Fig. 31 ) and the district and metro energy prices (shown in Table 42 and Table 43). Table 49 shows the total costs of the base case in $\mathbf{C S}_{\mathbf{d c L}}$ and the in $\mathbf{C S}_{\mathbf{D C L}}$ case for the different value changes. It can be seen that the change in relative benefits is relatively small for all the considered parameters, with benefits ranging from $26.4 \%$ to $34.2 \%$ (approx. $\pm 4 \%$ variation relative to the original benefits) in the studied sensitivity range. These results suggest that other systems in a similar setup are likely to present comparable synergies as the ones reported in this study.

TABLE 49. SENSITIVITY ANALYSIS FOR METRO ENERGY PROFILES (TOTAL COSTS WITH 194 EVS AND 250X4 HOUSEHOLDS).

\begin{tabular}{c|ccc} 
Parameter change & CS $_{\text {dcL }}(\mathbf{M} €)$ & CS $_{\text {DcL }}(\mathbf{M} €)$ & Change (\%) \\
\hline Original & 42.90 & 30.03 & $-30.0 \%$ \\
Metro profile $-20 \%$ & 39.93 & 28.19 & $-29.4 \%$ \\
Metro profile $+20 \%$ & 45.88 & 31.89 & $-30.5 \%$ \\
District energy price $-20 \%$ & 37.56 & 27.12 & $-27.8 \%$ \\
District energy price $+20 \%$ & 48.24 & 32.01 & $-33.7 \%$ \\
Metro energy price $-20 \%$ & 39.93 & 29.37 & $-26.4 \%$ \\
Metro energy price $+20 \%$ & 45.88 & 30.18 & $-34.2 \%$
\end{tabular}

It is important to remark that a large share of these benefits is produced by "opportunistic" synergies, caused by the different tariffs considered. In particular, the metro system with higher commercial tariffs is taking advantage of the cheaper energy coming from the EVs and the district (lower residential tariff), as shown in sections 6.3.1 and 6.3.2. Nevertheless, real synergies exist among systems, produced by genuine efficiency gains. This type of synergies can be more easily seen in the analysis carried out in chapter 7 , where all the considered systems buy and sell energy directly from the market (at the same energy price).

\subsubsection{SYSTEM SATURATION DUE TO EV PENETRATION.}

For the assessment of system saturation due to $\mathrm{EV}$ penetration, three case studies have been considered: $\mathbf{C S}_{\mathbf{2 5 0 d C L}} \mathbf{C S}_{\mathbf{2 5 0 D C L}}$ and $\mathbf{C S}_{\mathbf{2 5 0 D C l}}$. The first one does not implement DER systems but the metro-EV connection is available and not limited. The second one implements DER systems and does not limit the metro-EV connection (to analyse how the metro system profits from the DER systems placed in the district, taking extra energy from the district via the EVs). The third one implements DER systems but limits the metro-EV connection. In this 
case, the connection is available but the metro can only take from the EVs the same amount of energy stored from the regenerative braking, limiting the energy transfers between metro and EVs according to (76).

$$
\sum_{v, m, h} \text { DDisMetro }_{v, m, h} \leq \sum_{v, m, h} v \text { ChMetro }_{v, m, h}
$$

In all cases the district size remains constant (1000 houses), but the number of EVs goes up to 5000 vehicles to analyse the implications of larger EV penetration levels, and to determine the EV saturation point at which the system does not benefit further from more EV storage.

Looking at the metro energy costs (Fig. 38) and the energy transfers between the EV and the metro electrical substation (Fig. 39), the first results that stands out is that for $\mathbf{C S}_{\mathbf{2 5 0 D C l}}$, with the metro-EV energy transfer limited (energy flows from metro to EVs and the converse are both equal), the resulting costs are barely affected by the number of EVs and are considerably higher than those of the other cases. On the contrary, when the energy from the batteries to the metro is not limited, a much larger cost reduction takes place (see Fig. 38). Indeed, $\mathbf{C S}_{\mathbf{2 5 0 d C L}}$ and $\mathbf{C S}_{\mathbf{2 5 0 D C L}}$ present an important energy cost decrement (around $97 \%$ and $92 \%$, respectively) in comparison with their respective costs at $25 \mathrm{EVs}$, achieving a similar minimum cost value. This shows that, when it is allowed, more energy comes from the EVs to the metro system than the other way around, so the metro benefits largely from the free storage provided by the EVs. However, DER systems seem to play an important role in the saturation point. As can be seen in Fig. $38, \mathbf{C S}_{250 D C L}$ and $\mathbf{C S}_{\mathbf{2 5 0 d C L}}$ have significantly different EV saturation number, and for instance, with $300 \mathrm{EVs}$ the metro energy costs in $\mathbf{C S}_{250 \mathrm{dCL}}$ is 15 times larger than in $\mathbf{C S}_{\mathbf{2 5 0 D C L}}$.

Indeed, when DER investments are allowed, the saturation point is much lower, around 300 EVs, since cheap energy also comes from the installed DER. On the contrary, when no DER systems are allowed, even if the final costs are similar, the saturation point is much larger, around 2000 EVs. This happens since more storage is needed for the metro to profit from the cheap off-peak energy bought by the district from the grid (this is also shown in Fig. 42, where the detailed operation of the systems is further analysed). 


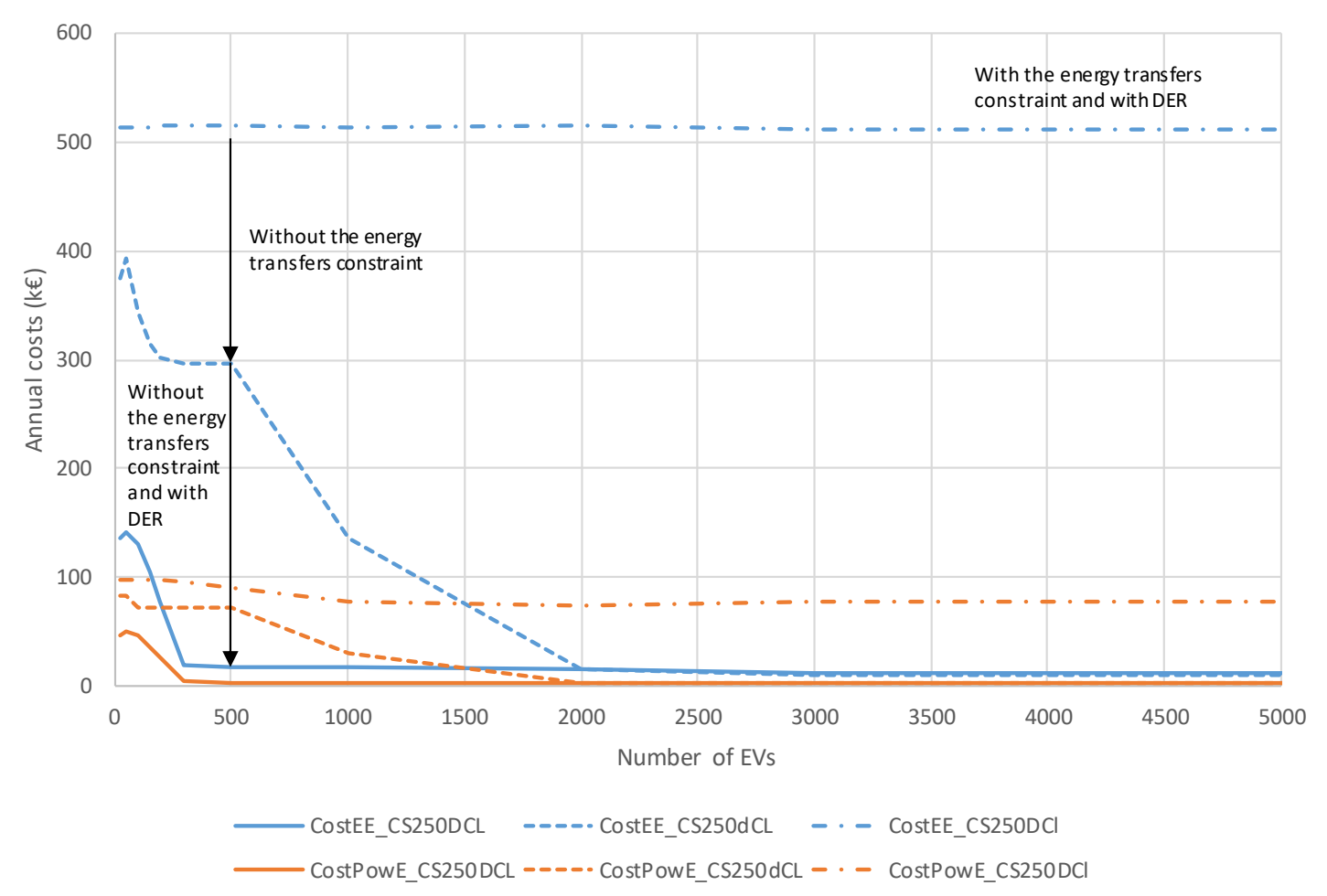

FIG. 38. ANNUAL METRO ELECTRICITY COSTS FOR CS $250 \mathrm{DCL}, \mathrm{CS}_{250 \mathrm{DCL}}$ AND CS250DCL, AND DIFFERENT LEVELS OF EV PENETRATION.

It should be noted that the benefits for the metro system do not increase anymore when the energy transfers metro-EV stop increasing, corresponding to the saturation point. This can be seen in Fig. 39, which shows the energy that goes from the EV to the metro and vice versa for the three case studies. Indeed, for $\mathbf{C S}_{\mathbf{2 5 0 D C L}}$ with more than $300 \mathrm{EVs}$, the metro system receives a constant annual energy flow of around 4050 MWh (this energy transfer is physically possible as it corresponds to $11.1 \mathrm{MWh}$ per day, which represents approximately 1 full discharge per EV in the 300 EVs case). A similar behaviour can be seen in $\mathbf{C S}_{\mathbf{2 5 0 d C L}}$, but needing 2000 EVs to stabilize (see Fig. 39, EV2Metro_CS250dCL). Note that in Fig. 39, the energy flow from the metro to the EVs is constant to all three case studies, corresponding to the regenerative braking energy available (i.e. all three blue lines and the red one of $\mathbf{C S}_{\text {250DCl }}$ are superimposed). Finally, it can be seen that, as expected, the energy going to the electrical substation is considerably larger than the energy sent to the EV parking lot, recovered from regenerative breaking (up to 6.2 times more), which means that the metro system profits from the DER generation and the cheaper energy bought from the grid at the off-peak time residential tariff (paid by the district). 


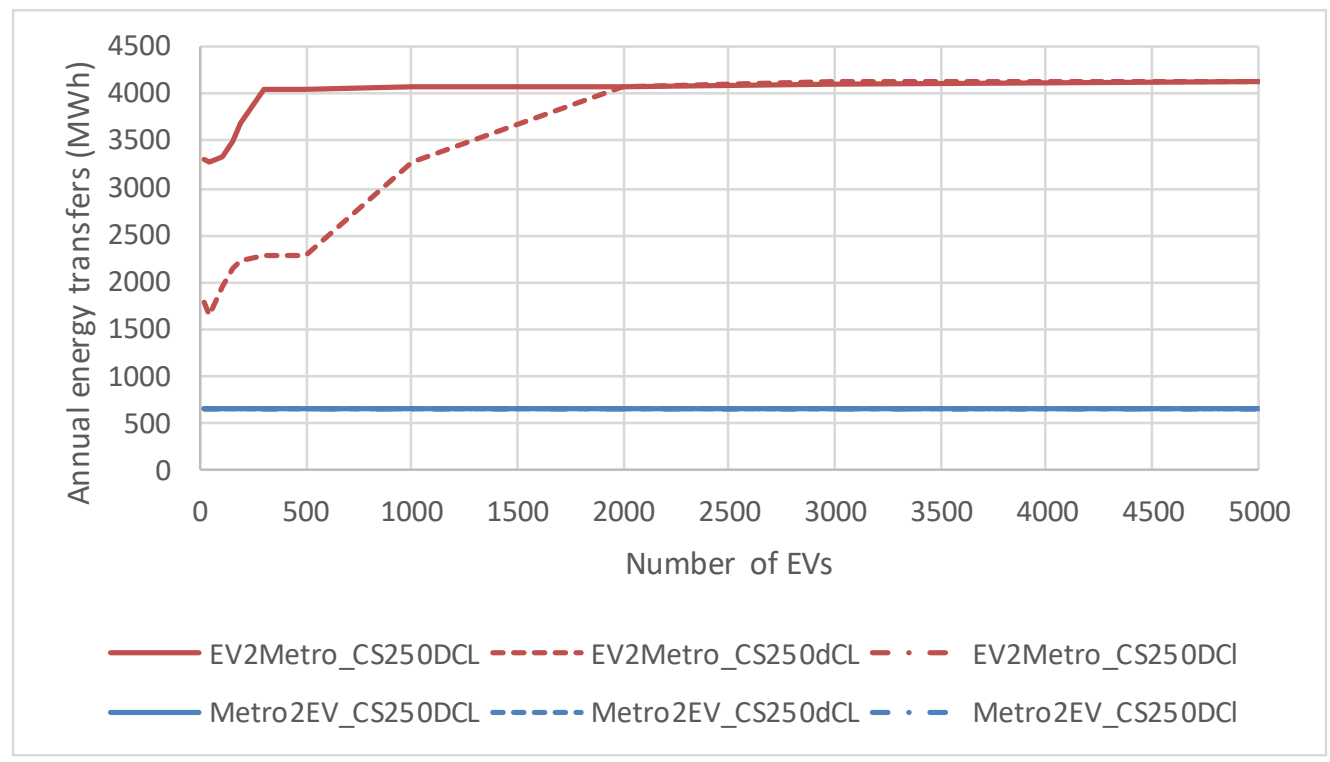

FIG. 39. ANNUAL ENERGY TRANSFERS METRO-EV FOR CS 250 DCL, CS $_{250 D C L}$ AND CS 250 DCL, AND DIFFERENT LEVELS OF EV PENETRATION.

Table 50 summarizes the effects on the three case studies at their EV saturation point in comparison with the 25 EVs case. It can be noted that:

- The metro energy costs reduction in the cases without the energy flow constraint can go over $90 \%$ (see the $\mathbf{C S}_{\mathbf{2 5 0 D c l}}$ and $\mathbf{C S}_{\mathbf{2 5 0 d C l}}$ columns in Table 50, and see Fig. 38), while the case with limited energy flows the cost reduction is almost zero (see the $\mathbf{C S}_{\mathbf{2 5 0 D C L}}$ column in Table 50, and Fig. 38).

- The presence of DER systems have a significant impact on the required number of EVs (300 EVs in $\mathbf{C S}_{250 \mathrm{DCl}}$, and 2000 in $\mathbf{C S}_{250 \mathrm{dcl}}$, see Table 50), to achieve the maximum cost reduction (see Fig. 38).

TABLE 50. IMPACTS ON THE THREE CASE STUDIES COMPARING THE 25 EVS CASE WITH THE EV SATURATION POINT.

\begin{tabular}{c|ccc} 
& CS $_{\text {250DCl }}$ & $\mathbf{C S}_{\mathbf{2 5 0 d C l}}$ & $\mathbf{C S}_{\mathbf{2 5 0 D C L}}$ \\
\hline Energy cost savings & $91 \%$ & $97 \%$ & $0.1 \%$ \\
Saturation point (EVs) & 300 & 2000 & 25 \\
EV2Metro transfers ratio & 6.2 & 6.2 & 1
\end{tabular}

Fig. 40 show the annual district electric energy and power costs (DER investments and operation and maintenance costs are not included here to analyse only the effect of the extra EV load on the district electricity demand). For all case studies, the electric energy costs increase linearly with the number of EVs, produced by the linear electric load increment of the vehicles. When no DER systems are installed ( $\mathbf{C S}_{250 \mathrm{dCL}}$, see Fig. 40), electric energy costs are around $38-50 \%$ larger than those of the other cases, as the district does not benefit 
from the solar generation or other DER systems. For $\mathbf{C S}_{250 \mathrm{DCl}}$ (with DER and the metro-EV transfer constraint), the electricity costs are slightly smaller (6-12\% in comparison with $\mathbf{C S}_{\mathbf{2 5 0 D C L}}$ ), proving once again that the metro system was taking advantage of the energy paid by the district (directly from the grid or indirectly as DER investments and operation and maintenance costs).

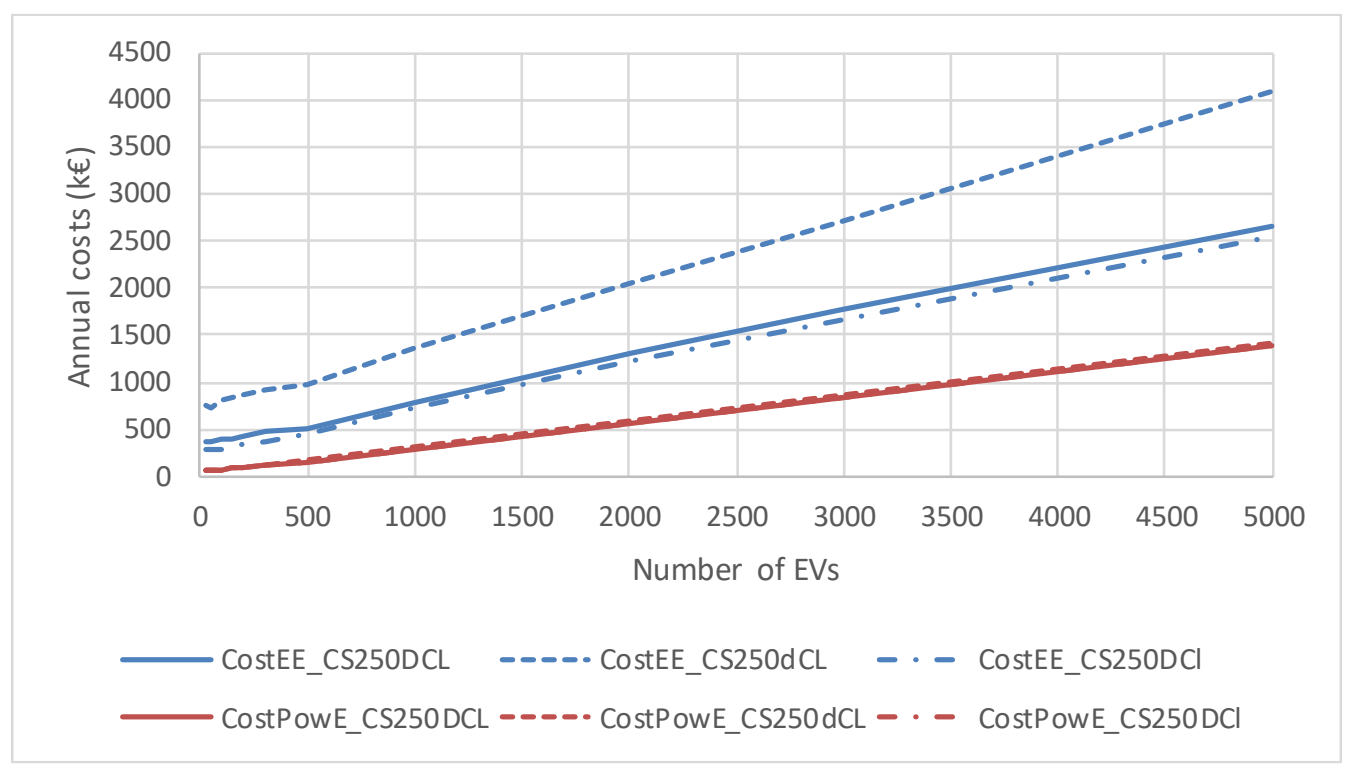

FIG. 40. DISTRICT ELECTRICITY COSTS FOR DIFFERENT LEVELS OF EV PENETRATION (WITH EV COSTS).

The total annual overall costs, just like the metro system costs, present an EV saturation point when no extra benefit is achieved. This is shown in Fig. 41 (zoomed to $0-1000$ EVs since all the saturation points of the considered case studies fall in this range), where the base EV energy charge costs have been removed (the original costs of charging the EV to meet the energy requirements of Fig. 32). For instance, $\mathbf{C S}_{\mathbf{2 5 0 D c L}}$ achieve a minimum total cost with $300 \mathrm{EVs}$, corresponding to the saturation point of the metro in the same case study (see Fig. 39). For $\mathbf{C S}_{\mathbf{2 5 0 D C l}}$ the saturation point is around $100-150$ EVs, showing that if the energy transfers to the metro are limited, less EV storage is used by the metro and more capacity becomes available to the district for a same number of EVs. Lastly, without DER systems in $\mathbf{C S}_{\mathbf{2 5 0 d c L}}$, the storage capacity provided by EVs is less used and the saturation point is reached around $100 \mathrm{EVs}$. This contrasts with the saturation point for the metro system in the same case study (2000 EVs, see Fig. 39). In other words, the district can only shift a certain amount of load (and store PV energy if available) using EV storage. Then, even if more storage capacity is available, the district does not take advantage of it anymore. However, the metro system can still use the discharged energy coming from the EVs. 


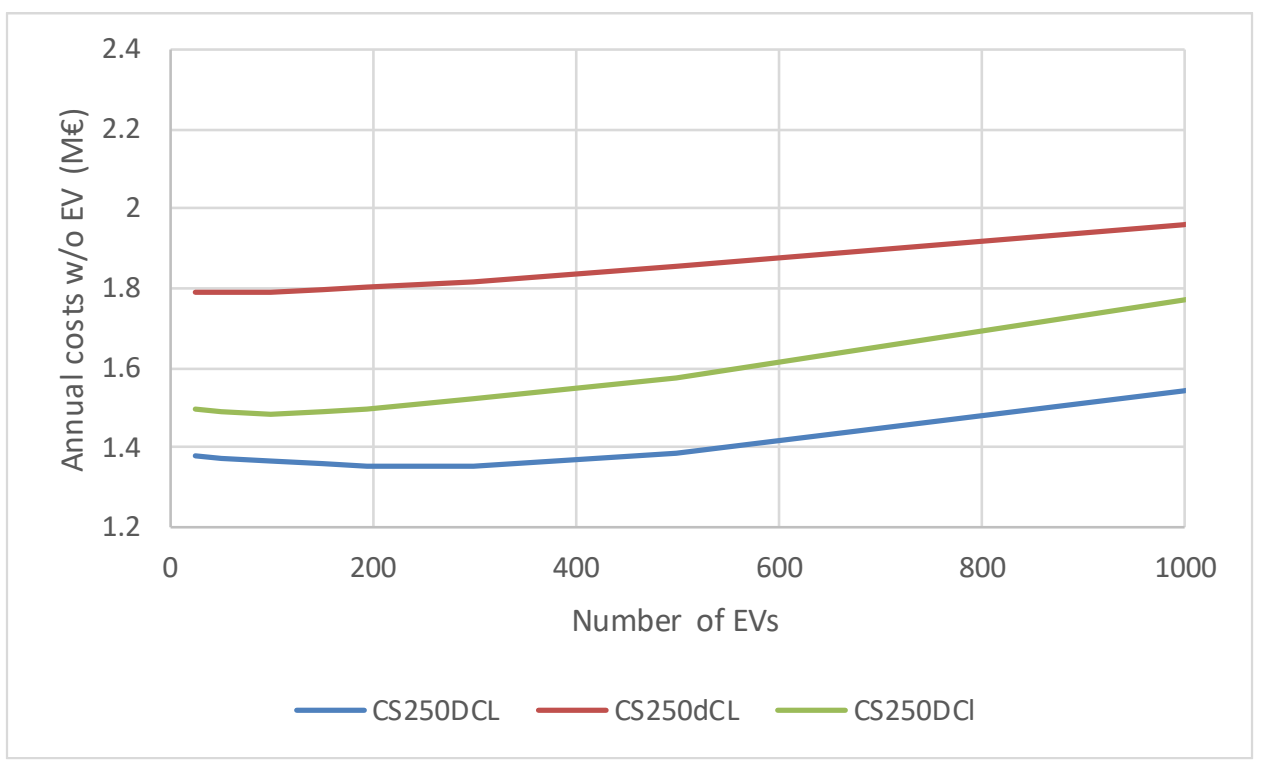

FIG. 41. ANNUAL TOTAL COSTS FOR DIFFERENT LEVELS OF EV PENETRATION (WITHOUT EV COSTS).

As discussed before, the metro benefits largely from the DER systems implemented in the district, and the energy transfers metro-EV are not the same to the transfers EV-metro (see Fig. 39). Fig. 42 demonstrates it further, looking at the hourly operation of the district and the two types of EV users (labelled as EV1 and EV2, see Fig. 42) in a typical summer day (July) in the $\mathbf{C S}_{\mathbf{2 5 0 D C L}}$. In this example, the energy from the grid (Grid Energy Transaction, see Fig. 42) is used to charge the EVs during the early hours with no solar production (labelled as ProdPV, see Fig. 42), to be discharged to the metro from $6 \mathrm{~h} 00$ to $8 \mathrm{~h} 00$. Then, when the solar production is large enough, it is used to charge the EVs. Note that the majority of the EV capacity is discharged to the metro and only a small part is used to meet the district demand (labelled as Demand new, see Fig. 42), which coincides with the time when the price of residential energy is more expensive than the metro commercial tariff. It can also be noted that there is at least one of the EV types available most of the time, making it less likely to use the more expensive battery systems if there is enough EV storage capacity. 


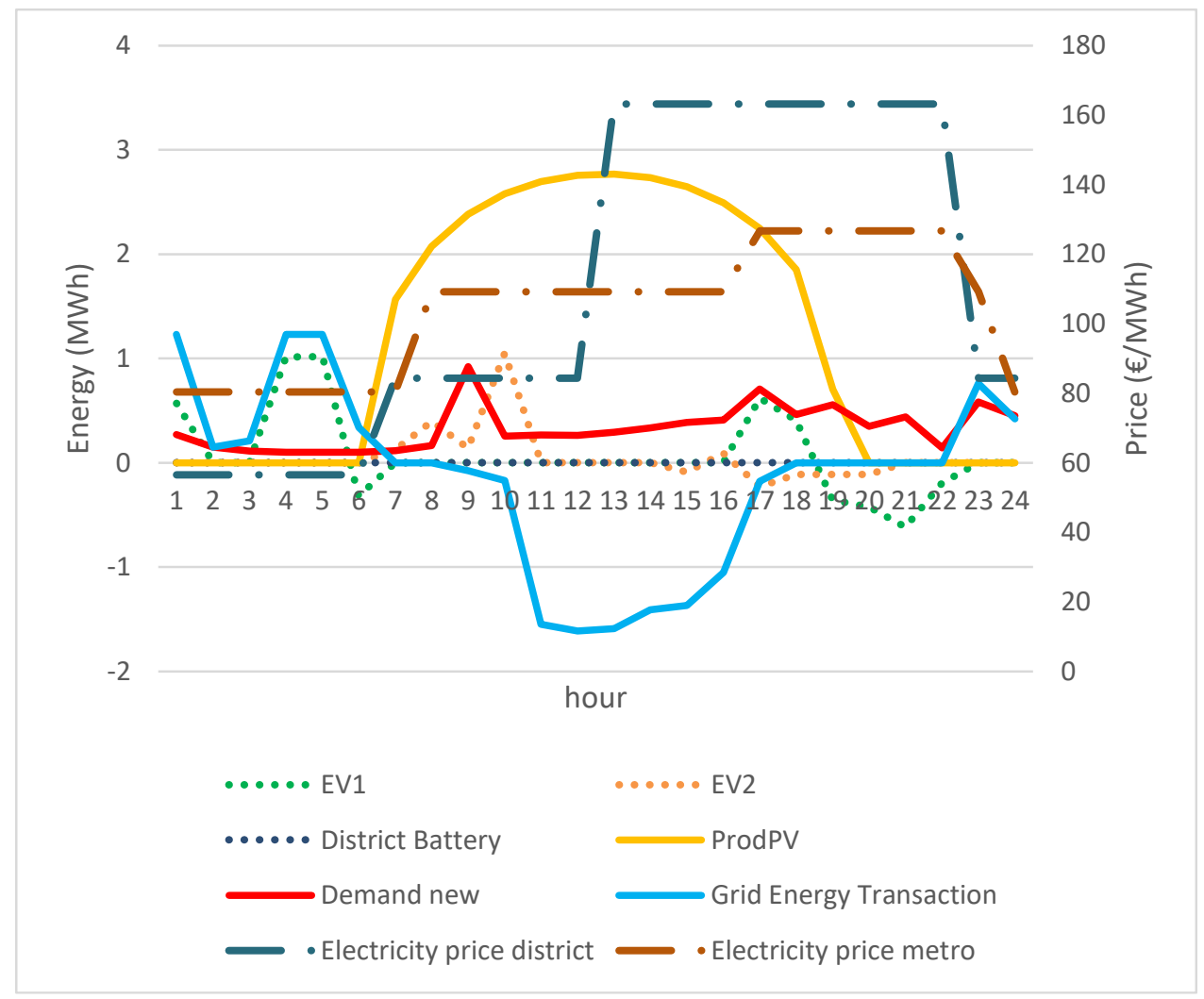

FIG. 42. OPERATION OF THE DISTRICT LOADS AND DER SYSTEMS FOR CS250DCL AND 150 EVS IN A SUMMER DAY.

To conclude this analysis, the total system costs of the three case studies reviewed in this section have been compared to the total costs of a disconnected "business-as-usual" base case (i.e. all the systems operate independently without any DER implementation or metroEV connection). Fig. 43 and Table 51 show the percentage of savings of the case studies. It can be noted that the DER systems produce the higher overall benefits $(15 \%-20 \%$ more than the case without DER systems $\mathbf{C S}_{\mathbf{2 5 0 d C L}}$ at $25 \mathrm{EVs}$ ). In the case with DER systems and the energy transfer constraint $\mathbf{C S}_{\mathbf{2 5 0 D C l}}$, the benefits are logically lower than those obtained when DER systems are installed and without energy transfer limits (average savings of 30 - 11\% in $\mathbf{C S}_{\mathbf{2 5 0 D C L}}$ vs $24-8 \%$ in $\mathbf{C S}_{\mathbf{2 5 0 D C l}}$, see Table 51). However, they still are considerably higher than the no-DER scenario ( $\mathbf{C S}_{\mathbf{2 5 0 d C L}}$, savings of $9-5 \%$, see Table 51 ). 


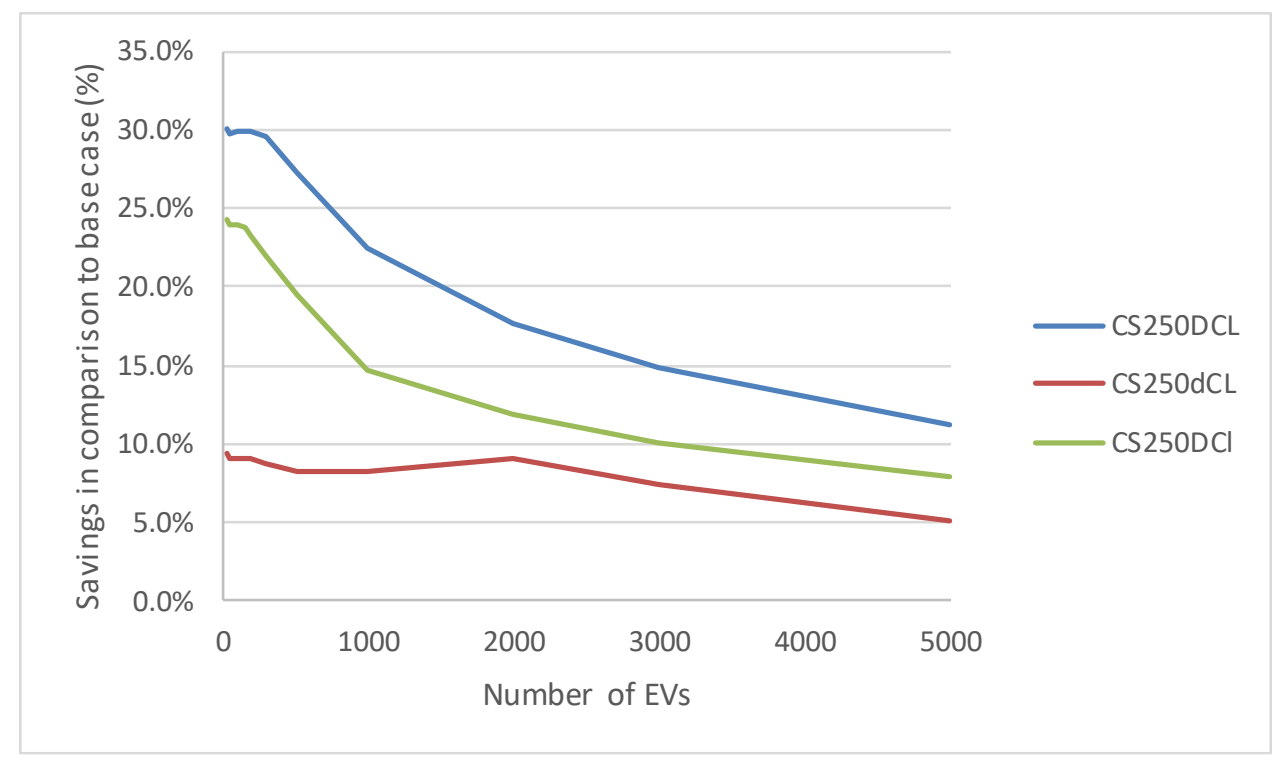

FIG. 43. OPERATION SAVINGS OF THE THREE CASE STUDIES IN COMPARISON WITH THE BASE CASE.

TABLE 51. SAVINGS OF THE CASE STUDIES IN COMPARISON WITH THE BASE CASE.

\begin{tabular}{c|ccc} 
Number of EVs & $\mathbf{C S}_{\mathbf{2 5 0 D C L}}$ & $\mathbf{C S}_{\mathbf{2 5 0 d C L}}$ & $\mathbf{C S}_{\mathbf{2 5 0 D C l}}$ \\
\hline 25 & $30.0 \%$ & $9.3 \%$ & $24.2 \%$ \\
100 & $29.9 \%$ & $9.1 \%$ & $24.0 \%$ \\
300 & $29.5 \%$ & $8.8 \%$ & $21.9 \%$ \\
500 & $27.2 \%$ & $8.2 \%$ & $19.5 \%$ \\
1000 & $22.4 \%$ & $8.2 \%$ & $14.8 \%$ \\
3000 & $14.9 \%$ & $7.4 \%$ & $10.1 \%$ \\
5000 & $11.2 \%$ & $5.0 \%$ & $7.9 \%$
\end{tabular}

\subsection{CONCLUDING REMARKS}

Synergies between urban systems are not always evident and their interactions are not always considered in the related literature. This chapter provides an example of three interconnected systems, a residential district with distributed energy resources, EVs and metro, and quantifies for different case studies how the systems can benefit from each other, revealing the underlying potential synergies.

The outcomes of this study show the high economic benefit that can be achieved by using the metro regenerative breaking and DER, but more importantly by interconnecting the systems. Indeed, the use of EVs as energy storage and the implementation of DER create 
large benefits not only to the EV owners and prosumers, but to the metro system as well, achieving a reduction of up to $30 \%$ on total costs.

However, results suggest that the metro system benefits more than the others do, since it takes advantage of the cheaper energy coming from the district via the EVs, due to the lower residential off-peak tariffs and the distributed generation. This phenomenon is due to the centralized optimization approach that minimizes the total cost of the complete system. However, despite of being profitable, this approach creates additional energy and investment costs in some of the systems, endangering the possible benefit and/or willingness of the participants to join the interconnected scheme (i.e. opportunistic synergies). An equilibrium problem, where each participant decides its investments and its operation optimizing its own benefit, could also be implemented as a more realistic approach, but with the drawback of extra complexity. Alternatively, adequate business models and benefits allocation procedures could be investigated to ensure that the benefits of the interconnected system are fairly shared between all participants.

DER investment decisions (under the proposed schemes) increase much more with the size of the considered district than with the number of EVs (when considering small EV numbers), with the exception of batteries which depend on both, increasing with the district size but decreasing at a rate of $60 \%$ with the number of EVs. Logically the replacement rate of the batteries with EV storage not only depends on the number of EVs, but also on the EV availability profiles.

Another interesting result is the EV saturation point for the proposed system, where extra EVs represent more load but do not provide additional useful storage to the system. This number can be relatively small when the energy transfer to the metro electrical substation is restricted, but it is also reduced by the presence of DER systems. Moreover, the overall cost reduction decreases with very large number of EVs, caused by the extra load of the EVs and the little or no use of the additional storage capacity. Both phenomena are important to consider at the planning level to maximize the benefit from the synergies between systems, although the number of EVs is an external input decided by other multiple considerations such as conventional vehicles replacement, regulation restrictions for conventional vehicles, EV costs and regulatory incentives, pollution considerations, etc.

It is important to note that the interconnection costs have not been considered in this study. However, taking into account that all systems are already connected to the electric grid, the implementation of such an interconnected scheme could be relatively easy, just investing on appropriate line reinforcements and information and communication technologies.

Finally, there are some remarks could be drawn from the study developed:

- The important savings obtained in the analysis, highlight the importance of synergies between urban systems.

- According to the case studies analysed and the sensitivity analysis developed, the input parameters that are more likely to have a significant impact on the results are the energy tariffs and DER costs, and in a lower degree, the metro energy profiles.

- Therefore, despite the potential difference on results under different urban contexts, the overall conclusions are likely to hold (as suggested by the results of the 
sensitivity analysis), showing the existence of synergies, both physical (due to different energy profiles) and opportunistic (due to different energy tariffs), between energy systems in the smart city.

- Lastly, it has been shown that it is important to take into account possible synergies between systems, including them in the planning and operation process, due to the potential cost savings. Hence, it seems reasonable to consider such an interconnected approach in the smart city energy model proposed in this thesis. 


\section{7}

\section{THE SMART CITY ENERGY}

MODEL: A CASE STUDY

This chapter presents the last task of the smart city energy model methodology described in section 1.3, corresponding to the analysis of the smart city energy model.

Picking up the knowledge obtained from all the previous analyses developed in this thesis, the complete smart city energy model is used in a case study that resembles a real smart city application, considering a similar setup than in chapter 6 but adapted to a larger area in southern Madrid, Spain. Hence, the main contribution of this chapter is the application of the smart city energy model in a more realistic case study that could give relevant information to policy makers and stakeholders. Results show the usefulness of the model, and provide insight on the possibilities of further smart city model applications.

\subsection{INTRODUCTION}

As it has been discussed throughout this document, the smart city is a very complex system, including numerous heterogeneous elements. These different elements can have important synergies, when managed in a coordinated way and when actively participating in the energy markets. This chapter applies the model presented throughout this thesis to a case study, trying to serve as an example of a real smart city application. This case study comprises an area of Madrid, Spain. However, the proposed model will have the possibility to be used in other contexts and cities, also including other technologies and energy systems.

The smart city energy model follows the mathematical description presented in chapter 3 . In this case study, the model includes the same energy systems described in chapter 6 (a metro electrical section connected to the grid and to public parking lots where EVs can be parked and used as storage for regenerated braking energy, in addition to energy districts representing an area of the city with household loads and DER systems. See Fig. 29), but with the market participation described in chapter 5 (an aggregator manages all the considered resources and buys or sells electric energy in the wholesale market). 
The MILP optimization problem constituting the model, has the objective of minimizing the costs of an aggregator that has to decide the schedule of energy transfers between metro and EVs, the charge and discharge of EVs, and the sizing and operation of the DER systems to be implemented in the considered residential districts. The programming model includes the constraints described in chapter 3 , also including the changes described in section 5.1.3 and with the same piecewise linear approximation for the energy costs curves shown in section 5.1.4, to add the price-maker stochastic formulation.

As described in chapter 3, model inputs include metro energy requirements for the selected area, EV availability and energy profiles, costs and performance values (e.g., electric efficiency, thermal efficiency, power rating, and losses) of the DER systems considered, geolocation characteristics (sun irradiation), districts energy requirements (consumer electric and thermal demand curves) and each scenario has been modelled with a set of market residual demand curves (described in chapter 5). These curves change depending on the type of model selected (stochastic or deterministic) and the case study considered. Outputs comprise optimal investments planning (installed capacities) and operation of DER systems, with the corresponding EV charge and discharge strategy. Other outputs include the new metro energy demand profiles, the grid energy buying and selling schedules, and the energy market price.

\subsection{CASE STUDY DESCRIPTION AND PARAMETERS}

\subsubsection{MOTIVATION FOR THIS STUDY}

The case study described here tries to replicate a possible application (pilot programme) of a smart city, where several districts including DER systems and EVs, and several metro lines are aggregated and managed optimally. Therefore, the main motivation for this study, is to find more realistic values of the potential costs and benefits of a smart city programme at a large district or municipality level. These results are intended to serve stakeholders and policy makers to plan and invest in real smart city applications.

Note that this case study takes elements from previous analysis of this thesis, and thus, some similarities appear. However, the size considered in previous analyses might have been too big (in chapter 5) or too small (in chapter 6), making the aggregation of resources unrealistic or impractical. In addition, this case study is altogether different from the other case studies developed in this thesis, as it considers elements that have not been modelled together yet, and replicates better a real smart city application.

The main characteristics and considerations for this case study are:

- Location: Madrid, Spain. The location is the same as in previous analyses. However, it is based in a real area within the city, modelling better the available elements. In some of the previous analysis, the number of houses considered has not been related to any particular location.

- Energy systems considered: residential district with DER systems (PV, HP, Batteries and demand response), EVs, and metro substations. The elements considered and the related assumptions are the same as in chapter 6 . These systems 
have been selected as they show important synergies when interconnected and managed in a coordinated way. Note that the same general setup (electrical connections and smart meter locations) as shown in Fig. 29, has been considered for this case study.

- District size: five residential districts, representing 350000 households. The district size is considerably bigger than in chapter 6 . However, it is reasonable to find such number of interconnected districts in a smart city of the size of Madrid. The analysis in chapter 5 considered significantly larger number of houses, up to 8 million. However, that analysis just considered that the houses could be managed by the same aggregator, but did not considered the houses to be concentrated in a particular smart city location, which is the case in the analysis developed in this chapter. The district size and location does not imply a change of the smart city energy model, but is an important characteristic to consider when implementing a real application, as it allows for a more realistic planning of all the available resources in the selected area (also affecting the resulting planning and operation), and the geographical concentrated system will be easier to implement and manage.

- Metro system size: five metro lines and 49 metro stations. This is also considerably more than in the analysis developed in chapter 6 , but correspond to the current metro lines and stations inside the selected area of Madrid.

- Number of EVs: four EV penetration scenarios: 1000, 5000, 10000 and 15000 EVs. The number of EVs, is larger than in chapter 6, and corresponds to the total public parking spots in the five selected districts (17713 parking places).

- Energy prices approach: Price-maker with active market participation, considering three energy price cases (as in chapter 5): two deterministic cases and an stochastic one. Similarly, as shown in the study developed in chapter 5 , the effect on market prices has been taken into account since in this example a considerable amount of resources are being aggregated.

- Network thermal constraints: Power line thermal constraints are not considered in the model. This is the same approach as in chapters 5 and 6, also implementing tariffs with power costs components. Following the analysis developed in chapter 4, it seems sensible to not consider network thermal constrains in the planning process under similar tariff frameworks, and if the smart city programme is implemented, the power lines reinforcements can be done when necessary (see chapter 4 for the full analysis).

\subsubsection{PARAMETER DESCRIPTION}

The full description of the parameters considered in this analysis is presented in this section.

Five districts in the southern part of the city of Madrid have been selected. Those districts are: Villaverde, Usera, Carabanchel, Latina, and Arganzuela (see the area surrounded by red lines in Fig. 44, taken from [237]). According to [236], the total number of inhabitants in the selected districts is almost 898000 , and considering the Spanish average number of persons per household is 2.51 [238], it can be assumed that the number of houses in these districts is slightly greater than 350 thousand houses. Therefore, it is considered in this case study 
the participation of 350000 residential customers, following the same energy consumption behaviour of the four types of households described in section 5.2.1 (87500 households per client type $=350000$ clients).

Note that the selected area and number of clients represent a market share that is relatively small in comparison with the district sizes considered for the study developed in chapter 5 (considering up to 8 million clients). Therefore, the electricity price changes presented in this study are considerably smaller (the impact on the price is analysed in section 7.3.1). The selection of the number of clients in chapter 5 has been done to assess the impact of aggregation at different levels, even if the largest level of aggregation could be impractical, while the number of clients considered in this case study tries to be more realistic.

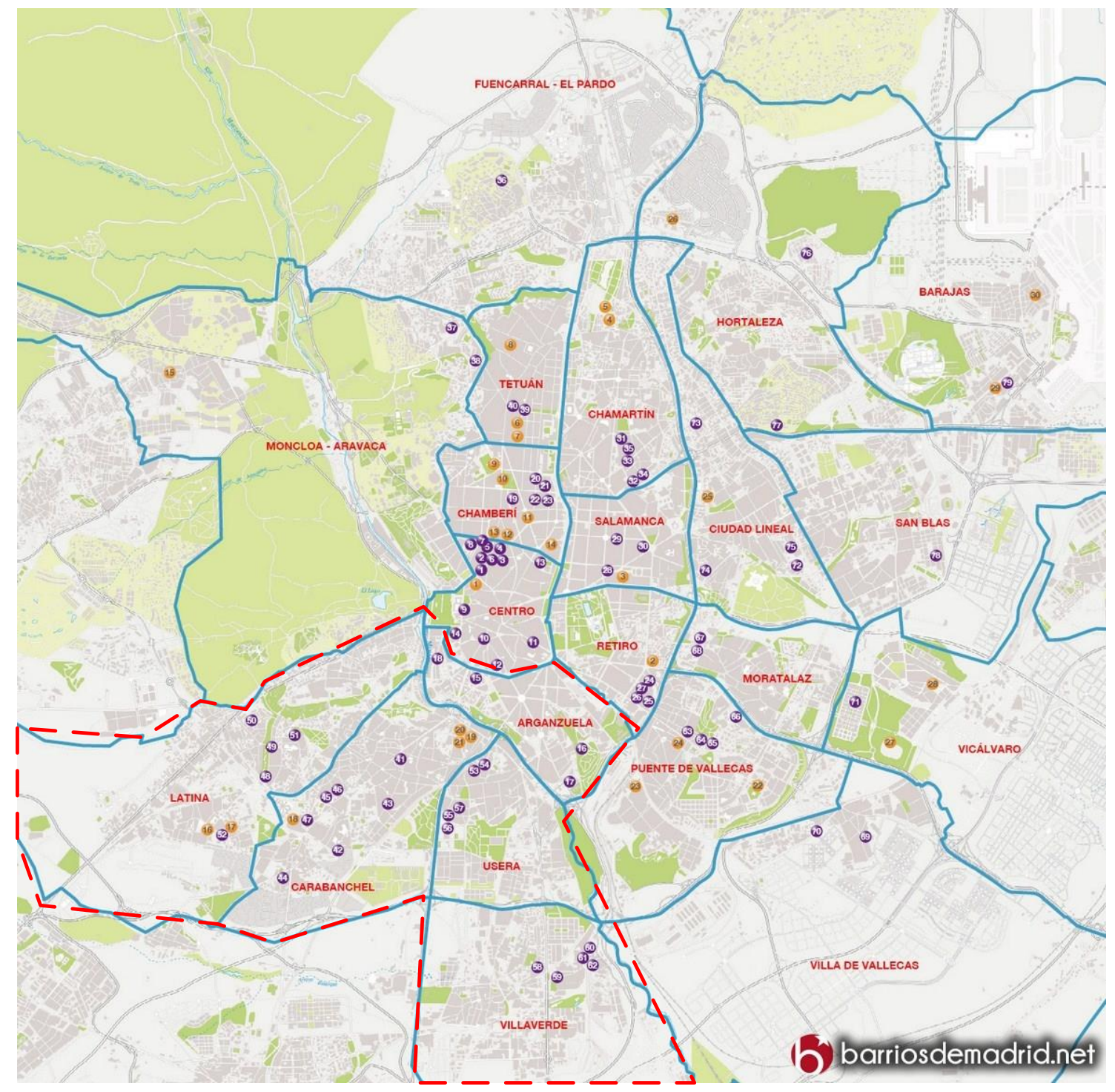

FIG. 44. DISTRICTS OF MADRID CITY AND SELECTED AREA FOR THIS STUDY.

The distributed energy resources considered for the selected districts (apart from the EV) are photovoltaic (PV) panels, air-source heat pump (HP), stationary batteries and demand 
response systems. Costs and performance parameters of the considered DER are listed in section 5.2.1.

There are 5 metro lines (lines 3, 5, 6, 10 and 11, in yellow, light green, grey, dark blue and dark green, respectively) and 49 metro stations within the selected area of Madrid (see Fig. 45 , taken from [239]). The metro energy profiles for the selected line sections (energy used and regenerated) are calculated with the same procedure described in section 6.2.1 (taking metro trip times from [225] and the train average energy consumption from [221]). The resulting aggregated metro profiles for all the considered lines are shown in Fig. 46.

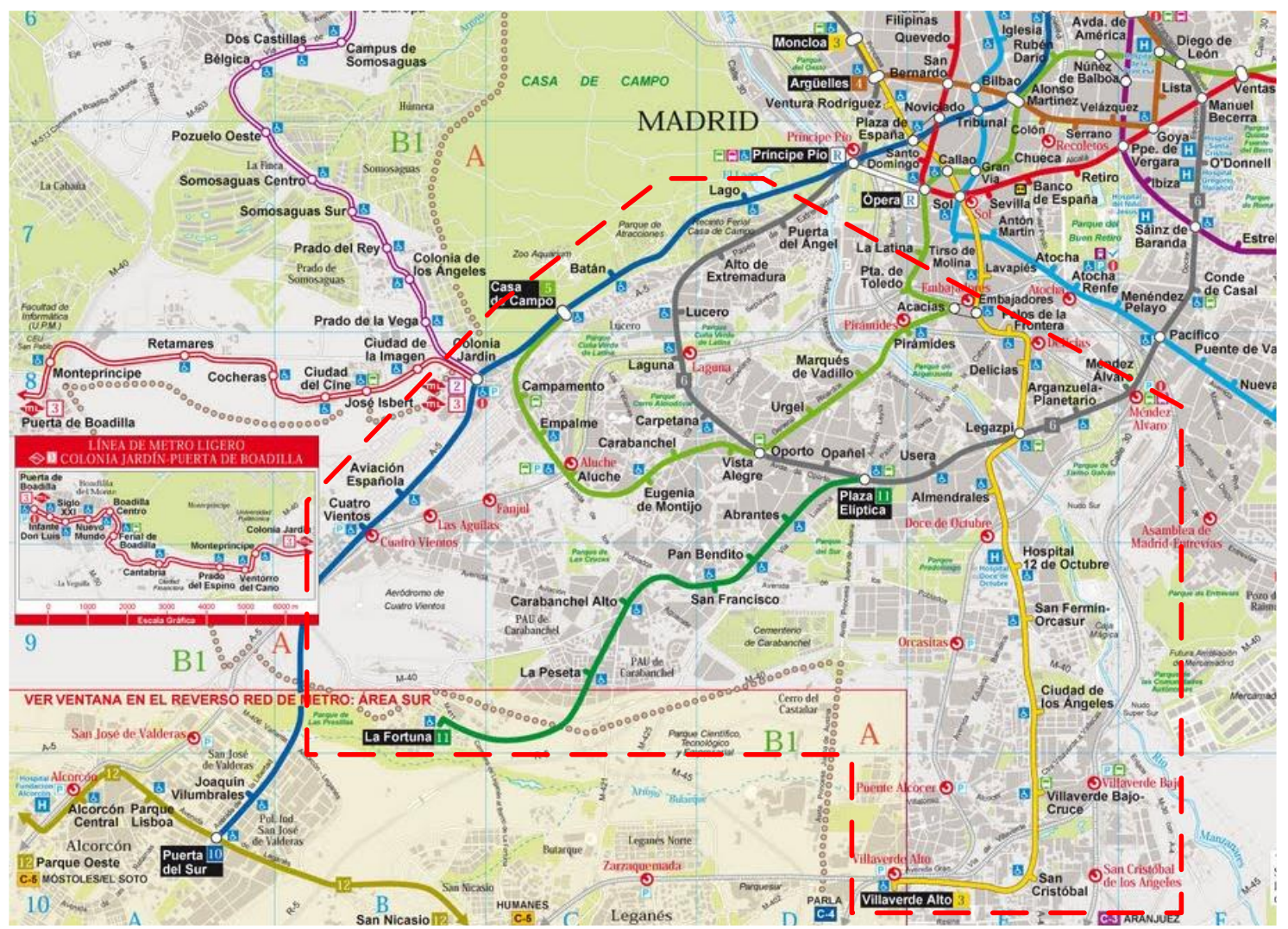

FIG. 45. SECTION OF A GEOGRAPHIC METRO MAP OF MADRID CITY. 


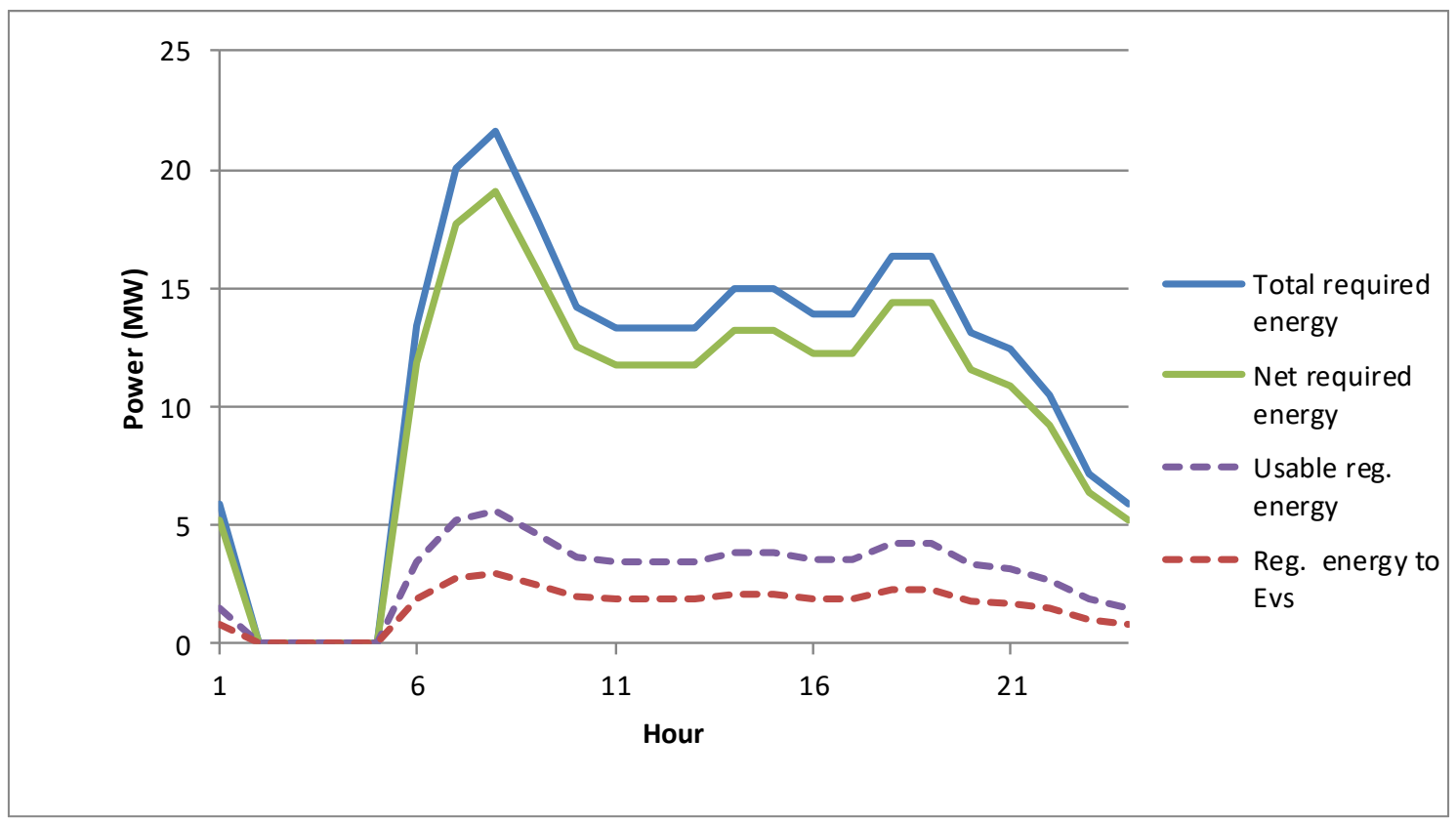

FIG. 46. TOTAL ELECTRIC ENERGY USAGE FOR THE SELECTED METRO LINES.

Different EV penetration levels have been considered. According to [227], there is a total of 17713 public parking spots in the 5 selected districts. Hence, four EV penetration scenarios have been analysed, corresponding to 1000, 5000, 10000 and 15000 EVs. Moreover, it has been considered that there are two types of EV users, as described in section 6.2.2.

Lastly, the same residual demand curves approach described in section 5.2.2 has been used to model the electricity wholesale market. The same three case studies are also considered:

- Case study A: Price-maker with deterministic approach (average scenario).

- Case study B: Price-maker with deterministic approach (most likely scenario).

- Case study C: Price-maker with stochastic approach (three pricing scenarios).

The residual demand curves have been computed using the same historic market data (year 2013) as in section 5.2.2, considering a total lifespan of 20 years and modelling one representative day per month of the year (one representative curve per hour and scenario, 24 hours per day and 12 representative days for the year). In addition, the residual demand curves are adjusted as shown in section 5.2.2.3, by removing the residential base load, the base metro load (before any management, see Fig. 46), and the base EV load according to the number of EVs. The EV base load is computed by uniformly charging the EVs during the time they are plugged-in (without any especial management), according to the EV profiles shown Fig. 32.

In the deterministic problem 288 representative residual demand curves have been computed, corresponding to one representative curve per hour, 24 hours per day and 12 representative days for the year. 


\subsection{RESULTS AND DISCUSSION}

\subsubsection{RESULT DISCUSSION AND CASE STUDY COMPARISON}

This section presents the results of this analysis. Different EV penetration levels have been considered, ranging from 1000 to 15000 vehicles, and taking the two EV types described in section 6.2.2. System operation examples with hourly detail are shown in the following section (7.3.2).

The following indicators have been computed:

- The market share of the loads of the considered system (districts, EVs and metro sections), with (66), as the mean of the hourly market shares (see section 5.3.1).

- The average change on electricity prices due to the aggregator actions and the impact on the electric energy costs on the considered district and metro section, using equations (67) - (73), shown in Table 55.

- The average energy weighted system price change, as in section 5.3.1, shown in Table 55.

- The total savings in comparison with a base case (operating the systems independently and without any DER implementation) using equation (74), and shown in Table 56.

The DER planning and total costs (including metro, EV and district energy and DER costs) results of the analysed case studies are presented in Table 52 and Table 53.

- Looking at the DER installed capacity; PV and HP grow almost linearly with the number of EVs (due to the extra EV energy demand).

- It is interesting to note that the PV installed capacity is bigger in case study B than in case study A. This is produced by the slightly higher prices in this case study in comparison with case study A, making it more profitable to sell energy back to the grid. Case study $\mathrm{C}$, on the other hand, presented smaller installed capacity (around $23 \%$ and $31 \%$ for case studies A and B, respectively, see Table 52), meaning that the higher variability of prices shown in the stochastic scenarios makes load shifting more profitable, relying less on the PV production to reduce costs. This effect has been analysed in detail in section 5.2 and it can be seen in section 7.3.2.

- For the battery storage, only case study $C$ has implemented any capacity, since the prices differences after load management in the other case studies have not been enough to compensate battery investments. As discussed in section 5.2, the better representation of the energy price variability and range shown in the stochastic scenarios have an important impact in the planning and operation of DER, especially for storage systems.

- The system total costs at the end of the project lifespan of 20 years (see Table 53), including energy and DER costs (calculated with the objective function described in 3.2.6), presented a similar linear pattern, with lower slope, than the PV and HP installed capacity.

- The total costs are slightly higher (less than 1\%, see Table 53) in case study B in comparison with case study A (due to higher overall prices), and the costs are considerably smaller in case C (around 18\%, see Table 53), showing once more that 
the aggregator takes advantage of the larger price variability, using demand response and battery systems (see section 5.3.1 for a similar analysis).

Comparing these results against those of previous analysis, it can be noted that:

- The PV capacity per house in this analysis is slightly larger (around 10\%) than in the analysis developed in chapter 5 (for a similar number of houses). For instance, for the price scenario in case study A, around 3kW of average PV (see Table 52) in comparison with $2.7 \mathrm{~kW}$ from chapter 5 (see Table 32). This increment can be attributed to the extra loads present in this system (EVs and metro) that had not been considered in chapter 5 .

- Comparing the PV capacity per house with the one obtained in chapter 6, the installed power is also slightly larger (around 6\%, with average values of $3 \mathrm{~kW}$ vs $2.83 \mathrm{~kW}$, see section 6.3.1). However, it is difficult to compare both analysis as they differ not only in the load sizes but in the electricity price approach as well.

- Regarding HP capacity per house, the difference between this analysis and the one in chapter 5 (for a similar number of houses) is negligible: $0.42 \mathrm{~kW}$ vs $0.417 \mathrm{~kW}$ (for the price scenario in case study A, see Table 52 and Table 32). This suggest that the HP thermal energy production is barely affected by other electric loads.

- Battery capacity is difficult to compare against the other analyses developed in this thesis, as they differ in many elements that affect battery implementation. For instance, the presence of EV (which is not considered in chapter 5) and the energy prices (which is considerably different from chapter 6, where typical commercial and residential tariffs have been used, instead of directly using market prices as in this chapter). Nevertheless, results remain coherent:

- Batteries are only installed in case study C (see Table 52), as in chapter 5 (see Table 32), and the capacity is in the same order of magnitude: around $100-250 \mathrm{MWh}$ in this chapter and around 350MWh in chapter 5 (see Table 32 ). The lower battery capacity value of this study is probably due to the additional free storage provided by the EVs, not considered in chapter 5 .

- Similarly, the total costs for the different studies should be compared with caution as they differ importantly in their considerations.

- Comparing the total costs per house in this study with those of chapter 5 (see Table 38), the added load of EVs and the metro system in this analysis make the total cost larger (around 15\%). For instance, in case study A, this analysis presents $20.9-22.2 \mathrm{k} €$ total cost per house (see Table 53), while in chapter 5 the cost are approximately $18.2 \mathrm{k} €$ (see Table 38).

- Comparing with the cost of chapter 6 (in particular, those shown in Table 48 ), it can be seen that the costs per house in this chapter are considerably lower: $27.9-30 \mathrm{k} €$ in chapter 6 (see Table 48) and $20.9-22.2 \mathrm{k} €$ for case study A in this chapter (see Table 53), for an average reduction of $32 \%$. This reduction is attributed to the active participation in the energy markets considered in this study, taking advantage of the price-maker approach and the higher variability of prices not present in the tariffs used in chapter 6 . However, the number of houses, EVs and metro lines are very different between both studies, making difficult to do a fair comparison. 
TABLE 52. DER INSTALLED CAPACITY FOR ALL CASE STUDIES.

\begin{tabular}{cc|ccccccccc}
$\begin{array}{c}\text { Number } \\
\text { of EVs }\end{array}$ & $\begin{array}{c}\text { Market } \\
\text { share } \\
\text { (\%) }\end{array}$ & \multicolumn{3}{c}{ PV (MW) } & \multicolumn{4}{c}{ Battery (MWh) } & \multicolumn{3}{c}{ HP (MW) } \\
& A & B & C & A & B & C & A & B & C \\
\hline 1000 & $0.71 \%$ & 998.07 & 1117.84 & 786.1 & 0 & 0 & 232.0 & 149.72 & 150.62 & 134.3 \\
5000 & $0.73 \%$ & 1026.81 & 1150.83 & 787.0 & 0 & 0 & 188.1 & 147.82 & 149.72 & 134.2 \\
10000 & $0.75 \%$ & 1050.32 & 1162.47 & 794.2 & 0 & 0 & 124.8 & 145.88 & 149.72 & 134.4 \\
15000 & $0.77 \%$ & 1065.1 & 1197.38 & 800.3 & 0 & 0 & 81.5 & 145.88 & 149.72 & 134.4
\end{tabular}

TABLE 53. TOTAL SYSTEM COST (METRO, EV AND DISTRICT ENERGY AND DER COSTS) FOR ALL CASE STUDIES (AT THE END OF THE 20 YEARS PROJECT LIFESPAN).

\begin{tabular}{cc|cccccc}
$\begin{array}{c}\text { Number } \\
\text { of EVs }\end{array}$ & $\begin{array}{c}\text { Market } \\
\text { share }\end{array}$ & \multicolumn{3}{|c}{ Total costs (M€) } & \multicolumn{3}{c}{ Total costs per household (k€) } \\
& (\%) & A & B & C & A & B & C \\
\hline 1000 & $0.71 \%$ & 7336.75 & 7378.10 & 6055.96 & 20.96 & 21.08 & 17.30 \\
5000 & $0.73 \%$ & 7463.23 & 7502.19 & 6146.13 & 21.32 & 21.43 & 17.56 \\
10000 & $0.75 \%$ & 7628.08 & 7667.48 & 6282.93 & 21.79 & 21.91 & 17.95 \\
15000 & $0.77 \%$ & 7796.76 & 7838.61 & 6382.19 & 22.28 & 22.40 & 18.23
\end{tabular}

Table 54 shows the average changes in electric energy costs for the district, the metro, and all the systems together, including EV energy costs (calculated with (73)). Note that these costs include only electric energy, not considering DER investment and maintenance, thermal energy or contracted power costs.

- Case studies A and B have almost the same total and district electricity costs for all $\mathrm{EV}$ scenarios. Also, the electric energy cost reduction is greater with larger number of EVs (around 5\% more for the largest number of EV, see Table 54). These extra benefits are caused by the extra storage capacity provided by the higher number of EVs, making possible more load shifting.

- Case study C presents a slightly smaller cost savings for the total and district costs (average of $40 \%$ in total energy costs savings in comparison with the average of $68 \%$ of savings in cases A and B). However, case study C presents the larger reduction for the metro system (up to $14 \%$, see Table 54), suggesting that the metro is taking advantage of the DER systems installed at the district and the EV storage. This is a similar effect to the study in chapter 6 . Also note that case study C implements less DER systems than the other case studies, and presents the lower overall costs (see Table 52 and Table 53), suggesting that the savings in other areas compensate for the slightly larger total electricity costs. 
- Note that the metro energy cost reduction presents a considerable smaller reduction in comparison with the corresponding results of chapter 6 (metro energy costs savings up to $44 \%$, see section 6.3.1). This shows that, in an aggregated approach where all the systems buy energy at the market price, the optimization problem prioritise its planning and operation to minimize the costs of the larger loads, which represent the biggest share of the costs. For this particular study the district loads are larger than the metro and EV loads, representing the largest costs.

TABLE 54. EFFECT ON ELECTRIC ENERGY COST FOR ALL CASE STUDIES.

\begin{tabular}{c|ccccccccc}
$\begin{array}{c}\text { Number } \\
\text { of EVs }\end{array}$ & \multicolumn{3}{|c}{ Total (\%) } & \multicolumn{4}{c}{ District (\%) } & \multicolumn{3}{c}{ Metro (\%) } \\
\hline 1000 & -65.5 & -65.4 & -40.2 & -69.3 & -69.2 & -42.1 & -6.8 & -6.6 & -10.1 \\
5000 & -67.9 & -67.9 & -39.8 & -71.0 & -71.0 & -40.1 & -7.5 & -7.3 & -12.5 \\
10000 & -69.7 & -69.8 & -40.0 & -72.0 & -72.2 & -38.3 & -7.4 & -7.1 & -13.8 \\
15000 & -70.1 & -70.2 & -40.0 & -71.6 & -71.8 & -36.7 & -7.2 & -7.3 & -14.1
\end{tabular}

Table 55 shows the average change on electricity prices due to the aggregator actions and the repercussion on the average electric energy costs of the system (calculated with (67) (73)).

- From Table 55 and the Fig. 47 to Fig. 50 (shown in section 7.3.2), it can be seen that distributed generation such as PV panels logically tends to reduce the overall electricity consumption from the grid, reducing the electricity price in all case studies (up to $0.5 \%$ in average, see the left columns in Table 55). This effect is more evident in the analysis developed in section 5.3.

- Note that the market share in this analysis is relatively small in comparison with the district sizes considered for the study developed in chapter 5 (reaching a market share up to $8 \%$, while here is $0.77 \%$ ). Therefore, the electricity price changes presented in this study are considerably smaller.

- Comparing the change on electricity prices, case study A shows a slightly bigger decrement in comparison with case study B (around $0.5 \%$ vs $0.3 \%$, see the left columns in Table 55). The slightly larger overall prices in case study B, promotes more PV installed capacity (see Table 52) to sell more energy back to the grid, but less load shifting than case study A. This can be seen in the system operation figures of section 7.3.2.

- For case study $\mathrm{C}$, it can be seen that the higher variability on the original prices can make the average price change appear small in comparison with previous case studies (around $0.25 \%$, see the left columns in Table 55). However, the absolute change is larger than for the other cases: around $1.15 \%$, in comparison with $1 \%$ and $0.7 \%$ for case studies A and B, respectively (see the central columns in Table 55). In other words, in case study $\mathrm{C}$ the price decrements have been more compensated with the prices increments, unlike the other cases that produced more decrements than increments on the electricity price, moving the average price down. 
- Lastly, the effect on the weighted average system price has also been calculated, resulting in decrement of around $0.54 \%$. This value is very similar to the equivalent change in the analysis of chapter 5 (change of $0.5 \%$ for an equivalent number of houses, see Table 34), showing that the overall market behaviour of both systems is comparable, affecting the energy prices in a similar way.

TABLE 55. EFFECT ON ELECTRICITY PRICES FOR ALL CASE STUDIES.

\begin{tabular}{cc|cccccccc}
$\begin{array}{c}\text { Number } \\
\text { of EVs }\end{array}$ & $\begin{array}{c}\text { Market } \\
\text { share }\end{array}$ & \multicolumn{3}{|c}{$\begin{array}{c}\text { Average price } \\
\text { change (\%) }\end{array}$} & \multicolumn{4}{c}{$\begin{array}{c}\text { Average abs. } \\
\text { price change (\%) }\end{array}$} & $\begin{array}{c}\text { Average system } \\
\text { price change }\end{array}$ \\
& (\%) & A & B & C & A & B & C & (\%) \\
\hline 1000 & $0.71 \%$ & -0.47 & -0.32 & -0.27 & 0.90 & 0.72 & 1.10 & -0.53 \\
5000 & $0.73 \%$ & -0.50 & -0.31 & -0.25 & 0.94 & 0.75 & 1.11 & -0.53 \\
10000 & $0.75 \%$ & -0.53 & -0.31 & -0.21 & 0.99 & 0.78 & 1.14 & -0.54 \\
15000 & $0.77 \%$ & -0.55 & -0.29 & -0.18 & 1.02 & 0.79 & 1.17 & -0.54
\end{tabular}

Additionally, the total costs of all the considered systems (including metro, EVs, district and DER costs) have been compared with a base case following a business-as-usual approach (not implementing any DER systems and managing all the systems independently). Hence, this comparison allows to assess the benefits of the optimal integrated management of metro, EVs, district loads and DER systems under different EV penetration levels. To create a fair assessment, each case study has been compared with its own base case (equal input parameters) without implementing any distributed energy resources, as described in (74). The results of such comparisons can be found in Table 56 .

Looking at the results, case study B, with slightly higher range of off-peak to peak prices in comparison with case study A, presents a small extra benefit from the interconnected scheme and DER systems (21\% approx. compared with $19 \%$ of case study A, see Table 56 ). However, the larger price variability of the scenarios in case study $\mathrm{C}$, provides even better results, achieving $30 \%$ of economic benefits (see Table 56). A similar behaviour occurs in the analysis of chapter 5 , where case study $C$ is the one with greater savings (see Table 39 ). Showing once more, the importance of a better representation of the real range and variability of energy prices, which is partially lost in the averaging process of case studies A and $B$ (see section 5.3 for a more detail discussion of this effect).

It is interesting to remark that the number of EVs has little impact on the total savings for all case studies (around $0.5 \%$ of difference). Also. the EVs add extra load that translate into higher costs. This suggest that for this particular application, the EVs have reached its saturation point (this effect is described in detail on section 6.3.3). 
TABLE 56. PERCENTAGE OF TOTAL SAVINGS (CONSIDERING ALL SYSTEMS AND ALL COSTS) IN COMPARISON WITH THE BASE SYSTEM COSTS OF EACH CASE STUDY.

\begin{tabular}{|c|c|c|c|c|}
\hline $\begin{array}{c}\text { Number of } \\
\text { EVs }\end{array}$ & $\begin{array}{c}\text { Market } \\
\text { share } \\
(\%)\end{array}$ & $\begin{array}{c}\text { Case study } \\
\text { A } \\
(\%)\end{array}$ & $\begin{array}{c}\text { Case study } \\
\text { B } \\
(\%)\end{array}$ & $\begin{array}{c}\text { Case study } \\
\text { C } \\
(\%)\end{array}$ \\
\hline 1000 & $0.71 \%$ & $19.4 \%$ & $21.1 \%$ & $30.5 \%$ \\
\hline 5000 & $0.73 \%$ & $19.4 \%$ & $21.1 \%$ & $30.5 \%$ \\
\hline 10000 & $0.75 \%$ & $19.3 \%$ & $20.9 \%$ & $30.3 \%$ \\
\hline 15000 & $0.77 \%$ & $19.1 \%$ & $20.7 \%$ & $30.1 \%$ \\
\hline
\end{tabular}

By analysing these results, some recommendations can be drawn for policy makers and stakeholders:

- Even though the results presented here are specific to the case study analysed, these results suggest that there are potential economic benefits for such integrated approach (in this analysis, up to 30\%). In addition, if environmental and health benefits due to renewable systems and EVs are also taken into account, smart city programmes, as the one presented here, could be of great interest for investors and policy makers.

- During the planning of systems, it can be seen that the stochastic scenarios represent better the real-life variability and range of energy prices, which translates to more robust capacity planning of DER systems and higher overall cost savings (see Table 56). Therefore, such a stochastic approach in the planning process is recommended.

- Certainly, the introduction of more EVs will bring extra load to the electric system, translating to extra cost. However, these costs can be compensated with the savings from the extra storage provided by the EVs, especially if the storage is not only used for energy arbitrage, but for ancillary services as well (which have not been considered in this thesis). Therefore, vehicle-to-grid (V2G) schemes should be supported to facilitate the introduction of EVs in smart cities.

\subsubsection{AGGREGATED SYSTEM BEHAVIOUR FOR ALL STUDY CASES}

This section analyses the operation of the systems considered for the three case studies. The first case study analysed is case study A, which is deterministic and considers the average residual demand curve of each hour. Fig. 47 to Fig. 50 show the electric energy transaction from the grid and its effect on electricity prices, for the considered clients implementing DER systems and the considered section of the metro system. These energy transactions refer to the net demand from the grid, considering consumption, generation and management of resources. For the sake of brevity, only two out of the twelve representative days have been shown (one for winter and one for summer), and two EV penetration scenarios (1000 EVs and $15000 \mathrm{EVs}$ ). In these figures, the higher part "a" correspond to the aggregated behaviour of district, EVs and metro. The middle figure " $b$ " shows only the 
district transaction with the grid (including the EV management), and the lower figure "c" corresponds to the managed metro load.

For the winter day, the original energy price (blue line, Fig. 47) has lower prices in the early morning (off-peak time) and higher prices from $16 \mathrm{~h}$ to $24 \mathrm{~h}$ (peak time).

- As expected, the original load curve changes, increasing the grid consumption in offpeak hours when the energy is cheaper, and decreasing the load in peak price when the energy is more expensive (see Fig. 47a). In addition, in the middle of the day, when solar production is available, the energy consumption from the grid is almost zero, as the solar energy is used to fulfil the demand.

- The metro energy consumption from the grid (net demand, calculated with equation (25) and shown in Fig. 47c) does not change as much as the district (Fig. 47b) due to its relatively low energy requirements in comparison with the considered district, and the changes in the metro energy curve are mainly to reduce power peaks (around $10-20 \%$ of the power peaks).

- Note that the metro load is considerably smaller than the district load (over an order of magnitude smaller), making the total energy consumption profile for all systems (Fig. 47a) and the consumption profile for the district (Fig. 47b) to be almost the same.

- In addition, the peak load of the district corresponds with the peak prices, whereas the peak load of the metro is at lower prices (see Fig. 47c), suggesting that the EV storage is mainly used by the district, instead of the EVs.

- In the energy price curve, the increments and decrements are minor (less than 1\%) given the relatively small load in the case study (around $0.75 \%$ of the total market). However, the price curve has a similar behaviour to the ones reviewed in section 5.3.2, increasing the price in off-peak hours and decreasing it in peak hours. 
a) Total energy transactions with the grid

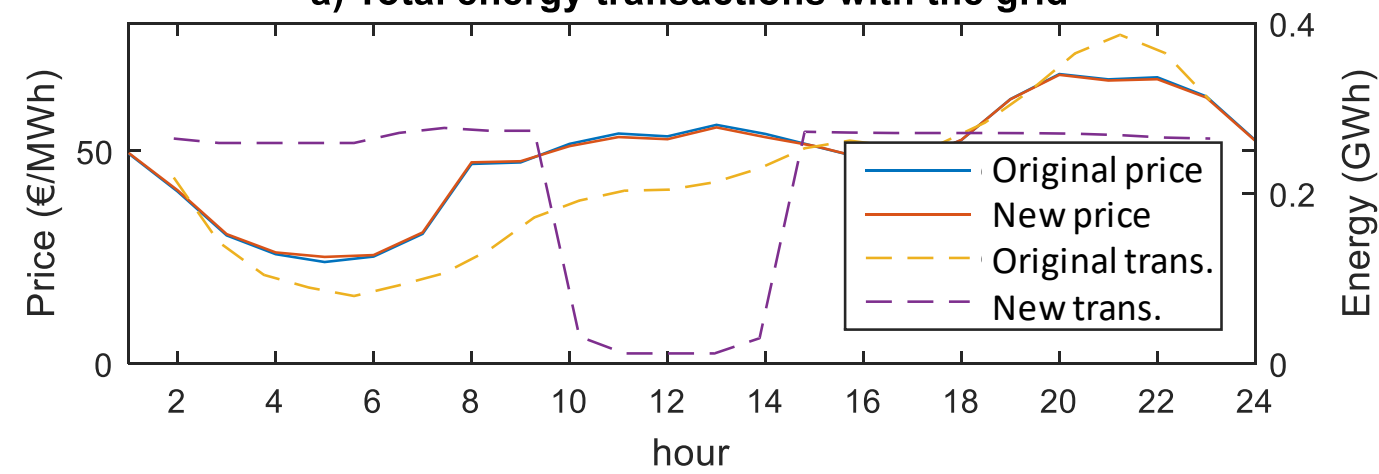

b) District load

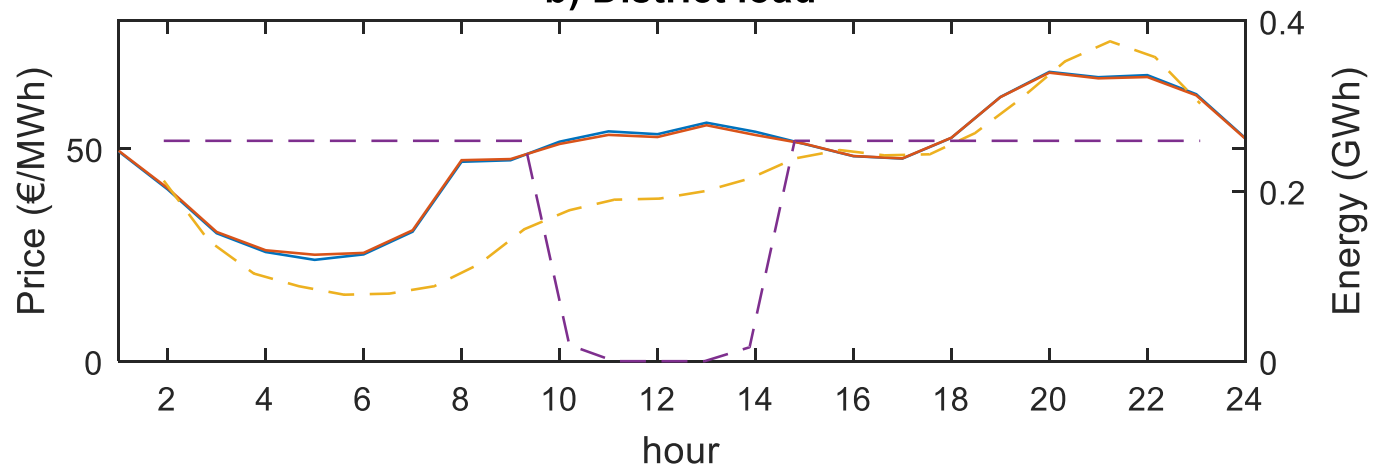

c) Metro load

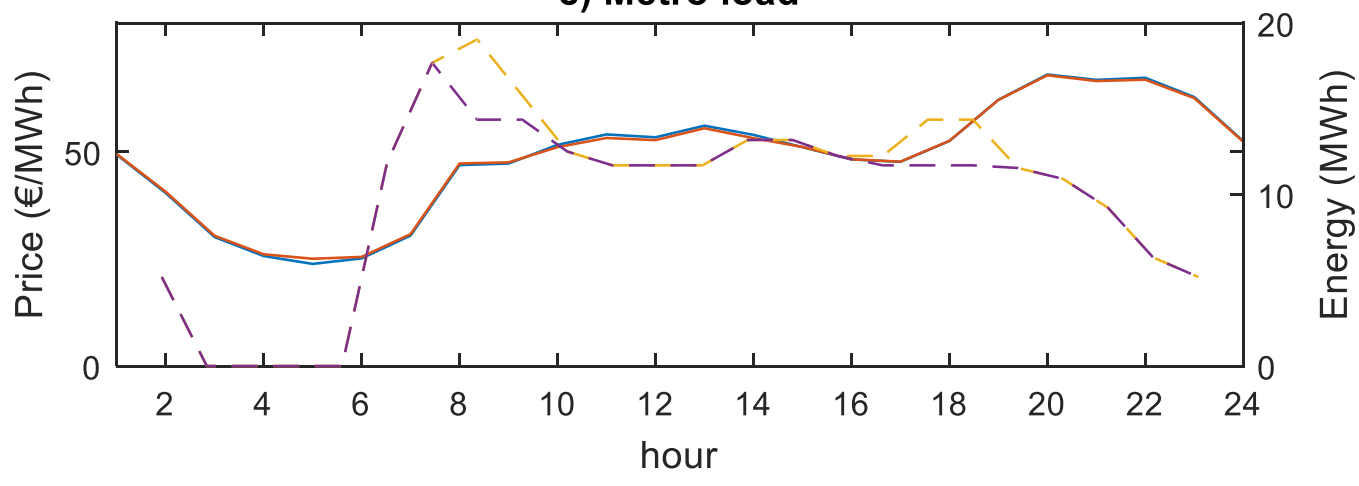

FIG. 47. AGGREGATOR ENERGY TRANSACTIONS AND EFFECT ON ENERGY PRICE FOR THE REPRESENTATIVE DAY OF JANUARY (CASE STUDY A) FOR 1000 EVS.

In the representative summer day, the original price curve (blue line, Fig. 48a) is flatter than its equivalent at winter. However, the behaviour of the aggregator is similar, reducing energy transactions at the middle of the day with the PV production, and shifting the district load to such hours. The new energy price (red line, Fig. 48) is lower (up to 5\%), especially at the sunny hours (mainly $8-18 \mathrm{~h}$ ). Regarding the metro load, the peak is also reduced in the beginning of the day, and the load curve also takes advantage of the solar production in the middle of the day, decreasing the overall energy consumption. More detail on overall energy price changes and costs can be found in section 7.3.1 (see Table 55). 
a) Total energy transactions with the grid

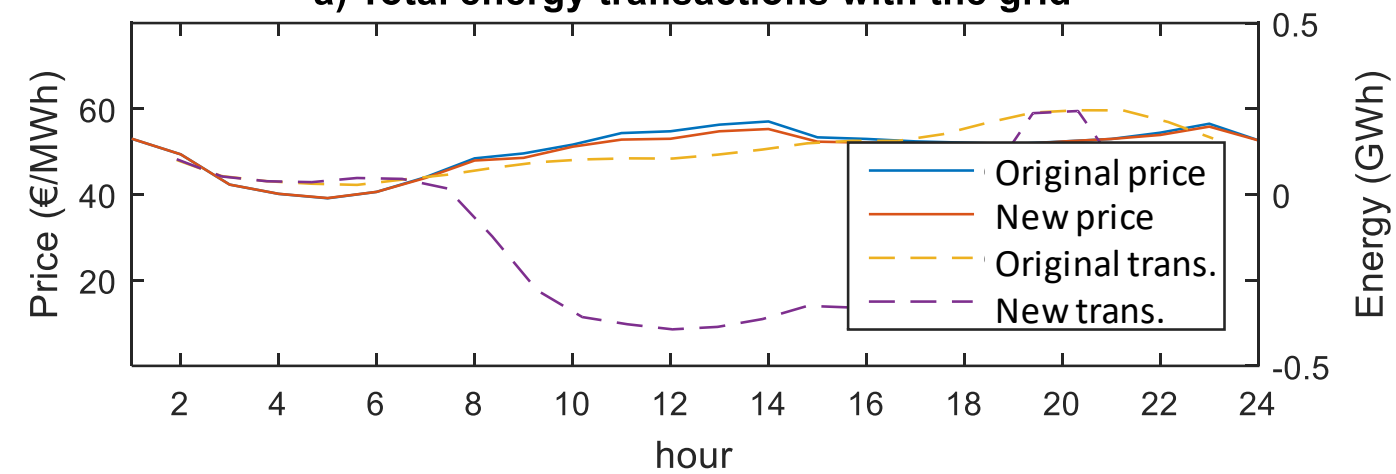

b) District load

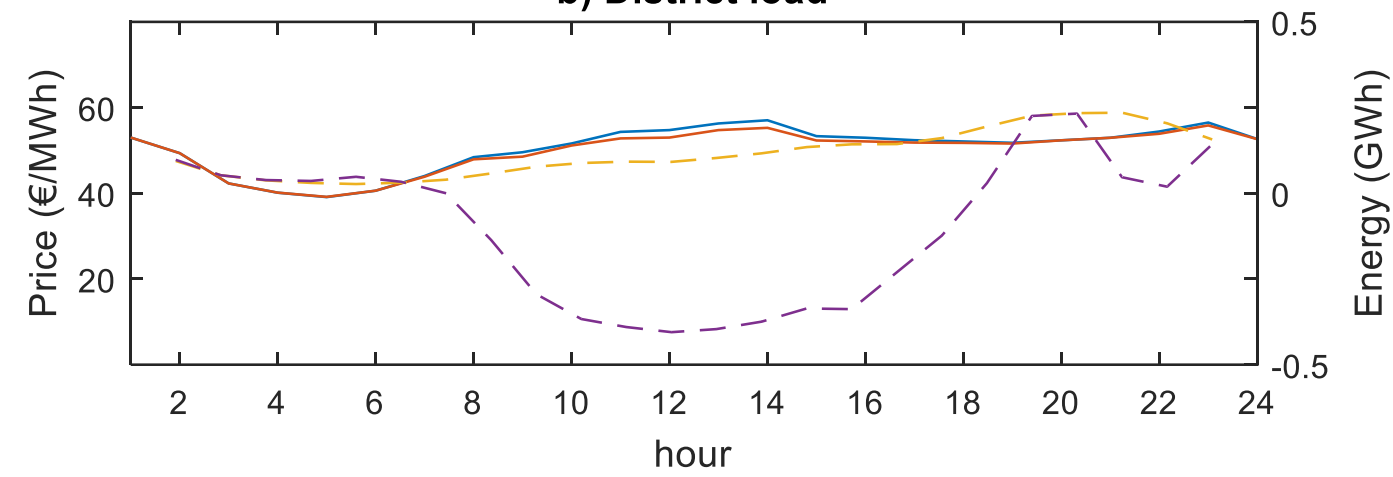

c) Metro load

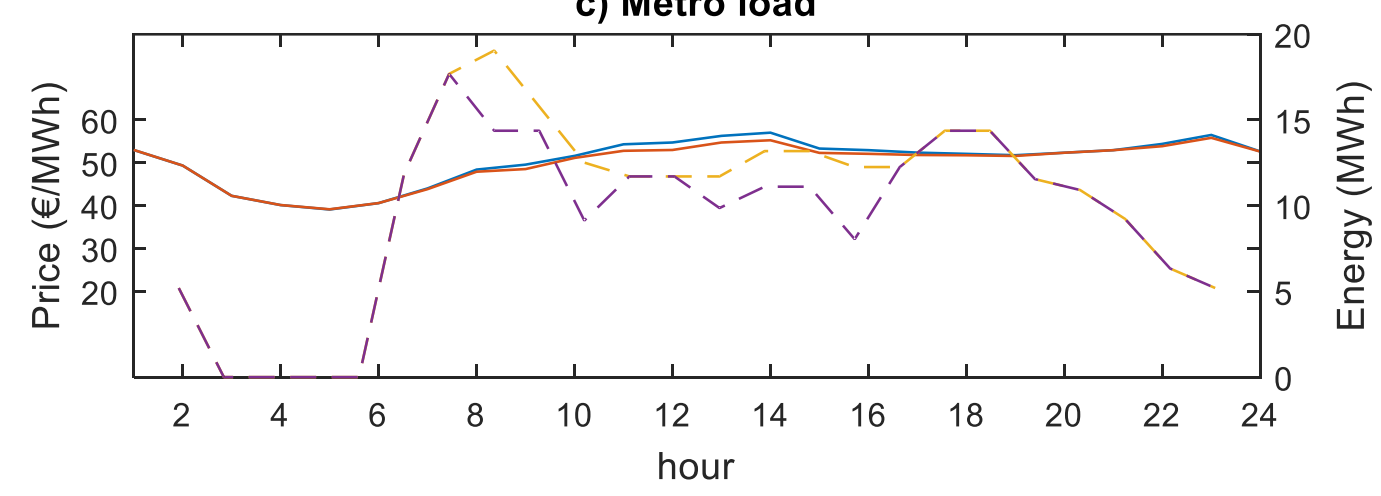

FIG. 48. AGGREGATOR ENERGY TRANSACTIONS AND EFFECT ON ENERGY PRICE FOR THE REPRESENTATIVE DAY OF JULY (CASE STUDY A) FOR 1000 EVS.

The case of 15000 EVs shows a similar behaviour to the 1000 EVs scenario. In the winter day (Fig. 49), the energy management of all the systems is very similar to the one shown in Fig. 47. The resulting load curves in summer time (Fig. 50) vary slightly more to the 1000 EVs case, but the overall behaviour is similar (increasing the load in off-peak hours, reducing it in peak hours, and selling energy when solar power is available). However, more energy is sold back to the grid. This suggest that the extra storage capacity provided by the EVs allows more load to be shifted and more energy to be sold. 
a) Total energy transactions with the grid

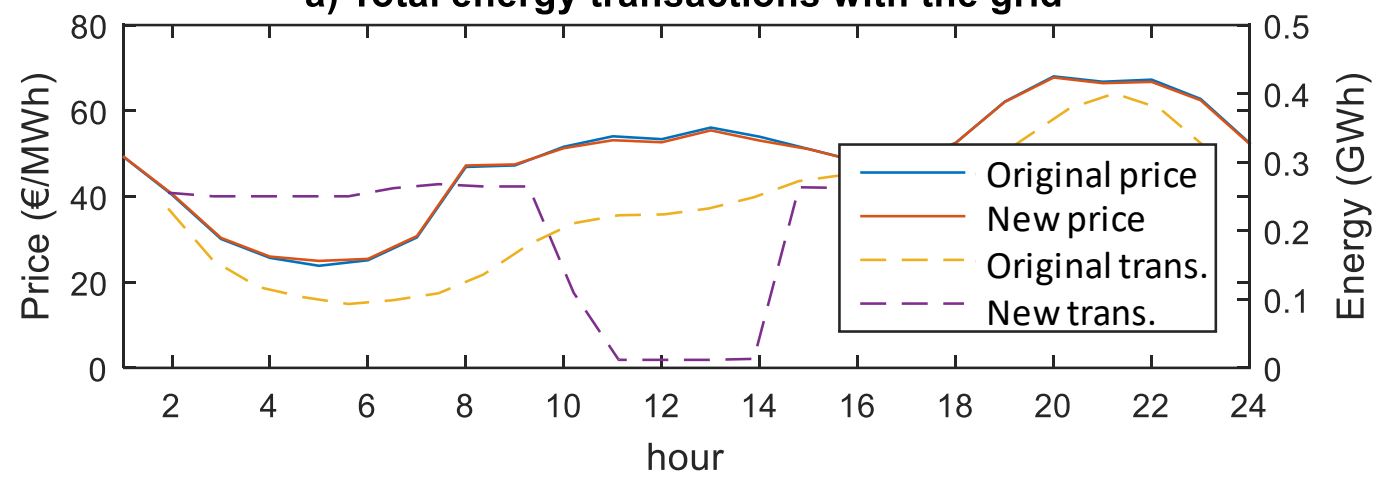

b) District load

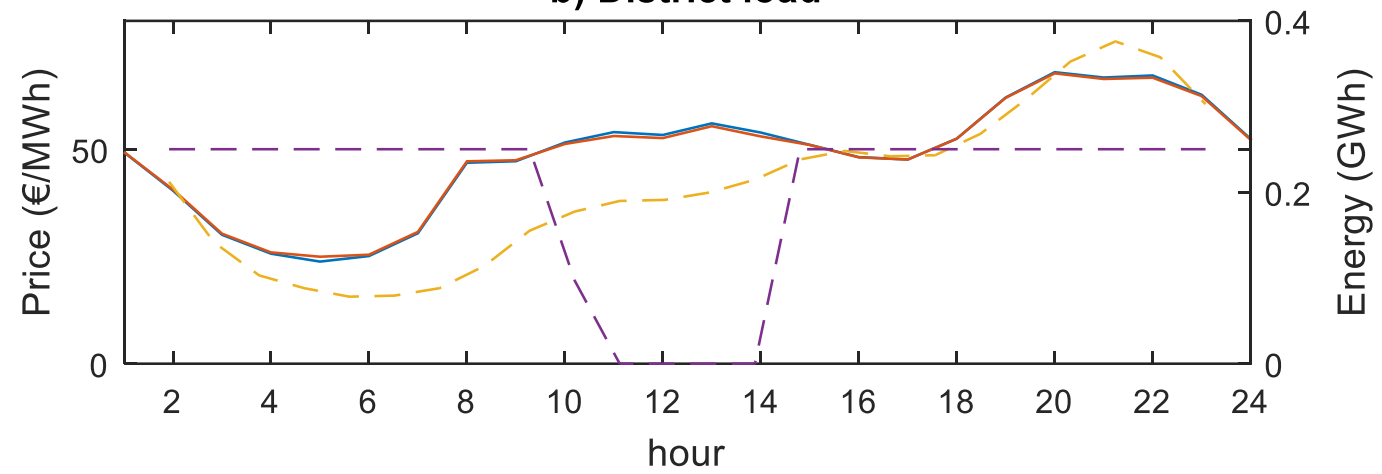

c) Metro load

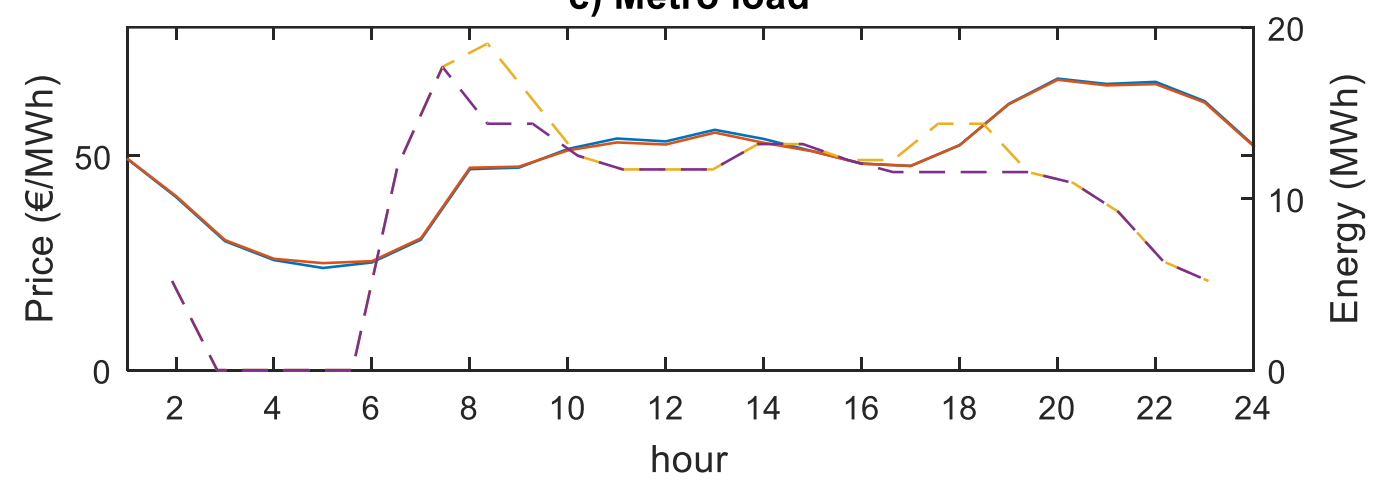

FIG. 49. AGGREGATOR ENERGY TRANSACTIONS AND EFFECT ON ENERGY PRICE FOR THE REPRESENTATIVE DAY OF JANUARY (CASE STUDY A) FOR 15000 EVS. 
a) Total energy transactions with the grid

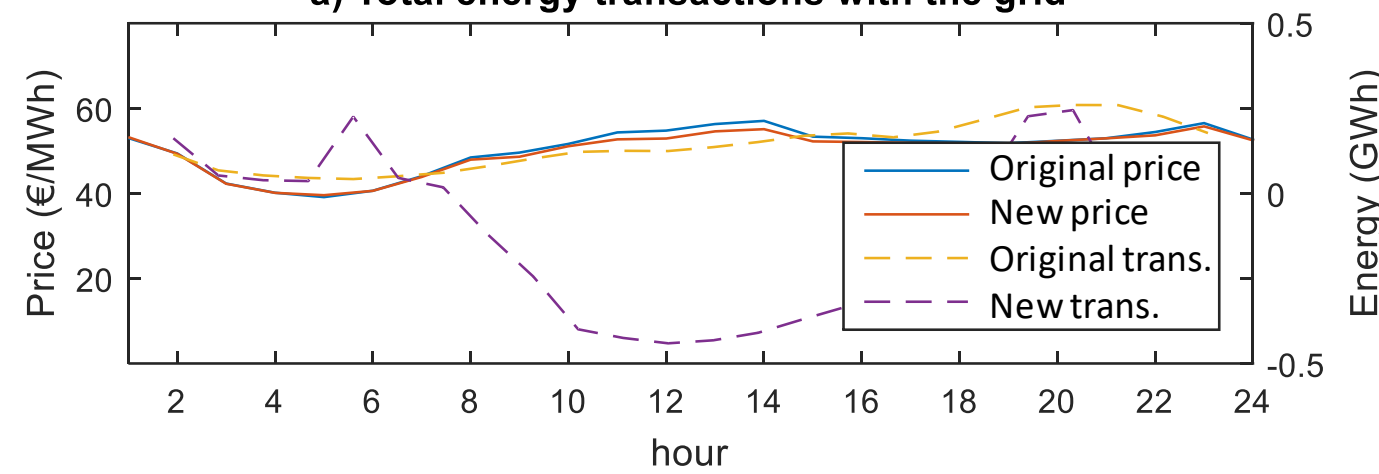

b) District load

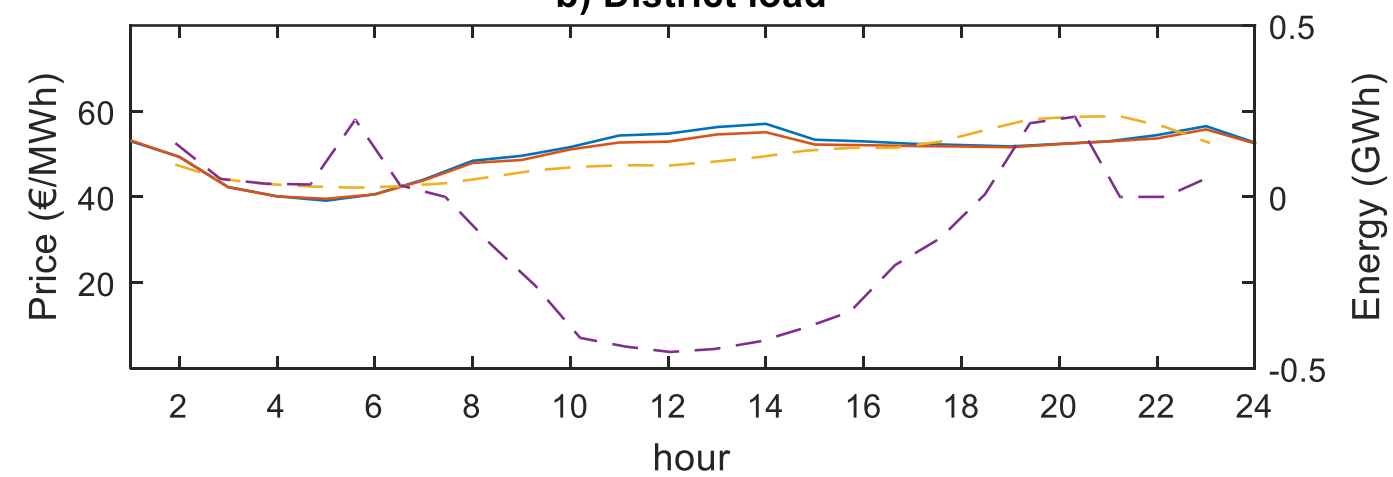

c) Metro load

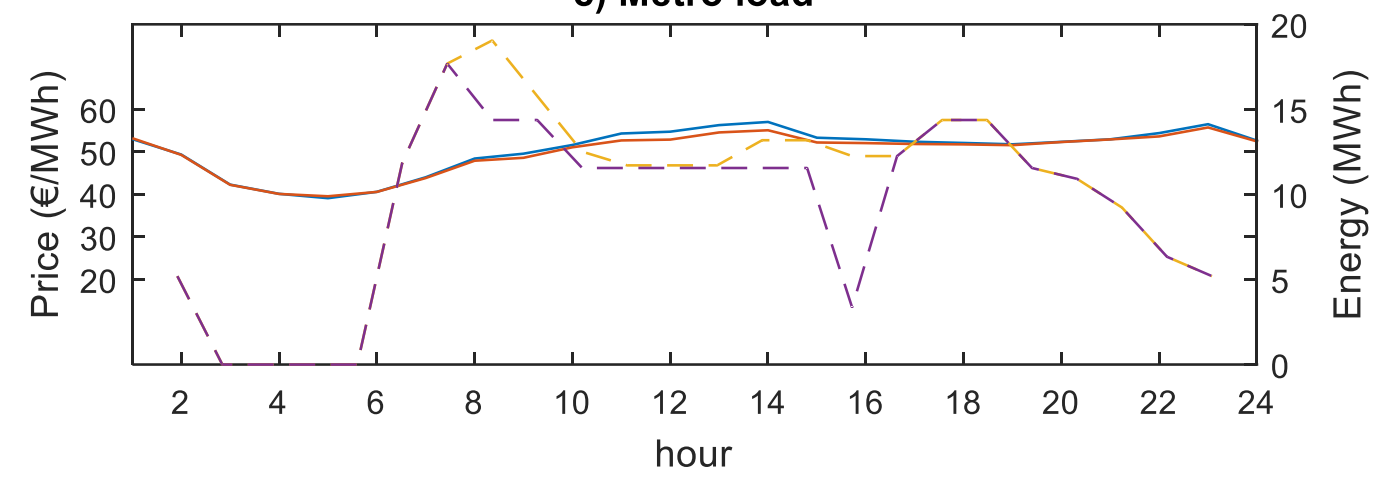

FIG. 50. AGGREGATOR ENERGY TRANSACTIONS AND EFFECT ON ENERGY PRICE FOR THE REPRESENTATIVE DAY OF JULY (CASE STUDY A) FOR 15000 EVS.

The operation in case study B is illustrated in Fig. 51 and Fig. 52, taking the most probable pricing scenario out of the stochastic ones (for the sake of brevity only the 15000 EVs scenario is shown). In this case study, the price curve has slightly higher prices in the middle of the day for both winter and summer time (over $60 € / M W h$ at $14 \mathrm{~h}$ in Fig. 52, in comparison with $57 € / M W h$ at $14 \mathrm{~h}$ in Fig. 50). This effect produces slightly more energy sold back to the grid in summer time. However, the overall behaviour is similar to case study A. 
a) Total energy transactions with the grid

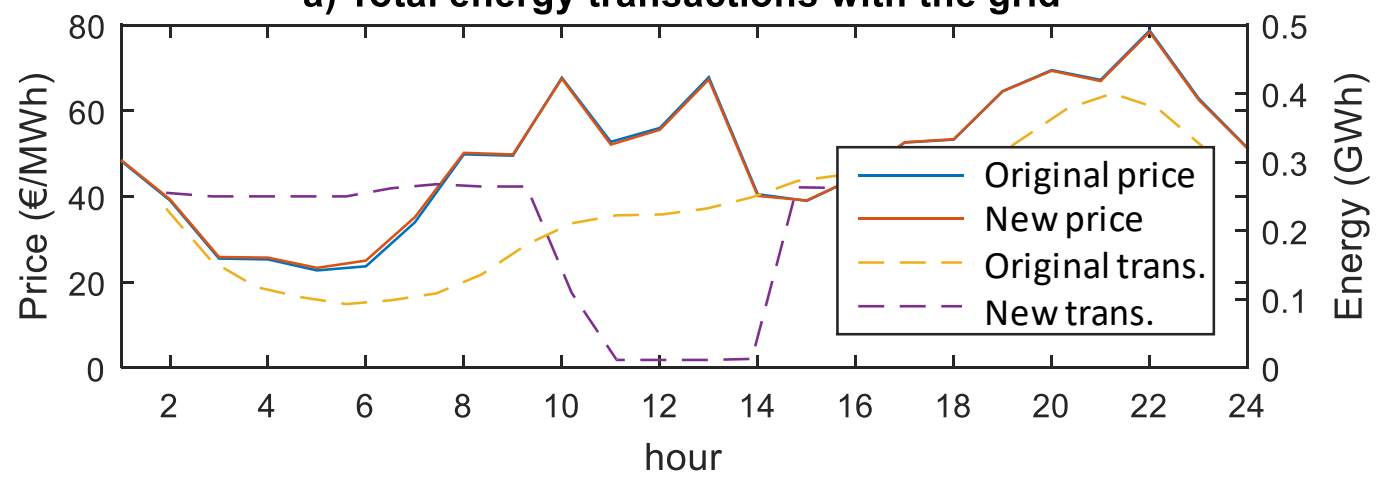

b) District load

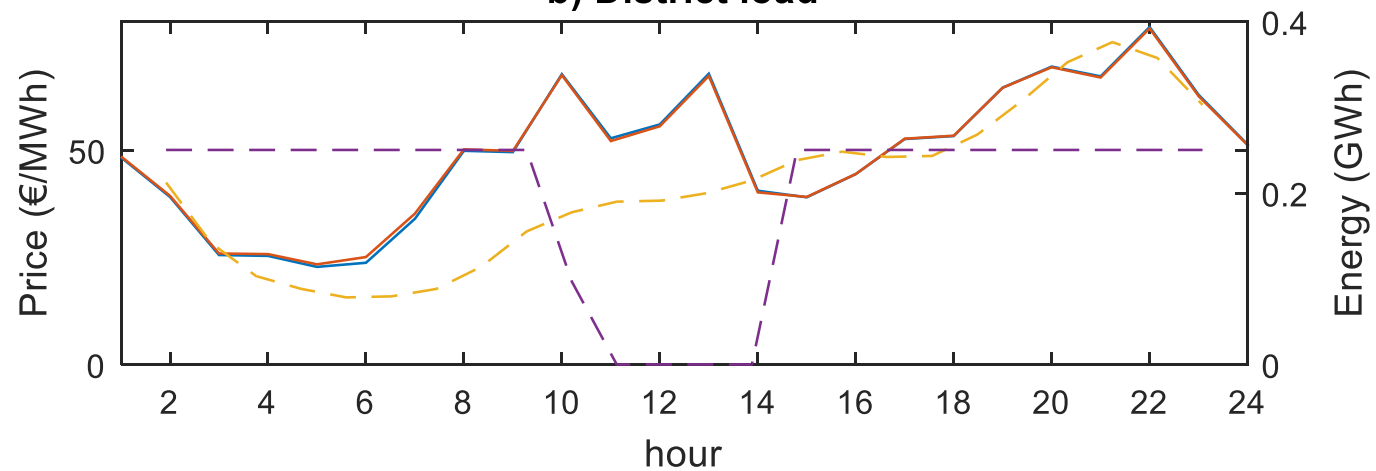

c) Metro load

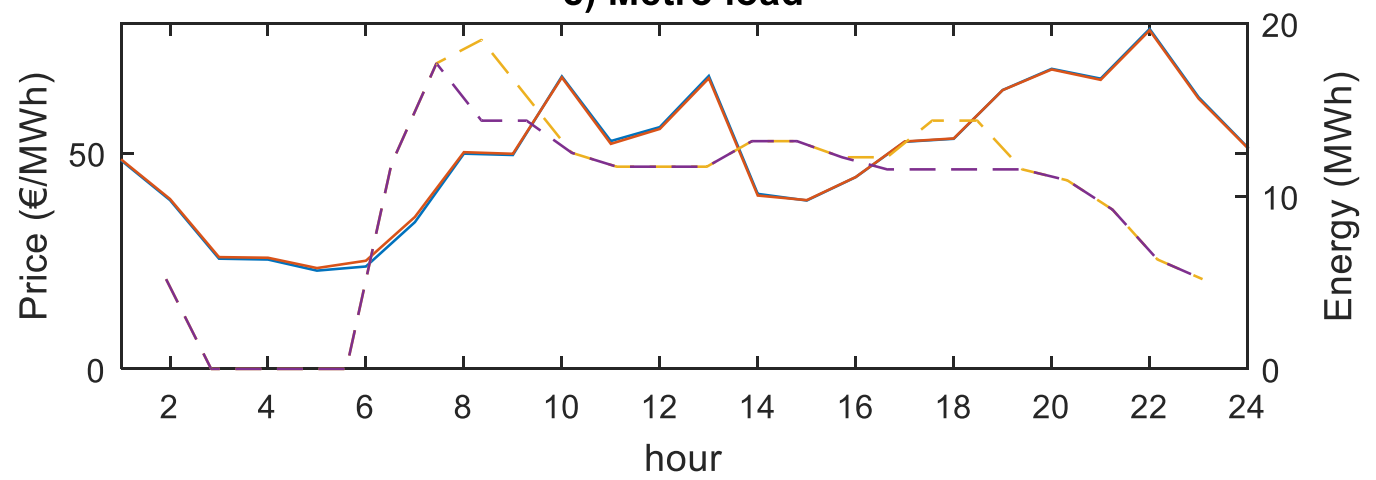

FIG. 51. AGGREGATOR ENERGY TRANSACTIONS AND EFFECT ON ENERGY PRICE FOR THE REPRESENTATIVE DAY OF JANUARY (CASE STUDY B) FOR 15000 EVS. 
a) Total energy transactions with the grid

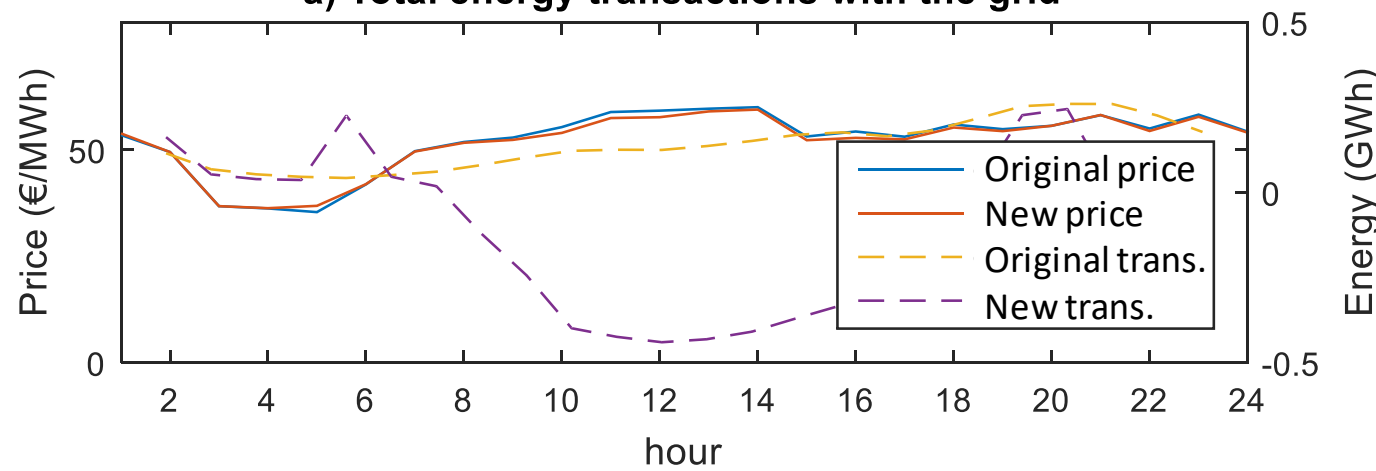

b) District load

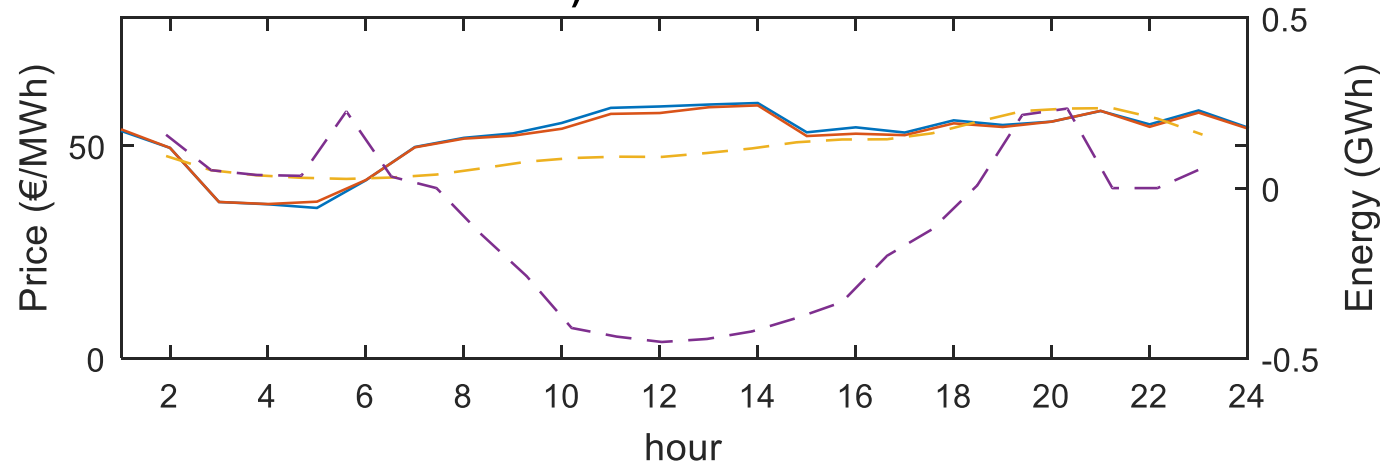

c) Metro load

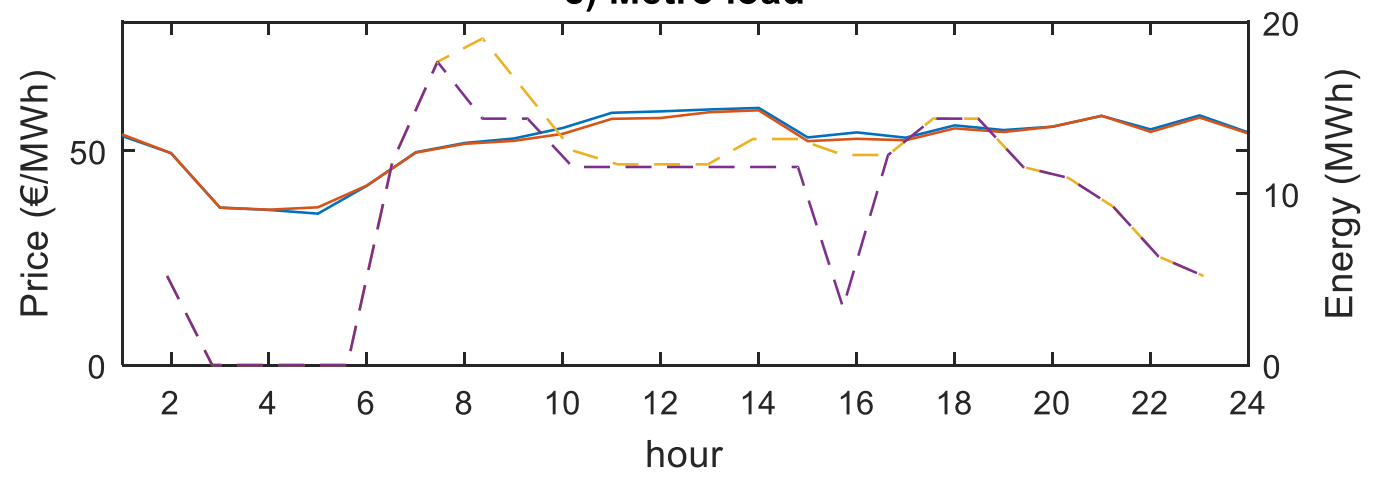

FIG. 52. AGGREGATOR ENERGY TRANSACTIONS AND EFFECT ON ENERGY PRICE FOR THE REPRESENTATIVE DAY OF JULY (CASE STUDY B) FOR 15000 EVS.

Case study C implements the stochastic model with 3 scenarios. Fig. 53 to Fig. 55 shows the aggregator behaviour for the three scenarios at winter time for the 15000 EVs case.

- It can be seen that these scenarios have larger variability and price differences in comparison with previous case studies, with prices ranging from 0 to $80 € / \mathrm{MWh}$ approximately. As mentioned in the analysis developed in chapter 5, this larger variability in prices is due to the larger granularity provided by more cluster representatives (see section 5.2.2). 
- Note that the stochastic scenarios represent better the real price range that is reduced in the deterministic scenario due to averaging (reducing peaks and valleys in the price curves).

- The larger price variability provokes the district to install more battery capacity (see Table 52), so the aggregator can buy more energy at the early hours of the day, when the prices are lower or even zero, to store it and use it (or sell it) when prices are higher.

- Unlike the district, that vary slightly more, the metro load curve is very similar to case studies A and B, suggesting that EV storage (used to shift loads) is mainly used by the district instead of the relatively small load of the metro.

a) Total energy transactions with the grid

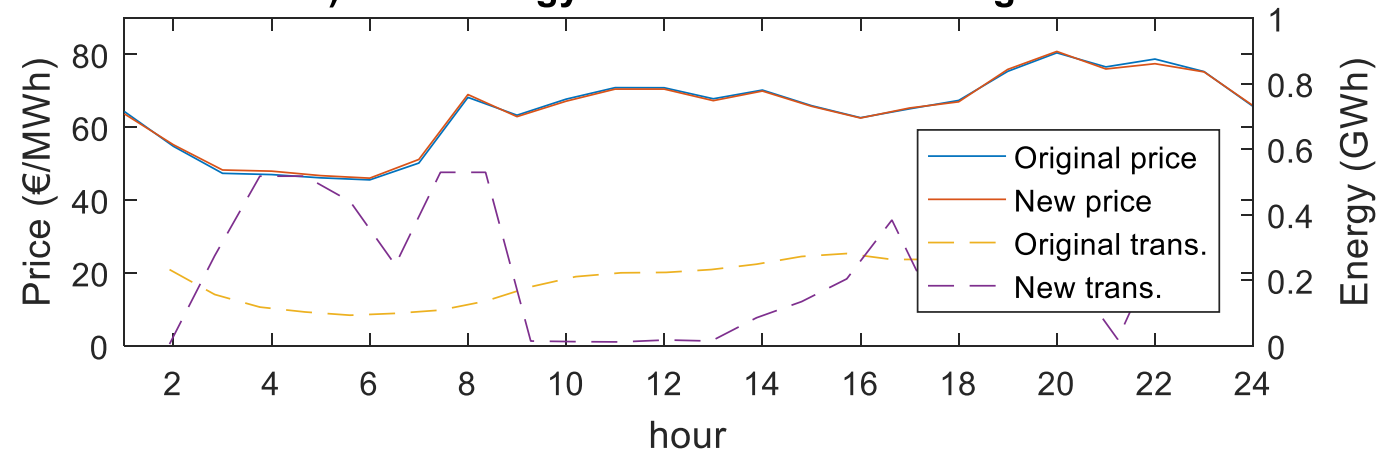

b) District load

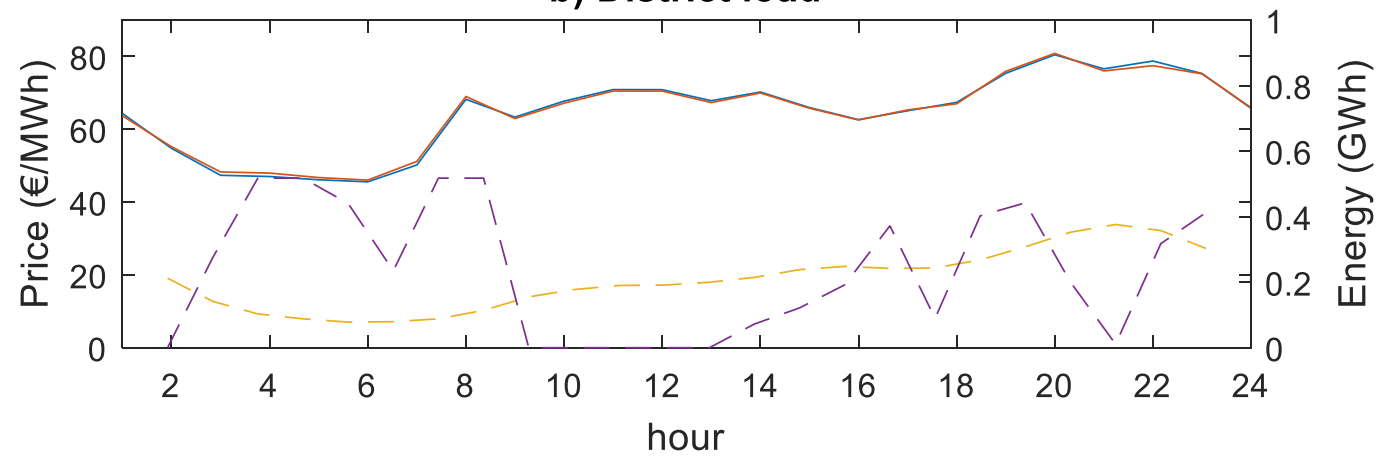

c) Metro load

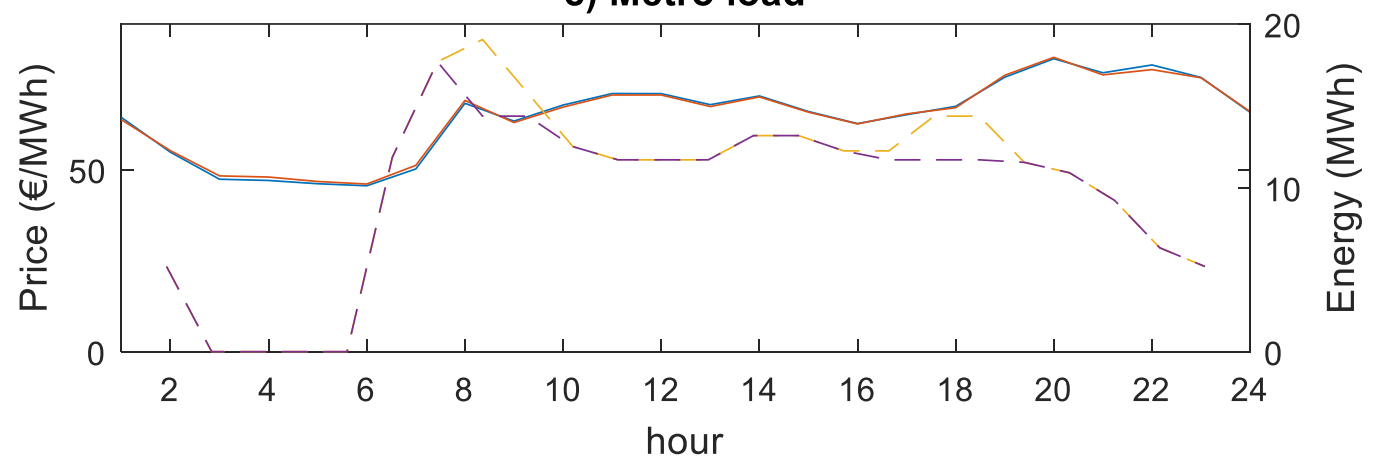

FIG. 53. AGGREGATOR ENERGY TRANSACTIONS AND EFFECT ON ENERGY PRICE FOR THE REPRESENTATIVE DAY OF JANUARY (CASE STUDY C, SCENARIO 1) FOR 15000 EVS. 
a) Total energy transactions with the grid

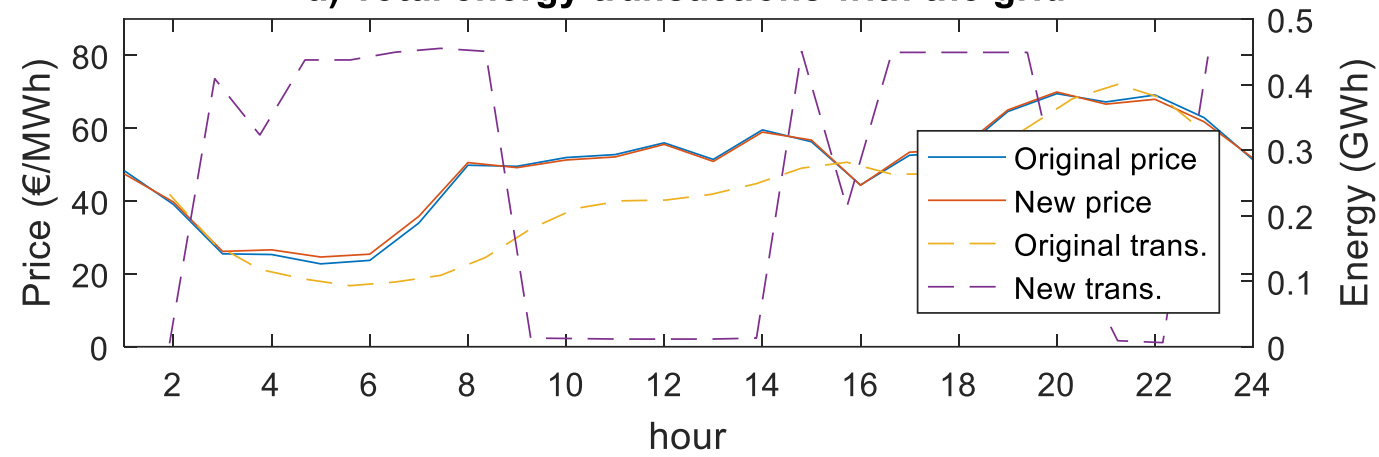

b) District load

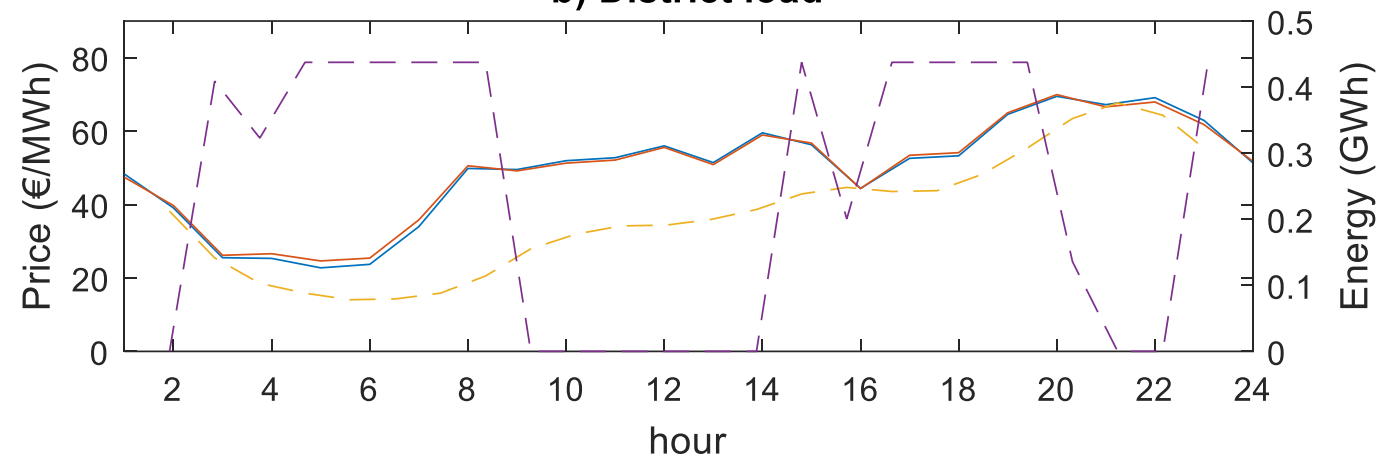

c) Metro load

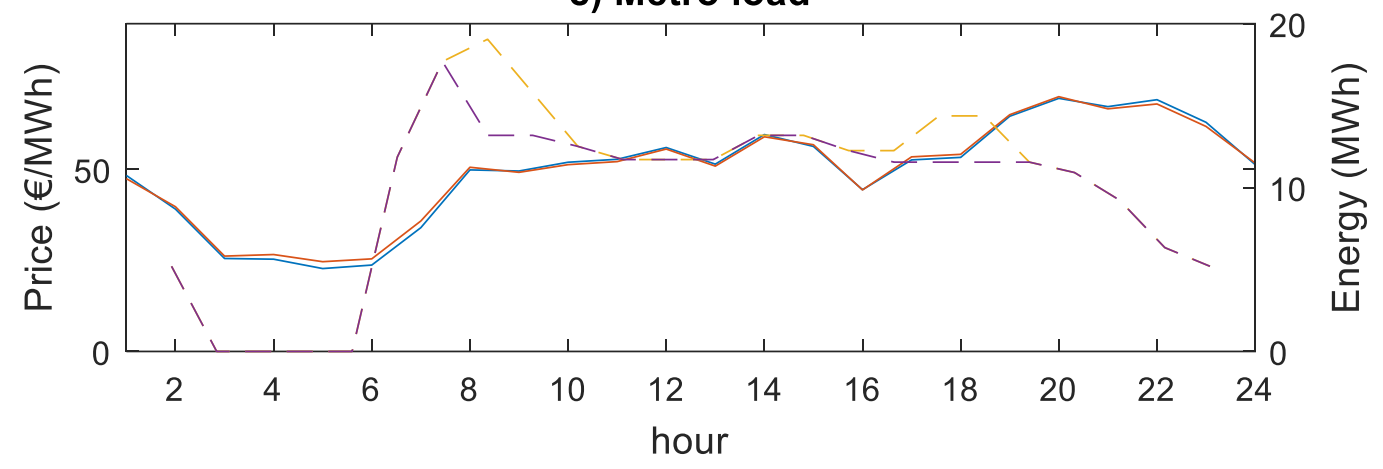

FIG. 54. AGGREGATOR ENERGY TRANSACTIONS AND EFFECT ON ENERGY PRICE FOR THE REPRESENTATIVE DAY OF JANUARY (CASE STUDY C, SCENARIO 2) FOR 15000 EVS. 
a) Total energy transactions with the grid

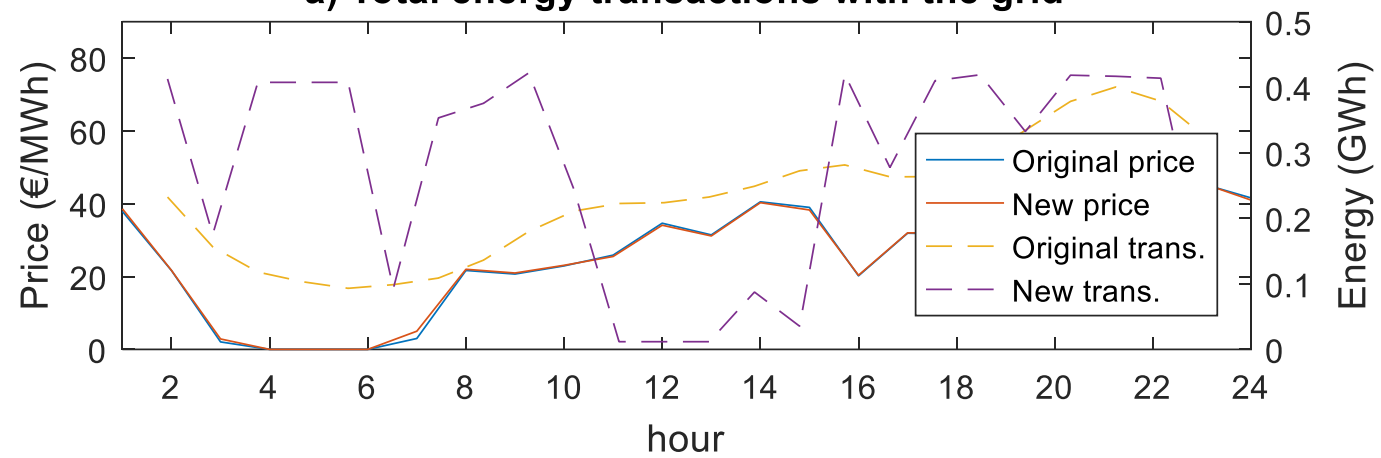

\section{b) District load}

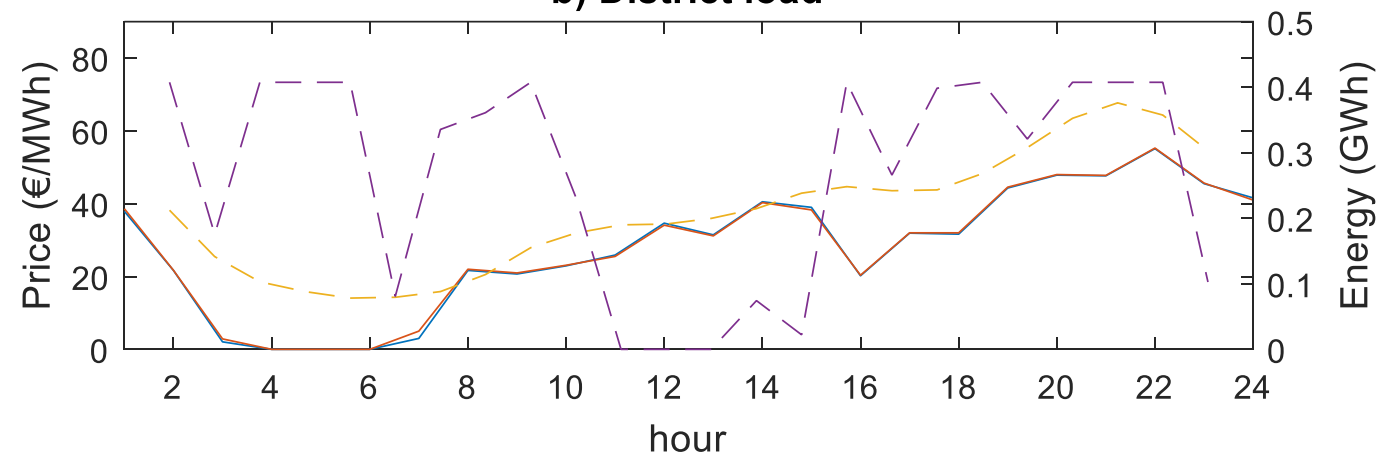

c) Metro load

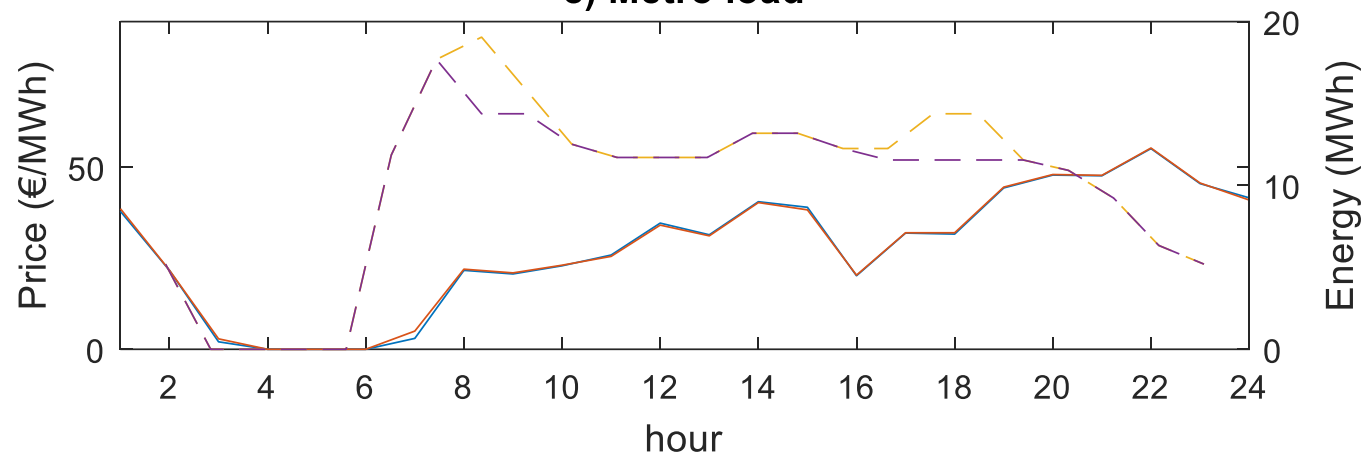

FIG. 55. AGGREGATOR ENERGY TRANSACTIONS AND EFFECT ON ENERGY PRICE FOR THE REPRESENTATIVE DAY OF JANUARY (CASE STUDY C, SCENARIO 3) FOR 15000 EVS.

The aggregator operation on the representative summer day is depicted in Fig. 56 to Fig. 58, again with 15000 EVs.

- Fig. 56 shows the price curve of scenario 1. Here, the original price curve is flatter than in winter, and thus, there is less load shifting throughout the day and most of the energy produced by the PV systems has been sold back to the grid, except when the energy price is lower (early hours).

- Scenario 2 (Fig. 57) presents a slightly larger variability in prices as in winter scenarios. This produces more load shifting and more energy sold back to the grid when the electricity price is higher (for instance, from $10 \mathrm{~h}$ to $16 \mathrm{~h}$ ). 
- Scenario 3 (Fig. 58) has a similar price curve to scenario 2, so the aggregator's strategy is similar than in scenario 2 .

- For all three scenarios, the metro load presents larger changes than in case studies $\mathrm{A}$ and $\mathrm{B}$, decreasing drastically the load in the hours of higher prices.

a) Total energy transactions with the grid

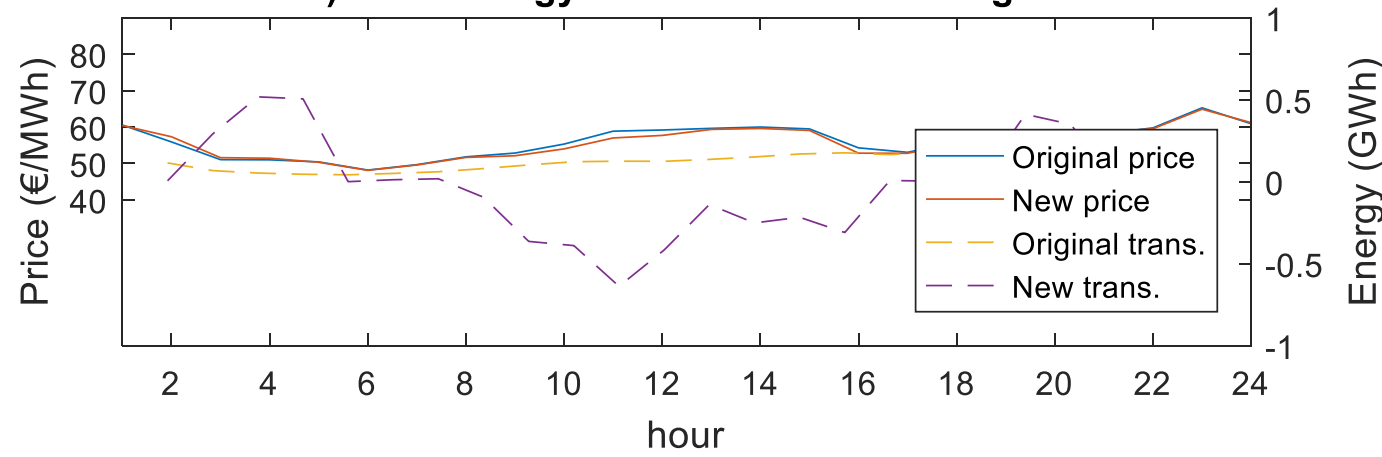

b) District load

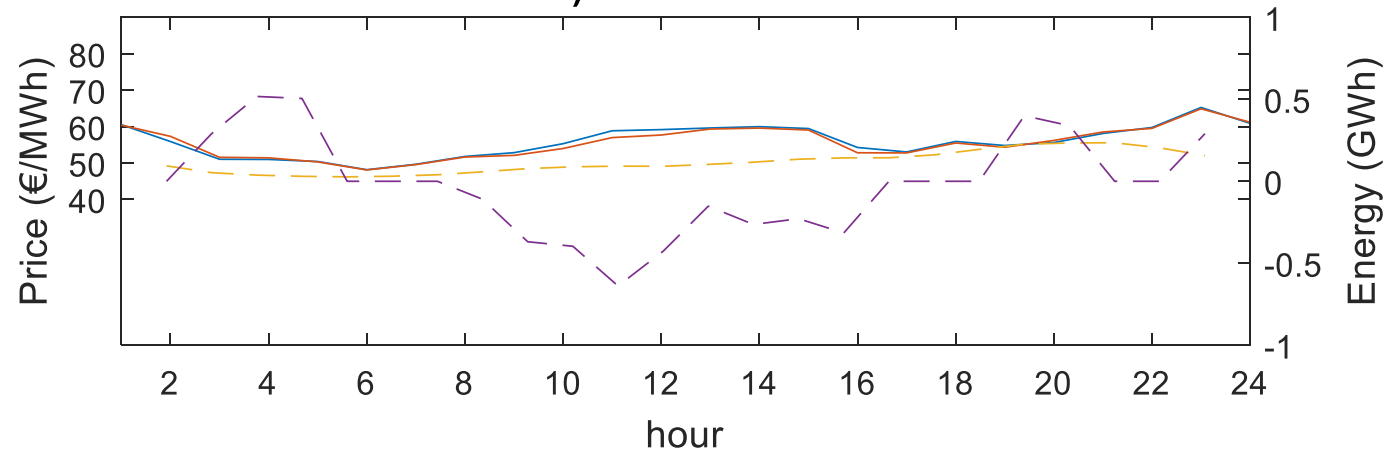

c) Metro load

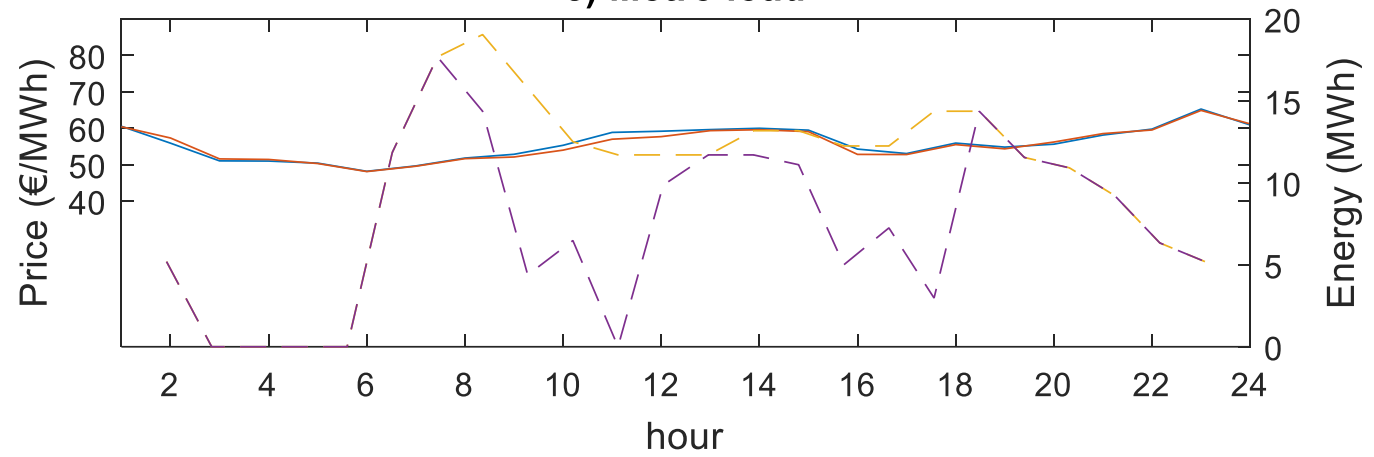

FIG. 56. AGGREGATOR ENERGY TRANSACTIONS AND EFFECT ON ENERGY PRICE FOR THE REPRESENTATIVE DAY OF JULY (CASE STUDY C, SCENARIO 1) FOR 15000 EVS. 
a) Total energy transactions with the grid

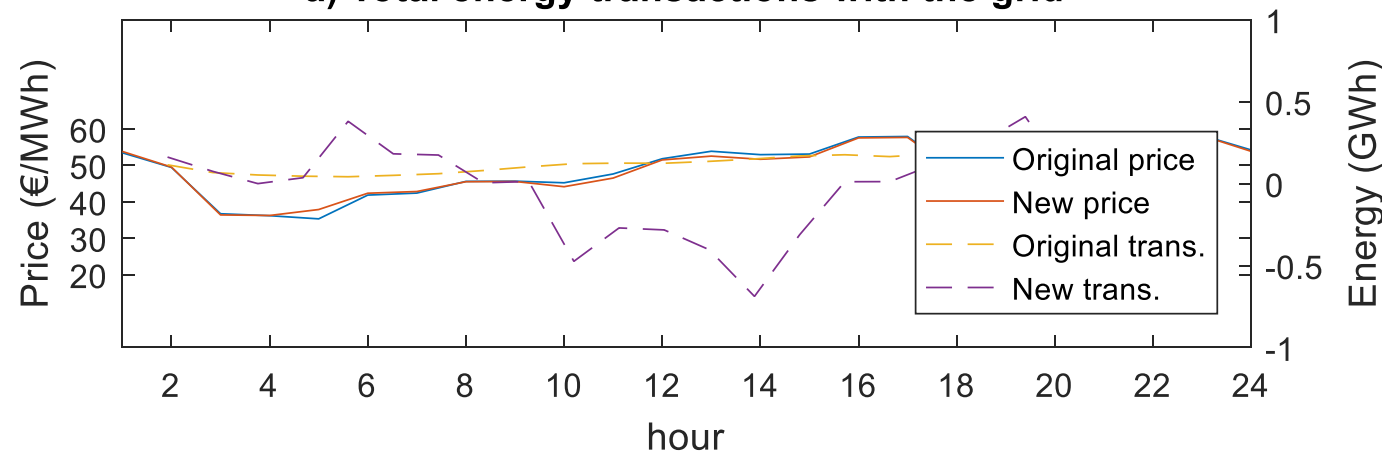

b) District load

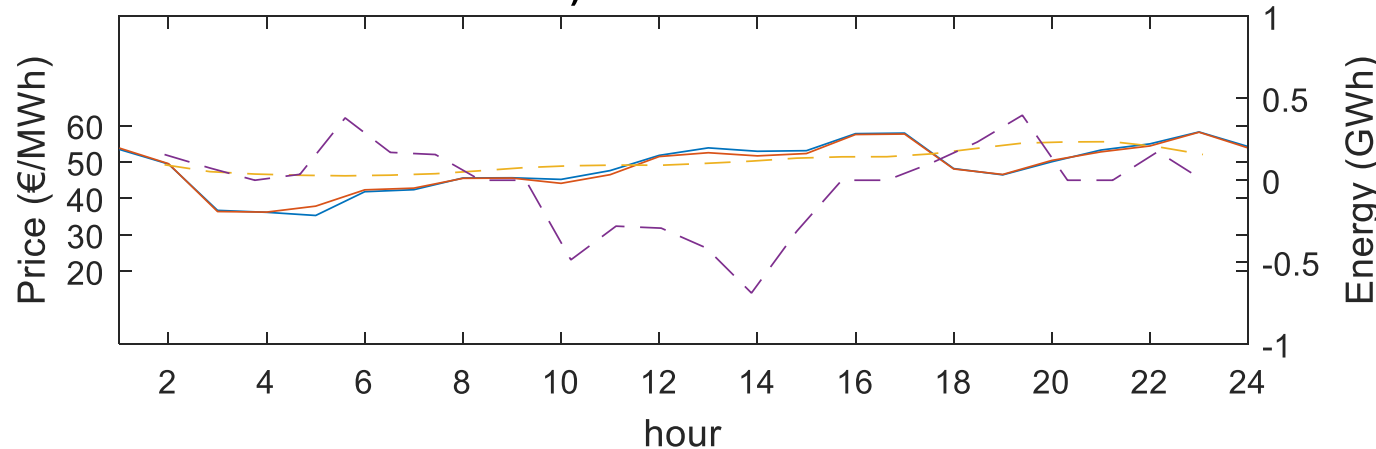

c) Metro load

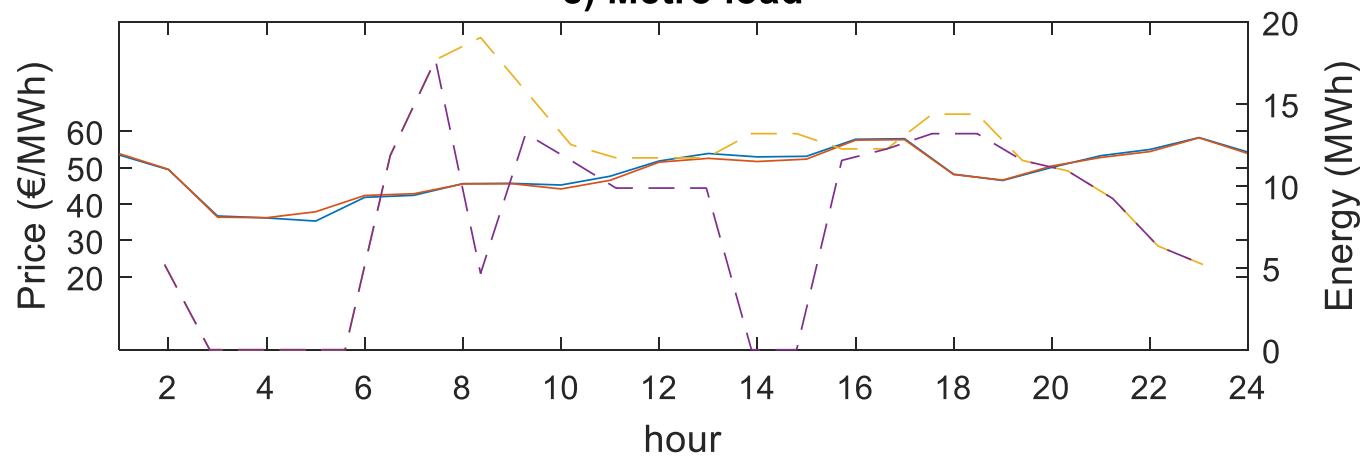

FIG. 57. AGGREGATOR ENERGY TRANSACTIONS AND EFFECT ON ENERGY PRICE FOR THE REPRESENTATIVE DAY OF JULY (CASE STUDY C, SCENARIO 2) FOR 15000 EVS. 
a) Total energy transactions with the grid

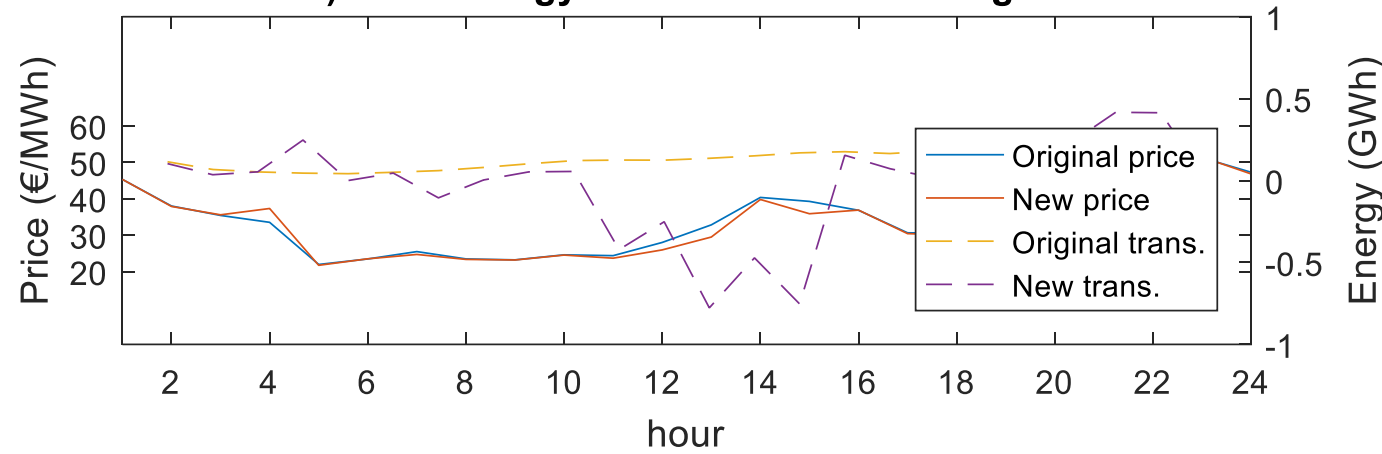

b) District load

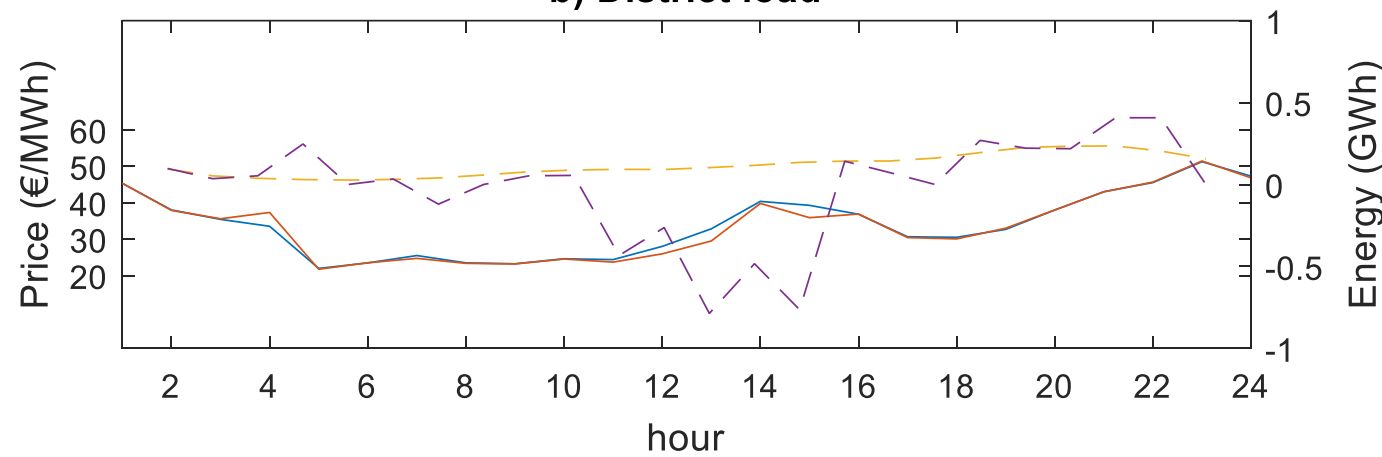

c) Metro load

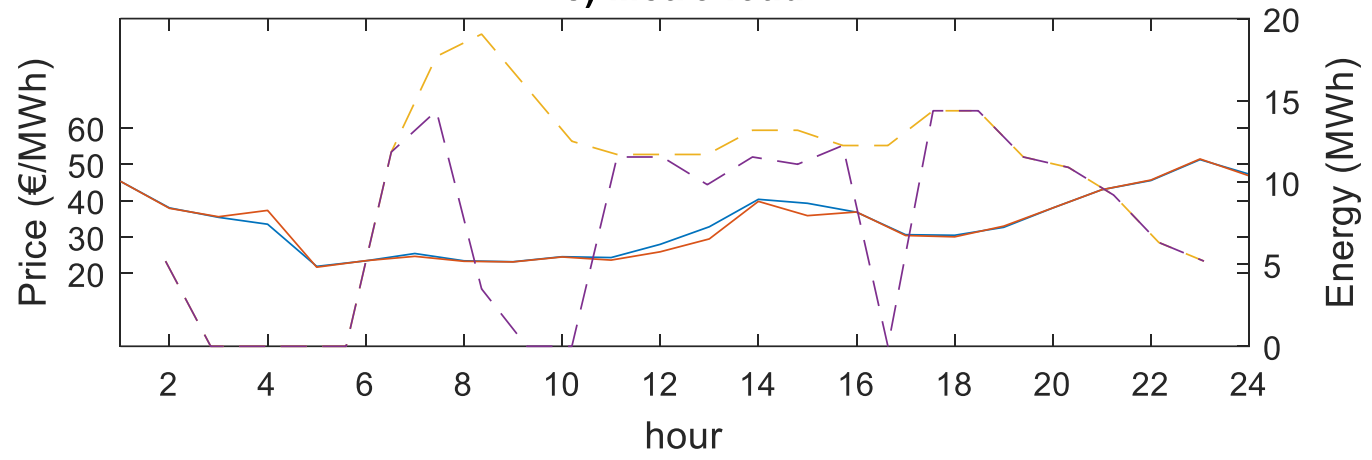

FIG. 58. AGGREGATOR ENERGY TRANSACTIONS AND EFFECT ON ENERGY PRICE FOR THE REPRESENTATIVE DAY OF JULY (CASE STUDY C, SCENARIO 3) FOR 15000 EVS.

\subsubsection{Remarks and discussion of system operation}

As shown in the previous figures (Fig. 47 to Fig. 58), the resource management is similar in all case studies, and it follows the overall behaviour shown in section 5.3.2. Firstly, it reduces the energy bought from the market at the middle of the day, which is also when the PV production is larger. Secondly, it shifts load from the peak hours to the off-peak ones, using the EV and battery storage, and/or the demand response scheme. Moreover, batteries have only been installed when load shifting still allows for prices differences that make battery investments profitable (in this example, the pricing scenarios of case study C).

Lastly, it is important to remark that the system costs and market data used are likely to affect significantly the range of benefits and synergies found in this analysis. For instance, 
other market inputs with higher prices, or higher differences between off-peak and peak hours are likely make the DER systems more profitable (and vice versa), affecting the planning of systems (especially the batteries), and overall benefits (see section 5.3.2.1 for further discussion). Nevertheless, these results provide insight on the synergies and expected benefits, and could serve as a starting point for the analysis of other smart city applications.

\subsection{CONCLUDING REMARKS}

The work presented in this chapter provides an example of a smart city model, taking advantage of the interconnection and coordinated operation of electricity powered transport systems (EVs and metro), residential loads and distributed energy systems (including PV panels, air-source HP, batteries and demand response schemes), while actively participating in the wholesale electricity market.

Similar to the analysis developed in previous chapters, results show that important economic benefits can be achieved by interconnecting and managing different systems in a coordinated way. The overall benefit can reach up to $32 \%$, in comparison with the independent systems with no DER systems installed. Note that this value decreases slightly (less than 1\%) when number of EVs increase, which suggest that for this particular scheme the system has reached its saturation point, where extra EVs only represents more load but no extra storage capacity is required (a more detailed analysis of this effect is provided in section 6.3.3).

Also, the total savings results of this chapter align with the results of chapter 5 , showing that the stochastic scenarios represent better the real life variability and range of energy prices, which translates to more robust capacity planning of DER systems and higher overall cost savings (see Table 56). Therefore, such a stochastic approach in the planning process is recommended.

Another interesting result of this scheme, in comparison with the results obtained in chapter 6 , is that the metro system does not benefit more than the other systems. This is due to the fact that all the loads (metro, EV and districts) are aggregated and they all see the same market prices (unlike the study in chapter 6, where the district uses a residential tariff and the metro a higher commercial tariff). Therefore, and considering that the objective is to minimize the overall costs, the systems that benefit more are the ones that have a higher demand during peak prices (which translates to higher costs). This effect is important to consider when planning smart city schemes, to ensure a fair sharing of benefits and costs.

It is important to remark that is difficult to do a fair comparison between these results and those of previous chapters as the analyses differ not only in size and systems considered, but in market approach as well. However, as discussed in this paper, results are in the same order of magnitude, suggesting consistency in the smart city energy model.

Once again, the model proposed and the analysis developed, despite being optimistic due to a perfect coordination among systems, provides insight on the importance of synergies between systems, the coordinated management and the active participation in energy markets, and shows the possibility to analyse and plan real smart city applications with 
important economic benefits. Moreover, if environmental and health benefits due to renewable systems and EVs are also taken into account, smart city programmes, as the example presented here, could be of great interest for investors and policy makers. 


\section{CONCLUSIONS,}

\section{CONTRIBUTIONS AND FUTURE WORK}

This last chapter summarizes the developments of this thesis, and discusses the main conclusions that can be drawn from the analyses carried out. In addition, the original contributions are highlighted, and the opportunities for improvement, as well as possible future research lines, are discussed.

\subsection{SUMMARY AND CONCLUSIONS}

Trying to model all the energy systems in a smart city could be an overwhelming task. The first part of this thesis was dedicated to analyse which technologies and systems should be considered. To this end, a detailed literature review was carried out in chapter 2, where several systems and technologies were identified and grouped in five intervention areas: Generation, Storage, Infrastructure, Facilities and Transport. In addition, a framework for smart city energy systems modelling was proposed, describing the elements that should be considered and providing modelling options and examples of data sources.

The next step was to decide if it was important to consider network constraints at the planning stage of DER systems. This was a big concern as it might potentially over complicate the smart city model, and, to the best of our knowledge, this had not been previously addressed in the literature by the time this analysis (in chapter 4) was carried out and published. Hence, different network topologies were tested to assess the benefits of considering or not the network thermal constraints at the low voltage distribution level.

With the network thermal constraint issue addressed, the efforts then focused on how to model the energy market. From the literature review, it was confirmed that the aggregation of energy resources could be one of the most accepted solutions to overcome the market entry barriers, so that DER and other smart city energy systems could benefit from their 
active participation in energy markets. It was also relevant to assess the impact of different aggregation sizes on the market spot price, for which a market price-maker approach was selected and tested with data from the Spanish market in chapter 5.

The synergies between different representative systems of each intervention area were explored in chapter 6, including DER systems, EVs and metro trains. For the sake of simplicity and to facilitate the analysis, in this first approach a price-taker model was used to study the synergies between systems and the impacts of different EV penetration levels. The global and partial optimization comparison allowed to assess the economic benefits of the synergies studied.

Lastly, to explore the applicability of the smart city energy model, a smart city case study was created with the aim of assessing the potential benefits of a more realistic smart city application (see chapter 7). All the systems described in chapter 6 were considered, based in the characteristics of five real districts of Madrid, Spain (metro lines, number EVs and number of houses), but following the price-maker approach of chapter 5 .

Note that, although the proposed smart city energy model did not include all the possible technologies and systems, and focused mainly on economic aspects (not considering sustainability metrics, and assuming that all the communication and information technologies are available), the research work developed in this thesis is a first step in assisting researchers and decision makers to assess and promote smart city technologies and systems.

The main conclusions produced with the work developed in this thesis are:

- It is sensible not to consider network thermal constraints at the low voltage distribution level in the planning of DER systems.

- Results in the considered case studies showed that, under the tariffs and reinforcement costs considered, the benefit decrement of considering network constraints was approximatively equivalent to the cost of reinforcing the network when necessary after planning without considering network constraints.

- Moreover, these extra costs are relatively small (less than $1 \%$ of the total costs), further motivating not taking into account the network thermal constraints in more complex analysis.

- The analysis also showed that different network topologies, despite of achieving slightly different overall benefits from DER systems, presented similar relative costs for considering or not network thermal constraints, and thus, the network topology does not seem to impact the main outcome of this analysis. However, other energy tariffs and higher power line reinforcement costs could have significant impact on these conclusions.

- Therefore, even if these results are hard to generalize or extrapolate to other networks, the analysis and networks tested strongly suggested the convenience of planning without considering network constraints (under similar tariff frameworks), reducing the complexity of the optimization problem. 
- Note that there are other network related problems produced by high penetration of DER systems (e.g. frequency variation, voltage dips, etc.), that have not been addressed in this thesis, as they are more relevant on the realtime operation of systems, and have little impact on the long-term planning problem addressed here.

- The level of aggregation affects the planning and overall benefits of DER systems, with the benefits increasing with the amount of aggregated resources, and achieving the maximum benefit with around $2 \%$ of the market share.

- Certainly, the amount of aggregated resources changed the expected benefits. The optimal level of aggregation in the analysis developed was around 1 million houses ( $2 \%$ of the market share). However, other energy systems are likely to present other optimal aggregation levels.

- The level of aggregation also impacted the energy prices, reducing the average electricity price up to $8 \%$, but with absolute price changes of up $23 \%$ in average for the largest aggregation scenario considered (8 million houses).

- It was also confirmed and quantified how aggregated DER systems tends to flatten the price curves, reducing prices at peak times and increasing prices at off-peak hours, basically profiting from load shifting and storage.

- A price-maker approach should be used with medium to large aggregation sizes (more than 50000 houses).

- Results confirmed that price-maker approaches could be more appropriate for the planning and operation of energy resources for medium to large aggregation sizes, but could be unnecessary for small sizes (less than 50000 households), with low expected impact on the market price (less than $0.25 \%$ price change).

- Even though business models are not explicitly studied here, it is expected that the aggregator's profit from managing residential loads and DER systems will be a small percentage from the overall profits. Therefore, the impact on prices even in relatively small aggregations (market shares from $0.2 \%$ ) could be very relevant for the aggregator, promoting the use of a price-maker approach.

- The optimisation approach considered (stochastic vs deterministic) affects significantly the results, with the stochastic case providing up to 1.5 times higher benefits.

- Indeed, the deterministic market approaches presented lower benefits (in chapter 7 , approx. $32 \%$ of benefits in the stochastic case vs. $20 \%$ in the deterministic ones) due to the price averaging of the deterministic cases (done in the clustering process), while the stochastic model provided more benefits as it represented better the variability and range of energy prices.

- This also affected the planning of DER systems, since battery systems were only implemented in the stochastic approach. In the deterministic cases, the price differences between peak and off-peak times were not large enough to make battery systems profitable.

- This suggests that it is important to follow an approach that represents as best as possible the range and variability of energy prices, as this heavily 
affects the planning of systems. For instance, technologies like batteries might not be implemented in certain scenarios, when they are likely to be profitable in a real-world application.

- It is important to remark that perfect market information was assumed. Knowing exactly how the market and the electricity prices behave, allowed for an optimal management of systems (e.g. when to charge and when to discharge the batteries to achieve maximum benefit). However, in a real case, uncertainty exists and the benefits obtained by DER systems (without perfect information) are likely to be lower.

- Synergies between different energy systems exist in an interconnected smart city context.

- Certainly, significant synergies were found. Results shown that the overall benefits of a joint management of systems were greater than those of the systems managed independently (in chapter $6,30 \%$ of benefits with the joint management, and up to $25 \%$ with independent management).

- As an example of the synergies, the metro system, with higher prices than the residential district, was able to take better advantage of the PV production and cheaper residential tariffs, while EV storage was being used for load shifting and PV energy storage until saturation (when the system could not benefit more from additional EV storage).

- It is important to remark that a large share of these benefits appear as "opportunistic" synergies, produced by the different types of energy tariffs considered. Nevertheless, real synergies caused by efficiency gains also exist. This type of synergies can be more easily seen in the analysis carried out in chapter 7 , where all the considered systems buy and sell energy directly from the market (same energy price).

Other complementing conclusions include:

- The load profiles and the energy price approach affect the share of costs and benefits between all the considered systems.

- As mentioned before, when the interconnected systems have different energy tariffs, opportunistic synergies appear, and the systems with the higher tariffs are the ones that benefit more. However, when all systems participate in the market (all consumers see the same market price), the systems that benefit more from the interconnected scheme are those that have a higher demand during peak prices (translating to higher costs).

- Such an effect is important to consider when designing business models to ensure a fair sharing of benefits and costs, and when exploring new synergies with other systems, suggesting that heterogeneous clients are likely to present more real synergies.

- For instance, in a centralized management approach like the one presented in this study, commercial clients, like offices and supermarkets, could be a promising addition to the proposed smart city programme due to their different load profiles, potentially taking more advantage of the EV availability and PV production in the middle of the day. 
- The approximation method (number of segments) in the piecewise linear function formulation for residual demand curves is highly important to achieve low approximation errors and accurate results.

- It was concluded that is worth compromising longer solution times, due to more segments in the piecewise linear function, to have better curve approximations and obtain more reliable results.

- In the study developed in chapter 5, a first approach was used with 6 segments in the piecewise linear function approximation, with solution times of less than 10 minutes, but with average approximation errors over $20 \%$. Therefore, a 22 segments approach was used, with solution times of several hours (even days) but with an average approximation error of less than $1 \%$.

- Battery systems were not straightforwardly replaced by EV storage

- Results showed that EV storage only partly replaced battery systems (in the analysis of chapter 6, for each kWh of extra EV storage, the battery system decreases its capacity in $0.6 \mathrm{kWh}$ approximately), even though batteries are more expensive than the "free" storage provided by EVs.

- This was caused by the limited availability shown in the EV usage profiles, where EVs are only plugged and available for certain hours of the day. Therefore, other types of EV users (different availability profiles) are likely to present different substitution rates.

\subsection{ORIGINAL CONTRIBUTIONS}

This thesis was conceived with the objective of pushing forward the research on smart city energy systems management and modelling. The main original contributions of this dissertation are the following:

\section{A comprehensive literature review, which helps to identify key energy systems in a smart city, and provides insight in potential synergies between systems, complemented with a consistent classification of the intervention areas.}

The developed literature review includes the main smart city energy related elements and modelling approaches developed so far. This review presents the following characteristics:

- The review included most smart city energy systems, including technologies and systems rarely addressed in other reviews, which commonly focus in a certain area (for instance, reviews of generation technologies, reviews of DER modelling tools, etc.). Such a comprehensive review has not been found previously in the literature.

- A classification of all the reviewed systems and technologies was proposed, grouping them in 5 intervention areas.

- Also, the way the information was organised and structured could be useful to researchers and policy makers to find quickly and easily relevant smart city data and references.

This literature review was developed in chapter 2 of the thesis, and it has been published in [10]. 
2. A framework to create smart city energy models, providing guidelines, modelling options and typical data sources, to assist on the development of similar energy models and further research on the area.

Using the knowledge from the literature review, a smart city energy modelling framework was proposed. The main characteristics of this framework are:

- The framework complements the literature review, and it is presented in a clear and structured way.

- It describes the modelling options and the energy systems that should be taken into account in smart city energy models.

- It provides examples of typical references and data sources (such as technology costs) required in the modelling tasks. Note that a similar modelling framework such as the one developed here, had not been found in the literature. Hence, it could serve to both researchers and decision makers in expanding the knowledge on the topic.

The proposed modelling framework was also developed in chapter 2 of the thesis, and it has been published in [10].

3. A comprehensive smart city energy model that can be used for different types of analyses and case studies, assisting on the implementation of smart city pilot programmes, as the case studies of this thesis.

A comprehensive smart city energy model has been proposed and implemented with the following characteristics:

- The model considers representative systems from all the intervention areas described in the literature review.

- It can be tailored to include different technologies and to be applied in different urban contexts. The model can also could be adapted to participate in different energy markets.

- The smart city energy model was applied to a case study simulating a real smart city implementation, which considered five real districts in the southern area of Madrid, Spain, including the metro lines and stations serving those districts, and several levels of EV penetration (according to the public parking capacity of the districts), in addition to other DER systems (PV, HP and batteries).

- This analysis allowed to assess the potential benefits of the implementation of a real smart city programme, and showed how the proposed smart city energy model could be used for the planning of pilot projects.

- To the best of our knowledge, such a smart city energy model had not been developed and applied yet, and no economic results in terms of the potential benefits of such a smart city initiative had been previously reported.

The proposed smart city energy model was described in chapter 3 , and it is used throughout this thesis. The smart city case study analysis was developed in chapter 7.

4. An assessment of including low-voltage network thermal constraints in DER systems planning, in a context similar to the Spanish one. 
The economic value of including network thermal constraints in the planning and operation of DER systems at a low voltage distribution level was assessed. The main characteristics of this assessment are:

- Analysis of DER system planning scenarios with and without network constraints, considering typical Spanish residential energy tariffs and different network topologies.

- The potential benefits were compared with the costs of reinforcing the network when needed.

- The need of considering or not network thermal constraints was a big concern in the literature, and it had not been previously addressed by the time this analysis was carried out and published.

- Results suggested that, under the considered reinforcement costs and tariff framework, it could be possible to not consider network constraints in the planning process, and just reinforce the network when needed. These outcomes could assist other researchers in reducing the complexity of their planning models.

This analysis was carried out in chapter 4 of the thesis, and it has been published in [11].

5. A price-maker DER systems planning and operation model, and an analysis of the impact on the energy market prices due to the aggregation levels, providing guidelines on when is recommended to follow a price-maker approach and when a price-taker one could be appropriate.

An assessment of market modelling approaches in DER system planning was carried out, also analysing the impact of aggregation on energy prices. The assessment considered the following characteristics:

- Aggregation of energy resources was implemented in the smart city energy model to overcome market entry barriers, taking advantage of the active participation in energy markets.

- A price-maker approach was selected and tested with data from the Spanish market (market competitors' behaviour was represented with residual demand curves), to assess the impact of different aggregation sizes on the market spot price.

- In DER systems planning, most of the available research work followed a price-taker approach, and the few price-maker models only considered the short-term operation. Hence, the proposed price-maker model filled a gap in the literature and provided a more realistic analysis of the changes of the market price curves produced by DER aggregation.

- The developed analysis also provides objective clues on when a price-maker approach should be preferred to the more common price-taker approach.

This assessment was developed in chapter 5 of the thesis, and it has been published in [12].

6. An analysis of synergies between different energy systems in an interconnected smart city context, also analysing the impact of $\mathrm{EV}$ penetration levels.

The synergies between different representative systems of each intervention area, defined in the literature review, were explored. The analysis included the following characteristics: 
- So far, researchers had focused in DER systems, only considering EVs from the transport area (but mainly modelling it as a battery). However, the interaction with other relevant energy systems had been overlooked.

- The analysis developed included metro systems besides the EVs and DER, showing that such a scheme could be very profitable to all the involved systems.

- Indeed, synergies between systems were found, which do not appear when the systems are managed independently. This showed the importance of the coordinated planning and operation of the smart city.

- Note that, to the best of our knowledge, a synergy analysis such as the one presented in this study has not been developed before.

These analyses of synergies were developed in chapters 6 and 7 of the thesis.

\subsubsection{PUBLICATIONS}

The research developed in this thesis had produced the following journal articles:

- C. F. Calvillo, A. Sánchez-Miralles, and J. Villar, 'Assessing low voltage network constraints in distributed energy resources planning', Energy, vol. 84, pp. 783-793, May 2015.

- C. F. Calvillo, A. Sánchez-Miralles, and J. Villar, 'Energy management and planning in smart cities', Renew. Sustain. Energy Rev., vol. 55, pp. 273-287, Mar. 2016.

- C. F. Calvillo, A. Sánchez-Miralles, J. Villar, and F. Martín, 'Optimal Planning and Operation of Aggregated Distributed Energy Resources with Market Participation', Applied Energy, vol. 182, pp. 340-357, Nov. 2016.

- C. F. Calvillo, A. Sánchez-Miralles, and J. Villar, "Synergies of Electric Urban Transport Systems and Distributed Energy Resources in Smart Cities," submitted to IEEE Transactions on Intelligent Transport Systems (accepted for publication).

In addition, the following journal articles are, at the time of writing, under review:

- C. F. Calvillo, A. Sánchez-Miralles, J. Villar, and F. Martín, "Impact of EV Penetration in the Interconnected Urban Environment of a Smart City," submitted to Energy.

Also, the following conference papers have been produced:

- C. Calvillo, K. Czechowski, L. Söder, A. Sánchez, J. Villar, "Vehicle-to-grid profitability considering EV battery degradation," IEEE PES Asia-Pacific Power and Energy Engineering Conference - APPEEC 2016, pp. 346-350, Xi'an, China, 25-28 Oct. 2016.

- C. Calvillo, A. Sánchez, J. Villar, "Price-maker optimal planning and operation of distributed energy resources," 13th International Conference on the European Energy Market - EEM16, Porto, Portugal, 06-09 Jun. 2016.

- F. Martín, C. Calvillo, A. Sánchez, J. Villar, L. Söder, "Optimal planning and operation of distributed energy resources considering uncertainty on EVs," 1st IEEE International Smart Cities Conference - ISC2-2015, pp. 1-6, Guadalajara, Mexico, 2528 Oct. 2015.

- C. Calvillo, A. Sánchez, J. Villar, "Evaluation and optimal scaling of distributed generation systems in a smart city," 8th International Conference on Urban Regeneration and Sustanability, pp. 845-857, Putrajaya, Malaysia, 03-05 Dec. 2013. 
- C. Calvillo, A. Sánchez, J. Villar, "Distributed energy generation in smart cities," 2nd International Conference on Renewable Energy Research and Applications - ICRERA 2013, pp. 161-166, Madrid, Spain, 20-23 Oct. 2013.

In addition to a book chapter:

- A. Sánchez, C. Calvillo, F. Martín, J. Villar, "Use of renewable energy systems in smart cities," in Use, operation and maintenance of renewable energy systems. Green energy and technology. Editor Sanz Bobi, Miguel A.. Ed. Springer. Berlin, Germany, 2014.

\subsection{FUTURE WORK}

Many future research lines result from the work developed in this thesis. This section presents some of these research directions:

- The first and probably more direct enhancement that could be performed to the smart city energy model is to improve the energy clients' representation. For instance:

○ Updated and more diverse residential load curves

- Adding commercial clients

- Better representation of the metro loads (if the data could be obtained)

- More types of EV users and vehicle fleets

- A more in depth assessment of DER system costs could be developed, and how they affect the investment decisions. This information could give further insight to investors and policy makers on which technologies are more promising, how much capacity should be implemented, and what is the minimum technology price needed to be profitable in that particular context. This assessment could include:

- Sensitivity analysis of DER investments costs and energy prices

- Technology substitution analysis

- Analysis of the elements that affect the profitability DER systems. Especially in the case of batteries and EVs, which are affected by multiple factors besides investment price, such as energy price variability and storage saturation points

- The next model improvement could be to consider other energy markets, such as ancillary services markets. So far, only the wholesale electricity market had been considered. However, it has been widely researched in the literature that DER systems could have an active participation in the ancillary service markets providing some kind of regulation or flexibility services.

- Sustainability metrics could be included to the smart city energy model. This would require modelling $\mathrm{CO}_{2}$ and other GHG emissions produced by facilities, DER technologies, EVs and other transport systems. This improvement could be very useful to decision makers in both private and public sectors to achieve their emission reduction targets at a minimum cost.

- Another research line could be a more in depth analysis on how the aggregated DER systems affect the energy system, by changing and flattening the electricity price curve. To model this appropriately, it will be required to also use a unit commitment model to analyse the impacts of the joint optimization of loads and DER systems on 
the power system and price profiles. This could be an important addition to the smart city energy model, providing insights for all energy market participants.

- The proposed model focused in the planning and operation of systems, considering the long-term analysis (20 years). However, it could be developed another version of the model for short-term operation, focusing on bid optimization for the energy markets. This would model better the DER management and market participation, further extending the applicability of the smart city model.

- Analysis of business models for aggregators, using the smart city energy model to assess economic relations between aggregators and clients, and the profitability for all stakeholders.

- In depth analysis on the implications of using the smart city energy model and transferring the results into real smart city applications, assessing the impact of the simplifications made and which areas could be improved.

- For instance, in the price-maker approach, it could be developed an analysis of the implications of the residual demand curves scenario selection, comparing different methodologies (different clustering techniques vs real curves) and number of scenarios.

- Last but not least, use the smart city energy model including other technologies in different urban contexts, to further extend its applicability.

- For instance, analysing geothermal HP and CHP technologies in district heating contexts, and how these technologies affect the planning of other DER systems.

- Also, other cities might provide different regulatory frameworks, which could potentially affect the operation and planning of energy systems. This could provide relevant insight for policy makers and investors. 


\section{REFERENCES}

[1] 'World's population increasingly urban with more than half living in urban areas | UN DESA | United Nations Department of Economic and Social Affairs'.

[2] 'European Context | EIP - Smart Cities and Communities Market Place'. [Online]. Available: https://eu-smartcities.eu/about/european_context. [Accessed: 28-May2017].

[3] C. Harrison et al., 'Foundations for Smarter Cities', IBM J. Res. Dev., vol. 54, no. 4, pp. 1-16, Aug. 2010.

[4] H. Chourabi et al., 'Understanding Smart Cities: An Integrative Framework', in 2012 45th Hawaii International Conference on System Science (HICSS), 2012, pp. 22892297.

[5] 'IBM TheSmarterCity: Energy \& Utilities - United States', 04-May-2012. [Online]. Available: http://www03.ibm.com/innovation/us/thesmartercity/energy/index.html. [Accessed: 11-Oct2013].

[6] B. Morvaj, L. Lugaric, and S. Krajcar, 'Demonstrating smart buildings and smart grid features in a smart energy city', in Proceedings of the 2011 3rd International Youth Conference on Energetics (IYCE), 2011, pp. 1-8.

[7] M. McLean and P. Shepherd, 'The importance of model structure', Futures, vol. 8, no. 1, pp. 40-51, Feb. 1976.

[8] 'Distributed Energy Resources Customer Adoption Model (DER-CAM) | Building Microgrid'. [Online]. Available: https://building-microgrid.lbl.gov/projects/dercam. [Accessed: 27-Sep-2016].

[9] T. Lambert, P. Gilman, and P. Lilienthal, 'Micropower System Modeling with Homer', in Integration of Alternative Sources of Energy, F. A. F. B. E. in E. E. Ph.D.essor M.Sc in Electrical Engineering and M. G. S. B. S. Editor M.Sc ,.Ph D. ,. D.Sc Member Chairman Associate, Eds. John Wiley \& Sons, Inc., 2005, pp. 379-418.

[10] C. F. Calvillo, A. Sánchez-Miralles, and J. Villar, 'Energy management and planning in smart cities', Renew. Sustain. Energy Rev., vol. 55, pp. 273-287, Mar. 2016.

[11] C. F. Calvillo, A. Sánchez-Miralles, and J. Villar, 'Assessing low voltage network constraints in distributed energy resources planning', Energy, vol. 84, pp. 783-793, May 2015.

[12] C. F. Calvillo, A. Sánchez-Miralles, J. Villar, and F. Martín, 'Optimal planning and operation of aggregated distributed energy resources with market participation', Appl. Energy, vol. 182, pp. 340-357, Nov. 2016.

[13] A. Sanchez-Miralles, T. Gomez San Roman, I. Fernandez, and C. Calvillo, 'Business Models Towards the Effective Integration of Electric Vehicles in the Grid', IEEE Intell. Transp. Syst. Mag., vol. 6, no. 4, pp. 45-56, winter 2014.

[14] G. Chicco and P. Mancarella, 'A unified model for energy and environmental performance assessment of natural gas-fueled poly-generation systems', Energy Convers. Manag., vol. 49, no. 8, pp. 2069-2077, Aug. 2008.

[15] A. Demirbas, 'Political, economic and environmental impacts of biofuels: A review', Appl. Energy, vol. 86, Supplement 1, no. 0, pp. S108-S117, Nov. 2009.

[16] P. M. and G.Chicco, 'CO2 Emission Reduction from Sustainable Energy Systems: Benefits and Limits of Distributed Multi-Generation', In: The Second International Conference on Bioenvironment, Biodiversity and Renewable Energies; 22 May 2011-27 May 2011; Venice. 2011., 2011. [Online]. Available: https://www.escholar.manchester.ac.uk/uk-ac-man-scw:147274. [Accessed: 26Nov-2012]. 
[17] R. Cossent, T. Gómez, and P. Frías, 'Towards a future with large penetration of distributed generation: Is the current regulation of electricity distribution ready? Regulatory recommendations under a European perspective', Energy Policy, vol. 37, no. 3, pp. 1145-1155, Mar. 2009.

[18] V. H. Méndez et al., 'Impact of distributed generation on distribution investment deferral', Int. J. Electr. Power Energy Syst., vol. 28, no. 4, pp. 244-252, May 2006.

[19] R. Cossent, T. Gómez, and L. Olmos, 'Large-scale integration of renewable and distributed generation of electricity in Spain: Current situation and future needs', Energy Policy, vol. 39, no. 12, pp. 8078-8087, Dec. 2011.

[20] B. Singh, V. Mukherjee, and P. Tiwari, 'A survey on impact assessment of DG and FACTS controllers in power systems', Renew. Sustain. Energy Rev., vol. 42, pp. 846882, Feb. 2015.

[21] S. Ruiz-Romero, A. Colmenar-Santos, F. Mur-Pérez, and Á. López-Rey, 'Integration of distributed generation in the power distribution network: The need for smart grid control systems, communication and equipment for a smart city - Use cases', Renew. Sustain. Energy Rev., vol. 38, pp. 223-234, Oct. 2014.

[22] mzentgraad, 'Study: Current and Future Cost of Photovoltaics - Long-term scenarios for Market Development, System Prices and LCOE of Utility-Scale PV Systems Fraunhofer ISE'. [Online]. Available: https://www.ise.fraunhofer.de/en/publications/studies/studie-current-andfuture-cost-of-photovoltaics-long-term-scenarios-for-market-development-systemprices-and-lcoe-of-utility-scale-pv-systems. [Accessed: 27-Sep-2016].

[23] 'Cost Maps for Unsubsidised Photovoltaic Electricity | SETIS - European Commission'. [Online]. Available: https://setis.ec.europa.eu/publications/jrc-setis-reports/costmaps-unsubsidised-photovoltaic-electricity. [Accessed: 27-Sep-2016].

[24] S. A. Kalogirou, 'Solar thermal collectors and applications', Prog. Energy Combust. Sci., vol. 30, no. 3, pp. 231-295, 2004.

[25] J. Usaola, 'Operation of concentrating solar power plants with storage in spot electricity markets', IET Renew. Power Gener., vol. 6, no. 1, pp. 59-66, Jan. 2012.

[26] A. Braunstein and A. Kornfeld, 'On the Development of the Solar Photovoltaic and Thermal (PVT) Collector', IEEE Trans. Energy Convers., vol. EC-1, no. 4, pp. 31-33, Dec. 1986.

[27] R. K. Brenden, W. Hallaj, G. Subramanian, and S. Katoch, 'Wind energy roadmap', in Portland International Conference on Management of Engineering Technology, 2009. PICMET 2009, 2009, pp. 2548-2562.

[28] Stephen Karekezi, Kusum Lata, and Suani Teixeira Coelho, "Traditional Biomass Energy Improving its Use and Moving to Modern Energy Use', presented at the Secretariat of the International Conference for Renewable Energies, Bonn, 2004.

[29] 'Biofuels Legislation in Europe'. [Online]. Available: http://www.biofuelstp.eu/biofuels-legislation.html. [Accessed: 27-Sep-2016].

[30] T. J. Hammons, 'Geothermal power generation worldwide', in Power Tech Conference Proceedings, 2003 IEEE Bologna, 2003, vol. 1, p. 8 pp. Vol.1.

[31] U. EPA, 'CHP Technologies'. [Online]. Available: http://www.epa.gov/chp/technologies.html. [Accessed: 24-Apr-2013].

[32] L. Mirani, 'Nobody in the fuel cell industry has ever made a profit-this CEO could be the first', Quartz. .

[33] O. Erdinc and M. Uzunoglu, 'Optimum design of hybrid renewable energy systems: Overview of different approaches', Renew. Sustain. Energy Rev., vol. 16, no. 3, pp. 1412-1425, Apr. 2012.

[34] S. Upadhyay and M. P. Sharma, 'A review on configurations, control and sizing methodologies of hybrid energy systems', Renew. Sustain. Energy Rev., vol. 38, pp. 4763, Oct. 2014. 
[35] A. Chauhan and R. P. Saini, 'A review on Integrated Renewable Energy System based power generation for stand-alone applications: Configurations, storage options, sizing methodologies and control', Renew. Sustain. Energy Rev., vol. 38, pp. 99-120, Oct. 2014.

[36] R. S. Adhikari, M. Buzzetti, and S. Magelli, 'Solar photovoltaic and thermal systems for electricity generation, space heating and domestic hot water in a residential building', in 2011 International Conference on Clean Electrical Power (ICCEP), 2011, pp. 461-465.

[37] G. Manfroi, M. Maistrello, and L. C. Tagliabue, 'Synergy of geothermal heat pumps and PV plant for buildings block', in 2011 International Conference on Clean Electrical Power (ICCEP), 2011, pp. 466-473.

[38] C. F. Calvillo, A. Sanchez, and J. Villar, 'Distributed energy generation in smart cities', in 2013 International Conference on Renewable Energy Research and Applications (ICRERA), 2013, pp. 161-166.

[39] C. F. Calvillo, A. Sánchez, and J. Villar, 'Evaluation and optimal scaling of distributed generation systems in a smart city', 2013, pp. 845-857.

[40] D. Connolly, H. Lund, B. V. Mathiesen, and M. Leahy, 'A review of computer tools for analysing the integration of renewable energy into various energy systems', Appl. Energy, vol. 87, no. 4, pp. 1059-1082, Apr. 2010.

[41] S. Sinha and S. S. Chandel, 'Review of software tools for hybrid renewable energy systems', Renew. Sustain. Energy Rev., vol. 32, pp. 192-205, Apr. 2014.

[42] I. Batas Bjelic and R. M. Ciric, 'Optimal distributed generation planning at a local level - A review of Serbian renewable energy development', Renew. Sustain. Energy Rev., vol. 39, pp. 79-86, Nov. 2014.

[43] G. Cardoso et al., 'Optimal investment and scheduling of distributed energy resources with uncertainty in electric vehicle driving schedules', Energy, vol. 64, pp. 17-30, Jan. 2014.

[44] Z. Chen, L. Wu, and Y. Fu, 'Real-Time Price-Based Demand Response Management for Residential Appliances via Stochastic Optimization and Robust Optimization', IEEE Trans. Smart Grid, vol. 3, no. 4, pp. 1822-1831, Dec. 2012.

[45] K. L. Anaya and M. G. Pollitt, "The role of distribution network operators in promoting cost-effective distributed generation: Lessons from the United States of America for Europe', Renew. Sustain. Energy Rev., vol. 51, pp. 484-496, Nov. 2015.

[46] H. Xu, I. U. Eronini, Z.-H. Mao, and A. K. Jones, 'Towards improving renewable resource utilization with plug-in electric vehicles', in Innovative Smart Grid Technologies (ISGT), 2011 IEEE PES, 2011, pp. 1-6.

[47] L. Maharjan, T. Yamagishi, and H. Akagi, 'Active-Power Control of Individual Converter Cells for a Battery Energy Storage System Based on a Multilevel Cascade PWM Converter', IEEE Trans. Power Electron., vol. 27, no. 3, pp. 1099-1107, Mar. 2012.

[48] T. Xing-guo, W. Hui, and L. Qing-min, 'Multi-port topology for composite energy storage and its control strategy in micro-grid', in Power Electronics and Motion Control Conference (IPEMC), 2012 7th International, 2012, vol. 1, pp. 351-355.

[49] M. H. Ali, B. Wu, and R. A. Dougal, 'An Overview of SMES Applications in Power and Energy Systems', IEEE Trans. Sustain. Energy, vol. 1, no. 1, pp. 38-47, Apr. 2010.

[50] 'Cost of Batteries for Electric Vehicles Falling More Rapidly than Projected'. [Online]. Available: http://www.theenergycollective.com/jessejenkins/2215181/costbatteries-electric-vehicles-falling-more-rapidly-projected. [Accessed: 27-Sep-2016].

[51] M. ud din Mufti, S. A. Lone, S. J. Iqbal, M. Ahmad, and M. Ismail, 'Super-capacitor based energy storage system for improved load frequency control', Electr. Power Syst. Res., vol. 79, no. 1, pp. 226-233, Jan. 2009. 
[52] R. Sebastián and R. Peña-Alzola, 'Control and simulation of a flywheel energy storage for a wind diesel power system', Int. J. Electr. Power Energy Syst., vol. 64, pp. 10491056, Jan. 2015.

[53] C. Cristofari, G. Notton, M. Ezzat, L. Stoyanov, J. L. Canaletti, and V. Lazarov, 'Pumped hydroelectric storage coupling wind-solar resources: A solution for increase ren on islands electrical grid', in 2010 Proceedings of the International Conference on Energy and Sustainable Development: Issues and Strategies (ESD), 2010, pp. 1-11.

[54] 'A Pollution-Free Hydrogen Economy? Not So Soon', MIT Technology Review. [Online]. Available: http://www.technologyreview.com/news/401988/a-pollution-freehydrogen-economy-not-so-soon/. [Accessed: 22-Nov-2012].

[55] A. A. Olajire, 'CO2 capture and separation technologies for end-of-pipe applications A review', Energy, vol. 35, no. 6, pp. 2610-2628, Jun. 2010.

[56] M. Saadat, F. A. Shirazi, and P. Y. Li, 'Modeling and control of an open accumulator Compressed Air Energy Storage (CAES) system for wind turbines', Appl. Energy, vol. 137, pp. 603-616, Jan. 2015.

[57] R. Madlener and J. Latz, 'Economics of centralized and decentralized compressed air energy storage for enhanced grid integration of wind power', Appl. Energy, vol. 101, pp. 299-309, Jan. 2013.

[58] A. González-Gil, R. Palacin, and P. Batty, 'Sustainable urban rail systems: Strategies and technologies for optimal management of regenerative braking energy', Energy Convers. Manag., vol. 75, pp. 374-388, Nov. 2013.

[59] 'Electricity Storage: How to Facilitate its Deployment and Operation in the EU • THINK - European University Institute'. [Online]. Available: http://www.eui.eu/Projects/THINK/Research/Topic8.aspx. [Accessed: 22-Feb2017].

[60] Y. Ma, A. Kelman, A. Daly, and F. Borrelli, 'Predictive Control for Energy Efficient Buildings with Thermal Storage: Modeling, Stimulation, and Experiments', IEEE Control Syst., vol. 32, no. 1, pp. 44-64, Feb. 2012.

[61] R. I. Dunn, P. J. Hearps, and M. N. Wright, 'Molten-Salt Power Towers: Newly Commercial Concentrating Solar Storage', Proc. IEEE, vol. 100, no. 2, pp. 504-515, Feb. 2012.

[62] S. Koohi-Kamali, N. A. Rahim, and H. Mokhlis, 'Smart power management algorithm in microgrid consisting of photovoltaic, diesel, and battery storage plants considering variations in sunlight, temperature, and load', Energy Convers. Manag., vol. 84, pp. 562-582, Aug. 2014.

[63] J. Goncalves de Oliveira, H. Schettino, V. Gama, R. Carvalho, and H. Bernhoff, 'Study on a doubly-fed flywheel machine-based driveline with an AC/DC/AC converter', IET Electr. Syst. Transp., vol. 2, no. 2, pp. 51-57, Jun. 2012.

[64] J. García-Villalobos, I. Zamora, J. I. San Martín, F. J. Asensio, and V. Aperribay, 'Plug-in electric vehicles in electric distribution networks: A review of smart charging approaches', Renew. Sustain. Energy Rev., vol. 38, pp. 717-731, Oct. 2014.

[65] J. Villar, C. A. Diaz, P. Gonzalez, and F. A. Campos, 'Wind and solar integration with plug-in electric vehicles smart charging strategies', in European Energy Market (EEM), 2014 11th International Conference on the, 2014, pp. 1-6.

[66] L. Pieltain Fernández, T. G. S. Román, R. Cossent, C. M. Domingo, and P. Frías, 'Assessment of the Impact of Plug-in Electric Vehicles on Distribution Networks', IEEE Trans. Power Syst., vol. 26, no. 1, pp. 206-213, 2011.

[67] J. Villar, C. A. Diaz, J. Arnau, and F. A. Campos, 'Impact of plug-in-electric vehicles penetration on electricity demand, prices and thermal generation dispatch', in European Energy Market (EEM), 2012 9th International Conference on the, 2012, pp. 1-8. 
[68] S. Beer et al., 'An Economic Analysis of Used Electric Vehicle Batteries Integrated Into Commercial Building Microgrids', IEEE Trans. Smart Grid, vol. 3, no. 1, pp. 517-525, 2012.

[69] I. J. Fernández, C. F. Calvillo, A. Sánchez-Miralles, and J. Boal, 'Capacity fade and aging models for electric batteries and optimal charging strategy for electric vehicles', Energy, vol. 60, pp. 35-43, Oct. 2013.

[70] B. Daryanian, R. E. Bohn, and R. D. Tabors, 'An experiment in real time pricing for control of electric thermal storage systems', IEEE Trans. Power Syst., vol. 6, no. 4, pp. 1356-1365, 1991.

[71] 'The Smart Grid: An Introduction | Department of Energy'. [Online]. Available: http://energy.gov/oe/downloads/smart-grid-introduction-0. [Accessed: 27-Sep2016].

[72] S. Karnouskos, 'Demand Side Management via prosumer interactions in a smart city energy marketplace', in 2011 2nd IEEE PES International Conference and Exhibition on Innovative Smart Grid Technologies (ISGT Europe), 2011, pp. 1-7.

[73] R. Cossent, L. Olmos, T. Gómez, C. Mateo, and P. Frías, 'Distribution network costs under different penetration levels of distributed generation', Eur. Trans. Electr. Power, vol. 21, no. 6, pp. 1869-1888, Sep. 2011.

[74] Y. Ding et al., 'Ecogrid EU - a large scale smart grids demonstration of real time market-based integration of numerous small DER and DR', in 2012 3rd IEEE PES International Conference and Exhibition on Innovative Smart Grid Technologies (ISGT Europe), 2012, pp. 1-7.

[75] M. Hable, C. Schwaegerl, L. Tao, A. Ettinger, R. Köberle, and E.-P. Meyer, 'Requirements on electrical power infrastructure by electric vehicles', in Emobility Electrical Power Train, 2010, 2010, pp. 1-6.

[76] T. G. San Román, I. Momber, M. R. Abbad, and Á. Sánchez Miralles, 'Regulatory framework and business models for charging plug-in electric vehicles: Infrastructure, agents, and commercial relationships', Energy Policy, vol. 39, no. 10, pp. 6360-6375, Oct. 2011.

[77] T.-S. Choi, K.-R. Ko, S.-C. Park, Y.-S. Jang, Y.-T. Yoon, and S.-K. Im, 'Analysis of energy savings using smart metering system and IHD (in-home display)', in Transmission Distribution Conference Exposition: Asia and Pacific, 2009, 2009, pp. 1-4.

[78] M. P. McHenry, 'Technical and governance considerations for advanced metering infrastructure/smart meters: Technology, security, uncertainty, costs, benefits, and risks', Energy Policy, vol. 59, pp. 834-842, Aug. 2013.

[79] 'Microgrids'. [Online]. Available: http://www.microgrids.eu/default.php. [Accessed: 27-Sep-2016].

[80] P. F. Keebler, 'Meshing power quality and electromagnetic compatibility for tomorrow's smart grid', IEEE Electromagn. Compat. Mag., vol. 1, no. 2, pp. 100-103, summer 2012.

[81] A. I. Dounis and C. Caraiscos, 'Advanced control systems engineering for energy and comfort management in a building environment-A review', Renew. Sustain. Energy Rev., vol. 13, no. 6-7, pp. 1246-1261, Aug. 2009.

[82] A. Rodriguez-Calvo, P. Frias, J. Reneses, and C. Mateo, 'Optimal degree of smart transformer substations in distribution networks for reliability improvement', in 2012 3rd IEEE PES International Conference and Exhibition on Innovative Smart Grid Technologies (ISGT Europe), 2012, pp. 1-7.

[83] F. Martin-Martínez, A. Sánchez-Miralles, and M. Rivier, 'A literature review of Microgrids: A functional layer based classification', Renew. Sustain. Energy Rev., vol. 62, pp. 1133-1153, Sep. 2016.

[84] R. M. Pulselli, E. Simoncini, and N. Marchettini, 'Energy and emergy based costbenefit evaluation of building envelopes relative to geographical location and climate', Build. Environ., vol. 44, no. 5, pp. 920-928, May 2009. 
[85] Z. Wang, R. Yang, L. Wang, R. C. Green, and A. I. Dounis, 'A fuzzy adaptive comfort temperature model with grey predictor for multi-agent control system of smart building', in 2011 IEEE Congress on Evolutionary Computation (CEC), 2011, pp. 728735.

[86] J. Byun and S. Park, 'Development of a self-adapting intelligent system for building energy saving and context-aware smart services', IEEE Trans. Consum. Electron., vol. 57, no. 1, pp. 90-98, Feb. 2011.

[87] X. Guan, Z. Xu, and Q.-S. Jia, 'Energy-Efficient Buildings Facilitated by Microgrid', IEEE Trans. Smart Grid, vol. 1, no. 3, pp. 243-252, Dec. 2010.

[88] A. Poredos and A. Kitanovski, 'District heating and cooling for efficient energy supply', in 2011 International Conference on Electrical and Control Engineering (ICECE), 2011, pp. 5238-5241.

[89] J. Li, X. Zhou, and Y. Ding, 'Analysis of Energy Demand of Building Envelope Modification Schemes in Hot-Humid Areas', in International Conference on Energy and Environment Technology, 2009. ICEET '09, 2009, vol. 1, pp. 27-32.

[90] H. Sozer, 'Improving energy efficiency through the design of the building envelope', Build. Environ., vol. 45, no. 12, pp. 2581-2593, Dec. 2010.

[91] 'SmartHouse/SmartGrid | JRC Smart Electricity Systems and Interoperability'. [Online]. Available: http://ses.jrc.ec.europa.eu/smarthousesmartgrid. [Accessed: 27-Sep-2016].

[92] 'ENERgy Saving Information Platform for Generation and Consumption Networks | Energy Research Knowledge Centre'. [Online]. Available: https://setis.ec.europa.eu/energy-research/project/energy-saving-informationplatform-generation-and-consumption-networks. [Accessed: 27-Sep-2016].

[93] 'Project - I3RES - ICT based Intelligent management of Integrated RES for the Smart Grid optimal operation'. [Online]. Available: https://www.citsem.upm.es/index.php/es/proyectoses?view=project\&task=show\&id=37. [Accessed: 27-Sep-2016]

[94] 'SmartC2Net Objectives - SmartC2Net'. [Online]. Available: http://www.smartc2net.eu/. [Accessed: 28-Sep-2016].

[95] 'FINSENY | Future Internet for Smart Energy'. [Online]. Available: http://www.fippp-finseny.eu/. [Accessed: 28-Sep-2016].

[96] 'INTEGRIS: INTELLIGENT ELECTRICAL GRID SENSOR COMMUNICATIONS'. [Online]. Available: http://fp7integris.eu/index.php. [Accessed: 28-Sep-2016].

[97] 'GreenCom EU Project - About us'. [Online]. Available: http://www.greencomproject.eu/. [Accessed: 28-Sep-2016].

[98] 'Micro-Request-Based Aggregation, Forecasting and Scheduling of Energy Demand, Supply and Distribution(MIRABEL)'. [Online]. Available: http://www.2020horizon.com/MIRABEL-Micro-Request-Based-Aggregation-Forecasting-and-

Scheduling-of-Energy-Demand-Supply-and-Distribution(MIRABEL)-s9343.html.

[Accessed: 11-Nov-2013].

[99] 'Advanced - Home'. [Online]. Available: http://www.advancedfp7.eu/. [Accessed: 28Sep-2016].

[100] Eplusproject, 'E+'. [Online]. Available: http://www.eplusproject.eu/. [Accessed: 28Sep-2016].

[101] 'BEYWATCH'. [Online]. Available: http://www.innovationseeds.eu/Virtual_Library/Results/BEYWATCH.kl. [Accessed: 28-Sep-2016].

[102] 'BEAMS'..

[103] 'SmartHG | SmartHG: Energy Demand Aware Open Services for Smart Grid Intelligent Automation'..

[104] 'EEPOS» Energy management and decision support systems for Energy POSitive neighbourhoods'. . 
[105] J. Villar, I. Trigo, C. A. Diaz, and P. Gonzalez, 'Cost-benefit analysis of plug-in electric vehicles penetration', in European Energy Market (EEM), 2013 10th International Conference on the, 2013, pp. 1-8.

[106] S. Rogerson, 'Road to realism [fuel cell vehicles]', Power Eng., vol. 19, no. 3, pp. 24-25, Jul. 2005.

[107] 'Nissan LEAF® All Electric Car', Nissan USA. [Online]. Available: http://www.nissanusa.com/electric-cars/leaf. [Accessed: 16-Sep-2013].

[108] '2013 Toyota Prius', The Car Connection. [Online]. Available: http://www.thecarconnection.com/overview/toyota_prius_2013. [Accessed: 28Sep-2016].

[109] 'Are Hydrogen Cars Better than Electric Ones? Sure, If You Can Find a Place to Fill it Up | Technology on GOOD', GOOD. [Online]. Available: http://www.good.is/posts/are-hydrogen-cars-better-than-electric-ones-sure-ifyou-can-find-a-place-to-fill-it-up. [Accessed: 16-Sep-2013].

[110] 'Hydrogen Cars Vs. Electric Cars -- It Comes Down To Efficiency (Elon Musk Video) -'. [Online]. Available: http://evobsession.com/hydrogen-cars-vs-electric-carsdetailed-comparison-efficiency/. [Accessed: 28-Sep-2016].

[111] S. Imai, N. Takeda, and Y. Horii, 'Total efficiency of a hybrid electric vehicle', in Power Conversion Conference - Nagaoka 1997., Proceedings of the, 1997, vol. 2, pp. 947-950 vol.2.

[112] '2014 Cruze Compact Car - Cruze Turbo Diesel | Chevrolet', www.chevrolet.com. [Online]. Available: http://www.chevrolet.com/cruze-compact-car.html. [Accessed: 16-Sep-2013].

[113] F. Klocke, D. Lung, R. Schlosser, B. Dobbeler, and S. Buchkremer, 'Ecological lifecycle assessment of an electric drive for the automotive industry', in Electric Drives Production Conference (EDPC), 2012 2nd International, 2012, pp. 1-6.

[114] J. C. Ferreira and J. L. Afonso, 'Mobi_System: A personal travel assistance for electrical vehicles in smart cities', in 2011 IEEE International Symposium on Industrial Electronics (ISIE), 2011, pp. 1653-1658.

[115] S. K. Zegeye, B. De Schutter, J. Hellendoorn, and E. A. Breunesse, 'Reduction of areawide emissions using an efficient model-based traffic control strategy', in 2011 IEEE Forum on Integrated and Sustainable Transportation System (FISTS), 2011, pp. 239244.

[116] Z. Solomon, 'Model-Based Traffic Control for Balanced Reduction of Fuel Consumption, Emissions, and Travel Time', 2009, pp. 149-154.

[117] 'NO VACANCY: PARK SLOPE'S PARKING PROBLEM | Transportation Alternatives'. [Online]. Available: https://www.transalt.org/news/releases/126. [Accessed: 28Sep-2016].

[118] H. Wang and W. He, 'A Reservation-based Smart Parking System', in 2011 IEEE Conference on Computer Communications Workshops (INFOCOM WKSHPS), 2011, pp. 690-695.

[119] M. Parent, 'Advanced Urban Transport: Automation Is on the Way', IEEE Intell. Syst., vol. 22, no. 2, pp. 9-11, Apr. 2007.

[120] F.-Y. Wang, P. B. Mirchandani, and Z. Wang, 'The VISTA project and its applications', IEEE Intell. Syst., vol. 17, no. 6, pp. 72-75, Dec. 2002.

[121] V. R. Vuchic, Urban Transit Systems and Technology. John Wiley \& Sons, 2007.

[122] A. González-Gil, R. Palacin, P. Batty, and J. P. Powell, 'A systems approach to reduce urban rail energy consumption', Energy Convers. Manag., vol. 80, pp. 509-524, Apr. 2014.

[123] M. OLIVER, 'La «metrolinera» llega a Madrid', ABC.es, 24-Feb-2014. [Online]. Available: $\quad$ http://www.abc.es/madrid/20140224/abcp-metrolinera-llegamadridmetro-recarga-20140224.html. [Accessed: 29-Sep-2016]. 
[124] A. Lajunen, 'Energy consumption and cost-benefit analysis of hybrid and electric city buses', Transp. Res. Part C Emerg. Technol., vol. 38, pp. 1-15, Jan. 2014.

[125] W. D. Jones, 'Take this car and plug it [plug-in hybrid vehicles]', IEEE Spectr., vol. 42, no. 7, pp. 10-13, Jul. 2005.

[126] D. Abbott, 'Keeping the Energy Debate Clean: How Do We Supply the World's Energy Needs?', Proc. IEEE, vol. 98, no. 1, pp. 42-66, Jan. 2010.

[127] L. S. C. Pun-Cheng, 'An Interactive Web-Based Public Transport Enquiry System With Real-Time Optimal Route Computation', IEEE Trans. Intell. Transp. Syst., vol. 13, no. 2, pp. 983-988, Jun. 2012.

[128] A. Bodhani, 'Smart transport', Eng. Technol., vol. 7, no. 6, pp. 70-73, Jul. 2012.

[129] H.-C. Li, 'Optimal delivery strategies considering carbon emissions, time-dependent demands and demand-supply interactions', Eur. J. Oper. Res., vol. 241, no. 3, pp. 739748, Mar. 2015.

[130] C.-I. Hsu, W.-T. Chen, and W.-J. Wu, 'Optimal delivery cycles for joint distribution of multi-temperature food', Food Control, vol. 34, no. 1, pp. 106-114, Nov. 2013.

[131] C. Xumei, J. Yulin, and L. Zhenyu, 'Several Thoughts on GHG Emission Reduction and Traffic Congestion Control in Urban Transport', in 2011 International Conference on Management and Service Science (MASS), 2011, pp. 1-4.

[132] P. Tulpule, V. Marano, S. Yurkovich, and G. Rizzoni, 'Energy economic analysis of PV based charging station at workplace parking garage', in 2011 IEEE Energytech, 2011, pp. 1-6.

[133] 'Madrid', Madrid. [Online]. Available: https://www.google.es/maps/place/Madrid/@40.4378698,3.8196207,11z/data=!3m1!4b1!4m5!3m4!1s0xd422997800a3c81:0xc436dec1618 c2269!8m2!3d40.4167754!4d-3.7037902. [Accessed: 31-May-2016].

[134] 'HERE WeGo - Mapas - Rutas - Direcciones - Todos los caminos entre A y B en un solo lugar'. [Online]. Available: https://wego.here.com/?map=40.4086,3.6922,10,normal. [Accessed: 18-Oct-2016].

[135] M. Peña-Alcaraz, A. Fernández, A. P. Cucala, A. Ramos, and R. R. Pecharromán, 'Optimal underground timetable design based on power flow for maximizing the use of regenerative-braking energy', Proc. Inst. Mech. Eng. Part F J. Rail Rapid Transit, vol. 226, no. 4, pp. 397-408, Jul. 2012.

[136] 'Article 8 - International Journal of Railway Research'. [Online]. Available: http://ijrare.iust.ac.ir/page.php?slct_pg_id=36\&sid=1\&slc_lang=fa. [Accessed: 28Sep-2016].

[137] S. C. Bhattacharyya and G. R. Timilsina, 'A review of energy system models', Int. J. Energy Sect. Manag., vol. 4, no. 4, pp. 494-518, Nov. 2010.

[138] A. Soroudi and M. Ehsan, 'A distribution network expansion planning model considering distributed generation options and techo-economical issues', Energy, vol. 35, no. 8, pp. 3364-3374, Aug. 2010.

[139] G. Celli and F. Pilo, 'Optimal distributed generation allocation in MV distribution networks', in 22nd IEEE Power Engineering Society International Conference on Power Industry Computer Applications, 2001. PICA 2001. Innovative Computing for Power Electric Energy Meets the Market, 2001, pp. 81-86.

[140] S. Karnouskos and T. N. de Holanda, 'Simulation of a Smart Grid City with Software Agents', in Third UKSim European Symposium on Computer Modeling and Simulation, 2009. EMS '09, 2009, pp. 424-429.

[141] 'DISCERN - Distributed Intelligence for Cost-effective and Reliable Solutions'. [Online]. Available: http://www.discern.eu/. [Accessed: 28-Sep-2016].

[142] 'Smart Distribution System OperaTion for MAximizing the INtegration of RenewABLE Generation | Energy Research Knowledge Centre'. [Online]. Available: https://setis.ec.europa.eu/energy-research/project/smart-distribution-systemoperation-maximizing-integration-renewable-generation. [Accessed: 28-Sep-2016]. 
[143] 'E-Gotham'. [Online]. Available: http://www.e-gotham.eu/. [Accessed: 28-Sep-2016].

[144] A. M. Foley, B. P. Ó Gallachóir, J. Hur, R. Baldick, and E. J. McKeogh, 'A strategic review of electricity systems models', Energy, vol. 35, no. 12, pp. 4522-4530, Dec. 2010.

[145] S. Malekpour, R. R. Brown, and F. J. de Haan, 'Strategic planning of urban infrastructure for environmental sustainability: Understanding the past to intervene for the future', Cities, vol. 46, pp. 67-75, Aug. 2015.

[146] I.-A. Yeo and J.-J. Yee, 'A proposal for a site location planning model of environmentally friendly urban energy supply plants using an environment and energy geographical information system (E-GIS) database (DB) and an artificial neural network (ANN)', Appl. Energy, vol. 119, pp. 99-117, Apr. 2014.

[147] I. Marić, M. Pucar, and B. Kovačević, 'Reducing the impact of climate change by applying information technologies and measures for improving energy efficiency in urban planning', Energy Build.

[148] J. Lenhart, B. van Vliet, and A. P. J. Mol, 'New roles for local authorities in a time of climate change: the Rotterdam Energy Approach and Planning as a case of urban symbiosis', J. Clean. Prod., vol. 107, pp. 593-601, Nov. 2015.

[149] S. Zubelzu, R. Álvarez, and A. Hernández, 'Methodology to calculate the carbon footprint of household land use in the urban planning stage', Land Use Policy, vol. 48, pp. 223-235, Nov. 2015.

[150] S. Zubelzu and R. Álvarez, 'Urban planning and industry in Spain: A novel methodology for calculating industrial carbon footprints', Energy Policy, vol. 83, pp. 57-68, Aug. 2015.

[151] 'Ratings Summary Page'. [Online]. Available: https://secure.solarrating.org/Certification/Ratings/RatingsSummaryPage.aspx. [Accessed: 28-Sep2016].

[152] European Commission - Joint ResearchCentre, 'Photovoltaic Geographical Information System (PVGIS)'. [Online]. Available: https://goo.gl/6QagIh. [Accessed: 28-Sep-2016].

[153] IDAE, 'Atlas Eolico de España'. [Online]. Available: http://atlaseolico.idae.es/meteosim/. [Accessed: 28-Sep-2016].

[154] 'Data and maps - European Environment Agency (EEA)'. [Online]. Available: http://www.eea.europa.eu/data-and-maps. [Accessed: 15-Oct-2014].

[155] 'Windfinder.com - Wind and weather forecasts and reports', Windfinder.com. [Online]. Available: http://www.windfinder.com/forecasts. [Accessed: 15-Oct2014].

[156] 'Energy price statistics - Statistics Explained'. [Online]. Available: http://ec.europa.eu/eurostat/statisticsexplained/index.php/Energy_price_statistics. [Accessed: 28-Sep-2016].

[157] 'EIA - Annual Energy Outlook 2016'. [Online]. Available: http://www.eia.gov/forecasts/aeo/. [Accessed: 28-Sep-2016].

[158] 'Heat and cooling demand and market perspective | SETIS - European Commission'. [Online]. Available: https://setis.ec.europa.eu/publications/jrc-setis-reports/heatand-cooling-demand-and-market-perspective. [Accessed: 28-Sep-2016].

[159] O. B. Cruz and L. D. Olavarrieta, 'A Bird's Eye View of Materials and Manufacturing Processes for Photovoltaic Cells', in 15th International Conference on Electronics, Communications and Computers, 2005. CONIELECOMP 2005. Proceedings, 2005, pp. 251-256.

[160] F. Martín-Martínez, A. Sánchez-Miralles, and M. Rivier, 'Prosumers' optimal DER investments and DR usage for thermal and electrical loads in isolated microgrids', Electr. Power Syst. Res.

[161] H. P. Kan, K. T. Chau, and M. Cheng, 'Development of doubly salient permanent magnet motor flywheel energy storage for building integrated photovoltaic system', 
in Sixteenth Annual IEEE Applied Power Electronics Conference and Exposition, 2001. APEC 2001, 2001, vol. 1, pp. 314-320 vol.1.

[162] A. K. Shukla, K. Sudhakar, and P. Baredar, 'Simulation and performance analysis of $110 \mathrm{kWp}$ grid-connected photovoltaic system for residential building in India: A comparative analysis of various PV technology', Energy Rep., vol. 2, pp. 82-88, Nov. 2016.

[163] A. A. Elbaset, H. Ali, and M. Abd El Sattar, 'New seven parameters model for amorphous silicon and thin film PV modules based on solar irradiance', Sol. Energy, vol. 138, pp. 26-35, Nov. 2016.

[164] M. Diekerhof, S. Vorkampf, and A. Monti, 'Distributed optimization algorithm for heat pump scheduling', in IEEE PES Innovative Smart Grid Technologies, Europe, 2014, pp. $1-6$.

[165] P. Mancarella, 'Distributed multi-generation options to increase environmental efficiency in smart cities', in 2012 IEEE Power and Energy Society General Meeting, 2012, pp. 1-8.

[166] N.-K. C. Nair and N. Garimella, 'Battery energy storage systems: Assessment for smallscale renewable energy integration', Energy Build., vol. 42, no. 11, pp. 2124-2130, Nov. 2010.

[167] 'How much energy does a refrigerator use? - by Mr. Electricity'. [Online]. Available: http://michaelbluejay.com/electricity/refrigerators.html. [Accessed: 25-Oct-2016].

[168] L. Brange, J. Englund, and P. Lauenburg, 'Prosumers in district heating networks - A Swedish case study', Appl. Energy, vol. 164, pp. 492-500, Feb. 2016.

[169] K. Richa, C. W. Babbitt, G. Gaustad, and X. Wang, 'A future perspective on lithium-ion battery waste flows from electric vehicles', Resour. Conserv. Recycl., vol. 83, pp. 6376, Feb. 2014.

[170] 'Replacing EV Batteries: Your Costs Will Vary', PluginCars.com. [Online]. Available: http://goo.gl/j4Fu4u. [Accessed: 26-May-2015].

[171] J. O. Petinrin and M. Shaaban, 'Impact of renewable generation on voltage control in distribution systems', Renew. Sustain. Energy Rev., vol. 65, pp. 770-783, Nov. 2016.

[172] K. Spiliotis, A. I. Ramos Gutierrez, and R. Belmans, 'Demand flexibility versus physical network expansions in distribution grids', Appl. Energy, vol. 182, pp. 613-624, Nov. 2016.

[173] 'BOE.es - Documento CE-D-2013-937'. [Online]. Available: http://boe.es/buscar/doc.php?id=CE-D-2013-937. [Accessed: 29-Sep-2016].

[174] C. M. Domingo, T. G. S. Román, A. Sánchez-Miralles, J. P. P. González, and A. C. Martínez, 'A Reference Network Model for Large-Scale Distribution Planning With Automatic Street Map Generation', IEEE Trans. Power Syst., vol. 26, no. 1, pp. 190-197, Feb. 2011.

[175] L. Gonzalez-Sotres, C. Mateo Domingo, A. Sanchez-Miralles, and M. Alvar Miro, 'LargeScale MV/LV Transformer Substation Planning Considering Network Costs and Flexible Area Decomposition', IEEE Trans. Power Deliv., vol. 28, no. 4, pp. 2245-2253, Oct. 2013.

[176] F. H. M. Rafi, M. J. Hossain, and J. Lu, 'Hierarchical controls selection based on PV penetrations for voltage rise mitigation in a LV distribution network', Int. J. Electr. Power Energy Syst., vol. 81, pp. 123-139, Oct. 2016.

[177] A. Rodriguez-Calvo, R. Cossent, and P. Frías, 'Integration of PV and EVs in unbalanced residential LV networks and implications for the smart grid and advanced metering infrastructure deployment', Int. J. Electr. Power Energy Syst., vol. 91, pp. 121-134, Oct. 2017.

[178] M. H. Khooban, T. Niknam, F. Blaabjerg, and T. Dragičević, 'A new load frequency control strategy for micro-grids with considering electrical vehicles', Electr. Power Syst. Res., vol. 143, pp. 585-598, Feb. 2017.

[179] M. Davis, 'PROJECT SECH-SPAHOUSEC Análisis del consumo energético del sector residencial en España (Analysis of the energy consumption of the Spanish residential 
sector)', Build Up, 25-Jan-2012. [Online]. Available: http://www.buildup.eu/en/node/23244. [Accessed: 29-Sep-2016].

[180] REE, 'Proyecto INDEL - Atlas de la demanda eléctrica española (INDEL proyect - atlas of the Spanish electric demand)'. [Online]. Available: https://goo.gl/6g4Xjg. [Accessed: 29-Sep-2016].

[181] 'Luz, gas y Electricidad para tu casa. Ofertas, contratos, precios | ENDESA CLIENTES', Endesa. [Online]. Available: /hogares.html. [Accessed: 29-Sep-2016].

[182] 'How much do smart meters cost? - WeblogPost by Chris King', 01-May-2013. [Online]. Available: https://blogs.siemens.com/smartgridwatch/stories/957/. [Accessed: 29-Sep-2016].

[183] A.-L. Barabási and R. Albert, 'Emergence of Scaling in Random Networks', Science, vol. 286, no. 5439, pp. 509-512, Oct. 1999.

[184] S. Bhattacharyya, J. M. A. Myrzik, and W. L. Kling, 'Consequences of poor power quality - an overview', in 2007 42nd International Universities Power Engineering Conference, 2007, pp. 651-656.

[185] B. Morvaj, R. Evins, and J. Carmeliet, 'Decarbonizing the electricity grid: The impact on urban energy systems, distribution grids and district heating potential', Appl. Energy, vol. 191, pp. 125-140, Apr. 2017.

[186] 'Comercializadores - Energía Eléctrica - Energía - Mo de Industria, Energía y Turismo'. [Online]. Available: http://www.minetur.gob.es/energia/electricidad/Distribuidores/Paginas/Comerci alizadores.aspx. [Accessed: 29-Sep-2016].

[187] R. Herranz, A. Munoz San Roque, J. Villar, and F. A. Campos, 'Optimal Demand-Side Bidding Strategies in Electricity Spot Markets', IEEE Trans. Power Syst., vol. 27, no. 3, pp. 1204-1213, Aug. 2012.

[188] H. Pandžić, J. M. Morales, A. J. Conejo, and I. Kuzle, 'Offering model for a virtual power plant based on stochastic programming', Appl. Energy, vol. 105, pp. 282-292, May 2013.

[189] M. Shabanzadeh, M.-K. Sheikh-El-Eslami, and M.-R. Haghifam, 'The design of a riskhedging tool for virtual power plants via robust optimization approach', Appl. Energy, vol. 155, pp. 766-777, Oct. 2015.

[190] M. Houwing, G. Papaefthymiou, P. W. Heijnen, and M. D. Ilić, 'Balancing wind power with virtual power plants of micro-CHPs', in PowerTech, 2009 IEEE Bucharest, 2009, pp. 1-7.

[191] D. T. Nguyen and L. B. Le, 'Risk-Constrained Profit Maximization for Microgrid Aggregators With Demand Response', IEEE Trans. Smart Grid, vol. 6, no. 1, pp. 135146, Jan. 2015.

[192] M. Honarmand, A. Zakariazadeh, and S. Jadid, 'Integrated scheduling of renewable generation and electric vehicles parking lot in a smart microgrid', Energy Convers. Manag., vol. 86, pp. 745-755, Oct. 2014.

[193] N. Mahmoudi, T. K. Saha, and M. Eghbal, 'Modelling demand response aggregator behavior in wind power offering strategies', Appl. Energy, vol. 133, pp. 347-355, Nov. 2014.

[194] A. Yoza and T. Funabashi, 'Optimal scheduling method of controllable loads in DCsmart house with deregulated electricity market', in Future Energy Electronics Conference (IFEEC), 2013 1st International, 2013, pp. 681-685.

[195] J. A. M. Sousa, F. Teixeira, and S. Faias, 'Impact of a price-maker pumped storage hydro unit on the integration of wind energy in power systems', Energy, vol. 69, pp. 3-11, May 2014.

[196] P. Zou, Q. Chen, Q. Xia, G. He, C. Kang, and A. J. Conejo, 'Pool equilibria including strategic storage', Appl. Energy, vol. 177, pp. 260-270, Sep. 2016. 
[197] S. Shafiee, P. Zamani-Dehkordi, H. Zareipour, and A. M. Knight, 'Economic assessment of a price-maker energy storage facility in the Alberta electricity market', Energy, vol. 111, pp. 537-547, Sep. 2016.

[198] F. Glover, 'Tabu Search-Part I', ORSA J. Comput., vol. 1, no. 3, pp. 190-206, Aug. 1989.

[199] S. Vázquez, P. Rodilla, and C. Batlle, 'Residual demand models for strategic bidding in European power exchanges: Revisiting the methodology in the presence of a large penetration of renewables', Electr. Power Syst. Res., vol. 108, pp. 178-184, Mar. 2014.

[200] L. A. Wolsey and G. L. Nemhauser, Integer and Combinatorial Optimization, 1 edition. New York; Chichester: Wiley-Interscience, 1999.

[201] 'Destino de tu factura | Iberdrola Hogares'. [Online]. Available: https://www.iberdrola.es/clientes/hogar/info/factura/facturaelectricidad/destino-factura. [Accessed: 29-Sep-2016].

[202] IPCC, Special Report on Renewable Energy Sources and Climate Change Mitigation. United Kingdom and New York, NY, USA: Cambridge University Press, 2011.

[203] 'World Energy Perspective: Cost of Energy Technologies'. [Online]. Available: https://www.worldenergy.org/publications/2013/world-energy-perspective-costof-energy-technologies/. [Accessed: 29-Sep-2016].

[204] 'Pages - Energy Consumption of Tanks and Vats'. [Online]. Available: http://www.spiraxsarco.com/Resources/Pages/Steam-Engineering-

Tutorials/steam-engineering-principles-and-heat-transfer/energy-consumption-oftanks-and-vats.aspx. [Accessed: 14-Jul-2016].

[205] 'COPs, EERs, and SEERs - How Efficient is Your Air Conditioning System? :: Power Knot': [Online]. Available: http://www.powerknot.com/how-efficient-is-your-airconditioning-system.html. [Accessed: 18-Jun-2016].

[206] A. Ugedo et al., 'Stochastic model of residual demand curves with decision trees', in IEEE Power Engineering Society General Meeting, 2003, 2003, vol. 2, p. 984 Vol. 2.

[207] 'Welcome | ESIOS electricity • data • transparency'. [Online]. Available: https://www.esios.ree.es/en. [Accessed: 29-Sep-2016].

[208] 'Inicio | OMIE'. [Online]. Available: http://www.omie.es/en/inicio. [Accessed: 29Sep-2016].

[209] A. Baillo, M. Ventosa, M. Rivier, and A. Ramos, 'Optimal offering strategies for generation companies operating in electricity spot markets', IEEE Trans. Power Syst., vol. 19, no. 2, pp. 745-753, May 2004.

[210] J. A. Hartigan and M. A. Wong, 'Algorithm AS 136: A K-Means Clustering Algorithm', Appl. Stat., vol. 28, no. 1, p. 100, 1979.

[211] F. A. Campos, A. M. S. Roque, E. F. Sánchez-Úbeda, and J. P. González, 'Strategic Bidding in Secondary Reserve Markets', IEEE Trans. Power Syst., vol. 31, no. 4, pp. 2847-2856, Jul. 2016.

[212] 'File Exchange - MATLAB Central'. [Online]. Available: https://es.mathworks.com/matlabcentral/fileexchange/21132-linesimplification/content/dpsimplify.m. [Accessed: 29-Sep-2016].

[213] P. J. Rousseeuw, 'Silhouettes: A graphical aid to the interpretation and validation of cluster analysis', J. Comput. Appl. Math., vol. 20, pp. 53-65, Nov. 1987.

[214] 'Silhouette plot - MATLAB silhouette - MathWorks España'. [Online]. Available: http://es.mathworks.com/help/stats/silhouette.html. [Accessed: 29-Sep-2016].

[215] C. G. Baslis and A. G. Bakirtzis, 'Optimal yearly scheduling of generation and pumping for a price-maker hydro producer', in Energy Market (EEM), 2010 7th International Conference on the European, 2010, pp. 1-6.

[216] E. CincoDias, 'El 43\% de los clientes eléctricos está ya en el mercado liberalizado', Cinco Días, 02-Jul-2014. [Online]. Available: http://cincodias.com/cincodias/2014/07/01/empresas/1404239492_758383.htm l. [Accessed: 29-Sep-2016]. 
[217] C. A. Díaz, J. Villar, F. A. Campos, and M. Á. Rodríguez, 'A new algorithm to compute conjectured supply function equilibrium in electricity markets', Electr. Power Syst. Res., vol. 81, no. 2, pp. 384-392, Feb. 2011.

[218] C. A. Díaz, F. A. Campos, J. Villar, and M. Á. Rodríguez, 'Endogenous computation of conjectured supply functions with network constraints', Electr. Power Syst. Res., vol. 90, pp. 117-125, Sep. 2012.

[219] H. Lund and W. Kempton, 'Integration of renewable energy into the transport and electricity sectors through V2G', Energy Policy, vol. 36, no. 9, pp. 3578-3587, Sep. 2008.

[220] Y. Warin, R. Lanselle, and M. Thiounn, 'Active substation', presented at the 9th World Congress on Railway Research - WCRR 2011, Lille, France, 2011.

[221] S. Su, T. Tang, and Y. Wang, 'Evaluation of Strategies to Reducing Traction Energy Consumption of Metro Systems Using an Optimal Train Control Simulation Model', Energies, vol. 9, no. 2, p. 105, Feb. 2016.

[222] E. E. País, 'Metro reduce los trenes en tres de las líneas más usadas', EL PAÍS, 12-Apr2009.

[Online]. Available: http://elpais.com/diario/2009/04/12/madrid/1239535458_850215.html. [Accessed: 03-Dec-2015].

[223] W. Carvajal-Carreño, A. P. Cucala, and A. Fernández-Cardador, 'Optimal design of energy-efficient ATO CBTC driving for metro lines based on NSGA-II with fuzzy parameters', Eng. Appl. Artif. Intell., vol. 36, pp. 164-177, Nov. 2014.

[224] 'Line 3 of Madrid's Metro'. [Online]. Available: http://www.planometromadrid.org/en-line-3-metro-madrid.php. [Accessed: 31May-2016].

[225] Metro de Madrid (Madrid's metro), 'Line 3 Time Schedule'. [Online]. Available: https://goo.gl/C1h8sD. [Accessed: 29-Sep-2016].

[226] M. Domínguez, A. Fernández-Cardador, A. P. Cucala, and R. R. Pecharromán, 'Energy Savings in Metropolitan Railway Substations Through Regenerative Energy Recovery and Optimal Design of ATO Speed Profiles', IEEE Trans. Autom. Sci. Eng., vol. 9, no. 3, pp. 496-504, Jul. 2012.

[227] Ayuntamiento de Madrid (Madrid City Council), 'Aparcamientos municipales (municipal parking lots)'. [Online]. Available: http://goo.gl/ihYlD2. [Accessed: 29Sep-2016].

[228] 'Eight Tips to Extend Battery Life of Your Electric Car', PluginCars.com. [Online]. Available: http://goo.gl/ExBCTW. [Accessed: 18-Jun-2015].

[229] E. Schaal, M. Articles, and 2015 November 12, '10 Electric Vehicles With the Best Range in 2015', The Cheat Sheet. .

[230] G. Pasaoglu Kilanc et al., 'Driving and parking patterns of European car drivers - a mobility survey', European Commission, EUR - Scientific and Technical Research Reports, 2012.

[231] 'Chevrolet Pressroom - United States - Spark EV', media.gm.com. [Online]. Available: https://media.gm.com/content/media/us/en/chevrolet/vehicles/sparkev/2016.html. [Accessed: 09-Sep-2016].

[232] Endesa, 'High voltage commercial time-of-use electric tariff'. [Online]. Available: https://www.endesaclientes.com/companies/optimum-rate.html. [Accessed: 29Sep-2016].

[233] Iberdrola, 'Residential time-of-use electric tariff. [Online]. Available: https://www.iberdrola.es/home/electricity. [Accessed: 29-Sep-2016].

[234] L. N. España, 'El desglose de la factura de la luz'. [Online]. Available: http://www.lne.es/economia/2014/02/07/desglose-factura-luz/1539219.html. [Accessed: 03-May-2016].

[235] 'Metro de Madrid S.A. - Suministro de Energía Eléctrica para el año 2015'. [Online]. Available: http://www.madrid.org/contratos- 
publicos/1354339805675/1209029494335/1354401131635.pdf. [Accessed: 29Sep-2016].

[236] 'Ayuntamiento de Madrid'. [Online]. Available: http://www2.munimadrid.es/TSE6/control/seleccionDatosBarrio. [Accessed: 29-Sep-2016].

[237] 'Distritos madrid | Barrios de Madrid'. [Online]. Available: http://barriosdemadrid.net/mapas/distritos/. [Accessed: 15-Sep-2016].

[238] 'área de prensa / Notas de prensa publicadas'. [Online]. Available: http://www.ine.es/prensa/prensa.htm. [Accessed: 15-Sep-2016].

[239] 'Metro | Barrios de Madrid'. [Online]. Available: http://barriosdemadrid.net/mapas/metro/. [Accessed: 15-Sep-2016]. 